
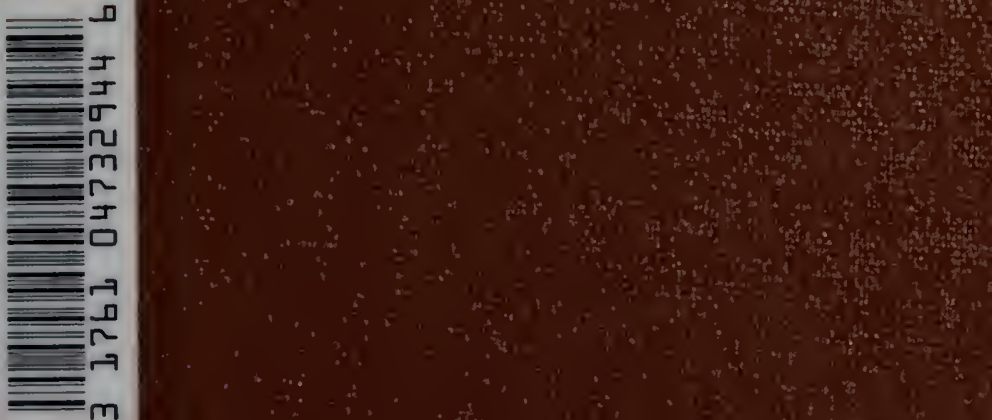

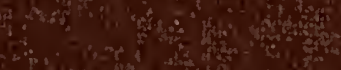


Digitized by Microsoft $\AA$ 
Digitized for Microsoft Corporation by the Internet Archive in 2007. From University of Toronto.

May be used for non-commercial, personal, research, or educational purposes, or any fair use. May not be indexed in a commercial service. 
Digitized by Microsoft ${ }^{\circledR}$ 


\section{POPULÄR-WISSENSCHAFTLICHE VORLESUNGEN.}


Von demselben Verfasser:

Die Geschichte und die Wurzel des Satzes der Erhaltung der Arbeit. Prag. I872. Calvesche Buchhandlung. $8^{0}$. $58 \mathrm{~S}$.

Optisch-akustische Versuche. Prag. 1873. (Johann Ambrosius Barth in Leipzig). $8^{\circ}$. I I $\mathrm{S}$.

Grundlinien der Lehre von den Bewegungsempfindungen. Leipzig. Engelmann. 1875. $8^{\circ}$. I $27 \mathrm{~S}$.

Die Mechanik in ihrer Entwicklung, historischkritisch dargestellt. Leipzig. Brockhaus. I901. 4. Aufl. $8^{0}$. $55^{\circ}$ S. m. 257 Abbildgn.

Beiträge zur Analyse der Empfindungen. Jena. Fischer. 1902. 3. Aufl. 286 S. m. 36 Abbildgn.

Die Prinzipien der Wärmelehre, historisch-kritisch dargestellt. Leipzig. Johann Ambrosius Barth. r 900 . 2. Aufl. 484 S. m. 105 Fig. u. 6 Port. 


\section{Mे1492p}

\section{POPUḶÄR-WISSENSCHAFTLICHE}

\section{VORLESUNGEN}

roN

\section{Dr. E. MACH}

EMER, PROFESSOR AN DER UNIVERSITÄT WIEN

3. VERMEHRTE UND DURCHGESEHENE AUFLAGE

MIT 60 ABBILDUNGEN
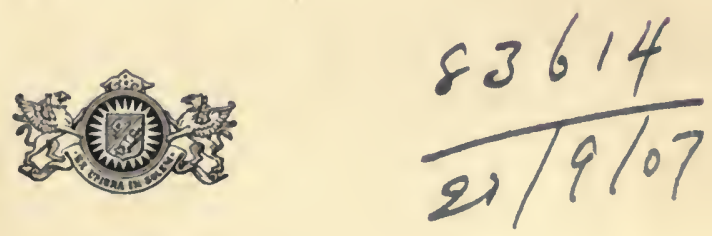

LEIPZIG

JOHANN AMBROSIUS BARTH 1903 
Alle Rechte, insbesondere das der Übersetzung, vorbehalten. 
HERRN PROFESSOR WILLIAM JAMES

IN SYMPATHIE UND HOCHACHTUNG

GEWIDMET

VOM VERFASSER. 
Digitized by Microsoft $\AA$ 


\section{Vorwort.}

Die von der "Open Court Publishing Compagny" in Chicago i. J. 1895 veranstaltete Sammelausgabe meiner "Popular scientific lectures" in der vorzüglichen Übersetzung des Herrn Mc. Cormack hat der Verlagshandlung den Gedanken nahe gelegt, diese Sammlung auch in deutscher Sprache erscheinen zu lassen. Dieselbe ist in dieser Gestalt vermehrt um die Artikel 4, 9 und 14. Der Artikel Io ist allein zuerst englisch erschienen in "The Monist", und stellt eine freie Bearbeitung vor eines Teiles meiner Schrift über die „Erhaltung der Arbeit" (Prag. Calve 1872), welche ich auf Wunsch des Herrn Dr. P. Carus, Herausgebers des "Monist", unternahm. Letztere Schrift, in welcher ich zuerst meinen Standpunkt in physikalischen Fragen darlegte, stellt nämlich in ihrer urspringlichen Form allzugroße Anforderungen an den Leser von populären Vorlesungen.

Die große Verschiedenheit der Artikel in Form, Geschmack, Stil, Stimmung und Ziel wird man entschuldigen, wenn man bedenkt, daß dieselben einen Zeitraum von mehr als dreißig Jahren umfassen. Im übrigen kann ich 
hier nur die Worte wiederholen, welche die englische Ausgabe begleiteten:

„Populäre Vorlesungen können mit Rücksicht auf die vorausgesetzten Kenntnisse und die zur Verfügung stehende Zeit nur in bescheidenem Maße belehrend wirken. Dieselben müssen zu diesem Zweck leichtere Stoffe wählen und sich auf die Darlegung der einfachsten und wesentlichsten Punkte beschränken. Nichts desto weniger kann durch geeignete Wahl des Gegenstandes die Romantik und die Poesie der Forschung fühlbar gemacht werden. Hierzu ist nur nötig, daß man das Anziehende und Spannende eines Problems darlegt, und zeigt, wie durch das von einer unscheinbaren Aufklärung ausstrahlende Licht zuweilen weite Gebiete von Tatsachen erleuchtet werden."

„Auch durch den Nachweis der Gleichartigkeit des alltäglichen und des wissenschaftlichen Denkens können solche Vorlesungen günstig wirken. Das Publikum verliert hierdurch die Scheu vor wissenschaftlichen Fragen und gewinnt jenes Interesse an der Untersuchung, welches dem Forscher so förderlich ist. Diesem hingegen wird die Einsicht nahe gelegt, daß er mit seiner Arbeit nur einen kleinen Teil des allgemeinen Entwicklungsprozesses vorstellt, und daß die Ergebnisse der Forschung nicht nur ihm und einigen Fachgenossen, sondern dem Ganzen zu gut kommen sollen."

Der deutsche Physiker wird in den nachfolgenden Artikeln und insbesondere in der erwähnten Schrift über „Erhaltung der Arbeit" manche Frage in früher Zeit er- 
örtert finden, die später unter andern Schlagworten von andern Autoren behandelt worden ist. Einige dieser Fragen stehen in naher Beziehung zu der lebhaften Diskussiou über „Energetik“, welche sich auf der Naturforscherversammlung $\mathrm{zu}$ Lübeck entwickelt hat. Einen Grund, meinen Standpunkt zu ändern, habe ich 'aber aus dieser Diskussion nicht schöpfen können.

W,i e n, Februar 1896.

\section{E. Mach.}

\section{Vorwort zur dritten Auflage.}

Die vorliegende dritte Auflage ist vermehrt um die Artikel IX, X, XVIII und XIX, von welchen die beiden letzten auch schon in die dritte englische Ausgabe aufgenommen waren. Für Leser, die nicht nur zur bloßen Unterhaltung in diesem Buche blättern wollen, habe ich einige Anmerkungen hinzugefuigt. Diese sind zum Unterschied von dem älteren Text mit Klammern und mit der Jahreszahl versehen.

Von den Ideen der Erkenntnistheorie, welche der weitaus überwiegenden Mehrzahl der Naturforscher sehr fern lagen, als ich sie vor Jahren in diesen Vorträgen darlegte, 
gehört vielleicht nicht eine einzige mir alle in an. Früher und später sind ähnliche Gedanken von anderen unabhängigen Forschern mehr oder weniger deutlich ausgesprochen worden. Die Spuren und Elemente derselben lassen sich zum teil sogar in weit entlegene Zeiten zuriick verfolgen. In dem Maße aber, als diese Gedanken mehr und mehr ihr subjektives persönliches Gepräge abstreifen, und sich als natürliche, wenn nicht gar notwendige Ergebnisse der allgemeinen Denkentwicklung darstellen, scheinen sie mir an Wert zu gewinnen, und auch der Aufmerksamkeit anderer würdiger $\mathrm{zu}$ werden.

Wi en, September 1902.

E. Mach. 


\section{In halt.}

I. Die Gestalten der Flüssigkeit . . . . . . . . . I

II. Über die Cortischen Fasern des Ohres . . . . . I7

III. Die Erklärung der Harmonie . . . . . . . . 32

IV. Zur Geschichte der Akustik . . . . . . . . 48

V. Über die Geschwindigkeit des Lichtes . . . . . . 59

VI. Wozu hat der Mensch zwei Augen? . . . . . . 78

VII. Die Symmetrie . . . . . . . . . . . . . 100

VIII. Bemerkungen zur Lehre vom räumlichen Sehen . . II7

IX. Über wissenschaftliche Anwendungen der Photographie und Stereoskopie : . . . . . . . . . . . . I24

$\mathrm{X}$. Bemerkungen über wissenschaftliche Anwendungen der Photographie . . . . . . . . . . . . . 130

XI. Über die Grundbegriffe der Elektrostatik (Menge, Potential, Capazität u. s. w.) . . . . . . . . 135

XII. Über das Prinzip der Erhaltung der Energie . . . I66

XIII. Die ökonomische Natur der physikalischen Forschung 2 I5

XIV. Über Umbildung und Anpassung im naturwissenschaftlichen Denken . . . . . . . . . . . . 243

XV. Ubber das Prinzip der Vergleichung in der Physik . 263

XVI. Uber den Einfluís zufälliger Umstände auf die Entwicklung von Erfindungen und Entdeckungen . . . 287

XVII. Über den relativen Bildungswert der philologischen und der mathematisch-naturwissenschaftlichen Unterrichtsfächer der höheren Schulen . . . . . . . . 309

XVIII. Über Erscheinungen an fliegenden Projektilen . . . 351

XIX. Über Orientierungsempfindungen . . . . . . 378 


$$
y=-\cdot
$$

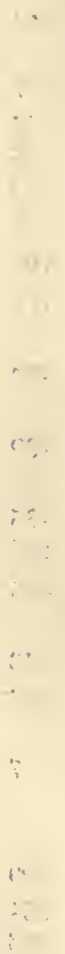

Digitized by Microsoft ${ }^{\circledR}$ 


\section{Die Gestalten der Flüssigkeit.*)}

Was meinst Du wohl, lieber Euthyphron, was das Heilige sei und was das Gerechte und was das Gute? Ist das Heilige deshalb heilig, weil es die Götter lieben, oder sind die Götter deshalb heilig, weil sie das Heilige lieben: Solche und ähnliche leichte Fragen waren es, durch welche der weise Sokrates den Markt zu Athen unsicher machte, durch 'welche er namentlich naseweise junge Staatsmänner von der Last ihres eingebildeten Wissens befreite, indem er ihnen rorhielt, wie verwirrt, unklar und widerspruchsvoll ihre Begrifie seien.

Sie kennen die Schicksale des zudringlichen Fragers. Die sogenannte gute Gesellschaft zog sich auf der.Promenade vor ihm zurück, nur Unwissende begleiteten ihn. Er :trank zuletzt den Giftbecher, den man auch heute noch manchem Rezensenten seines Schlags - wenigstens wünscht.

Was - wir aber von Sokrates gelernt haben, was uns geblieben, ist die wissenschaftliche Kritik. JJedermann,

*) Vortrag gehalten im deutschen Knsino zu Prag im Winter 8868.

$\mathrm{Mach}$, Vorlesungen. 3. Auff.

Digitized by Microsoft $\AA^{1}$ 
der sich mit Wissenschaft beschäftigt, erkennt, wie schwankend und unbestimmt die Begriffe sind, welche er aus dem gewöhnlichen Leben mitgebracht, wie bei schärferer Betrachtung der Dinge scheinbare Unterschiede sich verwischen, neue Unterschiede hervortreten. Und eine fortwährende Veränderung, Entwicklung und Verdeutlichung der Begriffe weist die Geschichte der Wissenschaft selbst auf.

Bei dieser allgemeinen Betrachtung des Schwankens der Begriffe, welche sich bis zur Unbehaglichkeit steigern kann, wenn man bedenkt, daß sich dasselbe so ziemlich auf alles erstreckt, wollen wir nicht verweilen. Wir wollen vielmehr an einem naturwissenschaftlichen Beispiel sehen, wie sehr sich ein Ding ändert, wenn man es immer genauer und genauer ansieht, und wie es hierbei eine immer bestimmtere Form annimmt.

Die meisten von Ihnen meinen wohl ganz gut zu wissen, was flüssig und was fest sei. Und gerade wer sich nie mit Physik beschäftigt hat, wird diese Frage für die leichteste halten. Der Physiker weiß_, daß sie zu den schwierigsten gehört, und daß die Grenze zwischen fest und flüssig kaum anzugeben ist. Ich will hier nur die Versuche von TRESCA erwähnen, welche lehren, daß feste Körper, einem hohen Druck ausgesetzt, sich ganz wie Flüssigkeiten verhalten, z. B. in Form eines Strahles aus der Bodenöffnung des Gefäßes, in welchem sie enthalten sind, ausfließen können. Der vermeintliche Artunterschied zwischen "flüssig und fest" wird hier zu einem bloßen Gradunterschied. 
Wenn man sich gewöhnlich erlaubt, aus der Abplattung der Erde auf einen ehemals flüssigen Zustand derselben zu schließen, so ist dies mit Rücksicht auf solche Tatsachen voreilig. Eine Kugel von einigen Zoll Durchmesser wird sich bei der Drehung freilich nur dann abplatten, wenn sie sehr weich, etwa aus frisch angemachtem Ton oder gar flüssig ist. Die Erde aber, sie mag aus dem festesten Gestein bestehen, muß sich durch ihre eigene ungeheure Last zerdrücken, und verhält sich dann notwendig wie eine Flüssigkeit. Auch die Höhe unserer Berge könnte nicht über eine gewisse Grenze wachsen, ohne daß sie eben zusammenbrechen müßten. Die Erde kann flüssig gewesen sein, aus der Abplattung folgt dies keineswegs.

Die Teilchen einer Flüssigkeit sind äußerst leicht verschiebbar, sie schmiegt sich dem Gefäbe genau an, sie hat keine eigentümliche Gestalt, wie Sie in der Schule gelernt haben. Indem sie sich in die Verhältnisse des Gefäßes bis in die feinsten Details hineinfindet, indem sie selbst an der Oberfläche, wo sie freies Spiel hätte, nichts zeigt, als das lächelnde, spiegelglatte, nichtssagende Antlitz, ist sie der vollendete Höfling unter den Naturkörpern.

Die Flüssigkeit hat keine eigentümliche Gestalt! Wenigstens für den nicht, der flüchtig beobachtet. Wer aber bemerkt hat, daß ein Regentropfen rund und niemals eckig ist, der wird dieses Dogma nicht mehr so unbedingt glauben wollen.

Wir können von jedem Menschen, selbst dem charakterlosesten annehmen, daß er einen Charakter hätte, wenn 
es eben in dieser Welt nicht zu schwierig wäre. So hätte wohl auch die Flïssigkeit ihre eigene Gestalt, "wenn es der Druck der Verhältnisse gestattete, wenn , sie , nicht durch ihr eigenes Gewicht zerdrückt wiirde.

Ein müssiger Astronom hat einmal berechnet, daß in der 'Sonne, selbst abgesehen von der unbehaglichen Tem: peratur, keine Menischen bestehen könnten, weil șie daselbst unter ihrer eigenen Last zusammenbrechen wiirden. Die größere Masse des Weltkörpers bringt nämlich auch ein größeres Gewicht des Menschenkörpers auf demselben mit sich. Dagegen könnten wir im Monde, weil wir daselbst viel leichter wären, mit der uns eigenen Muskelkraft fast turmhohe Sprünge ohne Schwierigkeit ausführen. Plastische Kunstwerke aus Syrup gehören wohl auch im, Monde zu den Fabeln. Doch zerfließt dort der Syrup wohl so langsam, daß inan wenigstens zum Scherz einen Syrupmann ausführen könnte, wie bei uns einen Schneemann.

Wenn also auch bei uns die Flüssigkeiten keine eigentümliche Gestalt haben, vielleicht haben' sie dieselbe im Monde oder auf einem noch. kleineren: und leichteren Weltkörper. Es handelt sich nur darum, die. Schwere zu. beseitigen, um die eigentiimliche Gestalt: der Flüssigkeit kennen zu: lernen.

Diesen, Gedanken hat Platead in Gent ausgefuhrt. Er taucht'eine Fliissigkeit (Öl) in eine andere von gleichem (spezifischem) Gewicht, in eine Mischung 'von Wasser und Weingeist. Das Öl verliert nun entsprechend den ARCHIMEDE's'schen Prinzip in dieser Mischung sein ganzes. Gewicht, es sinkt nicht mehr: unter seiner eigenen Last zu- 
sammen, die gestaltenden Kräfte des Öls, wären sie auch noch so schwach, haben jetzt freies Spiel.

In der Tat sehen wir jetzt zu unserer Überraschung; wie das Öl, statt sich in einer Schichte zu lagern, oder eine formlose Masse zu bilden, die Gestalt einer schönen, sehr vollkommenen Kugel - annimmt, welche frei in der Mischung schwebt wie der Mond im-Weltraum. Man kann so eine Kugel von mehreren Zoll Durchmesser aus Öl darstellen.

Bringt man in diese Ölkugel ein Scheibchen-an einem Draht, so kann man den Draht zwischen den Fingern und damit die ganze Ölkugel in Drehung versetzen. Sie plattet sich hierbei $a b$, und man kann es sogar dahin bringen, daß sich von derselben ein Ring, ähnlich'demjenigen des Saturnus, ablöst. Letzterer zerreißt schließlich, zerfällt in mehrere kleine Kugeln und gibt uns ungefähr ein Bild der Entstehung des Planetensystems nach der KANT'schen und LAPLACE'schen Auffassung.

Noch eigentümlicher werden die Erscheinungen,
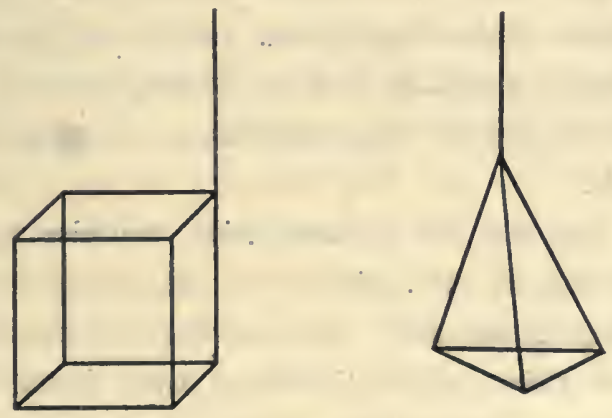

Fig. 1. 
wenn man die gestaltenden Kräfte der Flüssigkeit gewissermaßen stört, indem man einen festen Körper mit der Oberfläche der Flüssigkeit in Berührung bringt. Taucht man z. B. das Kantengerüst eines Würfels aus Draht in die Ölmasse, so legt sich diese überall an den Draht an. Reicht nun die Menge des Öls gerade hin, so erhält man einen Ölwürfel mit vollkommen ebenen Wänden. Ist zu viel oder $\mathrm{zu}$ wenig Öl vorhanden, so werden die Wände des Würfels bauchig, beziehungsweise hohl. Auf ganz ähnliche Weise kann man noch die verschiedensten geometrischen Figuren aus Öl herstellen, z. B. eine dreiseitige Pyramide, oder einen Cylinder, indem man im letzteren Falle das Öl zwischen zwei Drahtringe faßt u. s. w.

Interessant wird die Veränderung der Gestalt, die eintritt, sobald man von einem solchen Ölwürfel oder von der Ölpyramide fort und fort mit Hilfe eines Glasröhrchens etwas Öl wegsaugt. Der Draht hält das Öl fest. Die Figur wird im Innern immer schmächtiger, zuletzt ganz dünn. Sie besteht schließlich aus einer Anzahl dünner ebener Ölplättchen, welche von den Kanten des Würfels ausgehen und im Mittelpunkte in einem kleinen Tropfen Öl zusammenstoßen. Ähnlich bei der Pyramide.

Es liegt nun der Gedanke nahe, daß eine so dünne Flüssigkeitsfigur, die auch nur ein sehr geringes Gewicht hat, durch dieses nicht mehr zerdrückt werden kann, so wie eine kleine, weiche Tonkugel unter ihrem eigenen Gewicht auch nicht mehr leidet. Dann brauchen wir 
aber das Wasser-Weingeistgemisch nicht mehr zur Darstellung unserer Figuren, dann können wir sie im freien Luftraume darstellen. Wirklich fand nun Plateau, daß die dünnen Figuren, oder wenigstens sehr ähnliche, sich einfach in Luft darstellen lassen, indem man die erwähnten Drahtnetze für einen Augenblick in Seifenlösung taucht und wieder herauszielnt. Das Experiment ist nicht schwer. Die Figur bildet sich ohne Anstand von selbst. Die nachstehende Zeichnung vergegenwärtigt den Anblick,
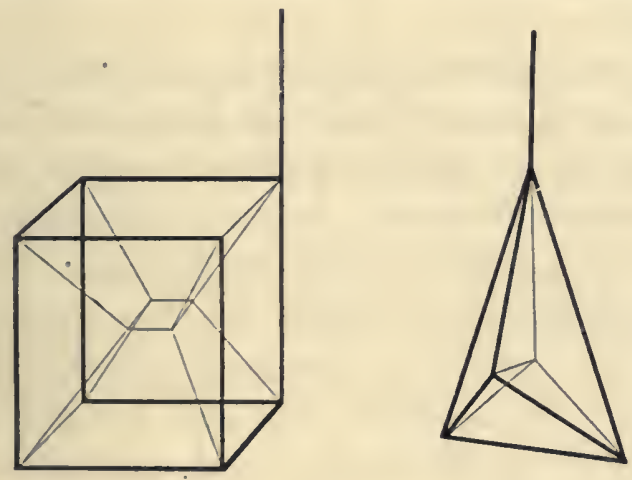

Fig. 2.

den man an dem Würfel- und Pyramidennetz erhält. Am Würfel gehen dünne, ebene Seifenhäutchen von den Kanten aus nach einem kleinen quadratischen Häutchen in der Mitte. An der Pyramide geht ron jeder Kante ein Häutchen nach dem Mittelpunkte der Pyramide.

Diese Figuren sind so schön, daß sie sich schwer entsprechend beschreiben lassen. Die hohe Regelmäßigkeit und geometrische Schärfe setzen jeden in Erstaunen, der sie zum erstenmale sieht. Leider sind sie nur von 
kurzer Dauer. Sie platzen beim Trocknen der Lösung an der Luft, nachdem sie uns zuvor das brillanteste Farbenspiel vorgeführt haben, wie dies so die Art der Seifenblasen ist. Teils die Schönheit der Figuren, teils die Absicht, sie genauer zu untersuchen, erregt den Wunsch, sie zu fixieren. Dies gelingt sehr einfach. Man taucht die Drahtnetze statt in Seifenlösung in geschmolzenes reines Kolophonium oder in Leim. Beim Herausziehen bildet sich sofort die Figur und erstarrt an der Luft.

Es ist zu bemerken, daß auch die massiven Flüssigkeitsfiguren sich in der freien Luft darstellen lassen, wenn man sie nur von hinlänglich kleinem Gewichte, also mit recht kleinen Drahtnetzen darstellt. Verfertigt man sich z. B. aus sehr feinem Draht ein IVürfelnetz von etwa $3 \mathrm{~mm}$ Seitenlänge, so braucht man dies nur einfach in Wasser zu tauchen, um ein massives kleines Wasserwürfelchen herauszuziehen. Mit etwas Löschpapier läßt sich leicht das überflüssige Wasser entfernen und das Würfelchen ebnen.

Noch eine einfache Art, die Figuren zu beobachten, läßt sich auffinden. Ein Tröpfchen Wasser auf einer befetteten Glasplatte zerfließt nicht mehr, wenn es klein genug ist, es plattet sich aber durch sein Gewicht, durch welches es gegen die Unterlage gepreßt wird, etwas ab. Die Abplattung ist desto geringer, je kleiner der Tropfen. Je kleiner der. Tropfen, desto mehr nähert er sich der Kugelform. Umgekehrt verlängert sich ein Tropfen, der an einem Stäbchen hängt, durch sein Gewicht. Die 
untersten Teile eines Tropfens auf der Unterlage werden gegen die Unterlage gepreßt, die oberen Teile gegen die unteren, weil letztere am Ausweichen gehindert sind. Fällt aber ein Tropfen frei herab, so bewegen sich alle Teile gleich schnell, keiner wird durch den anderen gehindert, keiner druickt also den anderen. Ein frei fallender Tropfen leidet also nicht unter seinem Gewicht, er verhält sich wie schwerlos, er nimmt die Kugelform an.

Wenn wir die Seifenhautfiguren, welche mit verschiedenen Drahtnetzen erzeugt wurden, tiberblicken, bemerken wir eine große Mannigfaltigkeit, die nichtsdestoweniger das Gemeinsame derselben nicht zu verdecken vermag.

"Alle Gestalten sind ähnlich, und keine : gleichet der anderen;

Und so deutet das Chor auf ein geheimes Gesetz - "

Platead hat dieses geheime Gesetz ermittelt. Es läßt sich zunächst ganz trocken in folgenden zwei Sätzen aussprechen:

I. Wo mehrere ebene Flüssigkeitshäutchen in der Figur zusammentreffen, sind sie stets drei an der Zahl, und je zwei bilden miteinander nahe gleiche Winkel.

2. Wo mehrere flüssige Kanten in der Figur zusammentrefien, sind sie stets vier an der Zahl, und.je zwei derselben bilden miteinander nahe gleiche Winkel.

Das sind nun freilich zwei recht kuriose Paragraphen eines trostlosen Gesetzes, dessen Grund wir nicht recht einzusehen vermögen. Diese Bemerkung können wir aber oft auch an anderen Gesetzen machen. Nicht immer sind der Fassung des Gesetzes die vernünftigen Motive 
des Gesetzgebers anzusehen. In der Tat lassen sich aber unsere beiden Paragraphen auf sehr einfache Gründe zurückführen. Werden nämlich diese Paragraphen genau befolgt, so kommt dies darauf hinaus, daß die Oberfläche der Flüssigkeit so klein ausfällt, als sie unter den gegebenen Umständen werden kann.

Wenn also ein äußerst intelligenter, mit allen Kniffen der höheren Mathematik ausgerüsteter - Schneider sich die Aufgabe stellen würde, das Drahtnetz eines Würfels so mit Tuch zu überziehen, daß jeder Tuchlappen mit dem Draht und auch mit dem übrigen Tuch zusammenhängt, wenn er. dies Geschäft mit der Nebenabsicht ausführen wollte, möglichst viel Stoff - bei seite zu legen; so würde er keine andere Figur zu stande bringen, als diejenige, welche sich auf dem Drahtnetz aus Seifenlösung von selbst bildet. Die Natur verfährt bei Bildung der Flüssigkeitsfiguren nach dem Prinzip eines habsüchtigen Schneiders, sie kümmert sich hierbei nicht um die Façon. Aber merkwürdig genug! die schönste Façon bildet sich dabei von selbst.

Unsere erwähnten beiden Paragraphen gelten zunächst nur für die Seifenfiguren, sie finden selbstverständlich keine Anwendung auf die massiren Ölfiguren. Der Satz aber, daß die Oberfläche der Flüssigkeit so klein ausfällt, als sie unter den gegebenen Umständen werden kann, paßt auf alle Flüssigkeitsfiguren. Wer nicht nur den Buchstaben, sondern die Motive des Gesetzes kennt, wird sich auch in Fällen zurechtfinden, in welchen der Buchstabe nicht mehr ganz paßt. So ist es nun auch mit dem Prinzip 
der kleinsten Oberfläche. Es führt uns überall richtig, auch wo die beiden erwähnten Paragraphen nicht mehr passen. Es handelt sich nun zunächst darum, uns anschaulich zu machen, daß die Flüssigkeitsfiguren nach dem Prinzip der kleinsten Oberfläche zu stande kommen. Das ÖI auf unserer Drahtpyramide in dem Wasser-Weingeistgemisch haftet an den Drahtkanten, die es nicht verlassen kann, und die gegebene Ölmenge trachtet sich nun so zu formen, daß die Oberfläche hierbei möglichst klein ausfällt. Versuchen wir diese Verhält. nisse nachzuahmen! Wir überziehen die Drahtpyramide mit einer Kautschukhaut, und an die Stelle des Drahtstiels setzen wir ein Röhrchen, welches ins Innere des von Kautschuk eingeschlossenen Raumes führt. Durch dieses Röhrchen können wir Luft einblasen oder aussaugen. Die vorhandene Luftmenge stellt uns die Menge des Öls vor, die ge-

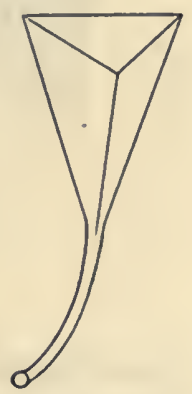

Fig. 3 . spannte Kautschukhaut aber, welche sich möglichst zusammenziehen will, und an den Drahtkanten haftet, repräsentiert die verkleinerungssüchtige Öloberfläche. Wirk lich erhalten wir nun beim Einblasen und Ausziehen der Luft alle Ölpyramidenfiguren von der bauchigen bis zur hohlwandigen. Schließlich, wenn wir alle Luft aussaugen, präsentiert sich uns die Seifenfigur. Die Kautschukblätter klappen": ganz aneinander, werden vollkommen eben und stoBen in vier scharfen Kanten im Mittelpunkte der Pyramide zusammen. 
An den Seifenhäutchen läßt-sich, wie VAN DER MENSRRUGGGHe gezeigt hat, das Verkleinerungsbestreben - direkt nachweisen. Taucht man ein Drahtquadrat mit einem Stiel in Seifenlösung, so erhält man an demselben eine schöne ebene Seifenhaut. Auf diese legen wir einen * dünnen Faden (Coconfaden), dessen beide Enden
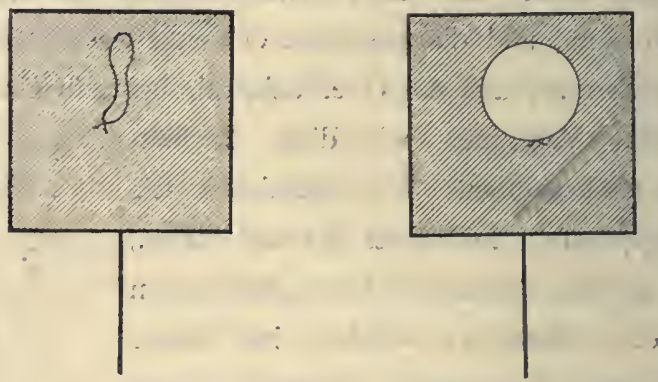

Fig. 4.

wir miteinander verknüpft haben. Stößt man die vom Faden umschlossene Flüssigkeit durch, so erhalten wir eine Seifenhaut mit einem kreisförmigen Loch, dessen Grenze der Faden bildet, ähnlich einer Sparherdplatte. Indem der Rest der Haut sich möglichst verkleinert, wird bei der unveränderlichen Länge des Fadens das Loch möglichst groß, was nur bei der Kreisform erreicht ist.

Nach dem Prinzip der kleinsten Oberfläche nimmt auch die frei schwebende Ölmasse die Kugelform an. Die Kugel ist die Form der kleinsten Oberfläche bei größtem Inhalt. Nähert sich doch ein Reisesack. desto mehr der Kugelform, je mehr wir ihn füllen.

Wieso das Prinzip der kleinsten Oberfläche unsere 
beiden sondẹrbaren Paragraphen zur Folge haben kann, wollen wir uns an einem, eirfacheren Falle aufklären. Denken wir uns über vier feste Rollen $a b c d$ und durch zwei bewegliche :Ringe $f: g$, eịne am Nagel $e$ befestigte glatte Schnur gewunden, welche :bei $\cdot h$ : mit einẹm Ge.
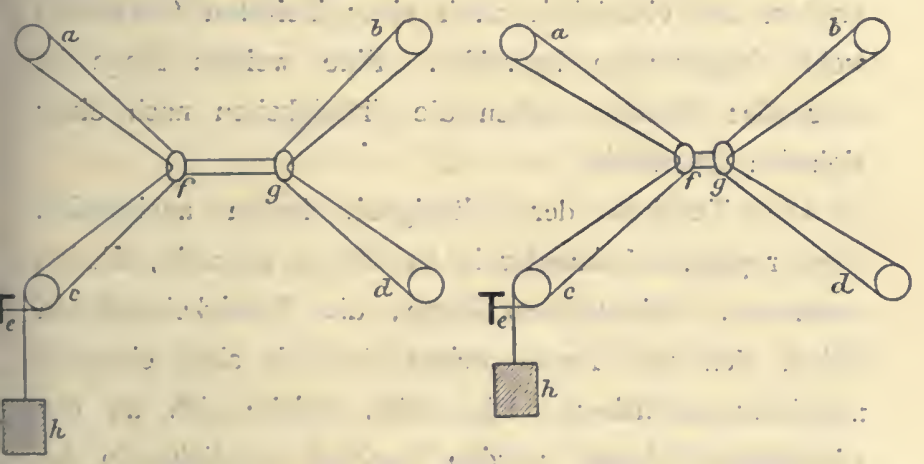

(

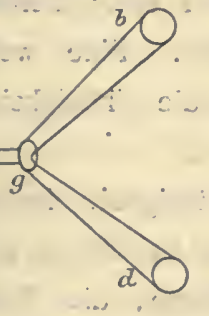

Fig. 5 .

wicht beschwert ist. :-Dies Gewicht hạt nun kein anderes Bestreben, als zu fallen, also den Schnurteil e.h möglichst zu verlängern, also den Rest. der Schnur, der siç über die Rollen schlingt, möglichst, zu yerkürzen. "Die Schnüre miissen', mit den' Rollen, und vermöge, der 'Ringe miteinander in Verbindung bleiben. Die :Verhältnisse sind also ähnliche, wie bei den Flüssigkeitsfiguren. Dạs Ergebnis ist auch ein ähuliches. Wenn; wie in ;er Figur, vier Schnurpaare zusammenstoßen ${ }_{f ;}$.so bleibt es nicht dabei $^{\circ}$ Das..Verkürzungsbestreben der Schnur hat zur Folge, daß die Ringe :auseinandertretely; 'so zwar, daß jetzt iberall nur drei Schnurpaare aneinanderstolsen, und zwar je zwei unter gleichen Winkeln (von , 120 ${ }^{\circ}$ ). In der 
Tat ist bei dieser Anordnung die größtmögliche Verkürzung der Schnur erreicht, wie sich elementar-geometrisch leicht nachweisen läßt.

Wir können hiernach das Zustandekommen der schönen und komplizierten Figuren durch das bloße Streben der Flüssigkeit nach einer kleinsten Oberfläche wohl einigermaßen begreifen. Eine weitere Frage ist aber die: Warum streben die Flüssigkeiten nach einer kleinsten Oberfläche?

Die Teilchen der Flüssigkeit haften aneinander. Die Tropfen, miteinander in Berührung gebracht, fließen zusammen. Wir können sagen, die Flüssigkeitsteilchen ziehen sich an. Dann suchen sie sich aber einander möglichst zu nähern. Die Teile, welche sich an der Oberfläche befinden, werden trachten, möglichst in das Innere der Masse einzudringen. Dieser Prozeß kann erst beendigt sein, wenn die Oberfläche so klein geworden ist, als es unter den gegebenen Umständen möglich ist, wenn so wenige Teilchen als möglich an der Oberfläche zurückgeblieben, wenn so viele Teile als möglich ins Innere eingedrungen sind, wenn die Anziehungskräfte nichts mehr $\mathrm{zu}$ leisten übrig behalten haben. *)

Der Kern des Prinzips der kleinsten Oberfläche, welches auf den ersten Blick ein recht ärmliches Prinzip $\mathrm{zu}$ sein scheint, liegt also in einem anderen, noch viel einfacheren Grundsatz, der sich etwa so anschaulich

*) Fast in allen gut durchgeführten Teilen der Physik spielen solche Maximum- oder Minimum-Aufgaben eine grofse Rolle. 
machen läßt. Wir können die Anziehungs- und Abstoßungskräfte der Natur als Absichten der Natur auffassen. Es ist ja der innere Druck, den wir vor einer Handlung fühlen, und den wir Absicht nennen, endlich nicht so wesentlich verschieden von dem Drucke des Steines auf seine Unterlage oder dem Drucke des Magneten auf einen anderen, daß es unerlaubt sein müßte, für beide wenigstens in gewisser Rücksicht denselben Namen zu gebrauchen. Die Natur hat also die Absicht, das Eisen dem Magnete, den Stein den Erdmittelpunkte zu nähern u. s. w. Kann eine solche Absicht erreicht werden, so wird sie ausgeführt. Ohne aber Absichten zu erreichen, tut die Natur gar nichts. Darin verhält sie sich vollkommen wie ein guter Geschäftsmann.

Die Natur will die Gewichte tiefer bringen. Wir können ein Gewicht heben, indem wir ein anderes größeres dafür sinken lassen, oder indem wir eine andere stärkere Absicht der Natur befriedigen. Meinen wir aber die Natur schlau zu benützen, so stellt sich die Sache, näher betrachtet, immer anders. Denn immer hat sie uns benützt, um ihre Absichten zu erreichen.

Gleichgewicht, Ruhe besteht immer nur dann, wenn die Natur nichts in ihren Absichten erreichen kann, wenn die Kräfte der Natur so weit befriedigt sind, als dies unter den gegebenen Umständen möglich ist. So sind z. B. schwere Körper im Gleichgewicht, wenn der sogenannte Schwerpunkt so tief wie möglich liegt, oder wenn so viel Gewicht, als es die Umstände erlauben, so tief wie möglich gesunken ist. 
Man kann sich kaum des Gedankens erwehren, daß dieser Grundsatz auch außer dem Gebiete der sogenannten unbelebten 'Natur seine Geltung' hat. Gleichgewicht im Staate besteht auch dann, wenn die Absichten der Parteien so weit erreicht sind, als es momentan möglich ist, oder wie man scherzweise in der.Sprache der Physik sagen könnte, wenn die soziale potentielle Energie ein Minimum geworden ist. $\%$ )

$\therefore$ 'Sie sehen; unser geizig kaufmännisches Prinzip ist reich 'an Folgerungen. Ein. Resultat der nüchternsten Forschung, ist es für die Physik so fruchtbar geworden, wie die trockenen Fragen des Sokrates für die Wissenschaft überhaupt. Erscheint auch das Prinzip zu wenig ideal, desto idealer sind dessen Früchte.

Und warum sollte sich auch die Wissenschaft eines solchen Prinzipes' schämen? Ist doch die Wissenschaft selbst nichts weiter als ein - Geschäft! ${ }^{*}$ ) Stellt sie :sich doch die:Aufgabe, mit möglichst wenig Arbeit; in möglichst kurzer Zeit, mit möglichst wenigen Gedanken sogar, möglichst: viel żu erwerben von der ewigen, unendlichen Wahrheit. ${ }^{*}$ )

"Ähnliche Betrachtungen finden sich bei Quételet, „du système sociale". ***) Die Wissenschaft selbşt läfst sich als eine Maximum- und Minimum. Aufgabe betrachten, so wie das Geschäft eines Kaufmannes. Überhaupt ist die geistige Tätigkeit des Forschers nicht so sehr verschieden von' jener des gewöhnlichen Lebens, als man sich dies gewöhnlich vorstellt.

wow) Vergl. Artikel XIII. 
II.

\section{Über die Corti'schen Fasern des Ohres.*)}

Wer das Reisen kennt, der weiß, daß die Wanderlust mit dem Wandern wächst. Wie schön muß sich wohl dies waldige Tal von jenem Hügel ausnehmen! Wo rieselt dieser klare Bach hin, der sich dort in dem Schilf verbirgt. Wenn ich nur wüßte, wie die Landschaft hinter jenem Berge aussieht. So denkt das Kind bei seinen ersten Ausflügen. So ergeht es auch dem Naturforscher.

Die ersten Fragen werden dem Forscher durch praktische Rücksichten aufgedrängt, die späteren nicht mehr. $\mathrm{Zu}$ diesen zieht ihn ein unwiderstehlicher Reiz, ein edleres Interesse, das weit über das materielle Bedürfnis hinaus geht. Betrachten wir einen besonderen Fall.

Seit geraumer Zeit fesselt die Einrichtung des Gehörorgans die Aufmerksamkeit der Anatomen. Eine bedeutende Anzahl wichtiger Entdeckungen wurde durch ihre Arbeit zu Tage gefördert, eine schöne Reihe von Tatsachen und Wahrheiten wurde festgestellt. Allein mit diesen T'at. sachen erschien eine Reihe von neuen merkwürdigen Rätseln.

*) Populäre Vorlesung gehalten i. J. 1864 zu Graz.

Mach, Vorlesungen. 3. Aufi. 
Während die Lehre von der Organisation und den Verrichtungen des Auges bereits zu einer verhältnismäßig bedeutenden Klarheit gediehen ist, während gleichzeitig die Augenheilkunde eine Stufe erreicht hat, welche das vorige Jahrhundert kaum ahnen konnte, während der beobachtende Arzt mit Hilfe des Augenspiegels tief ins Innere des Auges eindringt, liegt die Theorie des Ohres zum Teil noch in einem ebenso geheimnisvollen als für den Forscher anziehenden Dunkel.

Nehmen. Sie dies Ohrmodell in Augenschein! Schon bei jenem allgemein bekannten populären Teile, nach dessen Erstreckung in den Weltraum hinaus die Menge des Verstandes geschätzt wird, schon bei der Ohrmuschel beginnen die Rätsel. Sie sehen hier eine Reihe zuweilen sehr zierlicher Windungen, deren Bedeutung man nicht genau anzugeben vermag. Und doch sind sie gewiß nicht ohne Grund da.

Die Ohrmuschel ( $a$ in nebenstehen-

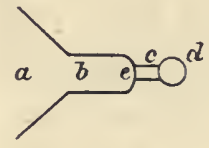

Fig. 6. dem Schema) führt den Schall in den mehrfach gekrümmten Gehörgang $b$, welcher durch eine dünne Haut, das sogenannte Trommelfell $e$ abgeschlossen ist. Dieses wird durch den Schall in Bewegung gesetzt und bewegt wieder eine Reihe kleiner sonderbar geformter Knöchelchen $(c)$. Den Schluß bildet das Labyrinth (d). Es besteht aus einer Anzahl mit Flüssigkeit gefüllter Höhlen, in welche die unzähligen Fasern des Gehörnervs eingebettet sind. Durch die Schwingung der Knöchelchen c wird die Labyrinthflüssigkeit erschüttert und der Gehörnerv gereizt. Hier beginnt der Prozeß des Hörens. So 
viel ist festgestellt. Die Einzelheiten aber sind ebenso viele unerledigte Fragen.

$\mathrm{Zu}$ allen diesen Rätseln hat MARChese A. CoRTi erst im Jahre $185 \mathrm{I}$ ein neues hinzugefügt. Und merkwürdig, gerade dieses Rätsel ist es, welches wahrscheinlich die erste richtige Lösung erfahren hat. Dies wollen wir heute besprechen.

CORTr fand nämlich in der Schnecke, einem Teil des Labyrinthes, eine große Anzahl skalenartig geordneter mit fast geometrischer Regelmäßigkeit nebeneinander gelagerter mikroskopischer Fasern. KöLLIKER zählte derselben an 3000. Max Schultze und Deiters haben sie ebenfalls untersucht.

Die Beschreibung der Einzelheiten könnte Sie nur belästigen, ohne größere Klarheit in die Sache zu bringen. Ich ziehe es deshalb vor, kurz zu sagen, was nach der Ansicht bedeutender Naturforscher wie HeLmholtz und Fechner das Wesentliche an diesen Corti'schen Fasern ist. Die Schnecke scheint eine große Anzahl elastischer Fasern ron abgestufter Länge (Fig. 7) zu enthalten, an welchen die Zweige des Hörnervs hängen. Diese ungleich langen CoRTr'schen Fasern müssen Fig. 7. offenbar auch von ungleicher Elastizität und demnach auf verschiedene Töne gestimmt sein. Die Schnecke stellt also eine Art Klavier vor.

Wozu mag nun diese Einrichtung, die sich sonst bei keinem anderen Sinnesorgan wiederfindet, taugen? Hängt sie nicht mit einer ebenso besonderen Eigenschaft des 
Ohres zusammen: Und in der Tat gibt es eine solche. Sie wissen wohl, daß es möglich ist, in einer Symphonie die einzelnen Stimmen für sich zu verfolgen. Ja sogar in einer Bach'schen Fuge geht dies noch an, und dies ist doch schon ein tüchtiges Stück Arbeit. Aus einer Harmonie sowohl, wie aus dem größten Tongewirre, vermag das Ohr die einzelnen Tonbestandteile herauszuhören. Das musikalische Ohr analysiert jedes Tongemenge. Das Auge hat eine analoge Eigenschaft nicht. Wer vermöchte es z. B. dem Weiß anzusehen, ohne es auf dem Wege des physikalischen Experimientes erfahren zu haben, daß es durch Zusammensetzung aus einer Reihe von Farben entsteht. Sollten nun die beiden Dinge, die genannte Eigenschaft und die von CORTI entdeckte Einrichtung des Ohres, wirklich zusammenhängen? Es ist sehr wahrscheinlich. Das Rätsel wird gelöst, wenn wir annehmen, daß jedem Ton von bestimmter Höhe eine besondere Faser des CoRTr'schen Ohrklaviers und demnach ein besonderer an derselben hängender Nervenzweig entspricht.

Damit ich jedoch in den Stand gesetzt werde, Ihnen dies vollständig klar zu machen, muß ich bitten, mir einige Schritte durch das dürre Gebiet der Physik zu folgen.

Betrachten Sie ein Pendel. Aus der Gleichgewichtslage gebracht, etwa durch einen Stoß, fängt das Pendel an in einem bestimmten Takte $z u$ schwingen, der von seiner Länge abhängt. Längere Pendel schwingen langsamer, kürzere rascher. Unser Pendel soll etıra einen Hin- und Hergang in einer Sekunde ausführen. 
Das Pendel kann leicht auf doppelte Art in heftige Schwingungen versetzt werden, entweder durch einen starken plötzlichen Stoß, oder durch eine Anzahl passend angebrachter kleiner Stöße. Wir bringen z. B. dem in der Gleichgewichtslage ruhenden Pendel einen ganz kleinen Stoß bei. Es führt dann eine sehr kleine Schwingung aus. Wenn es nun nach einer Sekunde zum drittenmal die Gleichgewichtslage wieder passiert, geben wir demselben wieder einen ganz kleinen Stoß in der Richtung des ersten. Abermals nach einer Sekunde beim fünten Durchgang durch die Gleichgewichtslage stoßen wir wieder u. s. f. - Sie sehen, bei einer solchen Operation werden unsere Stöße immer die bereits vorhandene Bewegung des Pendels unterstützen. Nach jedem kleinen Stoße wird es in seinen Schwingungen etwas weiter ausholen und endlich eine ganz beträchtliche Bewegung zeigen.*)

Dies wird uns jedoch nicht immer gelingen. Es gelingt nur, wenn wir in demselben Takte stoßen, in welchem das Pendel selbst schwingen will. Würden wir z. B. den zweiten Stofs schon anbringen nach einer halben Sekunde und in gleicher Richtung wie den ersten Stoß, so müßte dieser der Bewegung des Pendels gerade entgegen wirken. Überhaupt ist leicht einzusehen, daß wir die Bewegung des Pendels desto mehr unterstützen, je mehr der Takt unserer kleinen Stöße dem eigenen Takte des Pendels gleichkommt. Stoßen wir in einem anderen Takte, als das Pendel schwingt, so befördern

*) Dies Experiment mit den anschliefsenden Betrachtungen rührt von Galilei her. 
wir zwar auch in einigen Momenten dessen Schwingung, in anderen aber hemmen wir dieselbe wieder. Der Effekt wird im ganzen desto geringer, je mehr unsere Handbewegung von der Bewegung des Pendels verschieden ist. *)

Was vom Pendel gilt, kann man von jedem schwingenden Körper sagen. Eine tönende Stimmgabel schwingt auch, sie schwingt rascher wenn sie höher, langsamer wenn sie tiefer ist. Unserm Stimm-A entsprechen etwa 450 Schwingungen in der Sekunde.

Ich stelle zwei genau gleiche Stimmgabeln mit Re. sonanzkästchen versehen auf den Tisch nebeneinander. Die eine Gabel schlage ich kräftig an, so daß sie einen starken Ton gibt, und erfasse sie alsbald wieder mit der Hand, um den Ton zu unterdrücken. Nichtsdestoweniger hören Sie den Ton ganz deutlich fortsingen, und durch Betasten können Sie sich überzeugen, daß nun die andere nicht angeschlagene Gabel schwingt.

Ich klebe dann etwas Wachs an die Zinken der einen Gabel. Dadurch wird sie verstimmt, sie wird ein klein wenig tiefer. Wiederhole ich nun dasselbe Experiment mit

*) [Bei genauer Überlegung stellt sich der Vorgang etwas komplizierter dar. Wenn die schwingende Bewegung gar keinem Widerstand unterliegt und die Erregung g en a u in dem Takte der Schwingung erfolgt, so kann die Schwingungsweite ins Unbegrenzte wachsen. Weicht der Takt der erregenden Bewegung im geringsten von der Schwingungsdauer $a b$, so tritt nach einer Periode der Verstärkung, die von desto längerer Dauer ist, je kleiner jene Differenz ist, eine Periodé der Abschwächung von gleicher Dauer ein. Dieser Wechsel wiederholt sich fort und fort, wie man am besten beobachtet, wenn man durch eine galvanisch tönende Stimmgabel eine zweite von etwas verschiedener Stimmung erregt. Je geringer der Unterschied der Stimmung, desto länger dauert die Phase der Anschwellung, und eine desto gröfsere Schwin ungsweite kann die erregte Gabel erreichen. Igoz.] 
den zwei ungleich hohen Gabeln, indem ich die eine Gabel anschlage und dieselbe mit der Hand erfasse, so rerlischt in demselben Augenblicke der Ton, als ich die Gabel berühre.

Wie geht es nun bei diesen beiden Experimenten zu? - Ganz einfach! - Die schwingende Gabel bringt der Luft $45^{\circ}$ Stöße in der Sekunde bei, welche sich bis zur anderen Gabel fortptlanzen. Ist die andere Gabel auf denselben Ton gestimmt, schwingt sie also für sich angeschlagen in demselben Takte, so genügen die ersteren Stöße, so gering sie auch sein mögen, um sie in leb. haftes Mitschwingen zu versetzen. Dies tritt nicht mehr ein, sobald der Schwingungstakt beider Gabeln etwas verschieden ist. Man mag noch so viele Gabeln anschlagen, die auf A gestimmte Gabel verhält sich gegen alle Töne gleichgültig außer gegen ihren Eigenton oder demselben sehr nahe liegende Töne. Und wenn Sie 3, $4,5 \ldots$ Gabeln zugleich anschlagen, so tönt die AGabel nur dann mit, wenn sich unter den angeschlagenen auch eine A-Gabel befindet. Sie wählt also unter den angegebenen Tönen denjenigen aus, welcher ihr entspricht.

Man kann dasselbe von allen Körpern behaupten, welche zu tönen vermögen. Trinkgläser klingen beim Klavierspiel auf den Anschlag bestimmter Töne, ebenso die Fensterscheiben. Die Erscheinung ist nicht ohne Analogie in anderen Gebieten. Denken Sie sich einen Hund, der auf den Namen Phylax hört; er liegt unter dem Tische. Sie sprechen von Herkules und Plato, Siẹ 
rufen alle Heldennamen, die Ihnen einfallen. Der Hund rührt sich nicht, obgleich Ihnen eine ganz leise Bewegung seines Ohres andeutet das leise Mitschwingen seines Bewußtseins. Sowie Sie aber Phylax rufen, springt er Ihnen freudig entgegen. Die Stimmgabel ist ähnlich dem Hund; sie hört auf den Namen A.

Sie lächeln, meine Damen! - Sie rümpfen die Näschen - das Bild gefällt Ihnen nicht! - Ich kann noch mit einem anderen dienen. Zur Strafe sollen Sie's hören. Es ergeht Ihnen nicht besser als der Stimmgabel. Viele Herzen pochen Ihnen warm entgegen. Sie nehmen keine Notiz davon; Sie bleiben kalt. Das nuitzt Ihnen aber nichts; das wird sich rächen. Kommt nur einmal ein Herz, das so ganz im rechten Rhythmus schlägt, dann - hat auch Ihr Stündlein geschlagen. Dann schwingt auch Ihr Herz mit, Sie mögen wollen oder nicht. Dies Bild ist wenigstens nicht ganz neu, denn schon die Alten, wie die Philologen versichern; kannten - die Liebe.

Das für tönende Körper aufgestellte Gesetz des Mitschwingens erfährt eine gewisse Änderung für solche Körper, welche nicht selbst zu tönen vermögen. Solche Körper schwingen zwar viel schwächer, aber fast mit jedem Tone mit. Ein Cylinderhut tönt bekanntlich nicht. Wenn Sie aber im Konzert den Hut in der Hand halten, können Sie die ganze Symphonie nicht bloß hören, sondern auch mit den Fingern fühlen. Es ist wie bei den Menschen. Wer selbst den Ton anzugeben vermag, kümmert sich wenig um das Gerede der 
anderen. Der Charakterlose geht aber überall mit, der muf überall dabei sein, im Mäßigkeitsverein und beim Trinkgelage - überall, wo es ein Komitee zu bilden giebt. Der Cylinderhut ist unter den Glocken, was der Charakterlose unter den Charakteren.*)

Ein klangfähiger Körper tönt also jedesmal mit, sohald sein Eigenton entweder allein oder zugleich mit anderen Tönen angegeben wird. Gehen wir nun einen Schritt weiter. Wie wird sich eine Gruppe von klangfähigen Körpern verhalten, welche ihren Tonhöhen nach eine Skale bilden? - Denken wir uns z. B. eine Reihe von Stäben oder Saiten (Fig. 8), welche auf die Töne c d ef $g$.... gestimmt sind. Es werde auf einem musikalischen Instrument der Akkord ceg angegeben. Jeder der Stäbe (Fig. 8) wird sich umsehen, ob in dem Akkorde sein Eigenton ent-

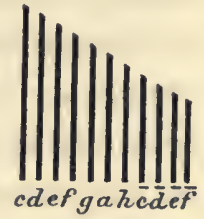

Fig. 8. halten ist, und wenn er diesen findet, wird er mittönen. Der Stab $c$ gibt also sofort den Ton $c$, der Stab $e$ den Ton $e$, der Stab $g$ den Ton $g$. Alle übrigen Stäbe bleiben in Ruhe, tönen nicht.

Wir brauchen nach einem solchen Instrumente, wie das hier erdichtete, nicht lange zu suchen. Jedes Klavier ist ein solcher Apparat, an welchem sich das erwähnte

*) [Finden die Schwingungen unter Widerstand statt, so vernichtet dieser nach einer Zeit, welche desto kürzer ist, je grörser der Widerstand, nicht nur die Eigenbewegung der Schwingung, sondern auch die Wirkung der Impulse. Der Einfluf́s der Vergangenheit verschwindet des:o rascher, je grölser _der Widerstand. Die Steigerung der Wirkung der Impulse ist also überhaupt auf eine kürzere Zeit beschränkt. Aber auch der Einflurs der Stimmungsdifferenz, welcher ebenfalls auf Summation in der Zeit beruht, kann sich nur in geringerem Grade bemerklich machen. 8902.$]$ 
Experiment in ganz auffallender Weise ausführen läßt. Wir stellen zwei gleichgestimmte Klaviere nebeneinander. Das erste verwenden wir zur Tonerregung, das zwèite lassen wir mitschwingen, nachdem wir die Dämpfung gehoben, und die Saiten also bewegungsfähig gemacht haben.

Jede Harmonie, die wir auf dem ersten Klavier kurz anschlagen, hören wir auf dem zweiten deutlich wiederklingen. Um nun nachzuweisen, daß es dieselben Saiten sind, die auf dem einen Klavier angeschlagen werden, und auf dem anderen wiederklingen, wiederholen wir das Experiment in etwas veränderter Weise. Wir lassen auch auf dem zweiten Klavier die Dämpfung nieder und halten auf diesem bloß die Tasten $c e g$, während wir auf dem ersten $c$ eg kurz anschlagen. Die Harmonie $c$ eg tönt auch jetzt in dem zweiten Klavier nach. Halten wir aber auf dem einen Klavier bloß $g$, indem wir auf dem anderen c e $g$ anschlagen, so klingt bloß $g$ nach. Es sind also die gleichgestimmten Saiten beider Klaviere, welche sich wechselseitig anregen.

Das Klavier vermag jeden Schall wiederzugeben, der sich aus seinen musikalischen Tönen zusammensetzen läßt. Es gibt z. B. einen Vokal, den man hineinsingt, ganz deutlich zurück. Und wirklich hat die Physik nachgewiesen, daß die Vokale sich aus einfachen musikalischen Tönen darstellen lassen.

Sie sehen, daß in einem Klavier durch Erregung bestimmter Töne in der Luft sich mit mechanischer Notwendigkeit ganz bestimmte Bewegungen auslösen. Es ließe sich dies zu manchem netten Kunststückchen ver- 
wenden. Denken Sie sich ein Kästchen, in welchem etwa eine Saite von bestimmter Tonhöhe gespannt wäre. Dieselbe gerät jedesmal in Bewegung, so oft ihr Ton gesungen oder gepfiffen wird. Der heutigen Mechanik würde es nun nicht sonderlich schwer fallen, das Kästchen so einzurichten, daß die schwingende Saite etwa eine galvanische Kette schließt und das Schloß aufspringt. Nicht viel mehr Mühe könnte es kosten, ein Kästchen zu verfertigen, welches auf den Pfiff einer bestimmten Melodie sich öffnet. Ein Zauberwort! und die Riegel fallen! $\mathrm{Da}$ hätten wir denn ein neues Vexierschloß; wieder ein Stück jener alten Märchenwelt, von welcher die Gegenwart bereits so viel verwirklicht hat, jener Märchenwelt, zu der Casellis Telegraph, durch welchen man mit eigener Handschrift einfach in die Entfernung schreibt, den neuesten Beitrag liefert. Was würde wohl der gute alte Herodot, der schon in Ägypten über manches den Kopf geschüttelt, zu allen diesen Dingen sagen? - , ,, $\mu о \iota$ $\mu \dot{\varepsilon} \nu$ ov่ $\pi \iota \sigma \tau \alpha^{\prime \prime, ~ " m i r ~ k a u m ~ g l a u b l i c h ", ~ s o ~ t r e u h e r z i g ~ w i e ~}$ damals, als er von der Umschiffung Afrikas hörte.

Ein neues Vexierschloß! - Wozu diese Erfindung? Ist doch der Mensch selbst ein solches Vexierschloł. Welche Reihe von Gedanken, Gefühlen, Empfindungen, werden nicht durch ein Wort angeregt. Hat doch jeder seine Zeit, da man ihm mit einem bloßen Namen das Blut zum Herzen treiben kann. Wer in einer Volkversammlung war, weiß die ungeheure Arbeit und Bewegung z.u schätzen, welche ausgelöst wird durch die unschuldigen Worte: Freiheit, Gleichheit, Brüderlichkeit! 
Kehren wir nun zu unserem ernsteren Gegenstande zurück. Betrachten wir wieder unser Klavier oder irgend einen anderen klavierartigen Apparat. Was leistet ein solches Instrument? Es zerlegt, es analysiert offenbar jedes in der Luft erregte Tongewirre in seine einzelnen Tonbestandteile, indem jeder Ton von einer anderen Saite aufgenommen wird: es führt eine wahre Spektralanalyse des Schalles aus. Selbst der vollständig Taube könnte mit Hilfe eines Klaviers, indem er die Saiten betastet oder mit dem Mikroskop deren Schwingungen beobachtet, sofort die Schallbewegung in der Luft untersuchen und die einzelnen Töne angeben, welche erregt werden.

Das Ohr hat dieselbe Eigenschaft wie das Klavier. Das Ohr leistet der Seele, was das beobachtete Klavier dem Tauben leistet. Die Seele ohne Ohr ist ja taub. Der Taube mit dem Klavier dagegen hört gewissermaßen, nur freilich viel schlechter und schwerfälliger als mit dem Ohre. Auch das Ohr zerlegt den Schall in seine Tonbestandteile. Ich täusche mich nun auch gewiß nicht, wenn ich annehme, daß Sie bereits ahnen, was es mit den Corti'schen Fasern für ein Bewandtnis hat. Wir können uns die Sache recht einfach vorstellen. Ein Klavier benutzen wir zur Tonerregung, das zweite denken wir uns in das Ohr eines Beobachters, an die Stelle der CoRTi'schen Fasern, welche ja wahrscheinlich einen ähnlichen Apparat vorstellen. An jeder Saite des Klaviers im Ohr soll eine besondere Faser des Gehörnerven hängen, so zwar, daß nur diese Faser gereizt wird, wenn die Saite in Schwingungen gerät. Schlagen wir nun auf dem 
äusseren Klavier einen Akkord an, so erklingt für jeden Ton desselben eine bestimmte Saite des inneren Klaviers, es werden so viele verschiedene Nervenfasern gereizt, als der Akkord Töne hat. Die von verschiedenen Tönen herrïhrenden gleichzeitigen Eindrücke können sich auf diese Weise unvermischt erhalten und durch die Aufmerksamkeit gesondert werden. Es ist wie mit den fünf Fingern der Hand. Mit jedem Finger können Sie etwas anderes tasten. Das Ohr hat nun an 3000 solcher Finger und jeder ist für das Tasten eines anderen Tones bestimmt.*) Unser Ohr ist ein Vexierschloß der erwähnten Art. Durch den Zaubergesang eines Tones springt es auf. Aber es ist ein ungemein sinnreiches Schloß. Nicht bloß ein Ton, jeder Ton bringt es zum Aufspringen, aber jeder anders. Auf jeden Ton antwortet es mit einer anderen Empfindung. Mehr als einmal ist es in der Geschichte der Wissen. schaft vorgekommen, daß eine Erscheinung durch die Theorie vorausgesagt und lange hernach erst der Beobach. tung zugänglich wurde. LEvERRIER hat die Existenz und den Ort des Planeten Neptun vorausbestimmt und erst später hat GaLL denselben an dem bestimmten Ort wirklich aufgefunden. Hamltos hat die Erscheinung der sogenannten konischen Lichtbrechung theoretisch erschlossen und Lloyd hat sie erst beobachtet. Ähnlich erging es nun auch der Helmholtz'schen Theorie der Corti'schen Fasern. Auch diese scheint durch die späteren Beobachtungen von $\mathrm{V}$. HeNsex im wesentlichen ihre Bestätigung

*) Weitere Ausführungen, welche über den hier dargelegten $\mathrm{Helmholtz}$. schen Gedanken hinausgehen, befinden sich in meinen „,Beiträgen zur Analyse der Empfindungen". Jena 1836. 3. Autlage 1902. 
erfahren zu haben. Die Krebse haben an ihrer freien Körperoberfläche Reihen von längeren und kürzeren, dickeren und dünneren, mutmaßlich mit Hörnerven zusammenhängende Härchen, welche gewissermaßen denCORTI'schen Fasern entsprechen. Diese Härchen sah Hessen bei Erregung von Tönen schwingen, und zwar gerieten bei verschiedenen Tönen auch verschiedene Haare in Schwingungen.

Ich habe die Tätigkeit des Naturforschers mit einer Wanderung verglichen. Wenn man einen neuen Hügel ersteigt, erhält man von der ganzen Gegend eine andere Ansicht. Wenn der Forscher die Erklärung eines Rätsels gefunden, so hat er damit eine Reihe anderer Rätsel gelöst.

Gewiß hat es Sie schon oft befremdet, daß man, die Skale singend und bei der Oktave anlangend die Empfindung einer Wiederholung, nahezu dieselbe Empfindung hat wie beim Grundtone. Diese Erscheinung findet ihre Aufklärung in der dargelegten Ansicht über das Ohr. Und nicht nur diese Erscheinung, sondern die gesamten Gesetze der Harmonielehre lassen sich von hier aus mit bisher nicht geahnter Klarheit überschauen und begründen. Für heute muß ich mich jedoch mit der Andeutung dieser reizenden Aussichten begnügen. Die Betrachtung selbst würde uns zu weit führen in andere Wissensgebiete.

So muß ja auch der Naturforscher selbst sich Gewalt antun auf seinem Wege. Auch ihn zieht es fort von einem Wunder zum anderen, wie den Wanderer von Tal zu Tal, wie den Menschen überhaupt die Umstände aus einem Verhältnis des Lebens ins andere drängen. Er forscht nicht sowohl selbst, als er vielmehr geforscht wird. Aber 
er benütze die Zeit! und lasse den Blick nicht planlos schweifen! Denn bald erglänzt die Abendsonne, und ehe er die nächsten Wunder noch recht besehen, faßt ihn eine mächtige Hand und entführt ihn - in ein neues Reich der Rätsel.

Die Wissenschaft stand ehemals in einem anderen Verhältnis zur Poesie als heute. Die alten indischen Mathematiker schrieben ihre Lehrsätze in Versen und in ihren Rechnungsaufgaben blühten Lotosblumen, Rosen und Lilien, reizende Landschaften, Seen und Berge.

„Du schiffst auf einem See im Kahn. Eine Lilie ragt einen Schuh hoch über den Wasserspiegel hervor. Ein Lüftchen neigt sie, und sie verschwindet zwei Schuh von ihrem früheren Orte unter dem Wasser. Schnell Mathematiker, sage mir, wie tief ist der See :“

So spricht ein alter indischer Gelehrter. Diese Poesie ist, und zwar mit Recht, aus der Wissenschaft verschwunden. Aber in ihren dürren Blättern, da weht eine andere Poesie, die sich schlecht genug beschreiben läßt für jenen, der sie nie empfunden. Wer diese Poesie ganz genieBen will, der muß selbst Hand ans Werk legen, muß selbst forschen. Deshalb genug davon! Ich schätze mich glücklich, wenn Sie dieser kleine Ausflug in ein blütenreiches Tal der Physiologie nicht gereut, und wenn Sie die Überzeugung mit sich nehmen, daß man auch ron der Wissenschaft ähnliches sagen kann, wie von der Poesie:

Wer das Dichten will verstehen, Mufs ins Land der Dichtung gehen;

Wer den Dichter will verstehen, Murs in Dichters Lande gehen. 
III.

\section{Die Erklärung der Harmonie.*)}

Wir besprechen heute ein Thema, vielleicht von etwas allgemeinerem Interesse: die Erklärung der Harmonie der Töne. Die ersten und einfachsten Erfahrungen über die Harmonie sind uralt. Nicht so die Erklärung der Gesetze. Diese wurde erst von der neuesten Zeit geliefert. Erlauben Sie mir einen historischen Rückblick.

Schon Pythagoras (540-500 v. Chr.) wußte daß der Ton einer Saite von bestimmter Spannung in die Oktave umschlägt, wenn man die Saitenlänge auf die Hälfte, in die Quinte, wenn man sie auf zwei Dritteile verkürzt, und daß dann der erstere Grundton mit den beiden anderen konsoniert. Er wußte überhaupt, daß dieselbe Saite bei gleicher Spannung konsonierende Töne gibt, wenn man ihr nach und nach Längen erteilt, welche in sehr einfachen Zahlenverhältnissen stehen, sich etwa wie I $: 2,2: 3,3: 4,4: 5$, u. s. w. verhalten.

Den Grund dieser Erscheinung vermochte Pythagoras nicht zu finden. Was haben die konsonierenden 'löne

4) Populäre Vorlesung gehalten i. J. 1864 zu Graz. 
mit den einfachen Zahlen zu tun? So würden wir heute fragen. Pythagoras aber muß dieser Úmstand weniger befremdlich als unerklärlich vorgekommen sein. Er suchte in der Naivetät der damaligen Forschung den Grund der Harmonie in dem geheimen wunderbaren Wesen der Zahlen. Dies hat wesentlich zur Entwickelung einer Zahlenmystik beigetragen, deren Spuren sich auch heute noch in den Traumbüchern finden und. bei solchen Gelehrten, welche das Wunderbare der Klarheit vorziehen.

Euklides (500 v. Chr.) gab bereits eine Definition der Konsonanz und Dissonanz, wie wir sie den Worten nach heute kaum besser hinstellen könnten. Die Konsonanz zweier Töne, sagt er, sei dic Mischung derselben, die Dissonanz hingegen die Unfähigkeit sich zu mischen, wodurch sie für das Gehör rauh werden. Wer dic heutige Erklärung der Erscheinung kennt, hört sie sozusagen aus Euklides Worten wiederklingen. Dennoch kannte er die wahre Erklärung der Harmonie nicht. Er war der Wahrheit unbewußt sehr nahe gekommen, ohne sie jedoch wirklich zu erfassen.

Lemsiz ( $1646-x$ i 6 n. Chr.) nahm. die von seinen Vorgängern ungelöst zurückgelassene Frage wieder auf. Er wußte wohl, daß die Töne durch Schwingungen erregt werden, daß der Oktave doppelt so viele Schwingungen entsprechen als dem Grundtone. Ein leidenschaftlicher Liebhaber der Mathematik, wie er war, suchte er die Erklärung der Harmonie in dem geheimen Zählen und Vergleichen der einfachen Schwingungszahlen und in der geheimen Freude der Seele an dieser Beschäftigung. Ja, Mach, Vorlesungen. 3. Auf. 
wie denn aber — werden Sie sagen - wenn jemand gar nicht ahnt, daß die Töne Schwingungen sind, dann wird wohl das Zählen und auch die Freude am Zählen so geheim sein müssen, daß kein Mensch darum weiß! Was doch die Philosophen treiben! Die langweiligste Beschäftigung, das Zählen, zum Prinzip der Ästhetik zu machen! Sie haben mit diesen Gedanken so unrecht nicht, und doch hat auch LeIBxiz gewiß nicht ganz Unsinniges gedacht, wenn gleich sich schwer klar machen läßt, was er unter seinem geheimen Zählen verstanden wissen wollte.

Ähnlich wie LeIBxiz suchte der große Euler (I $707-$ I783) die Quelle der Harmonie in der von der Seele mit Vergnügen wahrgenommenen Ordnung unter den Schwingungszahlen.

RAmeaU und d'Alembert (I 7 I $\left.7-I_{7} \delta_{3}\right)$ rückten der Wahrheit näher. Sie wußten, daß jeder musikalisch brauchbare Klang neben seinem Grundtone noch die Duodecime und die nächst höhere Terz hören lasse, daß ferner die Ähnlichkeit zivischen Grundton und Oktave allgemein auffalle. Hiernach mußte ihnen das Hinzufügen der Oktave, Quinte, Terz u.s. w. zum Grundtone als „natürlich" erscheinen. Allerdings hatten sie den richtigen Gesichtspunkt, allein mit der bloßen Natürlichkeit einer Erscheinung kann sich der Forscher nicht begnügen; denn gerade das Natürliche ist es, dessen Erklärung er sucht.

Rameaus Bemerkung schleppte sich nun durch die ganze neuere Zeit fort, ohne jedoch zur vollstäıdigen Auffindung der Wahrheit zu führen. MARx stellt sie an 
die Spitze seiner Kompositionslehre, ohne eine weitere Anwendung von derselben zu machen. Auch GoETHE und ZELTER in ihrem Briefwechsel streifen sozusagen die Wahrheit. Letzterem ist RaMeaus Ansicht bekannt. Sie werden nun gewiß erschrecken vor der Schwierigkeit dieses Problems, wenn ich Ihnen noch sage, daß bis auf dic neueste Zeit selbst die Professoren der Physik keine Auskunft zu geben wußten, wenn sie um die Erklärung der Harmonic befragt wurden.

Erst kürzlich hat Hecnholtz die Lüsung der Frage gefunden:*) Um Ihnen diese aber klar zu machen, muß ich. einige Erfahrungssätze der Physik und Psychologie erwähnen.

I. Bei jeden WahrnehmungsprozeB, bei jeder Beobachtung, spiclt die Aufmerksamkeit eine bedeutende Rolle. Nach Belegen hierfür brauchen wir nicht lange zu suchen. Sie erhalten cin Schreiben mit sehr schlechter Schrift; es will Ihnen nicht gelingen, dasselbe zu entziffern. Sie fassen bald diese, bald jene Linie zusammen, ohne daß sich daraus ein Buchstabe gestalten will. Erst wenn Sie Ihre Aufmerksamkeit auf Gruppen von Linien leiten, die wirklich zusammen gehören, ist das Lesen möglich. Schriften, die aus kłeineren Figuren und Verzierungen bestehen, sind nur aus größerer Entfernung zu lesen, wenn dic Aufmerksamkeit nicht mehr von den Gesamtkonturen auf dic Einzelheiten abgelenkt wird.

4) Kritische Ausführungen über die Unvollständigkeit dieser Lösung enthalten meine "Beiträge zur Analyse der Empfindungen" Jena 1886. 3. Auf. 1902. Vgl. auch den folgenden Artikel. 
Ein schönes hierher gehöriges Beispiel geben die bekannten Bilderscherze von Gruseppe ARCiMBoldo im Erdgeschosse der Belvedere-Gallerie zu Wien. Es sind dies symbolische Darstellungen des Wassers, Feuers u. s. w., menschliche Köpfe, zusammengesetzt aus Wassertieren und Feuermaterial. Man sieht aus geringer Entfernung nur die Einzelheiten, welche die Aufmerksamkeit auf sich ziehen, aus größerer Entfernung hingegen nur die Gesamtfigur. Doch erwählt man leicht eine Distanz, bei der es keine Schwierigkeit hat, durch bloße willkürliche Leitung der Aufmerksamkeit bald die ganze Figur zu sehen, bald die kleineren Gestalten, aus welchen sie sich zusammensetzt. Häufig findet man ein Bild, das Grab Napoleons rorstellend. Das Grab ist von dunklen Bäumen umgeben, zwischen welchen der helle Himmel als Grund durchblickt. Man kann dieses Bild lange betrachten, ohne etwas anderes zu bemerken als eben die Bäume. Plötzlich aber erblickt man die Gestalt $\mathrm{Napo-}$ leons zwischen den Bäumen, wenn man nämlich unwillkürlich dem hellen Grunde die Aufmerksamkeit zuwendet. An diesem Falle sieht man am deutlichsten, welche wichtige Rolle die Aufmerksamkeit spielt. Dasselbe sinnliche Objekt kann durch ihr Zutun allein zu ganz verschiedenen Wahrnehnungen Veranlassung geben.

Schlage ich irgend eine Harmonie am Piano an, so können Sie durch die bloße Aufmerksamkeit jeden Ton derselben fixieren. Sie hören dann am deutlichsten diesen fixierten Ton und alle übrigen erscheinen als bloße Zugabe, welche nur die Klangfarbe des ersteren verändert. Der Ein-

\section{Digitized by Microsoft $(B$}


druck derselben Harmonie verändert sich wesentlich, wenn wir andern und andern Tönen unsere Aufmerksamkeit zuwenden.

Versuchen Sie eine beliebige Harmoniefolge, z. B. und fixieren Sie einmal dic Oberstimme $e$, dann den Bass $e-a$, so hören Sie dieselbe Harmoniefolge in beiden Fällen ganz verschicden. Im ersten Falle erhalten Sic den Eindruck, als ob der fixierte Ton sich

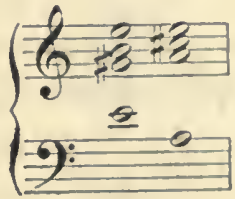

Fig. 9 . gleich bliebe und bloß seine Klangfarbe veränderte, im zweiten Falle hingegen scheint die ganze Klangmasse in die Tiefe $z u$ steigen. Es gibt eine Kunst des Komponisten, die'Aufmerksamkeit des Hörers zu leiten. Es gibt aber ebensowohl eine Kunst des Hörens, dic auch nicht jedermanns Sache ist.

Der Klavierspieler kennt die merkwürdigen Effekte, welche man erzielt, wenn man von einer angeschlagenen Harmonic irgend eine Taste losläßt.

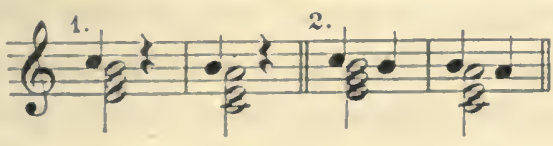

Fig. 10.

Der Satz I auf dem Piano gespielt klingt fast wie 2. Der Ton, welcher der losgelassenen Taste zunächst liegt, erklingt nach dem Loslassen der letzteren wic neu an. geschlagen. Die Aufmerksamkeit, von der Oberstimme nicht melur in Anspruch genommen, wird eben auf denselben hinüber geleitet.

Die Auflösung einer belicbigen Harmonie in die ein- 
zelnen Tonbestandteile vermag schon ein mäßig geübtes musikalisches $\mathrm{Ohr}$ auszuführen. Bei fortschreitender Übung gelangt man noch weiter. Dann zerfällt der bis-

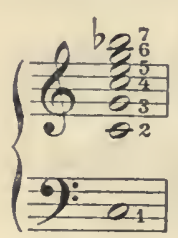

Fig. II. her für einfach gehaltene musikalische Klang in eine Reihe von Tönen. Schlägt man z. B. auf dem Piano I an, so hört man bei nötiger Anspannung der Aufmerksamkeit neben diesem starken Grundtone noch die schwächeren höheren Obertöne $2 \ldots 7$, also die Oktave, die Duodecime, die Doppeloktave, Terz, Quint und kleine Septime der Doppeloktave.

Ganz dasselbe bemerkt man an jedem musikalisch verwendbaren Klange. Jeder läßt neben seinem Grundtone, freilich mehr oder weniger stark, noch die Oktare, Duodecime, Doppeloktave u. s. f. hören. Namentlich ist dies leicht an den offenen und gedeckten Labialpfeifen der Orgel zu beobachten. Je nachdem nun gewisse Obertöne in einem Klange mehr oder weniger stark hervortreten, rerändert sich die Klangfarbe, jene Eigentümlichkeit des Klanges, durch welche wir den Klang des Klaviers von jenem der Violine, der Klarinette u. s.w. unterscheiden.

Am Piano lassen sich diese Obertöne sehr leicht auffallend hörbar machen. Schlage ich z. B. nach der letzten Notenangabe I kurz an, während ich nach einander die Tasten $1,2,3, \ldots 7$ bloß halte, so klingen nach dem Anschlag von I die Töne 2, 3, . . 7 fort, indem die rom Dämpfer befreiten Saiten ins Mitschwingen geraten.

Wie Sie wissen, ist dieses Mitschwingen der gleichDigitized by Microșoft ${ }^{\circledR}$ 
gestimnıten Saiten mit den Obertönen nicht als Sympathie, sondern vielmehr als dürre mechanische Notwendigkeit aufzufassen. Man hat sich also das Mitschwingen nicht so zu denken, wie es ein geistreicher Feuilletonist sich vorgestellt hat, der von BeETHOvens F-moll-Sonate Op. 2 eine schauerliche Geschichte erzählt, welche ich Ihnen nicht vorenthalten will. „Auf der letzten Londoner Industrieausstellung spielten neunzehn Virtuosen die F-moll-Sonate auf demselben Piano. Als nun der zwanzigste Virtuose hintrat, um zur Abwechslung die F-moll-Sonate zu spielen, da begann das Klavier selbst, zum Schrecken aller Anwesenden, die Sonate von sich zu geben. Der eben anwesende Erzbischof von Canterbury inußte ans Werk und den F-moll-Teufel austreiben."

Obgleich nun die besprochenen Obertöne bloß bei besonderer Aufmerksamkeit gehört werden, spielen sie doch die wichtigste Rolle bei Bildung der Klangfarbe sowohl, als auch bei der Konsonanz und Dissonanz der Klänge. Dies erscheint ihnen vielleicht befremdlich. Wie soll das, was nur unter besonderen Ümständen gehört wird, doch für das Hören überhaupt von solcher Bedeutung sein?

Zichen Sie doch Ihre tägliche Erfahrung zu Rate. Wie viele Dinge gibt es, die Sie gar nicht bemerken, die Ihnen erst dann auffallen, wenn sie nicht mehr da sind. Ein Freund tritt zu Ihnen herein; Sie wissen nicht, welche Veränderung mit ihm vorgegangen. Erst nach längerer Musterung finden Sie, daß sein Haar geschoren sei. Es ist nicht schwer, den Verlag eines Werkes nach dem bloßen Druck zu erkennen, und doch vermag kaum je-

\section{Digitized by Microsoft $\AA$}


mand genau anzugeben, wodurch sich diese Typen von jenen so auffallend unterscheiden. Oft erkannte ich èin gesuchtes Buch an einem Stückchen unbedruckten weißen Papiers, das unter dem Gewuihle der übrigen Bücher hervorsah, und doch habe ich das Papier nie genau gemustert, wüßte auch nicht anzugeben, wodurch es von anderen Papieren so sehr verschieden ist.

Wir wollen also festhalten, daß jeder musikalisch verwendbare Klang neben seinem Grundtone noch die Oktave, Duodecime,. Doppeloktave u. s. w. als Obertöne hören läßt, und daß diese für das Zusammenwirken mehrerer Klänge von Wichtigkeit sind.

2. Es handelt sich nun noch um eine zweite Tatsache. Betrachten Sie eine Stimmgabel. Dieselbe gibt angeschlagen einen ganz glatten Ton. Schlagen Sie aber zu dieser Gabel eine zweite etwas höhere oder tiefere an, welche für sich allein ebenfalls einen ganz glatten Ton gibt; so hören Sie, sobald Sie beide Gabeln zusammen auf den Tisch stemmen oder beide vor das Ohr halten, keinen gleichmäßigen Ton mehr, sondern eine Anzahl von Tonstößen. Diese Tonstöße werden rascher, wenn der Unterschied der Tonhöhen größer wird. Man nennt diese Tonstöße, welche für das Ohr sehr unangenehm werden, wenn sie etwa $33 \mathrm{mal}$ in der Sekunde stattfinden, Schwebungen.

Immer, wenn von zwei gleichen Tönen einer gegen den anderen verstimmt wird, entstehen Schwebungen. Ihre Zahl wächst mit der Verstimmung und sie werden gleichzeitig unangenehmer. Diese Rauhigkeit erreicht ihr Maximum bei etwa 33 Schwebungen in der Sekunde. Bei weiterer 
Verstimmung und noch größerer Zahl der Schwebungen nimmt dies Unangenehme wieder $a b$, so zwar, daß Töne, welche in ihrer Höhe bedeutend verschieden sind, keine beleidigenden Schwebungen mehr geben.

Um sich das Zustandekommen der Schwebungen einigermaßen klar zu machen, nehmen Sie zwei Metronome zur Hand und stellen dieselben nahezu gleich ein. Sie können geradezu beide gleich einstellen. Sie brauchen deshalb nicht zu fürchten, daß sie auch wirklich gleich schlagen. Die im Handel vorkommenden Metronome sind schlecht genug, um bei Einstellung auf gleiche Skalenteile merklich ungleiche Schläge zu geben. Setzen Sie nun diese etwas ungleich schlagenden Metronome in Gang, so bemerken Sie leicht, daß ihre Schläge abwechselnd bald aufeinander, bald zwischeneinander fallen. Die Abwechslung ist desto rascher, je verschiedener der Takt beider Metronome. In Ermangelung von Metronomen führen Sie das $\mathrm{Ex}-$ periment mit zwei 'Taschenuhren aus.

Auf ähnliche Weise entstehen dic Schwebungen. Die taktmäßigen Stöße zweier tönender Körper fallen bei ungleichen Tonhöhen bald aufeinander, bald zwischeneinander, wobei sie sich abwechselnd verstärken und schwächen. Daher das stoßweise unangenehme Anschwellen des Tones.

Nachdem wir nun die Obertöne und die Schwebungen kennen gelernt, gehen wir zur Beantwortung unserer Hauptfrage über. Warum bewirken gewisse Tonhöhenverhältnisse einen angenehmen Zusammenklang, eine Konsonanz, andere einen unangenehmen, eine Dissonanz? Es scheint, daß alles Unangenchme des Zusammen- 
klingens von den entstehenden Schwebungen herrihrt. Die Schwebungen sind nach Hezinoltz die einzige Sünde, das einzige Böse in der harmonischen Musik. Konsonanz ist Zusammenklang ohne merkliche Schwebungen.

Um Ihnen dies recht anschaulich darzustellen, habe ich ein Modell konstruiert. Sie sehen in Fig. I 2 eine Klaviatur. Oben an derselben befindet sich eine verschiebbare Leiste $a a$ mit den Marken $\mathrm{I}, 2 \ldots 6$. Bringe ich diese Leiste in irgend eine Stellung, etwa so, daß

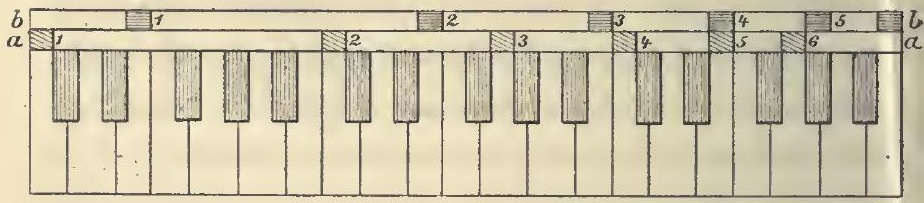

Fig. 12.

die Marke I auf den Ton c der Klaviatur fällt, so bezeichnen, wie Sie sehen, die Marken 2, 3 . . 6 die Obertöne von $c$. Dasselbe gilt, wenn die Leiste in eine andere Stellung gebracht wird. Eine zweite ganz gleiche Leiste $b b$ zeigt dieselbe Eigenschaft. Beide Leisten in irgend zwei Stellungen bezeichnen nun durch ihre Marken alle Töne, welche bei dem Zusammenwirken der durch die Marke I bezeichneten Klänge ins Spiel kommen.

Beide Leisten auf denselben Grundton eingestellt, lassen erkennen, daß auch sämtliche Obertöne zusammenfallen. Es wird der eine Klang durch den anderen eben nur verstärkt. Die einzelnen Obertöne ei nes Klanges liegen zu weit voneinander, um miteinander merkliche Schwebungen zu geben. Der zweite Klang fügt nichts Neues hinzu, 
demnach auch keine neuen Schwebungen. Der Einklang ist die vollkommenste Konsonanz.

Verschieben wir eine Leiste gegen die andere, so bedeutet dies eine Verstimmung des einen Klanges. Alle Obertöne des einen Klanges fallen nun neben jene des anderen, es treten sofort Schwebungen auf, der Zusammenklang wird unangenehm, wir erhalten eine Dissonanz. Wenn wir mit der Verschicbung der einen Leiste fortfahren, so finden wir, daß im allgemeinen die Obertöne immer nebeneinander fallen, immer Schwebungen und Dissonanzen veranlassen. Nur in ganz bestimmten Stellungen fallen die Obertöne beider Klänge zum Teil zusammen. Solche Stellungen bezeichnen eben einen höheren Grad des Wohlklanges, die konsonanten Intervalle.

Man kann diese konsonanten Intervalle leicht versuchsweise auffinden, wenn man Fig. 12 aus Papier ausschneidet und $b b$ gegen $a a$ verschiebt. Die vollkonmensten Konsonanzen sind die Oktave und die Duodecime, weil bei diesen die Obertöne des einen Klanges ganz auf die des anderen fallen. Bei der Oktave z. B. fällt $\mathrm{I} b$ auf $2 a, 2 b$. auf $4 a, 3^{b}$ auf $6 a$. Es können also keine Schwebungen entstehen. Konsonanzen sind also solche Zusammenklänge, welche nicht von unangenehmen Schwebungen begleitet sind.

Nur solche Klänge konsonieren, welche einen Teil ihrer Partialtöne gemeinsam haben. Natürlich wird man an solchen Klängen, auch wenn sie nacheinander angegeben werden, eine gewisse Verwandtschaft erkennen. Denn der folgende erregt eben, der gemeinsamen Obertöne wegen, zum Teil dieselbe Empfindung wie der vorlhergehende. 
Am auffallendsten ist dies bei der Oktave. Wenn die Skale bei der Oktave anlangt, glaubt man in der Tat den Grundton wieder zu hören. Die Grundlagen der Harmonie sind also auch jene der Melodic.

Konsonanz ist Zusammenklang ohne merkliche Schwebungen! Dieser Grundsatz genügt, um in die Lehren des Generalbasses eine wunderbare Ordnung und Konsequenz zu bringen. Die Kompendien der Harmonielehre, welche bisher an Feinheit der Logik - Gott sei's geklagt — den Kochbüchern-wenig nachgaben, werden ungemein klar und einfach. Noch mehr! Viel von dem, was geniale Musiker wie Palestrina, Mozart, BeEthoven unbewußt richtig getroffen, worüber bisher kein Lehrbuch Rechenschaft zu geben vermochte, erfährt durch obigen Satz seine Begründung.

Und das Beste an dieser 'Theorie ist, daß sie den Stempel ihrer Wahrheit an sich trägt. Sie ist kein Hirngespinst. Jeder Musiker kann die Schwebungen selbst hören, welche die Obertöne der Klänge miteinander geben. Jeder Musiker kann sich überzeugen, daß man die Schwebungen ihrer Zahl und Rauhigkeit nach für einen beliebigen Fall voraus berechnen kann, und daß sie in dem Maße eintreten, als die Theorie es bestimmt.

Dies ist die von Helmholtz ge gebene Beantwortung der von Pythagoras aufgeworfenen Frage, so weit sie sich nämlich mit jenen Mitteln darstellen läßt, die ich anwenden durfte. Ein langer Zeitraum liegt zwischen der Aufstellung der Frage und der Lösung. Mehr als einmal waren bedeutende Forscher näher an dieser Beantwortung, als sie selbst ahnten.

Der Forscher sucht die Wahrheit. Ich weiß nicht, Digitized by Microsoft (B) 
ob die Wahrheit auch den Forscher sucht. Wäre dem aber so, dann würde die Geschichte der Wissenschaft lebhaft an das von Malern und Dichtern oft verewigte bekannte Stelldichein erinnern. Eine hohe Gartenmauer, rechts der Jüngling, links das Mädchen. Der Jüngling seufzt, das Mädchen seufzt! Beide warten. Beide ahnen nicht, wie nahe sie sich sind.

In der Tat, die Analogie gefällt mir. Die Wahrheit läßt sich zwar den Hof machen, allein sie verhält sich passiv. Sie führt wohl gar den Forscher an der Nase herum. Sie will verdient sein und verachtet den, der sie $\mathrm{zu}$ rasch erlangen will. Und wenn sich der eine den Kopf zerbricht, was schadet's - es kommt ein anderer — und die Wahrheit bleibt ja immer jung. Zwar scheint es mitunter, als ob sie ihrem Verehrer gewogen wäre, aber das eingestehn — niemals! Nur wenn die Wahrheit besonders gut aufgeräumt ist, wirft sie dem Verehrer einen Sonnenblick zu. Denn wenn ich gar nichts tue, denkt die Wahrheit - zuletzt erforscht mich der Kerl gar nicht mehr.

Dies eine Stückchen Wahrheit haben wir nun. Die kommt uns nicht mehr los! Wenn ich aber bedenke, was sie gekostet, wie viel Arbeit, wie viele Denkerleben, wie sich durch Jahrhunderte ein halber Gedanke fortgequält, bis er zum ganzen geworden, wenn ich bedenke, dab es die Mühe von mehr als zwei Jahrtausenden ist, welche aus meinem unscheinbaren Modell spricht, dann - ohne zu heucheln - gereut mich fast mein Scherz. Und auch uns fehlt ja noch so vicl. Wenn man 
einst nach einem Jahrtausend Stiefel, Cylinderhüte und Krinolinen, Klaviere und Baßgeigen aus dem Schoß der Erde graben wird, aus dem jüngsten Alluvium, als Leitmuscheln des neunzehnten Jahrhunderts, wenn man über diese wunderlichen Gebilde und unsere moderne Ringstraße Studien machen wird, wie heute iber Steinaxt und Pfahlbau - dann wird man wohl nicht begreifen, wie wir an mancher großen Wahrheit so nahe sein konnten, ohne sie wirklich zu erfassen. Und so ist es ewig die ungelöste Dissonanz, ewig die trübende Septime, die uns überall entgegentönt; wir ahnen zwar, sie wird sich lösen, aber den reinen Dreiklang erleben wir nicht und - auch unsere Urenkel nicht.

Meine Damen! Wenn es Ihre reizende Lebensaufgabe ist, konfus $\mathrm{zu}$ machen, so ist es die meinige, klar zu sein. Und da muß ich Ihnen denn eine kleine Sünde eingestehen, deren ich mich der Klarheit wegen schuldig gemacht. Ich habe Sie nämlich ein wenig belogen. Sie werden mir diese Lüge verzeihen, wenn ich sie sofort wieder reuig verbessere. Das Modell (Fig. I 2) spricht nicht die volle Wahrheit, denn es ist für die sogenannte temperierte Stimmung berechnet. Die Obertöne der Klänge aber sind nicht temperiert, sondern rein gestimmt Durch diese kleine Unrichtigkeit fällt nun das Modell bedeutend einfacher aus. Dabei genügt es für die gewöhnlichen Zwecke vollständig, und wer an demselben seine Studien macht, darf keinen merklichen Irrtum befürchten.

Wenn Sie nun aber von mir die volle Wahrheit for- 
dern würden, so kömnte ich Ihnen diese nur in einer mathematischen Formel darstellen. Ich müßte die Kreide zur Hand nehmen und - pfui! - in Ihrer Gegenwart rechnen. Das könnten Sie mir übel nehmen. Es soll auch nicht geschehen. Ich habe mir vorgenommen heute nicht mehr zu rechnen. Ich rechne heute auf gar nichts mehr, als auf Ihre Nachsicht, und diese werden Sie mir nicht versagen, wenn Sie bedenken, daß ich ron meinem Rechte, Sie zu langweilen, doch einen beschränkten Gebrauch gemacht habe. Ich könnte ja noch länger sprechen, und bin demnach berechtigt, mit Lessixgs Epigramm zu schließen :

Wenn Du ron allem dem, was diese Blätter füllt, Mein Leser, nichts des Dankes wert gefunden;

So sei mir wenigstens für das verbunden,

Was ich zurück behielt. 
IV.

\section{Zur Geschichte der Akustik.*)}

Beim Suchen nach Arbeiten von Amoxtons kamen mir einige Bände der Memoiren der Pariser Akademie aus den ersten Jahren des 18 . Jahrhunderts in die Hände. Es ist schwer, das Vergnügen zu schildern, das man beim Durchblättern dieser Bände empfindet, indem man einige der wichtigsten Entdeckungen sozusagen miterlebt, indem man verschiedene Vissensgebiete von beinahe gänzlicher Unkenntnis bis zu fast vollständiger prinzipieller Klarheit sich entwickeln sieht.

Hier sollen nur die grundlegenden Untersuchungen von SAuveur über Akustik besprochen werden, welche für den feinsinnigen Musiker, dem diese Blätter gewidmet sind, ${ }^{*}$ ) nicht ganz ohne Interesse sein werden. Mit Überraschung nimmt man wahr, wie außerordentlich nahe SAUveUR dem Standpunkte war, welchen anderthalb Jahrhunderte später erst HELMHOLTZ vollständig gewonnen hat. Die „Histoire de l'Académie" von I 700, p. I3I, teilt

*) Dieser Artikel, welcher in den Mitteilungen der deutschen mathemathischen Gesellschaft zu Prag (1892) erschien, dient zur Erläuterung der vorigen. *rof Prof. H. Durège. 
uns mit, daß es SAuveur.gelungen sei, aus der Musik ein naturwissenschaftliches Forschungsobjekt zu machen, und daß er die betreffende neue Wissenschaft „Akustik genannt habe. Auf füf Blättern wird eine ganze Reihe von Entdeckungen erwähnt, welche in dem Bande des nächst. folgenden Jahres weiter erörtert werden.

Die einfachen Schwingungszahlenverhältnisse der Konsonanzen behandelt SAUvEUR als etwas allgemein Bekanntes.*) Er hofft durch weitere Untersuchungen die Hauptregeln der musikalischen Komposition zu ermitteln und in die sMetaphysik des Angenehmen ", als deren Hauptgesetz er die Verbindung der »Einfachheit mit der Mannigfaltigkeit« angiebt, einzudringen. Ganz wie später noch EULER *;) hält er eine Konsonanz fur desto besser, durch je kleinere ganze Zahlen das Schwingungsverhältnis ausgedrückt werden kann, weil je kleiner diese Zahlen, desto häufiger die Schwingungen beider Töne koïncidieren und desto leichter a $\mathrm{u} f \mathrm{z}$ ufassen sind. Als Grenze der Konsonanz gilt ihm das Verhältnis 5:6, wiewohl er sich nicht verhehlt, daß die Übung, die Schärfung der Aufmerksamkeit, die Gewohnheit, der Geschmack und sogar das Vorurteil bei dieser Frage mitspielt, daß dieselbe also keine rein naturwissenschaftliche ist.

SaUveurs Vorstellungen entwickeln sich nun dadurch, daß er iiberall genauer quantitativ zu untersuchen strebt,

4) Die folgende Darstellung ist aus den Bänden für 8700 (erschienen 1703) und 1702 (erschienen 1704) geschöpft und teils der "Histoire de l'Académie", teils den ,Memoiren" entnommen. Die späteren Arbeiten kommen hier weniger in Betracht.

*) Euler, Tentamen novae theorize musicae. Petropoli 1739.

Mach, Vorlesungen. 3. Auf. 
als dies vorher geschehen war. Zunächst wünscht er einen fixen Ton von Ioo Schwingungen als Grundlage der musikalischen Stimmung so zu bestimmen, daß derselbe jederzeit leicht dargestellt werden kann, da ihm die Fixierung der Stimmung durch die üblichen Stimmpfeifchen, deren Schwingungszahl unbekannt war, ungenügend erscheint. Nach Mersenne (Harmonie universelle 1636) macht eine gegebene Saite von I 7 Fuß Länge, mit 8 livres gespannt, 8 unmittelbar sichtbare Schwingungen in der Sekunde. Durch Verkleinerung der Länge in einem bestimmten Verhältnis kann man also eine in demselben Verhältnis vergrößerte Schwingungszahl erhalten. Doch scheint ihm dies Verfahren zu unsicher, und er verwendet zu dem bezeichneten Zwecke die den Orgelbauern seiner Zeit bekannten Schwebungen (battemens), die er richtig durch das abwechselnde Koïncidieren und Alternieren gleicher Schwíngungsphasen ungleich gestimmter Töne erklärt.*;) Jeder Koïncidenz entspricht eine Tonanschwellung und demnach der Zahl dèr Stöße in der Sekunde die Differenz der Schwingungszahlen. Stimmt man also zwei Orgelpfeifen zu einer dritten im Verhältnis der kleinen und großen Terz, so bilden erstere zu einander das Schwingungszahlen. verhältnis $24: 25$, das heißt auf je 24 Schwingungen der tieferen fallen 25 der höheren und ein 'Tonstoß. Geben beide Pfeifen zusammen vier Schwebungen in der Sekunde, so hat die höhere den fixen Ton ron 100 Schwingungen. Die betreffende offene Pfeife hat dann die Länge von fünf

*) Als Sa u ve u r das Schwe bungsexperiment der Akademie vorführen wollte, gelang es nur sehr mangelhaft. „Histoire de l'Académie“, Année 1700, p. 136 
Fuß. Hiermit sind auch die absoluten Schwingungszahlen aller übrigen Töne bestimmt.

Es ergibt sich sofort, daß die $8 \mathrm{mal}$ längere Pfeife von $40 \mathrm{FuB}$ die Schwingungszahl I $21 / 2$ gibt, welche SAUveUR dem tiefsten hörbaren Ton zuschreibt, sowie daß die $64 \mathrm{mal}$ kürzere 6400 Schwingnngen ausführt, welche Zahl SAuveur für die obere Hörgrenze hält. Die Freude über die gelungene Zählung der sunwahrnehmbaren Schwingungen« bricht hier unverkennbar durch, und sie ist berechtigt, wenn man bedenkt, daß auch heute noch das Sauveursche Prinzip mit einer geringen Modifikation das feinste und einfachste Mittel ist zur genauen Bestimmung derSchwingungszahlen. Viel wichtiger war aber noch eine andere Beobachtung, die Sauveur beim Studium der Schwebungen machte, und auf die wir noch zurückkommen.

Saiten, deren Länge durch verschiebbare Stege abgeändert werden kann, sind bei den erwähnten Untersuchungen viel leichter $z u$ handhaben als Pfeifen. Es war also natïrlich, daß SAUveur sich bald mit Vorliebe dieses Mittels bediente.

Durch einen zufällig nicht vollkommen anliegenden Steg, welcher die Schwingungen nur unvollkommen hemmte, entdeckte er die harmonischen Obertöne der Saite zunächst durch das Ohr, und erschloß hieraus die Abteilung derselben in Aliquotteile. Die gezupfte Saite gab z. B. die Duodecime ihres Grundtones, wenn der Steg in einem Dritteilungspunkte stand. Wahrscheinlich auf Vorschlag eines Akademikers*) wurden nun verschieden gefärbte

\$) Histoire de l'Académie, Année 170r, p. 134.

$$
\text { Digitized by Microsoft } \stackrel{4^{*}}{\circledR}
$$


Papierreiter auf die Knoten (nœuds) und Bäuche (ventres) gesetzt, und die Saitenteilung bei Angabe der zu ihrem Grundton (son fondamental) gehörigen Obertöne (sons harmoniques) war hiermit auch sichtbar gemacht. An die Stelle des hemmenden Steges trat bald die zweckent. sprechendere Feder oder der Pinsel.

Bei diesen Versuchen beobachtete SAUveur auch das Mitschwingen einer Saite bei Erregung einer anderen gleichgestimmten; er fand auch, daß der Oberton einer Saite durch eine andere auf denselben gestimmte Saite ansprechen kann. Er ging noch weiter und fand, daß bei Erregung einer Saite an einer anderen ungleichgestimmten Saite der ge me in s a me Oberton anspricht, z. B. bei Saiten von dem Schwingungszahlenverhältnis $3: 4$ der vierte der tieferen und der dritte der höheren. Es folgt hieraus unabweislich, daß die erregte Saite mit ihrem Grundton zugleich Obertöne gibt. Schon früher war SAUvEUR von anderen Beobachtern darauf aufmerksam gemacht worden, daß man bei fernen Musikinstrumenten, namentlich bei Nacht, die Obertöne heraushört.*) Er selbst bespricht das gleichzeitige Erklingen der Obertöne und des Grundtones.*) Daß er diesem Umstande nicht die gebührende Beachtung schenkt, wird, wie sich alsbald zeigt, für seine Theorie verhängnisvoll.

Beim Studium der Schwebungen macht Sauveur die Beobachtung, daß dieselben dem Ohr unangenehm seien. Er meint nun die Schwebungen nur dann gut

*) Mémoires de l'Académie, Année 170r, p. 298.

\%) Histoire de l'Académie, Année 1702, p. 91.

Digitized by Microsoft $\left({ }^{\circ}\right.$ 
zu hören, wenn weniger als sechs in der Sekunde stattfinden. Schwebungen in größerer Zahl hält er für nicht gut beobachtbar und für nicht störend. Er versucht nun den Unterschied zwischen' Konsonanz und Dissonanz auf die Schwebungen zurückzuführen. Hören wir ihn selbst. *)

„Les battemens ne plaisent pas à l'Oreille, à cause de l'inégalité du son, et l'on peut croire avec beaucoup d'apparence que ce qui rend les Octaves**) si agréables, c'est qu'on n'y entend jamais de battemens.

En suivant cette idée, on trouve que les accords dont on ne peut entendre les battemens, sont justement ceux que les Musiciens traitent de Consonances, et que ceux dont les battemens sé font sentir, sont les Dissonances, et que quand un àccord èst-Dissonance dans une certaine octave et Consonance dans une autre, c'est qu'il bat dans l'une, et qu'il ne bat pas dans l'autre. Aussi est il traité de Consonance imparfaite. Il est fort aisé par les principes de $\mathbf{M}^{r}$ Sauveur qu'on a établis ici, de voir quels accords battent, et dans quelles Oc: taves au-dessus ou au-dessous du son fixe. Si cette hypothèse est vraye, elle découvrira la véritable source des Règles de la composition; inconnue jusqu'à présent à la Philosophie, qui s'en remettait presque entièrement au jugement de l'Oreille. Ces sortes de jugemens na. turels, quelque bisarres qu'ils paroissent quelquefois, ne le sont point, ils ont des causes très réelles, dont la

\$) Diese Stelle ist der Histoire de l'Académie, Année 1700, p. 139 entnommen.

Weil alle in der Musik gebräuchlichen Oktaven einen zu grorsen Schwingungszahlenunterschied darbieten. 
connaissance appartient à la Philosophie, pourveu qu'elle s'en puisse mettre en possession.«

SaUveur erkennt also richtig in den Schwebungen die Störung des Zusammenklanges, auf welche „mutmaßlich" alle Disharmonie zurückzuführen ist. Man sieht aber sofort, dafs nach seiner Auffassung alle weiten Intervalle Konsonanzen, alle engen Dissonanzen sein müßten. Auch verkennt er die gänzliche prinzipielle Verschiedenheit seiner eingangs erwähnten älteren Auffassung von der neuen, welche er vielmehr $\mathrm{zu}$ verwischen sucht.

R. SiIth *) referiert die SAUveursche Theorie und bemerkt den ersteren der zuvor erwähnten Mängel. Indem er selbst im wesentlichen in der älteren SAUveurschen, meist EuLER zugeschriebenen Auffassung, befangen bleibt, kommt er doch bei seiner Kritik der heutigen Ansicht wieder um einen kleinen Schritt näher, wie dies aus folgenden Stellen hervorgeht.**)

»The truth is, this gentleman confounds the distinction between perfect and imperfect consonances, by comparing imperfect consonances which beat because the succession of their short cycles $\%$ ) is periodically confused and interrupted, with perfect ones which cannot beat, because the succession of their short cycles is never confused nor interrupted.

* R. Smith, Harmonics or the philosophy of musical Sounds. Cambridge 1749 . Ich habe dieses Buch 1864 nur flüchtig sehen können und habe auf dasselbe in einer 1866 erschienenen Schrift (Einleitung in die Helmholtzsche Musiktheorie) aufmerksam gemacht. Erst vor drei Jahren bin ich dieser Schrift wieder habhaft geworden und konnte von deren Inhalt genauere Kenntnis nehmen.

tow) Harmonics, p. 118 und p. 243.

* Short cycle ist die Periode, nach welcher sich dieselben Phasen beid e r zusammenwirkenden Töne wiederholen. 
"The fluttering roughness above mentioned is perceivable in all other perfect consonances, in a smaller degree in proportion as their cycles are shorter and simpler, and their pitch is higher; and is of a diffe. rent kind from the smother beats and undulations of tempered consonances; because we can alter the rate of the latter by altering the temperament, but not of former, the consonance being perfect at a given pitch: And because a judicious ear can often hear, at the same time, both the flutterings and the beats of a tempered consonance; sufficiently distinct from each other. -

$\gg$ For nothing gives greater offence to the hearer, though ignorant of the cause of it, than those rapid, piercing beats of high and loud sounds, which make imperfect consonances with one another. And yet a few slow beats, like the slow undulations of a close shake now and then introduced, are far from being disagreeable.

Smith ist also darüber im Klaren, daß außer den von SAUveur in Betracht gezogenen Schwebungen noch andere "Rauhigkeiten" existieren, und diese würden sich bei weiterer Untersuchung unter Festhalten des Sauveurschen Gedankens als die Schwebungen der Obertöne enthüllt haben, womit die Theorie den HeLMroltzschen Standpunkt erreicht hätte.

Wenn wir die Unterschiede der Sauveurschen Auffassung von derHeLмноцтzschen überblicken, so finden wir folgendes:

I. Die Ansicht, nach welcher die Konsonanz auf der häufigen regelmäßigen Koïncidenz der Schwingungen, auf der leichten Zählbarkeit derselben beruht, erscheint auf 
dem neuen Standpunkte als unzulässig. "Wohl sind die einfachen Schivingungszahlenverhältnisse mathematis che Merkmale der Konsonanz und physikalische Bedinguingen derselben, da hieran die Koïncidenz der Obertöne mit ihren weiteren physikalischen und phy siologischen Folgen gebunden ist. Allein eine physiologische oder psychologische Erklärung der Konsonanż ist hiermit nicht gegeben, schon deshalb nicht, weil in dem akustischen Nervenerregungsiprozesse nichts mehr von der Periodicität des Schallreizes zu finden ist.

2. In der Anerkennung der Schwebungen als Störungen der Konsonanz stimmen beide Theorien überein. Die Sauveursche Theorie berücksichtigt jedoch nicht, daß der Klang zusammengesetzt ist, und daß vorzugsweise durch die Schwebungen der Obertöne die Stö، rungen des Zusammenklanges weiter Intervalle entstehen. Ferner hat Sauveur mit der Behauptung, daß die Zahl der Schwebungen weniger als $\dot{s e c h s}$ in der Sekunde betragen müsse, um Störungen $z \mathbf{u}^{\prime}$ bewirken, nicht das Richtige getroffen. Schon Sмiтн weiß, daß sehr lang' same Schwebungen nicht stören, und HeLsholtz hat für das Maximum der Störung eine viel höhere Zahl (33) gefunden. Endlich hat SAUveur këine Rücksicht darauf genommen, daß die $\mathrm{Zahl}$ der Schwebungen zwar mit der Verstimmung zunimmt, dafür aber die Stärke derselben abnimmt. Auf das Prinzip der spezifischen Energien und die Gesetze des Mitschwingèns gestützt findet die neue Theorie, daß zwei Luftbewegungen von gleicher 
Amplituide, aber verschiedener Periode, $a \sin (r t)$ und $a \sin [(r+\varrho)(t+\tau)], \mathrm{nicht}$ in gleicher Amplitüde auf dasselbe Nervenendorgan übertragen werden können. Vielmehr spricht das Endorgan, welches auf die Periode $r$ am meisten reagiert, auf die Periode $r+\varrho$ schwächer an, so daß die beiden Amplitüden im Verhältnis $a: \varphi \cdot a$ stehen. Hierbei nimmt $\varphi$ ab, wenn $\varrho$ wächst und wird $=1$ für $\varrho=\dot{0}$, so daß nur der Reizanteil $\varphi \cdot a$ den Schwebungen unterliegt, $(\mathrm{r}-\varphi) a$ aber ohne Störung glatt abfließt.

Darf man aus der Geschichte dieser Theorie eine Moral ziehen, so kann es in anbetracht der Sauveurschen Irrtümer, die so nahe an der Wahrheit liegen, nur die sein, auch der neuen Theorie gegenüber einige Vorsicht zu üben. Und in der That scheint hierzu Grund vorhanden zu sein.

Der Umstand, daß der Musiker niemals einen besser konsonierenden Akkord auf einem schlechter gestimmten Klavier mit einem weniger konsonanten auf einem guten Klavier verwechseln wird, obgleich die Rauhigkeit in beiden Fällen die gleiche sein kann, lehrt hinlänglich, daß der Grad der Rauhigkeit nicht die e in $\mathbf{z}$ ig e Charakteristik einer Harmonie ist. Wie der Musiker weib, sind selbst die harmonischen Schönheiten einer BeEthovenschen Sonate auf einem schlecht gestimmten Klavier schwer umzubringen; sie leiden hierbei kaum mehr als eine RapHaELsche Zeichnung in groben und rauhen Strichen ausgefürt. Das positive physiologisch. psychologische Merkmal, welches eine Harmonie 
von der anderen unterscheidet, ist durch die Schwebungen nicht gegeben. Dieses Merkmal kann auch nicht darin liegen, daß z. B. beim Erklingen der großen Terz der fünfte Partialton des tieferen Klanges mit. dem vierten des höheren zusammenfällt. Dieses Merkmal hat ja nur Geltung für den untersuchenden abstrahierenden Verstand; wollte man dasselbe auch für die Empfindung als maßgebend ansehen, so würde man in einen fundamentalen Irrtum verfallen, der ganz analog wäre dem sub I angefuihrten.

Die positiven physiologischen Merkmale der Intervalle würden sich wahrscheinlich bald enthüllen, wenn es möglich wäre, den einzelnen tonempfindenden Organen unperiodische (z. B. galvanische) Reize zuzuführen, wobei also Schwebungen ganz wegfallen müßten. Leider kann ein derartiges Experiment kaum als ausführbar betrachtet werden. Die Zuführung von kurz dauernden, also ebenfalls schwebungslosen akustischen Reizen führt aber wieder den Übelstand einer nur ungenau bestimmten Tonhöhe mit sich. ${ }^{*}$ )

*; Vergl. Beiträge zur Analyse der Empfindungen. Jena 1886, S. I13 u. ff. 3. Auf. S. 219 u. ff. 
V.

\section{Über die Geschwindigkeit des Lichtes. *)}

Wenn der Kriminalrichter einen recht feinen Schurken vor sich hat, der es wohl versteht, sich durchzulügen, so ist es seine Hauptaufgabe, ihm durch einige geschickte Fragen ein Geständnis abzupressen. In einem ähnlichen Falle fast scheint sich der Naturforscher der Natur gegenüber zu befinden. Zwar dürfte er sich hier nicht sowohl als Richter, wie vielmehr als Spion fühlen, aber das Ziel bleibt ziemlich dasselbe. Die geheimen Motive und Gesetze des Wirkens sind es, welche die Natur gestehen soll. Von der Schlauheit des Forschers hängt es ab, ob er etwas erfährt. Nicht ohne Grund hat also Baco von Verulam die experimentelle Methode ein Befragen der Natur genannt. Die Kunst besteht darin, die Fragen so $z u$ stellen, daß sie ohne Verletzung der Etikette nicht unbeantwortet bleiben können.

Betrachten Sie nun noch die zahlreichen Instrumente, Werkzeuge und Quälapparate, mit welchen man der Natur forschend zu Leibe geht, und die des Dichterwortes spotten

*) Vortrag gehalten zu Graz i. J. 1866. 
, was sie Dir nicht offenbaren mag, zwingst Du ihr nicht ab mit Hebeln und mit Schrauben \& - betrachten Sie diese Apparate, und die Analogie mit der Tortur liegt nahe.

Die Auffassung der Natur, als der absichtlich verhïllten, die man nur mit Zwangsmitteln oder auf unredliche Weise entschleiern könne, lag manchem älteren Denker näher als uns. Ein griechischer Philosoph äußerte sich über die Naturforschung seiner Zeit und meinte, es könnte den Göttern nur unangenehm sein, wenn die Menschen das zu erspüren suchten, was jene ihnen nicht offenbaren wollten.*) Freilich waren hiemit bei weitem nicht alle Zeitgenossen einverstanden. Spuren dieser Anschauung finden sich auch heute noch. Im ganzen jedoch sind wir nicht mehr so engherzig. Wir glauben nicht mehr, daß die Natur sich absichtlich verbirgt. Wir wissen jetzt aus der Geschichte der Wissenschaft, daß unsere Fragen zuweilen unsinnig gestellt sind, und daß deshalb keine Antwort erfolgen kann. Bald werden wir vielmehr sehen, wie der Mensch selbst mit seinem ganzen Denken und Forschen nichts ist als ein Stück Naturleben.

Mögen Sie nun die Instrumente des Physikers als Quäl- oder als Liebkosungsapparate auffassen, was Ihnen mehr zusagt, jedenfalls wird Sie ein Stückchen Geschichte dieser Werkzeuge interessieren, jedenfalls wird es Ihnen nicht unangenehm sein, zu erfahren, welche eigentümlichen

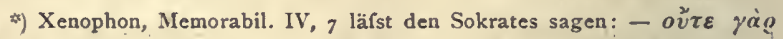

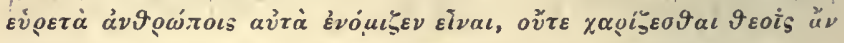

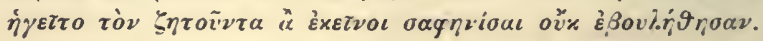


Schwierigkeiten $\mathrm{zu}$ so sonderbaren Formen der Apparate gefuhrt haben.

Galilei (geb. ${ }^{56}{ }_{4}$ zu Pisa - gest. $\mathbf{r}_{42}$ zu Arcetri) war der erste, welcher sich die Frage vorlegte, wie groß wohl die Geschwindigkeit des Lichtes, d. h. wie viel Zeit nötig sei, damit ein irgendwo aufleuchtendes Licht in einer bestimmten Entfernung sichtbar werde. *)

Die Methode, welche GaLilei ersann, war ebenso einfach, als natürlich. Zwei mit verdeckten Laternen versehene und geübte Beobachter sollten zur Nachtzeit in bedeutender Entfernung aufgestellt werden, der eine in $A$, der andere in $B . A$ hatte den Auftrag, zu einer be-

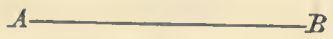

Fig. 13.

stimmten Zeit seine Laterne abzudecken. Sobald dies $B$ bemerkte, mußte er das Gleiche tun. Nun ist klar, daß die Zeit, welche $A$ zählt von der Abdeckung der eigenen Laterne bis zum Sichtbarwerden der Laterne von $B$, diejenige ist, die das Licht benötigt, um von $A$ nach $B$ und von $B$ nach $A$ wieder zurück zu kommen. Der Versuch wurde nie ausgeführt und konnte, wie Galilei selbst einsah, gar nicht gelingen.

Wie wir heute wissen, geht nämlich das Licht viel $\mathrm{zu}$ rasch, um so beobachtet zu werden. Die Zeit zwischen der Ankunft des Lichtes in $B$, und der Wahrnehmung desselben durch den Beobachter, die Zeit zwischen dem Entschluß und der Tat der Abdeckung der Laterne ist,

*) Galilei, Disçorsi e dimostrazione matematiche Leyden $863^{8}$. Dialogo primo. 
wie wir heute wissen, unvergleichlich größer, als die Zeit, welche das Licht auf irdischen Strecken verweilt. Die Größe der Geschwindigkeit wird sofort ersichtlich, wenn man beachtet, daß ein Blitz in dunkler Nacht eine weit ausgedehnte Landschaft auf einmal sichtbar macht, während die einzelnen an verschiedenen Orten reflektierten Donnerschläge in beträchtlichen Zwischenzeiten das $\mathrm{Ohr}$ des Beobachters treffen.

GaLiLEIS Bemühungen um die Ermittelung der Lichtgeschwindigkeit blieben also bei seinen Lebzeiten erfolg. los. Dennoch ist die spätere Geschichte der Messung der Lichtgeschwindigkeit eng verknüpft mit seinem Namen, denn er entdeckte mit dem von ihm konstruierten Fernrohr die vier Jupiterstrabanten, und diese wurden das Mittel zur Bestimmung der Lichtgeschwindigkeit.

Die irdischen Räume waren zu klein für GaLILEIS Versuch. Die Bestimmung gelang erst, als man die Räume des Planetensystems zu Hilfe nahm. Olor RöMER (geb. I644 zu Aarhuus - gest. I7io zu Kopenhagen) war es, dem dies (1675-I676) gelang. Er beobachtete mit CASSINI auf der Pariser Sternwarte die Umläufe der Jupitersmonde.

$A B$ sei die Jupitersbahn. Es bedeute $S$ die Sonne, $E$ die Erde, $J$ den Jupiter und $T$ den ersten Trabanten. Wenn die Erde in $E_{1}$ steht, sieht man den Trabanten regelmäßig in den Schatten des Jupiter eintreten und kann aus dieser periodischen Verfinsterung die Umlaufszeit berechnen. RöMER fand für dieselbe 42 Stunden 27 Minuten 33 Sekunden. Wenn nun die Erde in ihrer Digitized by Microsoft ( 
Bahn fortschreitend über $C$ bis $E_{2}$ kommit, so scheinen dabei die Umläufe des Trabanten langsamer zu werden, die Verfinsterungen treten etwas später ein. Die Ver-
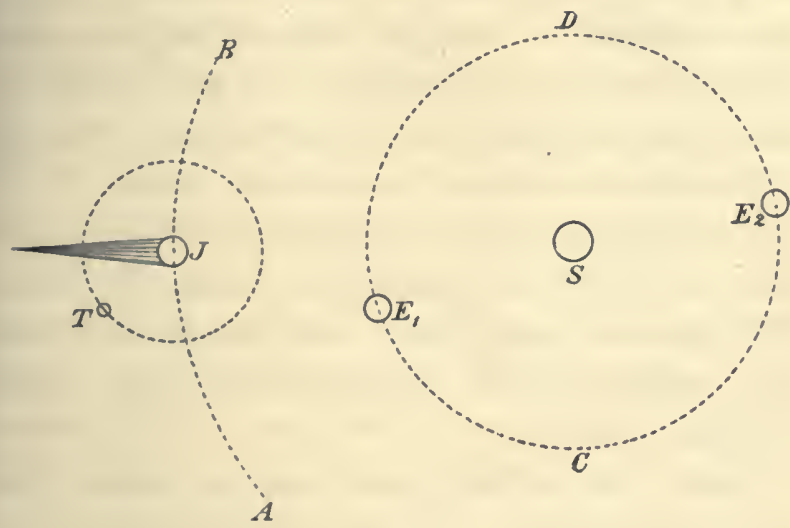

Fig. 14.

spätung der Verfinsterung, wenn die Erde in $E_{2}$ ist, beträgt 16 Minuten 26 Sekunden. Wenn die Erde wieder über $D$ nach $E_{1}$ sich zurückbewegt, werden die Umläufe scheinbar wieder rascher, und sie erfolgen ebenso schnell wie früher, sobald die Erde in $E_{1}$ angelangt ist. $\mathrm{Zu}$ bemerken ist, daß der Jupiter bei einem Bahnumlauf der Erde seine Stelle nur wenig ändert. Römer erriet sofort, $\mathrm{da} ß$ diese periodischen Veränderungen der Umlaufszeit nicht wirkliche, sondern bloß scheinbare sein können, welche mit der Lichtgeschwindigkeit zusammenhängen.

Machen wir uns die Erscheinung durch ein Bild klar. Wir erfahren durch die regelmäßige Post von dem Stande der politischen Ereignisse in einer Stadt. Soweit wir auch 
von der Stadt entfernt sind, wir hören zwar von jedem Vorgange später, aber von allen gleich spät. Die Vorgänge erscheinen uns so rasch, als sie. wirklich sind. Wenn wir nun aber reisen und uns dabei von der genannten Stadt entfernen, so hat .jede folgende Nachricht einen längern Weg zu uns zuriickzulegen, und die Vorgänge erscheinen uns langsamer, als sie wirklich sind. Das Umgekehrte würde stattfinden, wenn wir uns nähern.

Ein Musikstück hört man in jeder Entfernung, solange man in Ruhe ist, in demselben Tempo. Das Tempo muß scheinbar rascher werden, wenn wir der Musikbande rasch entgegen fahren, langsamer, wenn wir schnell fortfahren.

Denken Sie sich ein gleichförmig um seinen Mittelpunkt gedrehtes Kreuz, z. B. Windmühlflügel. Das Kreuz erscheint Ihnen offenbar langsamer gedreht, wenn Sie sich sehr rasch von demselben entfernen. Denn die Lichtpost,

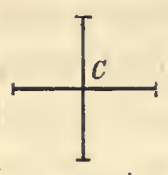

Fig. I 5. welche Thnen die Nachricht von den Stellungen des Kreuzes bringt, hat in jedem folgenden Moment einen längern Weg zu Ihnen zurückzulegen.

Ähnlich muß es sich nun bei der Drehung (dem Umlauf) des Jupiterstrabanten verhalten. Die größte Verspätung der Verfinsterung, während die Erde von $E_{1}$ nach $E_{2}$ geht, sich also um den Erdbahndurchmesser von Jupiter entfernt, entspricht offenbar der Zeit, welche das Licht zum Durchlaufen des Erdbahndurchmessers braucht. Der Erdbahndurchmesser ist bekannt; die Verspätung auch. Hieraus berechnet. sich die Lichtgeschwindigkeit, d. i. der 
vom Licht in einer Sekunde zurückgelegte Weg zu 42,000 geographischen Meilen, oder 300,000 Kilometern.

Die Methode ist ähnlich jener GaliLeis. Nur sind die Mittel besser gewählt. Statt der kleinen Distanz verwenden wir den Erdbahndurchmesser (4I Millionen Meilen), die Stelle der ab- und zugedeckten Laterne vertritt der abwechselnd verfinsterte und aufleuchtende Jupitermond. Galilei konnte also seine Messung nicht ausführen, aber die Laterne hat er gefunden, mit der sie ausgefülhrt wurde

Diese schöne Entdeckung wollte den Physikern bald nicht mehr genügen. Man suchte nach bequemeren Mitteln, die Lichtgeschwindigkeit auf der Erde zu messen. Man konnte dies tun, nachdem die Schwierigkeiten offen dalagen. FizeaU (geb. I 8 Ig zu Paris) führte i 849 eine solche Messung aus.

Ich will es versuchen, Ihnen das Wesen des FuzEAuschen Apparates klar zu machen. $S$ sei eine am Rande mit Löchern versehene um ihren Mittelpunkt drehbare Scheibe.

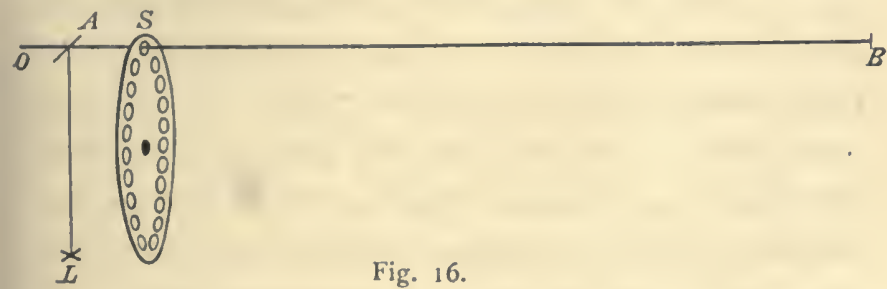

$L$ sei eine Lichtquelle, welche ihr Licht auf die gegen die Axe der Scheibe um $45^{\circ}$ geneigte unbelegte Glasplatte $A$ sendet. Dieses wird dort reflektiert, geht durch ein Loch der Scheibe hindurch senkrecht auf den Spiegel $B$, der etwa 
eine deutsche Meile weit von $S$ aufgestellt ist. Vom Spiegel $B$ wird das Licht abermals in sich zurückgeworfen, geht wieder durch das Loch in $S$, dann durch die Glasplatte in das Auge $O$ des Beobachters. $O$ sieht also das Spiegelbild der Lichtflamme $L$ durch die Glasplatte und das Loch der Scheibe hindurch im Spiegel $B$.

Wenn nun die Scheibe in Drehung versetzt wird, so werden an die Stellen der Löchẹr abwechselnd die Zwischenräume treten, und das Auge $O$ wird jetzt nur in Unterbrechungen das Lichtbild in $B$ sehen. Bei rascherer Drehung werden jedoch diese Unterbrechungen für das Auge wieder unmerklich, und es sieht den Spiegel $B$ gleichförmig erleuchtet.

Alles dies gilt jedoch nur für nicht sehr große Geschwindigkeiten der Scheibe, wenn nämlich das Licht, welches durch ein Loch in $S$ nach $B$ gegangen ist, bei seiner Rückkehr das Loch fast noch an derselben Stelle trifft und zum zweitenmale hindurchkommt. Denken Sie sich nun die Geschwindigkeit so weit gesteigert, daß das Licht bei seiner Rückkehr an der Stelle des Loches einen Zwischenraum vorfindet, so kann es nicht mehr zum Auge $O$ hindurch. Man sieht dann den Spiegel $B$ nur, wenn er kein Licht aussendet, sondern eben welches zu ihm hingeht; derselbe ist hingegen verdeckt, wenn Licht von ihm kommt. Der Spiegel wird also immer dunkel erscheinen.

Würde nun die Drehungsgeschwindigkeit noch weiter gesteigert, so könnte das durch ein Loch hindurchgegangene Licht bei seiner Rückkehr wohl nicht mehr dasselbe, da- 
für aber etwa das nächstfolgende Loch antreffen und wieder zum Auge gelangen.

Es muß also bei fortwährend gesteigerter Rotationsgeschwindigkeit der Spiegel $B$ abwechselnd hell und dunkel erscheinen. Offenbar kann man nun, wenn die Löcherzahl der Scheibe, die Umdrehungszahl in der Sekunde und der Weg $S B$ bekannt ist, die Lichtgeschwindigkeit berechnen. Das Ergebnis stimmt mit dem RöMERschen.

Die Sache ist übrigens nicht ganz so einfach, wie ich sie dargestellt habe. Es muß dafür gesorgt werden, daB das Licht den meilenlangen Weg $S B$ und zurück $B S$ unzerstreut zuriicklegt. Dies geschieht mit Hilfe von Fernrohren.

Sehen wir den Fizeauschen Apparat etwas näher an, so finden wir in ihm einen alten Bekannten, die Disposition des Galileischen Versuches. $L$ ist die Laterne, $A$, die rotierende durchlöcherte Scheibe, besorgt das regelmäßige Ab- und Zudecken derselben. Statt des ungeschickten Beobachters $B$ finden wir den Spiegel $B$, der nun gewi 3 in dem Momente aufleuchtet, in welchem das Licht von $S$ ankommt. Die Scheibe $S$, indem sie das rückkehrende Licht bald durchläßt, bald nicht, unterstützt nun den Beobachter $O$. Der GaliLEIsche Versuch wird hier sozusagen unzählige Male in einer Sekunde ausgeführt, und das Gesaintergebnis läßt sich nun wirklich beobachten. Dirfte ich die Darwinsche Theorie in diesem Gebiete anwenden, so würde ich sagen, der Fizeausche Apparat stammt von der GaliLeischen Laterne $a b$.

Eine noch feinere Methode zur Messung der LichtDigitized by Microsoff ${ }^{*}{ }^{*}$ 
geschwindigkeit hat FouCAult angewandt, doch würde uns die Beschreibung derselben hier zu weit führen.

Die Messung der Schallgeschwindigkeit gelingt nach der GAliLeischen Methode. Man hatte es also nicht nötig, sich weiter den Kopf zu zerbrechen. Der Gedanke aber, welcher durch die Not hervorgebracht war, der griff nun Platz auch in diesem Gebiete.

KöNIG in Paris verfertigt einen Apparat zur Messung der Schallgeschwindigkeit, welcher an die Fizeausche Methode erinnert. Die Vorrichtung ist sehr einfach. Sie besteht aus zwei elektrischen Schlagwerken, welche vollkommen gleichzeitig etwa Zehnteile von Sekunden schlagen. Stellt man beide Werke unmittelbar nebeneinander auf, so hört man überall, wo man auch stehen mag, die Schläge gleichzeitig. Stellt man sich aber neben dem einen Werke auf, und bringt das andere in größere Entfernung, so findet im allgemeinen kein Zusammenfallen der Schläge mehr statt. Die entsprechenden Schläge des ferneren Werkes kommen durch den Schall später an. Es fällt z. B. der erste Schlag des ferneren Werkes unmittelbar nach dem ersten des nahen u. s. f. Bei Vergrößerung der Distanz kann man es dahin bringen, daß wieder ein Zusammenfallen eintritt. Es fällt z. B. der erste Schlag des ferneren Werkes auf den zweiten des näheren, der zweite des ferneren auf den dritten des näheren u. s. f. Schlagen nun die Werke Zehnteile von Sekunden, und man entfernt sie so lange, bis das erste Zusammenfallen der Schläge eintritt, so wird ihre Entfernung vom Schall offenbar in einem Zehnteil einer Sekunde zurückgelegt. 
Oft begegnen wir derselben Erscheinung wie hier, daß3 ein Gedanke Jahrhunderte braucht, um sich mühsam zu entwickeln; ist er aber einmal da, dann wuchert er sozusagen. Er macht sich's uiberall bequem, auch in solchen Köpfen, in welchen er niemals hätte wachsen können. Er ist einfach nicht mehr umzubringen.

Die Bestimmung der Lichtgeschwindigkeit ist nicht der einzige Fall, in welchem die unmittelbare Auffassung unserer Sinne zu langsam und schwerfällig wird. Das gewöhnliche Mittel, für die unmittelbare Beobachtung zu rasche Vorgänge zu studieren, besteht darin, daß man mit den zu untersuchenden Vorgängen andere bereits bekannte, ihrer Geschwindigkeit nach mit ihnen vergleichbare in Wechselwirkung setzt. Das Ergebnis ist meist sehr augenfällig und läßt auf dieArt des noch unbekanntenVorganges schließen.

Die Fortpflanzungsgeschwindigkeit der Elektrizität läßt sich durch unmittelbares Beobachten nicht finden. WHEATSTONE hat sie aber zu ermitteln versucht, indem er den elektrischen Funken in einem enorm rasch rotierenden Spiegel (von bekannter Geschwindigkeit) betrachtete.

Wenn man einen Stab irgendwie willkürlich hin- und herbewegt, so läßt die bloße Betrachtung nicht erkennen,

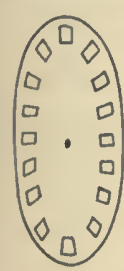

Fig. I 7 . wie schnell er sich in jedem Punkte seiner Bahn bewegt. Betrachten wir aber den Stab durch die Randlöcher einer rasch rotierenden Scheibe. Wir sehen dann den bewegten Stab nur in bestimmten Stellungen, wenn eben ein Loch vor dem Auge vorbeigeht.

Die einzelnen Stabbilder verbleiben dem 
Auge einige Zeit. Wir meinen mehrere Stäbe zu sehen, etwa wie die unten folgende Zeichnung, Fig. I8, dies andeutet. Wenn nun die Löcher der Scheibe gleich weit abstehen und dieselbe gleichmäßig gedreht wurde, so sehen wir daraus deutlich, daß sich der Stab von $a$ bis $b$ langsam, schneller von $b$ bis $c$, schneller von $c$ bis $d$, am schnellsten ron $d$ bis $e$ bewegt hat.

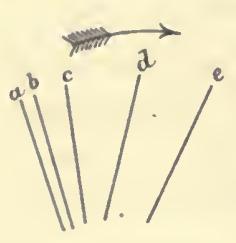

Fig. 18 .

Ein Wasserstrahl, der aus einem Gefäß ausfließt, erscheint ganz ruhig und gleichmäßig. Beleuchtet man ihn jedoch im Dunkeln nur momentan mit dem elektrischen Funken, so sieht man, daß der Strahl aus einzelnen Tropfen besteht. Indem diese Tropfen rasch fallen, verwischen sich.ihre Bilder, und der Strahl erscheint gleichmäßig. Betrachten wir den Strahl durch die rotierende Scheibe. Die Scheibe würde so rasch gedreht, daß, während , das zweite Loch an die Stelle des ersten tritt, auch $1{ }^{2}$ der 'Tropfen I bis an die Stelle von 2, 2 an die $\mathrm{Y}^{3}$ Stelle von 3 u. s. f. fällt. Dann sieht man immer an denselben Stellen Tropfen. Der Strahl scheint Fig. 19. in Ruhe zu sein. Drehen wir nun die Scheibe ctwas langsamer, so wird, während das zweite Loch an die Stelle des ersten getreten ist, der Tropfen etwas unter 2, 2 etwas unter 3 gefallen sein u. s. f. Wir werden durch jedes folgende Jooch 'Tropfen an etwas tieferen Stellen sehen. Der Strahl erscheint langsam abwärts fließend.

Drehen wir nun aber die Scheibe schneller. Dann kann, während das zweite Loch an die Stelle des ersten 
tritt, der 'Tropfen I nicht ganz an die Stelle von 2 gelangen, sondern wir finden ihn etwas ober 2, 2 etwas ober 3 u. s. f. Wir sehen durch jedes folgende Loch Tropfen an etwas höheren Stellen. Es hat nun den Anschein, als ob der Strahl nach oben flösse, als ob die Tropfen aus dem unteren Geräß in das obere aufsteigen würden.*)

Sie merken, die Physik wird nach und nach furchtbar. Bald wird es der Physiker in seiner Macht haben, die Rolle des Krebses im Mohriner See zu spielen, die KopIsch im folgenden Gedicht so schauerlich beschreibt.

\section{Der grolse Krebs im Mohriner See von Kopisch.}

Die Stadt Mohrin hat immer acht, Guckt in den Sce bei Tag und Nacht:

Kein gutes Christenkind erlebt's,

Dafs los sich reifst der grofse Krebs!

Er ist im See mit Ketten geschlossen unten an, Weil er dem ganzen Lande Verderben bringen kann!

Man sagt: er ist viel Meilen grofs

Und wend't sich oft, und kommt er los,

So währt's nicht lang, er kommt ans Land,

Ihm leistet keiner Widerstand:

Und weil das Rüekwärtsgehen bei Krebsen alter Brauch, So mufs dann alles mit ihm zurücke gehen auch.

Das wird ein Rückwärtsgehen sein!

Steclit einer was ins Maul hinein,

So kehrt der Bissen, vor dem Kopf,

'Zurück zum Teller und zum Topf!

Das Brot wird wieder zu Mehle, das Mehl wird wieder zu Korn Und alles hat beim Gehen den Rücken dann von vorn.

*) Vgl. Artikel X. 
Der Balken löst sich aus dem Haus

Und rauseht als Baum zum Wald linaus;

Der Baum krieeht wieder in den Keim,

Der Ziegelstein wird wieder Leim,

Der Oclise wird zum Kalbe, das Kalb geht naeh der Kuh,

Die Kuh wird auch zum Kalbe, so geht es immer zu!

Zur Blume kehrt zurüek das Waehs,

Das Hemd am Leibe wird zu Flaehs,

Der Flachs wird wieder blauer Lein

Und krieeht dann in den Aeker ein.

Man sagt, beim Bürgermeister zuerst die Not beginnt, Der wird vor allen Leuten zuerst ein Päppelkind.

Dann mufs der edle Rat daran,

Der wohlgewitzte Sehreiber dann;

Die erbgesess'ne Bürgersehaft

Verliert gemaeh die Bürgerkraft.

Der Rektor in der Sehule wird wie ein Sehülerlein,

Kurz eines naeh dem andern wird Kind und dumm und klein.

Und alles kehrt im Erdensehofs

Zuruek zu Adams Erdenklofs.

Am längsten hält, was Flïgel hat;

Doeh wird zuletzt auch dieses matt:

Die Henne wird zum Küehlein, das Küehlein krieeht ins Ei, Das sehlägt der grofse Krebs dann mit seinem Schwanz entzwei!

Zum Glüeke kommt's wohl nie so weit !

Noch blüht die Welt in Fröhliehkeit:

Die Obrigkeit hat wacker aeht,

Dafs sich der Krebs nicht loeker macht;

Aueh für dies arme Liedchen yär' das ein schleehtes Glüek:

Es lief vom Mund der Leute ins Tintenfafs zurüek.

Erlauben Sie mir nun einige allgemeine Betrachtungen. Sie haben schon bemerkt, daß einer ganzen Reihe von Apparaten zu verschiedenen Zwecken oft dasselbe Prinzip zu Grunde liegt. Häufig ist es eine ganz unscheinbare Idee, welche sehr fruchtbar wirkt und in die 
physikalische Technik überall umgestalterd eingreift. Es ist hier eben nicht anders als im gewöhnlichen praktischen Leben.

Das Rad am Wagen erscheint uns ganz einfach und unbedeutend. Aber der Erfinder desselben war sicher ein Genie. Zufällig mochte vielleicht ein runder Baumstamm zu der Bemerkung geführt haben, wie leicht sich eine Last auf einer Walze fortbewegen läßt. Da scheint nun der Schritt von der einfach untergelegten Walze zur befestigten Walze, zum Rade, ein sehr bequemer. Uns freilich, da wir von Kindheit an das Rad kennen, scheint dies sehr leicht. Denken wir uns aber lebhaft in die Lage eines Menschen, der nie ein Rad gesehen hat, der erst das Rad erfinden soll, so werden wir anfangen, die Schwierigkeiten zu fühlen. Ja, es mufs uns sogar zweifelhaft werden, ob ein Mensch dies zu stande gebracht, ob nicht vielmehr Jahrhunderte nötig waren, um aus der Walze das erste Rad zu bilden.

Die Fortschrittsmänner, welche das erste Rad gebaut, nennt keine Geschichte, sie liegen weit hinaus über die historische Zeit. Keine Akademie hat sie gekrönt, kein Ingenieurverein zum Ehrenmitglied erwählt. Sie leben nur fort in den großartigen Wirkungen, die sie hervorgerufen. Nehmen Sie uns das Rad - und werig wird von der Technik und Industrie der Neuzeit ïbrig bleiben. Es verschwindet alles. Vom Spinnrade bis zur Spinn. fabrik, von der Drehbank bis zum Walzwerke, rom Schiebkarren bis zum Eisenbahnzuge, alles išt weg!

Dieselbe Bedeutung hat das Rad in der Wissenschaft. Die Drehapparate, als das einfachste Mittel, rasche Be- 
wegungen olıne bedeutende Ortsveränderung zu erzielen, spielen in allen Zweigen der Physik eine Rolle. Sie kennen WHEatstoses rotierenden Spiegel, Fizeaus gezahntes Rad, Plateaus durchlöcherte rotierende Scheiben u. S. w. - Allen diesen Apparaten liegt dasselbe Prinzip 7.u Crunde. Sie unterscheiden sich von einander nicht mehr, als sich das Taschenmesser vom Messer des Anatomen, rom Messer des Winzers seinem Zweck nach unterscheiden muß. Fast dasselbe ließe sich über die Schraube sagen.

Es wird Ihnen wohl schon klar geworden sein, daß neue Gedanken nicht plötzlich entstehen. Die Gedanken bedüren ihrer Zeit, zu keimen und zu wachsen, sich zu entwickeln wie jedes Naturwesen; denn der Mensch mit seinem Denken ist eben auch ein Stïck Natur.

Langsaın, allınählich und mühsam bildet sich ein Gedanke in den andern um, wie es wahrscheinlich ist, daß eine Tierart allmählich in neue Arten übergeht. Viele Ideen erscheinen gleichzeitig. Sie kämpfen den Kampf ums Dasein nicht anders wie der Ichthyosaurus, der Brahmane und das Pferd.:

Wenige bleiben übrig, um sich rasch über alle Gebiete des Wissens auszubreiten, um sich abermals zu entwickeln, zu teilen und den Kampf von neuem zu beginnen. Wie manche längst überwundene, einer vergangenen Zeit an. gehörige Tierart noch fortlebt in abgelegenen Gegenden, wo sie von ihren Feinden nicht aufgestöbert werden konnte, so finden wir auch längst überwundene Ideen noch fort-

*) Vgl. Artikel XIV. 
lebend in manchen Köpfen. Wer sich genau beobaclitet, muß gestehen, daß sich die Gedanken so hartnäckig um ihr Dasein wehren wie die Tiere. Wer möclite leugnen, daß manche überwundene Anschauungsweise noch lange in abseitigen Winkeln des Gehirnes fortspukt, die sich in die klaren Gedankenreihen nicht mehr hinauswagt? Welcher Forscher weiß nicht, daß er bei Umwandlung seiner Ideen den härtesten Kampf mit sich selbst zu.bestehen hat?

Ähnliche Erscheinungen begegnen dem Naturforscher auf allen Wegen, in den unbedeutendsten Dingen. Was so ein rechter Naturforscher ist, der forscht überall, auch auf der Promenade, auch auf der Ringstraße. Wenn er nun nicht zu gelehrt ist, so bemerkt er, daß gewisse Dinge, wie etwa die Damenhüte, der Veränderung unterliegen. Ich habe über diesen Gegenstand keine besonderen Forschungen angestellt, aber eines ist mir erinnerlich, dab eine Form allmählich in die andere ïbergegangen. Man trug Hüte mit weit vorstehendem Rand. Tief darin, kaum mit einem Fernrohr erreichbar, lag das Antlitz der Schönen verborgen. Der Rand wurde immer kürzer, das Hütchen schrumpfte zur Ironie eines Hutes zusammen. Nun fängt oben ein mächtiges Dach an hervorzuwachsen und die Götter wissen, wie groß es noch werden soll. Es ist nicht anders bei den Damenhüten wie bei den Schmetterlingen, deren Formmannigfaltigkeit oft nur darauf beruht, da 3 ein kleiner.Auswuchs am Flügel bei einer verwandten Art sich zu einem mächtigen Lappen entwickelt. Auch die Natur hat ihre Moden, sie währen aber Jahrtausende. Ich könnte dies noch an manchem Beispiel, etwa an der Entstehung 
des Fracks, erläutern, wenn ich nicht fürchten müßte, daß meine Causerie zu ungemütlich wird.

Wir haben nun ein Stückchen Geschichte der Wissenschaft durchwandert! Was haben wir gelernt? Eine kleine, ich möchte sagen, unbedeutende Aufgabe, die Messung der Lichtgeschwindigkeit - und mehr als zwei Jalırhunderte haben an der Lösung derselben gearbeitet! Drei der bedeutendsten Naturforscher, GaLlLei ein Italiener, Römer ein Däne und FizeaU ein Franzose, haben redlich die Mühe geteilt. Und so geht es bei unzähligen andern Fragen. Wenn wir so die vielen Gedankenblüten betrachten, die alle welkend fallen müssen, bevor eine reift, dann lernen wir's erst recht verstehen, das ernste, aber wenig tröstliche Wort :

Viele sind berufen, aber wenige sind auserwählt.

So spricht jedes Blatt der Geschichte! Aber ist die Geschichte auch gerecht? Sind wirklich nur jene auserwählt, welche sie nennt? Haben die umsonst gelebt und gekämpft, die keinen Preis errungen?

Fast möcht' ich das bezweifeln. Jeder wird es bezweifeln, welcher die Gedankenqual der schlaflosen Nächte kennt, die, oft lange ohne Erfolg, endlich doch zum Ziele fuihrt. Kein Gedanke wurde da umsonst gedacht, jeder, auch der unbedeutendste, der falsche sogar, der scheinbar unfruchtbarste diente dazu, den folgenden fruchtbaren rorzubereiten. Wie im Denken des Einzelnen nichts umsonst, so auch in jenem der Menschheit!

Galıleı wollte die Lichtgeschwindigkeit messen. Er 
mußte die Augen schließen, ohne daß es ihm gelungen war. Aber er hat wenigstens die Laterne gefunden, mit der es sein Nachfolger vermochte. Und so darf ich denn behaupten, daß wir alle, sofern wir nur wollen, an der künftigen Kultur arbeiten. Wenn wir nur alle das Rechte anstreben, alle sind wir dann berufen und alle. sind wir auserwählt! 
VI.

\section{Wozu hat der Mensch zwei Augen?:)}

Wozu hat der Mensch zwei Augen?

Daınit die schöne Symmetrie des Gesichtes nicht gestört werde, könnte vielleicht der Künstler antworten. Damit das zweite Auge einen Ersatz biete, wenn das erste verloren geht, sagt der vorsichtige Ökonom. Damit wir unit zwei Augen weinen können über die Sünden der Welt, meint der Frömmler. Das klingt eigentümlich. Sollten Sie aber mit dieser Frage gar an einen modernen Naturforscher geraten, so können Sie von Glück sagen, wenn Sie mit dem bloßen Schreck davon kommen. Entschuldigen Sie, mein Fräulein! spricht der mit strenger Miene, der Mensch hat seine Augen zu gar nichts; die Natur ist keine Person und daher auch nicht so ordinär, irgend welche Zwecke zu verfolgen. Das ist noch nichts! Ich kannte einen Professor, der hielt seinen Schülern vor Entsetzen das Maul zu, wenn sie eine so unwissenschaftliche Frage stellen wollten.

Fragen Sie nun noch einen Tolerantern, fragen Sie

4) Vortrag gehalten zu Graz i. J. 1866. 
mich. Ich weiß eigentlich nicht genau, wozu der Mensch zwei Augen hat, ich glaube aber zum Teil auch dazu, daß ich Sie heute hier versammelt sehen, und mit Ihnen über dieses hübsche Thema sprechen kann.

Sie lächeln schon wieder ungläubig. Nun es ist dies schon eine jener Fragen, die hundert Weise zusammen nicht vollkommen zu beantworten vermögen. In der Tat, Sie haben bisher nur 5 Weise gehört und wollen gewiß von den übrigen 95 verschont bleiben. Dem ersten werden Sie einwenden, daß wir als Kyklopen einherschreitend uns ebenso hübsch ausnehmen würden; dem zweiten, da $\beta$ wir nach seinem Prinzip noch besser 4 oder 8 Augen hätten und in dieser Hinsicht entschieden gegen die Spinnen zurückstehen; dem dritten, daß Sie nicht Lust haben zu weinen; dem vierten, daß das bloße Verbieten der Frage Ihre Neugier mehr reizt als befriedigt, und um mich abzutun, sagen Sie, mein Vergniggen sei nicht so hoch anzuschlagen, um das Doppelauge bei allen Menschen seit dem Sündenfalle zu rechtfertigen. Weil Sie aber auch mit meiner kurzen und einleuchtenden Antwort nicht zufrieden sind, haben Sie sich die Folgen selbst zuzuschreiben. Sie müssen nun eine längere und gründlichere hören, so gut ich sie eben geben kann.

Da nun abér die naturwissenschaftliche Kirche einmal die Frage nach dem Wozu verbietet, so wollen wir, um ganz orthodox zu sein, so fragen: Der Mensch hat einmal zwei Augen; was kann er mit zwei Augen mehr sehen als mit einem? 
Erlauben Sie, daß ich Sie ein wenig spazieren führe! II ir befinden uns in einem Walde. Was ist es wohl, was den wirklichen Wald so rorteilhaft von einem noch so trefflich gemalten Walde unterscheidet, was ihn so viel reizender erscheinen läßt? Ist es die Lebendigkeit der larben, die Licht- und Schattenverteilung? Ich glaube nicht. Fs scheint mir im Gegenteil, als ob darin die Malerei sehr viel zu leisten vermöchte.

Die geschickte Hand des Malers kann uns mit einigen Pinselstrichẹn sehr plastische Gestalten vortäuschen. Noch mehr erreicht man mit Hilfe anderer Mittel. Photographien nach Reliefs sind so plastisch, daß man meint, die Erhöhungen und Vertiefungen greifen zu können. Eins aber vermag der Maler nie mit der Lebendigkeit zu geben wie die Natur, - den Unterschied von nah und fern. Im wirklichen Walde sehen Sie deutlich, daß Sie einige Baumstäınme greifen können, daß andere unerreichbar weit sind.

Das Bild des Malers ist starr. Das Bild des wirklichen Waldes ändert sich, wennSie die geringsteBewegung ausfiihren. Jetzt verbirgt sich ein Zweig hinter dem andern. Jetzt tritt ein Baumstamm hervor, der durch den andern verdeckt war.

Betrachten wir diesen Umstand etwas genauer. Wir bleiben zur Bequemlichkeit der Damen auf der Straße $I, I I$. Rechts und links ist der Wald. Wenn wir bei $I$ stehen, sehen wir etwa 3 Bäume $(\mathbf{I}, 2,3$ ) in einer Richtung, sodaß der fernere immer durch den nähern gedeckt wird. So wie wir fortschreiten, ändert sich dies. Wir müssen von $I I$ aus nach dem fernsten Baume 3 nicht soweit umblicken als nach dem nähern 2, und nach diesem 
wieder weniger als nach $\mathbf{I}$. Es scheinen also beim Fortschreiten die nähern Gegenstände gegen die fernern zurückzubleiben, und $z$ war desto mehr, je näher sie sind. Sehr ferne Gegenstände, gegen welche man beim Fortgehen lange in fast derselben Richtung hinsehen muß, werden mitzugehen scheinen. So begleitet der Mond den Eisenbahnzug, welcher die Landschaft durchrast.

Wenn wir nun irgendwo hinter einem Hügel zwei Baumwipfel hervorragen sehen, über deren Entfernung von uns wir im Unklaren sind, so können wir sehr leicht darüber entscheiden. Wir gehen nur einige Schritte,

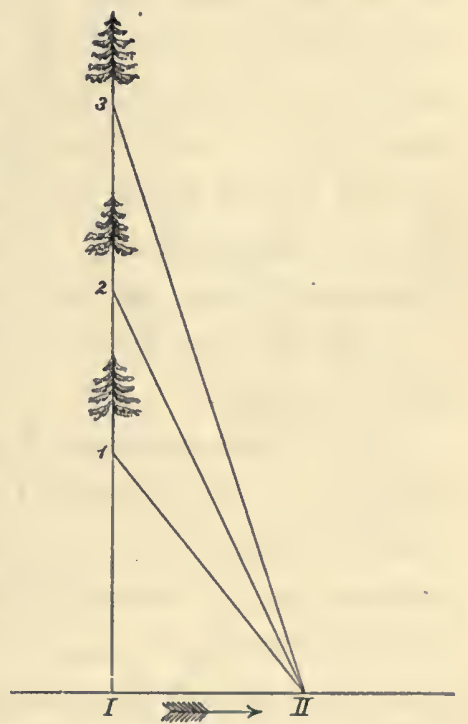

Fig. 20. etwa nach rechts, und welcher Wipfel nun mehr nach links zurückweicht, der ist der nähere. Ja, der Geometer könnte sogar aus der Größe des Zurückweichens die Entfernung bestimmen, ohne jemals zu den Bäumen hinzugelangen. Nichts anderes als die wissenschaftliche Ausbildung unserer Bemerkung ist es, welche das Messen der Entfernungen der Gestirne ermöglicht.

Also aus der Veränderung des Anblickes $\mathrm{Mach}$, Vorlesungen. 3. Aufl. 
beim Fortschreiten kann man die Entfernung der Gegenstände im Gesichtsfeld bemessen.

Streng genommen haben wir aber das Fortschreiten gar nicht nötig. Denn jeder Beobachter besteht eigentlich aus zwei Beobachtern. Der Mensch hat zwei Augen. Das rechte ist dem linken um einen kleinen Schritt nach rechts voraus. Beide Augen werden also verschiedene Bilder desselben Waldes erhalten. Das rechte Auge wird die nähern Bäume nach links verschoben sehen, und zwar desto mehr, je näher sie sind. Diese Verschiedenheit genügt, um die Entfernungen zu beurteilen.

In der Tat können Sie sich von folgenden Tatsachen leicht überzeugen:

I. Sie haben mit einem Auge (wenn Sie das andere schließen) ein sehr unsicheres Urteil über die Entfernung. Es gelingt Ihnen z. B. schwer, einen Stab durch einen vorgehaltenen Ring zu stecken, meist fahren Sie vor oder hinter demselben vorbei.

2. Sie sehen mit dem rechten Auge denselben Gegenstand anders als mit dem linken.

Stellen Sie einen Lampenschirm gerade vor sich auf den Tisch, mit der breitern Seite nach unten, und betrachten Sie ihn von oben. Sie sehen mit dem rechten Auge das Bild 2, mit dem linken das Bild r. - Stellen Sie hingegen den Schirm mit der weitern Öffnung nach oben, so erhält das rechte Auge das Bild 4, das linke das Bild 3. Schon Euklides führt solche Bemerkungen an.

3. Endlich wissen Sie, daß mit beiden Augen die Entfernung leicht zu erkennen ist. Dies Erkennen muß 
also wohl aus der Zusammenwirkung der beiden Augen hervorgehen. In dem obigen Beispiele erscheinen uns die
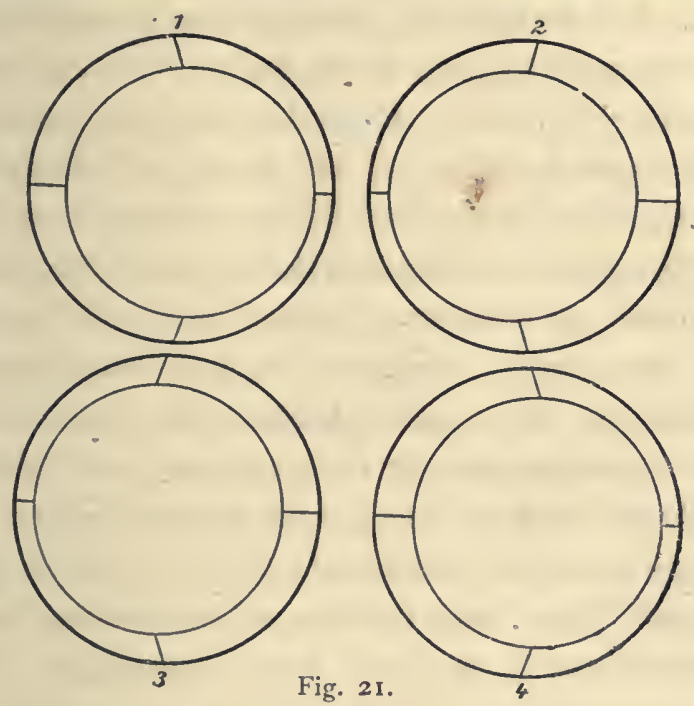

Öffnungen in den Bildern beider Augen gegen einander verschoben, und diese Verschiebung genügt, um die eine Öfnung für näher $\mathrm{zu}$ halten als die andere.

Ich zweiffe nicht daran, meine Damen, daß Sie schon sehr viele und feine Komplimente über Ihre Augen gehört haben, aber das hat Ihnen gewiß noch niemand gesagt, - ich weiß auch nicht, ob es Ihnen schmeicheln wird - Sie haben in Ihren Augen, einerlei ob schwarz oder blau - kleine Geometer!

Sie wissen nichts davon? Ja, ich weiß eigentlich auch nichts. Aber es kann doch nicht gut anders sein. Sie verstehen doch nicht viel von Geometrie? Ja, das geben 
Sie zu. Und mit Hilfe Ihrer beiden Augen messen Sie die Finternungen? Das ist doch eine geometrische Aufgabe. Und die Auflösung dieser Aufgabe kennen Sie doch, denn Sie schätzen ja die Entfernungen. Wenn aber Sie die Aufgabe nicht lösen, so müssen das die kleinen Geometer in Ihren Augen heimlich tun, und Ihnen die Auflösung zuflüstern. Ich zweifle also nicht, daß es selır flinke Kerlchen sind!

Was mich dabei wundert, bleibt nur, daß Sie von den Geometern nichts wissen. Vielleicht wissen aber auch die ron Ihnen nichts. Vielleicht sind es so recht pünktliche Beamte, die sich um nichts kümmern als um ihr Bureau. Dann könnten wir aber die Herren ein wenig aufs Eis führen.

Bieten wir dem rechten Auge ein Bild, welches ganz so aussicht wie der Lampenschirm für das rechte Auge, und dem linken Auge ein Bild, welches aussieht wie der Iampenschirm für das linke Auge, so meinen wir in der Tat, den Lampenschirm körperlich vor uns zu sehen.

Sie kennen den Versuch! Wer Übung im Schielen hat, kann ihn gleich an der Figur anstellen, mit dem rechten Auge das rechte Bild, mit dem linken das [linke Bild betrachten. In dieser Weise wurde das Experiment zuerst von ELLIOT I 834 ausgefuhrt. Eine Vervollkommnung desselben ist das von WHEATSTONE 1838 angegebene und von BREwSTER zu einem so populären und nützlichen Apparat umgestaltete Stereoskop.*)

Man kann sich durch das Stereoskop mit Hilfe der Photographie, indem man zwei Bilder desselben Gegenstandes von zwei verschiedenen Punkten (den beiden Augen

*) Brewster, The Stereoscope. London 1856 . S. $18,19,56,57$. 
entsprechend) aufnimmt, eine sehr klare räumliche Anschauung ferner Gegenden oder Gebäude verschaffen.

Das Stereoskop bietet aber noch mehr. Es kann Dinge zur Anschauung bringen, die man mit gleicher Klarheit an wirklichen Gegenständen nie sieht. Sie wissen, daß, wenn Sie beim Photographen nicht die gehörige Ruhe beobachten, Ihr Bildnis gleich einer indischen Gottheit mit mehreren Köpfen oder Armen ausgestattet erscheint, welche an jenen Stellen, wo sie sich überdecken, zuweilen beide mit gleicher Deutlichkeit erscheinen, so daß man das eine Bild durch das andere hindurch sieht. Wenn eine Person noch vor der Beendigung der Aufnahme sich rasch entfernt, so erscheinen sofort auch die Gegenstände hinter derselben auf dem Bilde; die Person wird durchsichtig. Hierauf beruhen die photographischen Geistererscheinungen.

Man kann nun von dieser Bemerkung sehr nützliche Anwendungen machen. Wenn man eine Maschine z. B. stereoskopisch photographiert und während der Operation einen Teil nach dem andern entfernt (wobei natürlich die Aufnahme Unterbrechungen erleiden muB), so erhält man eine körperliche Durchsicht, in welcher auch das Ineinandergreifen sonst verdeckter Teile deutlich zur Anschauung kommt.*)

Sie sehen, die Photographie macht riesige Fortschritte, und es ist große.Gefahr, daß demnächst ein tückischer Photograph seine arglose Kundschaft in der Durchsicht mit allem was das Herz birgt, und mit den geheimsten Gedanken aufnimmt. Welche Ruhe im Staate! Welch' reiche Ausbeute für die löbl. Polizei!

*) Vgl. Artikel IX. 
Durch die vereinigte Wirkung beider Augen gelangen wir also zur Kenntnis der Entfernungen und demnach auch der Körperformen. Erlauben Sie, daß ich noch andere hierher gehörige Erfahrungen bespreche, welche uns zum Verständnis gewisser Erscheinungen der Kulturgeschichte verhelfen werden.

Sie haben schon oft gehört und selbst bemerkt, daß fernere Gegenstände perspektivisch verkleinert erscheinen. In der Tat überzeugen Sie sich leicht, daß Sie das Bild eines wenige Schritte entfernten Menschen mit dem in geringer Entfernung vor dem Auge gehaltenen Finger verdecken können. Dennoch merken Sie gewöhnlich nichts von dieser Verkleinerung. Sie glauben im Gegenteil den Menschen am Ende des Saales ebenso groß zu sehen, wie in Threr unmittelbaren Nähe. Denn das Auge erkennt die Entfernung und schätzt dementsprechend fernere Gegenstände größer. Das Auge weiß sozusagen um die perspektivische Verkleinerung und läßt sich durch dieselbe nicht irre führen, auch wenn sein Besitzer nichts ron derselben weiß. Wer versucht hat, nach der Natur zu zeichnen, hat die Schwierigkeit empfunden, welche diese übergroße Fertigkeit des Auges der perspektivischen Auffassung entgegensetzt. Erst wenn die Beurteilung der Entfernung unsicher wird, wenn sie $\mathrm{zu}$ groß wird und das Maß abhanden kommt, oder wenn sie sich zu schnell ändert, tritt die Perspektive deutlich hervor.

Wenn Sie auf einem rasch dahin brausenden Eisenbahnzuge plötzlich Aussicht gewinnen, so sehen Sie wohl 
mitunter die Menschen auf einem Hügel als kleine zierliche Püppchen, weil Ihnen das Maß für die Entfernung fehlt. Die Steine am Eingang des Tunnels werden deutlich größer beim Einfahren, sie schrumpfen sichtlich zusammen beim Ausfahren.

Beide Augen wirken gewöhnlich zusammen. Da nun gewisse Ansichten sich sehr häufig wiederholen und immer zu ganz ähnlichen Entfernungsschätzungen führen, so müssen sich die Augen in der Auslegung eine besondere Fertigkeit erwerben. Diese Fertigkeit*) wird wohl zuletzt so groß, daß auch schon ein Auge allein sich in der Auslegung versucht.

Erlauben Sie mir, dies durch ein Beispiel zu erläutern. Was kann Ihnen geläufiger sein, als die Fernsicht in eine Gasse? Wer hätte nicht schon erwartungsvoll mit beiden Augen in eine Gasse gesehen und die Tiefe derselben ermessen? Sie kommen nun in die Kunstausstellung und finden ein Bild, die Fernsicht in eine Gasse darstellend; der Künstler hat kein Lineal gespart, um die Perspektive richtig zu machen. Der Geometer in Ihrem linken Auge, der denkt: Ach, den Fall hab' ich ja schon hundertmal gerechnet, den weiß ich ja auswendig. Das ist eine Fernsicht in eine Gasse - spricht er — da, wo die Häuser niedriger werden, ist das fernere Ende. Der Geometer im rechten Auge ist auch $\mathrm{zu}$ bequem, um seinen vielleicht mürrischen Kollegen $\mathrm{zu}$ fragen, und sagt dasselbe. Doch sofort erwacht wieder das Pflichtgefühl der pünktlichen

*) Diese Fertigkeit ist durch die individuelle Erfahrung allein nicht erklärbar. Vgl. "Analyse d. Empfindungen.“ 3. Auf. 1902. S. r59 u. ff. 
Beamten, sie rechnen wirklich und finden, daß alle Punkte des Bildes gleich weit, d. h. auf einem Blatt sind.

Was glauben Sie jetzt, die erste oder die zweite Aussage? Glauben Sie die erste, so sehen Sie deutlich eine Fernsicht, glauben Sie die zweite, so sehen Sie nichts als eine mit verzerrten Bildern bemalte Tafel.

Es.scheint Ihnen Spaß, ein Bild zu betrachten und seine Perspektive $z \mathrm{u}$ verstehen. Und doch sind Jahrtausende vergangen, bevor die Menschheit diesen Spaß erlernt hat,. und die meisten von Ihnen haben ihn erst durch die Erziehung erlernt.

Ich weiß mich sehr wohl $z$ e erinnern, daß mir in einem. Alter von etwa drei Jahren alle perspektivischen Zeichnungen als Zerrbilder der Gegenstände erschienen. Ich konnte nicht begreifen, warum der Maler den Tisch an der einen Seite so breit, an der andern so schmal dargestellt hat. Der wirkliche Tisch erschien mir ja am ferneren Ende ebenso breit als am nähern, weil mein Auge ohne mein Zutun rechnete. Daß aber das Bild des Tisches auf der Fläche nicht als bemalte Fläche zu sehen sei, sondern nur einen Tisch bedeute und ebenso in die Tiefe ausgelegt werden müsse, war ein Spaß, den ich nicht verstand. Ich tröste mich darüber, denn ganze Völker haben ihn auch nichț verstanden.

Es gibt naive Naturen, welche den Scheinmord auf der Bühne für einen wirklichen Mord, die Scheinhandlung für eine wirkliche Handlung halten, und welche den im Schạuspiele Bedrängten entrüstet zu Hilfe eilen wollen. Andere können wieder nicht vergessen, daß die Kulissen 
nur gemalte Bäume sind, daß Richard III. bloß der Schauspieler M. ist, den sie schon öfter in Gesellschaft gesehen. Beide Fehler sind gleich groß.

Um ein Drama und ein Bild richtig zu betrachten, muß man wissen, dah beide Schein sind und etwas Wirkliches bedeuten. Es gehört dazu ein gewisses Übergewicht des geistigen inneren Lebens ïber das Sinnenleben, wobei das erstere durch den unmittelbaren Eindruck nicht mehr umgebracht wird. Es gehört dazu eine gewisse Freiheit, sich seinen Standpunkt selbst .zu bestimmen, ein gewisser Humor, möchte ich sagen, der dem Kinde und jugendlichen Völkern entschieden fehlt.

Betrachten wir einige historische Tatsachen. Ich will nicht so gründlich sein, bei der Steinzeit zu beginnen, obgleich wir auch aus dieser Zeit Zeichnungen. besitzen, die in der Perspektive sehr originell sind.

Wir betreten vielmehr die Grabhallen und Tempelruinen des alten Ägypten, die mit ihren zahllosen Reliefs und mit ihrer Farbenpracht den Jahrtausenden getrotzt haben. Ein reiches, buntes Leben geht uns hier auf. Wir finden die Ägypter in allen Verhältnissen des Lebens dargestellt. Was uns an diesen Bildern sofort auffält, ist die Feinheit der technischen Ausführung. - Die Konturen sind äußerst zart und scharf. Dagegen finden sich nur wenige grelle Farben ohne Mischung und Übergang. Der Schatten fehlt vollständig. Die Flächen sind gleichmäßig angestrichen.

Schreckenerregend für das moderne Auge ist die Perspektive. Alle Figuren sind gleich groh, mit: Ausnahme 
des Königs, der unverhältnismäßig vergrößert dargestellt wurde. Nahes und Fernes erscheint gleich groß. Eine perspektivische Verkürzung tritt nie ein. Ein Teich mit Wasservögeln wird in der Vertikalebene so dargestellt, als ob seine Wasserfläche wirklich rertikal wäre.

Die menschlichen Figuren sind so abgebildet, wie man sie nie sieht, die Beine von der Seite, das Gesicht im Profil. Die Brust liegt immer der ganzen Breite nach in der Zeichnungsebene. Der Kopf des Rindes erscheint im Profil, während die Hörner doch wieder in der Zeichnungsebene liegen. Das Prinzip, welches die Ägypter befolgten., ließe sich vielleicht am besten aussprechen, wenn man sagte: Die Figuren sind in die Zeichnungsebene gepreßt wie die Pflanzen in einem Herbarium.

Die Sache erklärt sich einfach. Wenn die Ägypter gewohnt waren, mit beiden Augen unbefangen die Dinge zu betrachten, so konnte ihnen die Auslegung eines perspektivischen Bildes in 'den Raum nicht geläufig sein. Sie sahen alle Arme, Beine an den wirklichen Menschen in der natürlichen Länge. Die in die Ebene gepreßten Figuren waren natürlich den Originalen in ihren Augen ähnlicher als perspektivische.

Man begreift dies noch besser, wenn man bedenkt, daß die Malerei aus dem Relief sich entwickelt hat. Die kleineren Unähnlichkeiten zwischen den gepreßten Figuren und den Originalen mußten nach und nach allerdings zur perspektivischen Zeichnung hindrängen. Physiologisch ist die ägyptische Malerei ebenso berechtigt, als die Zeichnungen unserer Kinder es sind.

\section{Digitized by Microsoft ${ }^{\circledR}$}


Einen kleinen Fortschritt gegen Ägypten bietet schon Assyrien. Die Reliefs, welche aus den Trümmerhügeln ron Nimrod bei Mossul gewonnen wurden, sind im ganzen den ägyptischen ähnlich. Sie sind uns vorzugsweise durch den verdienstvollen LAYARD bekannt geworden.

In eine neue Phase tritt die Malerei bei den Chinesen. Dieselben haben ein entschiedenes Gefühl für Perspektive und für richtige Schattierung, ohne jedoch hierin sehr konsequent zu sein. Sie haben auch hier, wie es scheint, den Anfang gemacht, ohne weit zu kommen. Dem entspricht ihre Sprache, welche, wie jene der Kinder, sich noch nicht bis zur Grammatik entwickelt hat, oder welche vielmehr, nach moderner Auffassung, noch nicht his zur Grammatik verfallen ist. Dem entspricht ihre Musik, die sich mit einer fünftönigen Leiter begnügt.

Die Wandgemälde zu Herculanum und Pompeji zeichnen sich nächst der Anmut der Zeichnung durch ein ausgesprochenes Gefühl für Perspektive und richtige Beleuchtung aus, doch sind sie durchaus nicht ängstlich in der Konstruktion. Auch hier finden wir Verkürzungen noch vermieden, und die Glieder werden dafür mitunter in eine unnatürliche Stellung gebracht, in welcher sie in ihrer ganzen Länge erscheinen. Häufiger zeigen sich Verkürzungen an bekleideten als an unbekleideten Figuren.

Das Verständnis dieser Erscheinungen ist mir zuerst an einigen einfachen Experimenten aufgegangen, welche lehren, wie verschieden man denselben Gegenstand je nach der willkürlichen Auffassung sehen kann, wenn man einige Herrschaft uber seine Sinne gewonnen hat. 
Betrachten Sie die nebenstehende Zeichnung. Dieselbe kann ein geknicktes Blatt Papier vorstellen, welches Ihnen

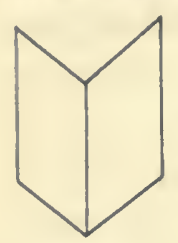

Fig. 22. die hohle oder die erhabene Seite zukehrt. Sie können in dem einen und in dem andern Sinne die Zeichnung auffassen, und sie wird Ihnen in beidenFällen verschieden erscheinen.

Wenn Sie nun wirklich ein geknicktes Papier vor sich auf den Tisch stelleı, mit der scharfen Kante Ihnen zugewandt, so können Sie bei der Betrachtung mit e inem Auge das Blatt abwechselnd erhaben sehen, wie es wirklich ist, oder hohl. Dabei tritt nun eine. merkwïrdige Erscheinung auf. Wenn Sie das Blatt richtig sehen, hat weder die Beleuchtung noch die Form etwas Auffallendes. So wie es umgebrochen erscheint, sehen Sie es perspektivisch verzerrt, das Licht und der Schatten erscheint viel heller, beziehungsweise dunkler, wie dick mit grellen Farben aufgetragen. Licht und Schatten sind nun unmotiviert; sie passen nicht mehr zur Körperform und werden viel auffallender.

Im gewöhnlichen Leben verwenden wir die Perspektive und Beleuchtung der gesehenen Gegenstände, um ihre Form und Lage zu erkennen. Wir bemerken dementsprechend die Lichter, Schatten und Verzerrungen nicht. Sie treten erst mit Macht ins Bewußtsein, wenn wir eine andere als die gewöhnliche räumliche Auslegung anwenden. Wenn man das ebene Bild einer. Camera, obscura betrachtet, erstaunt man über die Fülle der Lichter und die 'Tiefe der .Schatten, die man beide" an den wirklichen Gegenständen kaum beruerkt. 
In meiner frühesten Jugend erschienen mir alle Schatten ind Lichter auf Bildern als unmotivierte Flecke. Als ich in früher Jugend zu zeichnen begann, hielt ich das Schattieren für eine bloße Manier. Ich porträtierte einmal den Herrn Pfarrer, einen Freund des Hauses, und schraffierte nicht aus Bedürfnis, sondern weil ich es an andern Bildern so gesehen hatte, die Hälfte seines Ge. sichts ganz schwarz. Darob hatte ich eine harte Kritik von meiner Mutter zu bestehen, und mein tief verletzter Künstlerstolz ist wohl der Grund, daß mir diese Tatsachen so im Gedächtnis geblieben sind.

Sie sehen also, nicht bloß̣ im Leben des Einzelnen auch im Leben der Menschheit, in der Kulturgeschichte, erklärt sich manches aus der einfachen Tatsache, daß der Mensch zwei Augen hat.

Verändern Sie das Auge des Menschen, und Sie verändern seine Weltanschauung. Nachdem wir unsere nähern Verwandten, die Ägypter, Chinesen und Pfahlbauer besucht, sollen auch unsere fernen Verwandten, die Affen und andere Tiere nicht leer ausgehen. Wie ganz anders muß die Natur den Tieren erscheinen, welche mit wesentlich andern Augen versehen sind als der Mensch, etwa den Insekten. Aber dies zur Anschauung zu bringen, darauf muß die Wissenschaft vorläufig verzichten, da wir die Wirkungsweise dieser Organe nocl zu wenig kennen. Uns ist es schon ein Rätsel, wie den Menschen verwandteren Tieren die Natur entgegentritt, etwa den Vögeln, welche fast kein Ding mit beiden Augen zugleich 
sehen, die im Gegenteil, weil die Augen zu beiden Seiten des Kopfes stehen, für jedes ein besonderes Gesichtsfeld haben. *)

Die Menschenseele ist eingesperrt in ihr Haus, in den Kopf; sie betrachtet sich die Natur durch ihre beiden Fenster, durch die Augen. Sie möchte nun gerne auch wissen, wie sich die Natur durch andere Fenster ansieht. Das scheint unerreichbar. Aber die. Liebe zur Natur ist erfinderisch. Auch darin ist schon manches gelungen. Wenn ich einen Winkelspiegel vor mich hinstelle, welcher aus zwei wenig gegen einander geneigten ebenen Spiegeln

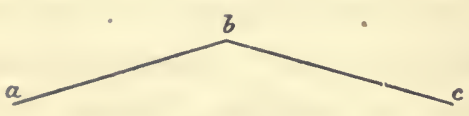

Fig.. 23. besteht, so sehe ich mein Gesicht zweimal. Im rechten Spiegel habe ich eine Ansicht von der rechten, im linken Spiegel eine Ansicht von der linken Seite. So sehe ich auch das Gesicht einer vor mir stehenden Person mit dem rechten Auge mehr von rechts, mit dem linken mehr von links. Um aber von einem Gesicht so sehr verschiedene Ansichten zu erhalten wie in dem Winkelspiegel, müßten meine beiden Augen viel, viel weiter von einander entfernt sein, als sie es wirklich sind. **) Wenn ich nun mit dem rechten Auge auf das Bild im rechten Spiegel, mit dem linken auf das Bild im linken Spiegel schiele, so verhalte ich mich wie ein Riese mit ungeheurem Kopf und weit ab-

क) Joh. Müller, vergleichende Physiologie des Gesichtssinnes. Leipzig 1826 . S. 99 u. ff. zakehrt.

a6) Es wird hierbei angenommen, dafs der Spiegel mir die hohle Seite 
stehenden Augen. Dementsprechend ist der Eindruck, den mir mein Gesicht macht. Ich sehe es dann einfach und körperlich. Bei längerer Betrachtung wächst von Sekunde zu Sekunde das Relief, die Augenbrauen treten weit vor die Augen, die Nase scheint zu Schuhlänge anzuwachsen, der Schnurrbart tritt springbrunnartig aus der Lippe hervor, die Zähne erscheinen unerreichbar weit hinter den Lippen. Das Schrecklichste bei der Erscheinung ist die Nase. Ich gedenke auf diesen einfachen Apparat ein Privilegium $\mathrm{zu}$ nehmen und ihn der spanischen Regierung zur Verwendung in ihren Bureaux zu empfehlen.

Interessant in dieser Richtung ist das von HeLmholtz angegebene Telestereoskop. Man betrachtet eine Gegend, indern man mit dem rechten

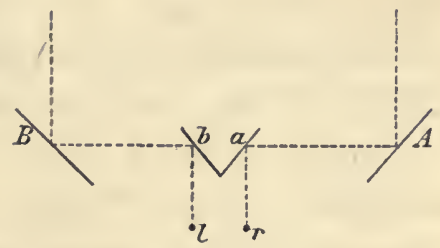

Fig. 24. Auge durch den Spiegel $a$ in den Spiegel $A$ und mit dem linken durch $b$ in den Spiegel $B$ sieht. Die Spiegel $A$ und $B$ stehen weit von einander ab. Man sieht wieder wie mit den weit abstehenden Augen eines Riesen. Alles erscheint verkleinert und genähert. Die fernen Berge sehen aus wie mit Moos bewachsene Steine, die zu Ihren Füßen liegen. Dazwischen finden Sie das verkleinerte Modell einer Stadt, ein wahres Liliput. Sie möchten fast über den zarten Wald und die Stadt mit der Hand hinstreichen, wenn Sie nicht fürchten würden, $d a ß$ Sie sich an den feinen nadelscharfen Turmspitzen stechen, oder da $\beta$ dieselben knisternd abbrechen. Liliput ist keine Fabel, man 
braucht nur Swifs Augen, um dasselbe zu sehen, d. i. das 'T'elestereoskop.

Denken Sie sich den ungekehrten Fall! Wir wären so klein, daß wir in einem Walde von Moos spazieren gehen könnten und unsere Augen wären entsprechend nahe aneinander. Die Moose würden uns baumartig erscheinen. Darauf kröche ungeheures, unförmliches, zuvor nie gesehenes Getier herum. Die Äste der Eiche aber, an deren Fuß der Mooswald liegt, den wir durchwandelı, erscheinen uns als unbewegliche, dunkle, verzweigte Wolken hoch an den Himmel gemalt, sowie etwa die Saturnusbewohner ihren Ring sehen mögen. An den Stämmen des Mooswaldes finden wir mächtige durchsichtige, glänzende Kugeln von einigen Fuß im Durchmesser, die eigentümlich langsam im Winde wogen. Wir nähern uns neugierig und finden, daß diese Kugeln, in denen sich lustig einige Tiere herumtummeln, daß sie flüssig, daß sie Wasser sind. Noch eine unvorsichtige Berührung und - o weh! schon zieht eine unsichtbare Gewalt meinen Arm mächtig ins Innere der Kugel und hält mich unerbittlich fest! - Da hat einmal der Tautropfen mittelst Kapillarität ein Menschlein aufgesogen, aus Rache dafür, daß der Mensch so viele Tropfen zum Frühstück aufsaugt. Du hättest auch wissen sollen, du kleines Naturforscherlein, daß bei der lumpig kleinen Masse, die du heute hast, mit der Kapillarität nicht zu spaßen ist.")

Der Schreck bei der Sache bringt mich zur Besinnung. Ich werke, daß ich zu idyllisch geworden bin. Sie müssen mir verzeihen! Ein Stück Rasen, Moos- oder Erikawald

\%) Vigl. Artikel $\mathrm{x}$. 
mit seiner kleinen Bevölkerung hat für mich ungleich mehr Interesse als manches Stück Litteratur mit seiner Vergötterung des Menschlichen. Hätte ich das Talent, Novellen zu schreiben, darin würde sicher nicht Hans und nicht Grethe vorkommen. Auch an den Nil und in die Pharaonenzeit des alten Ägypten würde ich mein Paar nicht versetzen, obwohl schon eher als in die Gegenwart. Denn ich muß aufrichtig gestehen, ich hasse den historischen Schund, so interessant er als bloße Erscheinung ist, weil man ihn nicht bloß betrachten kann, weil man ihn auch fühlen muß, weil er uns mit höhnender Arroganz und unüberwunden entgegentritt.

Der Held meiner Novelle müßte ein Maikäfer sein, der sich im fünften Lebensjahre mit den neugewachsenen Flügeln zum ersten Male frei in die Lüfte schwingt.*) Es könnte in der Tat nicht schaden, wenn der Mensch seiner angeborenen und anerzogenen Beschränktheit dadurch zu Leibe ginge, daß er sich mit der Weltanschauung verwandter Wesen vertraut $\mathrm{zu}$ machen suchte. Er müßte dabei noch entschieden mehr gewinnen als der" Kleinstädter, der, zum Weltumsegler geworden, die Anschauungen fremder Völker gelernt hat.

Ich habe Sie nun auf mancherlei Wegen und Stegen so recht über Stock und Stein geführt, um Ihnen zu zeigen, wohin man überall durch konsequente Verfolgung einer einzigen naturwissenschaftlichen Tatsache gelangen kann. Die genauere Betrachtung der beiden Augen des

*) Der Dichter der Maikäfer hat sich einstweilen gefunden. Vgl. J. V. Wid. mann's reizende „Maikäferkomödie“. 1897.

M a ch, Vorlesungen. 3. Aun. 
Menschen hat uns nicht nur in das Kindesalter der Menschheit, sie hat uns auch iber den Menschen hinausgeleitet.

Es ist Ihnen gewiß schon oft aufgefallen, daß man die Wissenschaften in zwei Klassen teilt, daß man die sogenannten humanistischen, zur sogenannten ,höhern Bildung“ gehörigen den Naturwissenschaften schroff gegenüberstellt.

Ich muß gestehen, ich glaube nicht an dieses Zweierlei der Wissenschaft. Ich glaube, daß diese Ansicht einer gereiftern Zeit ebenso naiv erscheinen wird wie uns die Perspektivlosigkeit der ägyptischen Malerei. Sollte man wirklich aus einigen alten Töpfen und Pergamenten, die doch nur ein winziges Stuickchen Natur sind, allein die „höhere Bildung" schöpfen, aus ihnen allein mehr lernen können als aus der ganzen übrigen Natur? Ich glaube, daß beide Wissenschaften nur Stücke derselben Wissenschaft sind, die an verschiedenen Enden begonnen haben. Wenn auch beide Enden noch als Montecchi und Capuletti sich geberden, weun sogar deren Diener aufeinander loshauen, so glaube ich, sie tun nur so spröde. Hier ist doch cin Romeo und dort eine Julie, welche hoffentlich mit minder tragischem Ausgang die beiden Häuser vercinigen werden.

Dic Philologie hat mit der unbedingten Verehrung und Vergötterung der Griechen begonnen. Schon zieht sie andere Sprachen, andere Völker und deren Geschichte in den Bereich ihrer Untersuchungen; schon schließt sie, wenn auch noch vorsichtig, durch Vermittelung der vergleichenden Sprachforschung Freundschaft mit der Physiologie.

Die Naturwissenschaft hat in der Hexenküche be- 
gonnen. Schon erstreckt sie sich über die organische und unorganische Welt, schon ragt sie mit der Physiologie der Sprachlaute, mit der Theorie der Sinne, wenn auch noch etwas naseweis, in das Gebiet des Geistigen hinein.

Kurz gesagt, wir lernen manches in uns nur verstehen durch den Blick nach außen, und umgekehrt. Jedes Objekt gehört beiden Wissenschaften an. Sie, meine Damen, sind gewiß sehr interessante und schwierige Probleme für den Psychologen. Sie sind aber auch recht hübsche Naturerscheinungen. Kirche und Staat sind Objekte des Historikers, nicht minder aber Naturerscheinungen, und zwar zum Teil recht sonderbare.

Wenn schon die historischen Wissenschaften den Blick erweitern, indem sie uns die Anschauungen verschiedener Völker vorführen, so tun dies in gewissem Sinne noch mehr die Naturwissenschaften. Indem sie den Menschen in dem All geradezu verschwinden lassen, geradezu vernichten, zwingen sie ihn, seinen unbefangenen Standpunkt außer sich zu nehmen, mit anderem als kleinbürgerlich menschlichem Maße zu messen.

Wenn Sie mich aber jetzt fragen würden: Wozu hat der Mensch zwei Augen! so müßte ich antworten:

Damit er sich die Natur recht genau ansehe, damit er begreifen lerne, daß er selbst mit seinen richtigen und unrichtigen Ansichten, mit seiner haute politique bloß ein vergängliches Stück Naturerscheinung, daß er, mit Mephisto zu sprechen, cin Teil des 'Teils sei, und daß es gänzlich unbegründet,

Wenn sich der Mensch, die kleine Narrenwelt, Gewöhnlich für ein Ganzes hält. 
VII.

\section{Die Symmetrie. ${ }^{*}$ )}

Ein alter Philosoph meinte, die Leute, welche über die Natur des Mondes sich den Kopf zerbrächen, kämen ihm vor, wie Menschen, welche die Verfassung und Einrichtung einer fernen Stadt besprächen, von der sie doch kaum mehr als den bloßen Namen gehört haben. Der wahre Philosoph, sagt er, müsse seinen Blick nach Innen wenden, sich und seine Begriffe von Moral studieren, daraus würde er wirklichen Nutzen ziehen. Dieses alte Rezept, glücklich zu werden, ließe sich in die deutsche Philistersprache etwa so übersetzen: Bleibe im Lande und nähre dich redlich.

Wenn nun dieser Philosoph aufstehen und wieder unter uns wandeln könnte, so würde er sich wundern, wie ganz anders die Dinge heute liegen.

Die Bewegungen des Mondes und anderer Weltkörper sind genau bekannt. Die Kenntnis der Bewegungen unseres eigenen Körpers ist lange noch nicht so vollendet. Die Gebirge und Gegenden des Mondes sind in genauen

*) Vortrag gehalten im deutschen Kasino zu Prag im Winter $x 87 x$. 
Karten verzeichnet. Eben fangen die Physiologen erst an, in den Gegenden unseres Hirns sich zurecht $z u$ finden. Die chemische Beschaffenheit vieler Fixsterne ist bereits untersucht. Die chemischen Vorgänge des Tierkörpers sind viel kompliziertere und schwierigere Fragen. Die mécanique céleste ist da. Eine mécanique soziale oder eine mécanique morale von gleicher Zuverlässigkeit bleibt noch zu schreiben.

In der Tat, unser Philosoph würde eingestehen, daß wir Menschen Fortschritte gemacht haben. Allein wir haben sein Rezept nicht befolgt. Der Patient ist gesund geworden, er hat aber ungefähr das Gegenteil von dem getan, was der Herr Doktor verordnet hat.

Die Menschen sind nun von der ihnen entschieden widerratenen Reise in den Weltraum etwas klüger zurïckgekehrt. Nachdem sie die einfachen großen Verhältnisse dort draußen im Reich kennen gelernt, fangen sie an, ihr kleines verzwacktes Ich mit kritischem Auge zu mustern. Es klingt absurd, ist aber wahr, nachdem wir über den Mond spekuliert, können wir an die Psychologie gehen. Wir mußten einfache und klare Ideen gewinnen, um uns in dem Komplizierten zurecht $\mathrm{zu}$ finden, und diese hat uns hauptsächlich die Astronomie verschafft.

Eine Schilderung der gewaltigen wissenschaftlichen Bewegung, welche von der Naturwissenschaft ausgehend, sich in das Gebiet der Psychologie erstreckt, hier zu versuchen, wäre Vermessenheit. Ich will es nur wagen, Ihnen. an einigen der einfachsten Beispiele zu zeigen, wie man, von den Erfahrungen der physischen Welt ausgehend, in 
das Gebiet der Psychologie und zwar zuerst in das nächstliegende der Sinneswahrnelımung eindringen kann. Auch soll meine Ausfuihrung keineswegs einen Maßstab für den Stand derartiger wissenschaftlicher Fragen abgeben.

Es ist eine bekannte Sache, daß manche Gegenstände uns gefällig erscheinen, andere nicht. Im allgemeinen gibt ein Produziieren nach einer bestimmten, konsequent festgehaltenen Regel etwas leidlich Hübsches. Wir sehen deshalb die Natur selbst, welche immer nach festen Regeln handelt, eine Menge solcher gefälliger Dinge hervorbringen. Täglich fallen dem Physiker in seinem Laboratorium die schönsten Schwingungsfiguren, Klangfiguren, Polarisationserscheinungen und Beugungsgestalten "auf.

Eine Regel setzt immer eine Wiederholung voraus. Es spielt also die Wiederholung wohl eine Rolle im Angenehmen. Hiermit ist freilich das Wesen des Angenehmen nicht er: schöpft. Die Wiederholung eines physikalischen Vorganges kann auch nur dann zur Quelle des Angenehmen werden wenn sie mit einer Wiederholung der Empfindung verbunden ist.

Ein Beispiel dafür, daß Wiederholung der Empfindung angenehm sein kann, bietet das Schreibheft jedes Schuljungen, welches eine Fundgrube für dergleichen Dinge ist; und in der Tat nur eines Abbé Domenech bedarf, um beruihmt zu werden. Irgend eine noch so abgeschmackte Gestalt einige Male wiederholt und in eine Reihe gestellt, gibt immer ein leidliches Ornament. 
Die angenehme Wirkung der Symmetrie beruht nun ebenfalls auf der Wiederholung. der Empfindungen.' Geben

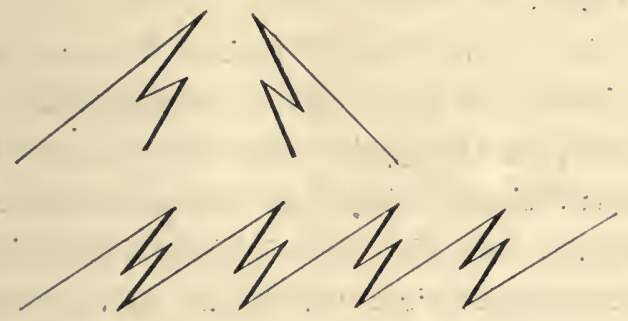

Fig. 25.

wir uns einen Augenblick diesem Gedanken hin, ohne'zu glauben, daß wir damit das Wesen des Angenehmen oder gat des Schönen vollständig durchschauen.

Verschaffen wir uns zunächst eine deutlichere Vor: stellung von der Symmetrie. Hierzu ziehe ich aber ein. lebendiges Bild einer Definition vor. Sie wissen, daß das Spiegelbild eines Gegenstandes eine große Ähnlichkeit mit dem Gegenstande selbst hat. Alle Größenverhältnisse und Formen sind dieselben. Doch besteht zwischen dem Gegenstande und seinem Spiegelbild auch ein gewisser Unterschied.

Bringen Sie Ihre rechte Hand vor den Spiegel, so erblicken Sie in demselben eine linke Hand. Ihr rechter Handschuh ergänzt sich vor dem Spiegel zu einem Paare; denn Sie könnten nimmermehr das Spiegelbild zur Bekleidung der rechten, sondern nur der linken Hand benützen, wenn es Ihnen leibhaftig vorgelegt würde. Ebenso gibt Ihr rechtes Ohr als Spiegelbild ein linkes, 
und sehr leicht gelangen Sie zu der Einsicht, daß überhaupt die linke Körperhälfte als Spiegelbild der rechten gelten könnte.

So wie nun an die Stelle eines fehlenden rechten Ohres niemals ein linkes gesetzt werden könnte, man müßte denn, das Ohrläppchen nach oben oder die Öffnung der Ohrmuschel nach hinten gekehrt, das Ohr ansetzen; so kann auch trotz aller Formengleichheit das Spiegelbild eines Gegenstandes nicht den Gegenstand vertreten.*)

Diese Verschiedenheit von Gegenstand und Spiegelbild hat einen einfachen Grund. Das Bild erscheint so weit hinter dem Spiegel, als der Gegenstand sich vor dem Spiegel befindet. Die Teile des Gegenstandes, welche gegen den Spiegel hin rücken, werden also auch im Bilde näher an die Spiegelebene heranrïcken. Dadurch wird - aber die Folge, die Ordnung der Teile im Spiegelbilde umgekehrt, wie man am besten an dem Bilde eines Uhrzifferblattes oder einer Schrift sieht.

Man kann nun leicht bemerken, daß, wenn man einen Punkt des Gegenstandes mit dem Spiegelbild desselben Punktes verbindet, diese Verbindungslinie senkrecht zum Spiegel ausfallt und durch denselben halbiert wird. Dies gilt für alle entsprechenden Punkte von Gegenstand und Spiegelbild.

Wenn man nun einen Gegenstand durch eine Ebene so in zwei Hälften zerlegen kann, daß jede Hälfte das Spiegelbild der andern in der spiegelnden Teilungsebene

\$) Kast hat zu einem andern Zwecke (Prolegomena zu einer jeden künfcigen Metaphysik) auf diesen Fall hingewiesen.

\section{Digitized by Microsoft ${ }^{\circledR}$}


sein könnte, so nennt man diesen Gegenstand symmetrisch und die erwähnte Teilungsebene die Symmetrieebene.

Ist die Symmetrieebene vertikal, so kann man sagen, der Körper sei von vertikaler Symmetrie. Ein Beispiel dafür ist ein gotischer Dom.

Ist die Symmetrieebene horizontal, so wollen wir den betreffenden Gegenstand horizontal symmetrisch nennen. Eine Landschaft an einem See nebst ihrem Spiegelbilde in dem See ist ein System von horizontaler Symmetrie.

Hier zeigt sich nun sofort ein bemerkenswerter Unterschied. Die vertikale Symmetrie eines gotischen Domes fält uns sofort auf, während man am Rhein auf und ab reisen kann, ohne die Symmetrie zwischen Bild und Gegenstand recht gewahr zu werden. Die Vertikalsymmetrie ist gefallig, während die Horizontalsymmetrie gleichgiltig ist, und nur von dem erfahrenen Auge bemerkt wird.

Woher kommt dieser Unterschied? Ich sage daher daß die Vertikalsymmetrie eine Wiederholung derselben Empfindung bedingt, die Horizontalsymmetrie aber nicht. Daß dem so sei, will ich sofort nachweisen.

Betrachten wir folgende Buchstaben:

$$
\begin{array}{ll}
d & b \\
q & p
\end{array}
$$

Es ist eine Müttern und Lehrern bekannte Tatsache, daß Kinder bei ihren ersten Schreib. und Leseversuchen $\mathrm{d}$ und $\mathrm{b}$, ebenso $\mathrm{q}$ und $\mathrm{p}$ fort und fort verwechseln, nie hingegen $d$ und $q$ oder $b$ und $p$. Nun sind $d$ und $b$ ebenso wie $q$ und $p$ die beiden Hälften einer vertikal symmetrischen, hingegen $d$ und $q$, sowie $b$ und $p$ die 
beiden Hälften einer horizontal symmetrischen Figur. Zwischen den erstereh tritt'Verwechslung ein, was nur zwischen solchen Dingen möglich ist; welche gleiche oder ähnliche Empfindungen erregen.

Man findet häufig Figuren zur. Garten- oder Sálonverzierung, zwei Blumenträgerinnen, von welchen die eine in der rechten, die andere in der linken Hand deń Blumenkorb trăgt: Wenn man nun nicht sehr aufmerksam ist, verwechselt man diese Figuren fortwährend mit einander.

Während. man die Umkehrung von rèchts nach links meist gar nicht merkt, verhält sich dàs Auge nicht so gleichgiltig. gegen eine Umkehrung von oben nach unten. Ein von oben nach uniten umgekehrtes menschliches $\mathrm{Ge}$ : sicht ist kaum als solches wiederzuerkennen und hat etwas durchaus Fremdes. Dies liegt nicht nur in der Ungewohnheit des Anblickes, denn es ist ebenso schwer, eine umgekehrte Arabeske, bei welcher die Gewohnheit gar nichts zu sagen hat, wiederzuerkennen. Hierauf beruhen die bekannten Scherze, welche man sich mit den Porträts unbeliebter Persönlichkeiten erlaubt, die man so zeichnet, $\mathrm{d} a \mathrm{~B}$ bei aufrechter Stellung dieses Blattes sich ein getreues Conterfei, bei Umkehrung desselben aber irgend ein populäres Tier präsentiert.

Es ist also Tatsache, die beiden Hälften einer vertikal symmetrischen Figur werden sehr leicht mit einander verwechselt und bedingen also wahrscheinlich sehr ähnliche Empfindungen. Es handelt sich also darum, anzugeben, warum die beiden. Hälften einer vertikal symmetrischen Figur gleiche oder ähnliche Empfindungen hervorbringen. 
Die Antwort darauf ist die: Weil unser Sehapparat, bestehend aus zwei Augen, selbst vertikal symmetrisch ist. So ähnlich ein Auge auch äußerlich dem andern ist, so sind sie doch nicht gleich. Das rechte Auge des Menschen kann die Stelle des linken nicht vertreten, so wenig wie wir unsere beiden Ohren oder Hände vertauschen könnèn. Man kann künstlich die Rolle der beiden Augen vertauschen und befindet sich dann sofort in einer neuen ganz ungewohnten Welt. Alles Erhabene erscheint 'uns dann hohl und 'alles Hohle erhaben, "das Fernere näher, das Nähere ferner u. s. w.

Das linke Auge ist das Spiegelbild des rechten, und namentlich ist die lichtempfindende Netzhaut des linken Auges in allen ihren organischen Einrichtungen ein Spiegelbild der rechten Netzhaut.

Die Linse des Auges entwirft wie eine laterna magica ein Bild der Gegenstände auf der Netzhaut. Und. Sie können sich nun die lichtempfindende Netzhaut mit ihren unzähligen Nerven wie eine Hand mit unzähligen Fingern denken, bestimmt, das Lichtbild zu tasten. Die Nervenenden sind nun wie die Finger verschieden. Die beiden Netzhäute verhalten sich wie eine rechte und linke tastende Hand.

Denken Sie sich etwa die rechte Hälfte eines T hier : $\Gamma$. Statt der beiden Netzhäute, auf welche beide dieses Bild fällt, denken Sie sich meine beiden ausgestreckten tastenden Hände. Das $\Gamma$, mit der rechten Hand angefaßt, gibt nun eine andere Empfindung, als mit der linken Hand gefaßt, denn es kommt auch auf die tastenden Stellen an. Kehrẹn 
wir nun dieses Zeichen von rechts nach links um ( 1 ), so gibt es nun dieselbe Empfindung in der linken Hand, die es friher in der rechten gab. Es wiederholt sich die Emprindung.

Nehmen wir ein ganzes $\mathrm{T}$, so löst die rechte Hälfte in der rechten Hand dieselbe Empfindung aus, welche die linke Hälfte in der linken Hand auslöst und umgekehrt.

Die symmetrische Figur gibt dieselbe Empfindung zweimal.

Stürze ich das $\mathrm{T}$ so: - oder kehre ich das halbe $\mathrm{T}$ nun etwa so: $\mathrm{L}$, so kann ich, so lange ich die Lage meiner Hände nicht wesentlich verändere, diese Betrachtung nicht mehr anwenden.

Die Netzhäute sind in der Tat ganz wie meine beiden Hănde. Auch sie haben eine Art Daumen, wenn gleich zu Tausenden und Zeigefinger, wenn gleich wieder zu Tausenden, sagen wir etwa die Daumen nach der Nasen-, die übrigen Finger nach der Außenseite zu.

Ich hoffe, Ihnen hiermit vollständig klar gemacht zu haben, wie die gefällige Wirkung der Symmetrie auf Wiederholung der Empfindung beruht, und wie ferner diese Wirkung bei symmetrischen Gestalten auch nur da eintritt, wo es eine Wiederholung der Empfindung gibt. Die angenchme Wirkung regelmäßiger Gestalten, der Vorzug, welcher den geraden Linien, namentlich den vertikalen und horizontalen vor beliebigen anderen eingeräumt wird, beruht auf einem ähnlichen Grunde. Die gerade Linie kann in horizontaler und in vertikaler Lage auf beiden Netzhäuten dasselbe Bild entwerfen, welches zudem auf 
einander symmetrisch entsprechende Stellen fällt. Hierauf beruht, wie es scheint, der psychologische Vorzug der Geraden vor der Krummen und nicht etwa auf der Eigenschaft, die Kürzeste zwischen zwei Punkten zu sein. Die Gerade wird, um es kurz zu sagen, als symmetrisch zu sich selbst empfunden, so wie die Ebene. Das Krumme empfinden wir als Abweichung vom Geraden, als Abweichung von der Symmetrie.*) Wenn nun auch von Geburt Einäugige ein gewisses Gefühl für Symmetrie haben, so ist dies allerdings ein Rätsel. Freilich kann das optische Symmetriegefühl, wenn auch zunächst durch die Augen erworben, nicht auf diese beschränkt bleiben. Es muß sich wohl auch noch in anderen Teilen des Organismus durch mehrtausendjährige Übung des Menschengeschlechtes festsetzen, und kann dann nicht mit dem Verlust des einen Auges sofort wieder verschwinden.

Alles das gründet sich aber doch im ganzen, wie es scheint, auf 'die eigentümliche Struktur unserer Augen. Man sieht leicht ein, daß unsere Vorstellungen von schön und unschön sofort eine Veränderung erfahren müßten, wenn unsere Augen anders würden. Ist die ganze Betrachtung richtig, so wird man notwendig an dem sogenannten ewig Schönen etwas irre. Es ist dann kaum zu glauben, daß die Kultur, welche dem Menschenleib ihren

*) Der Umstand, dafs man den ersten und zweiten Differentialquotienten einer Kurve unmittelbar sieht, die höheren' aber nicht, erklärt sich einfach. Der erste gibt die Lage der Tangente, die Abweichung der Geraden von der Symmetrielage, der zweite die Abweichung der Kurve von den Geraden. - Es ist vielleicht nicht unnïtz, hier zu bemerken, daf́s die gewöhnliche Prüfung des Lineals und ebener Platten (durch umgekehrtes Anlegen) in der Tat die Abweichung von der Symmetrie zu sich selbst ermittelt. 
unverkennbaren Stempel aufprägt, nicht auch die Vorstellungen vom Schönen ändern sollte. Mußte doch ehedem alles musikalisch Schöne sich in dem engen Rahmen einer fünftönigen Leiter entwickeln.

Die Erscheinung, daß Wiederholung der Empfindungen angenehm wirkt, beschränkt sich nicht auf das Sichtbare. Der Musiker und Physiker wissen heute beide, daß die harmonische oder melodische Hinzufügung eines Klanges zu einem andern dann angenehm berührt, wenn der neu hinzugefügte Klang einen Teil der Empfindung wiedergibt, welche der frühere erregt. Wenn ich zum Grundtone die Oktave hinzufüge, so höre ich in der Oktave einen Teil dessen, was im Grundtone zu hören ist. Dies hier genauer auszufuhren, ist jedoch nicht mein Zweck. Wir wollen uns vielmehr für heute die Frage vorlegen, ob etwas Ähnliches wie die Symmetrie der Gestalten nicht auch im Reiche der Töne rorkommt.

Betrachten Sie ein Klavier in Spiegel.

Sie werden leicht bemerken, daß Sie ein solches Klavier in Wirklichkeit noch nicht gesehen haben, denn es hat seine hohen Töne links, seine tiefen rechts. Ein solches Klavier wird nicht gebaut.

Wenn Sie nun an ein solches Spiegelklavier hintreten und in Ihrer gewöhnlichen Weise spielen wollten, so würde offenbar jeder Tonschritt, den Sie nach oben auszufuhren meinen, ein ebenso großer Tonschritt nach unten sein. Der Effekt wäre nicht wenig überraschend.

Für den geübten Musiker, welcher gewöhnt ist, beim Anschlag bestimmter Tasten auch bestimmte Töne zu ver- 
nehmen, ist es schon ein sehr frappantes Schauspiel, dem Spieler im Spiegel zuzusehen und zu beobachten, wie er gerade immer das Gegenteil von dem tut, was man hört.

Noch merkwürdiger aber wäre der Effekt, wenn Sie versuchen würden, auf dem Spiegelklavier eine Harmonie anzuschlagen. Für die Melodie ist es nicht einerlei, ob ich einen Tonschritt hinauf oder den gleichen hinab ausfiihre. Für die Harmonie kann ein so großer Unterschied durch die Umkehrung nicht entstehen. Ich behalte immer die gleiche Konsonanz, ob ich zu einem Grundton eine Ober- oder Unterterz hinzufüge. Nur dic Ordnung der Intervalle einer Harmonie wird umgekehrt.

In der Tat, wenn wir auf dem Spiegelklavier einen Gang in Dur ausführen, vernehmen wir einen Klang in Moll und umgekehrt.

Es handelt sich nun darum, die besprochenen Experimente auszuführen. Statt nun auf dem Klavier.im Spiegel zu spielen, was unmöglich ist, oder statt uns ein solches Klavier bauen zu lassen, was ziemlich kostspielig wäre, können wir unsere Versuche einfacher auf folgende Art anstellen:

I. Wir spielen auf unserem gewöhnlichen Klavier, sehen in den Spiegel und spielen auf demselben Klavier nochmals, was wir in dem Spiegel gesehen haben. Dadurch verwandeln wir alle Tonschritte nach oben in gleich große Tonschritte nach unten. Wir spielen einen Satz und dann den in Bezug auf die Tastatur symmetrischen Satz.

2. Wir legen unter das Notenblatt einen Spiegel, in welchem sich die Noten wie in einer Wasserfläche ab- 
bilden, und spielen aus dem Spiegel. Dadurch werden ebenfalls alle Schritte nach oben in gleich große Schritte nach unten umgekehrt.

3. Wir kehren das Notenblatt um und lesen von rechts nach links und von unten nach oben. Hierbei haben wir alle Kreuze als b und alle b als Kreuze anzusehen, weil sie halben Linien und Zwischenräumen entsprechen. Außerdem kann man bei Verwendung des Notenblattes nur den Baßschlüssel gebrauchen, weil in diesem allein die Tonschritte bei der symmetrischen Umkehrung nicht verändert werden.

Aus den in der Notenbeilage S. II 3 folgenden Beispielen können Sie den Effekt dieser Experimente entnehmen. Die obere Zeile enthält den einen, die untere Zeile den symmetrisch umgekehrten Satz.

Die Wirkung unseres Verfahrens läßt sich kurz bezeichnen. Die Melodie wird unkenntlich, die Harmonie erfährt eine Transposition aus Dur in Moll oder umgekehrt. Das Studium dieser interessanten Tatsache, welche den Physikern und Musikern bekannt ist, wurde in neuester Zeit wieder durch v. Öttingen angeregt.*;)

Obgleich ich nun in allen obigen Beispielen die Schritte nach oben in gleich große nach unten verkehrt, also wie man mit Recht sagen kann, zu jedem Satz den symmetrischen ausgeführt habe, so merkt. das $\mathrm{Ohr}$ doch wenig oder nichts von Symmetrie. Die Umkehrung aus Dur in Moll ist die einzige Andeutung der Symmetrie, welche übrig bleibt. Die Symmetrie ist da für den Ver-

") A. v. Ötringen, Harmoniesystem in dualer Entwickelung. Dorpat 1866. 
1.

2.

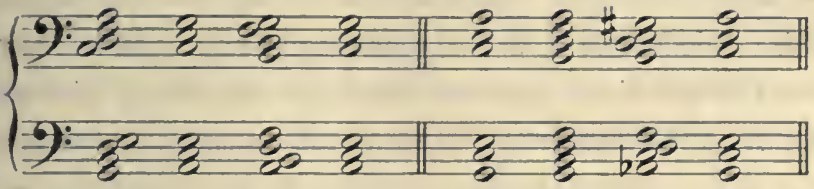

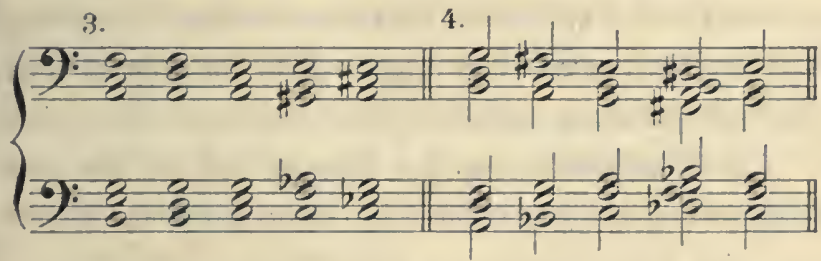

5.

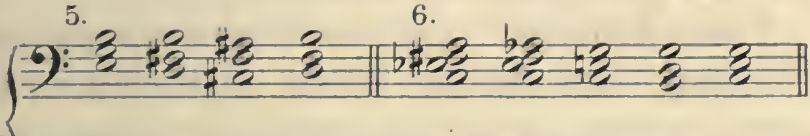

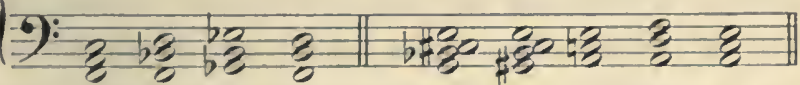

$6 \div \cdots \cdots \cdots \cdots$

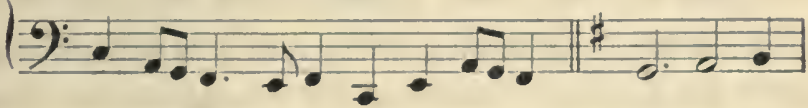

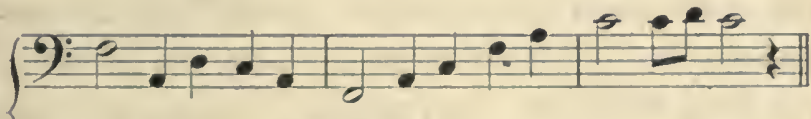

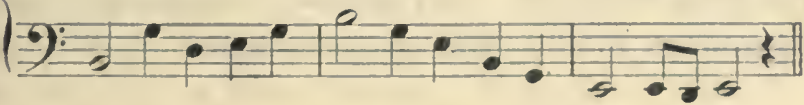

(Siehe Seite $1 \times 2$ und $1 \times 4$. )

Mach, Vorlesungen; 3 ifized by Microsoft 8 
stand, sie fehlt für die Empfindung. Für das Ohr gibt es keine Symmetrie, weil eine Umkehrung der Tonschritte keine Wiederholung der Empfindung bedingt. Hätten wir ein Ohr für die Höhe und eines für die Tiefe, wie wir cin Auge für rechts und eines für links haben, so würden sich auch symmetrische Tongebilde hierzu finden. Der Gegensatz von Dur und Moll beim Ohr entspricht einer Umkehrung von oben nach unten beim Auge, welche auch nur für den Verstand Symmetrie ist, aber nicht als solche empfunden wird.

Zur Vervollständigung des Ganzen will ich für den mathematisch unterrichteten Teil meiner verehrten Zuhörer noch eire kurze Bemerkung hinzufigen.

Unsere Notenschrift ist im wesentlichen eine graphische Darstellung des Musikstïckes in Form von Kurven, wobei die Zeit als Abscisse, der Logarithmus der Schwingungszahl als Ordinate aufgetragen wird. Die Abweichungen der Notenschrift von diesem Prinzipe sind nur solche, welche entweder die Übersicht erleichtern, oder einen historischen Grund haben.

Wenn man nun noch bemerkt, daß auch die Empfindung der Tonhöhe proportional geht dem Logarithmus der Schwingungszahl, sowie daß die Tastenabstände den Differenzen der Logarithmen der Schwingungszahlen entsprechen: so liegt darin die Berechtigung, die im spiegel gelesenen Harmonien und Melodien in gewissem Sinne symmetrisch zu den Originalen zu nennen.

Ich wollte Ihnen durch diese höchst fragmentarische Auseinandersetzung nur zu Gemüte führen, daß die Fort- 
schritte der Naturwissenschaften für jene Teile der Psychologie, die es nicht verschmäht haben, sich mit denselben in Beziehung zu setzen, nicht ohne Nutzen geblieben sind. Dafuir fängt aber auch die Psychologie an, die mächtigen Anregungen, welche sie von der Naturwissenschaft erhaiten hat, gleichsam wie zum Danke zurückzugeben.

Jene Theorien der Physik, welche alle Erscheinungen auf Bewegung und Gleichgewicht kleinster Teile zurückführen, die sogenannten Moleculartheorien, sind durch die Fortschritte der Theorie der Sinne und des Raumes bereits etwas ins Schwanken geraten, und man kann sagen, daß ihre Tage gezählt seien.

Ich habe anderwärts zu zeigen versucht, daß die Tonreihe nichts weiter sei, als eine Art Raum, jedoch von einer einzigen (und zwar einseitigen) Dimension. Wenn nun jemand, der bloß hören wïrde, versuchen wollte, sich eine Weltanschauung in seinem linearen Raume $\mathrm{zu}$ entwickeln, so würde er damit beträchtlich zu kurz kommen, indem sein Raum nicht im stande wäre, die Vielseitigkeit der wirklichen Beziehungen $z u$ fassen. Es ist aber nicht mehr berechtigt, wenn wir meinen, die gesamte Welt, auch so weit sie nicht gesehen werden kann, in den Raum unseres Auges pressen zu können. In diesem Falle befinden sich aber sämtliche Moleculartheorien. Wir besitzen einen Sinn, welcher in Bezug auf die Vielseitigkeit der Beziehungen, welche er fassen kann, reicher ist, als jeder andere. Es ist unser Verstand. Dieser steht über den Sinnen. Er allein ist im stande, eine dauerhafte und ausreichende Weltanschauung zu begründen. Die mechanische Digitized by Microsoff ${ }^{8 *}$ 
Weltanschauung hat seit GaLiLEI Gewaltiges geleistet. Doch wird sie jetzt einem freieren Blicke Platz machen müssen.*) I)as hier weiter auszuführen, kann nicht meine Absicht sein.

Ich wollte Ihnen nur einen andern Punkt klar machen. Jene Weisung unseres zitierten Philosophen, sich auf das Nächstliegende und Nützliche beim Forschen zu beschränken, welche in dem heutigen Ruf der Forscher nach Selbstbeschränkung und Teilung der Arbeit einigermaßen einen Wiederklang findet - es ist nicht immer an der Zeit, sie zu befolgen. Wir quälen uns in unserer Stube rergebens ab, ein Werk zu stande zu bringen, und die Mittel, es $z u$ vollenden, liegen vielleicht vor der Türe.

$M u B$ der Forscher schon ein Schuster sein, der nur an seinem Leisten klopft, so darf er doch vielleicht ein Schuster sein wie HAxs SAcHS, der es nicht verschmäht, nach des Nachbars Werk zu sehen, und der darüber seine Glossen zu machen. Dies zu meiner Entschuldigung, wenn ich mir für heute erlaubt, über meinen Leisten hinweg zu s ehen.:

5) Dieser wird von selbst dazu führen, dafs man die Abhängigkeit der Naturerscheinungen von einander statt räumlich und zeitlich durch blofse Zahlen. bezichungen ausdrücken wird. - Vgl. Meine Note in Fichtes Zeitschrift für Philosophie 1866. Ygl, auch Artikel XIII.

Weitere Ausfitihrungen über die hier besprochenen Probleme finden sich in meiner Schrift: "Beiträge zur Analyse der Emprindungen." Jena ₹886. 3. Auf. 1902. Auch J. P. Soret, "Sur la perception du beau," (Geneve 1892) betrachtet die Wiederholung als ein Prinzip der Ästhetik. Sorets Ausfuhrungen über .̈̈sthetik sind weitläufiger als die meinigen. In Bezug auf die psychologische und physiologische Begründung des Prinzipes glaube ich jedoch tiefer gegangen zu sein. - Zum erstenmal wurden die hier dargelegten Gedanken ausgesprochen in dem folgenden Artikel VIII. 


\section{Bemerkungen zur Lehre vom räumlichen Sehen.*)}

Nach Herbart beruht das räumliche Sehen, auf Re: produktionsreihen. Natürlich sind hierbei, wenn dies richtig ist, die Größen der Reste, mit welchen die Vorstellungen verschmolzen. sind (die Verschmelzungshülfen) von wesentlichem Einfluß. Da ferner die Verschmelzungen erst zu stande kommen müssen, bevor sie da sind, und da bei ihrem. Entstehen die Hemmungsverhältnisse ins Spiel kommen, sö hängt schließlich, die zufällige Zeitfolge, in welcher die Vorstellungen g e g e be n werden, abgerechnet, bei der räumlichen Wahrnehmung alles von den Gegensătzen und Verwandtschaften, kurz von den $Q$ ualitäten der Vorstellungen ab, welche in Reihen eingehen.

Sehen wir zu, wie sich diese Theorie den speziellen Tatsachen gegenüber verhält.

I. Wenn nur sich durchkreuzende Reihen, vor-. und rückwärts durchlaufend, zum Entstehen der räumlichen

*) Dieser Artikel, welcher zur historischen Erläuterung des vorigen dient, erschien in Fichtes, "Zeitschrift für Philosophie"i. J. 1865. 
Wahrnehmung nötig sind, warum finden sich nicht Analoga derselben bei allen Sinnen?

2. Warum messen wir Verschiedenfarbiges, Buntes, mit Einem Raummaße? Wie erkennen wir Verschiedenfarbiges als gleich groß? Woher nelımen wir überhaupt das Raummaß und was ist dieses?

3. Woher kommt es, daß gleiche verschiedenfarbige Gestalten sich gegenseitig reproduzieren und als gleich erkannt werden?

An diesen Schwierigkeiten sei es genug! Herbart vermag sie nach seiner Theorie nicht zu lösen. Der Unbefangene wird sofort einsehen, daß dessen „Hemmung wegen der Gestalt" und „Begünstigung wegen der Gestalt“ einfach unmöglich ist. Man überlege das Herbartsche Beispiel von den roten und schwarzen Buchstaben.

Die Verschmelzungshülfe ist sozusagen ein $\mathrm{Paß}$, der auf den Namen und die Person der Vorstellung lautet. Eine Vorstellung, welche mit einer andern verschmolzen ist, kann nicht alle andern qualitativ verschiedenen reproduzicren, bloß weil diese untereinander in gleicher We ise verschmolzen sind. Zwei qualitativ verschiedene Reihen reproduzieren sich gewiß nicht deshalb, weil sie dieselbe Folge der Verschmelzungsgrade darbieten.

Wenn es feststeht, daß nur Gleichzeitiges und Gleiches sich reproduziert, ein Prinzip der Herbartschen Psychologie, welches selbst der genaueste Empirist nicht bezweifeln wird, so bleibt nichts übrig, als die Theorie der räumlichen Wahrnehmung zu modifizieren, oder für sie ein neues Prinzip in der eben angedeuteten Weise zu erfinden, wozu 
sich schwerlich jemand entschließen wird. Das neue Prinzip würde nämlich nebenbei die ganze Psychologie in dié gräulichste Verwirrung stürzen.

Was nun die Modifikation betrifft, so kann man darüber nicht leicht in Zweifel sein, wie dieselbe in Anbetracht der Tatsachen nach Herbarts eigenen Prinzipien durchzuführen sei. Wenn zwei verschiedenfarbige gleiche Gestalten sich reproduzieren und als gleich erkannt werden, so ist dies nur durch in beiden Vorstellungsreihen ent. haltene qualitativ gleiche Vorstellungen möglich. Die Farben sind verschieden. Es müssen also an die Farbèn von diesen unabhängige gleiche Vorstellungen geknüpft sein. Wir brauchen nicht lange nach ihnen zu suchen, es sind die gleichen Folgen von Muskelgefühlen des Auges bei beiden Gestalten. Man könnte sagen, wir gelangen zum räumlichen Sehen, indem sich die Lichtempfindungen in ein Register von abgestuften Muskelempfindungen einordnen.*)

Nur einige Betrachtungen, welche die Rolle der Muskelempfindungen wahrscheinlich maçhen. Der Muskelapparat e in es Auges ist unsymmetrisch. Beide Augen zusammen bilden ein System von vertikaler Symmetrie. Hieraus erklärt sich schon manches.

I. Die Lage einer Gestalt hat Einfluß auf ihre Betrachtung. Es kommen je nach der Lage bei der Betrachtung verschiedene Muskelempfindungen ins Spiel, der Eindruck wird ein anderer. Um verkehrte Buchstaben

\#) Vgl. Cornelius, über das Sehen - Wundt, Theorie der Sinneswahrnehmung. 
als solche zu erkennen, dazu gehört lange Erfahrung. Der beste Beweis hierfür sind die Buchstaben d, b, p, q, welche durch dieselbe Figur in verschiedenen Lagen dargestellt und dennoch als verschieden festgehalten werden.*)

2. Dem aufmerksamen Beobachter entgeht es. nicht, da $B$ aus densèlben Gründen, sogar bei derselben Figur und Lage noch der Fixationspunkt von Einfluß ist. Die Figur scheint sich während der Betrachtung zu ändern. Ein achteckiger Stern z. B., den man konstruiert, indem man konsequent in einem regulären Achteck die I. Ecke mit der 4., die 4. mit der 7. u. S. f., immer zwei Ecken übergehend verbindet, hat, je nachdem man ihn fixiert, abwechselnd bald einen mehr architektonischen, bald einen freieren Charakter. Vertikale und horizontale Linien werden stets anders aufgefaßt als schiefe.

3. Daß wir die vertikale Symmetrie als etwas Besonderes bevorzugen, während wir die horizontale Symmetrie unmittelbar gar nicht erkennen, hat in der vertikalen Symmetrie des Augenmuskelapparates seinen Grund: Die linke Hälfte $a$ einer vertikal symmetrischen Figur löst in dem

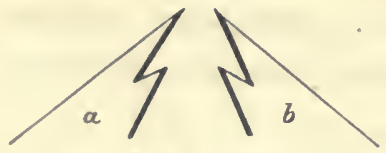

Fig. 26. linken Auge dieselben Muskelgefühle aus, wie. die rechte Hälfte $b$ in dem rechten. Das Angenehme der Symmetrie hat zunächst in der Wiederholung der Muskelgefühle seinen Grund. Daß hier eine Wiederholung stattfindet, welche sogar zur Verwechslung führen kann;

\footnotetext{
*) V Vl. Mach, über das Sehen von Lagen und Winkein, Sitzungsb. der Wiener Akademie $186 \mathrm{x}$.
} 
beweist nächst der Theorie die Tatsache, welche jedem, q uem dii oderunt, bekannt ist, daß Kinder häufig Figuren von rechts nach links' (nie von oben naclit unten) verkehren; z. B. $\varepsilon$ statt 3 schreib en, bis : sie endlich den geringen Unterschied doch mérken. 'Daß aber die Wiederholung' von Muskelgefühlen angenehm sein kann, 'lehrt $c$ in Figur 27. Wie man sich leicht klar machen kann,

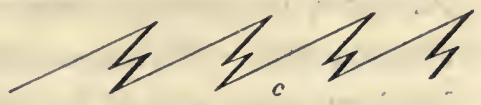

Fig. 27 .

bièten vertikale und horizontale Gerade den symmetrischen Figuren ähnliche Verhältnisse, die sofort gestört. werden wenn man die Lage der Linie schief wählt. .Man ver+ gleiche, was Helsholtz über die Wiederholung und das Zusammenfallen der Partialtöne sagt.

Es sei erlaubt, hier eine allgemeinere Bemerkung anzuknüpfen. Es ist eine ganz allgemeine Erscheinung in der Psychologie, daß gewisse qualitativ ganz verschiedene Reihen von Vorstellungen sich gegenseitig wach rufen; gegenseitig reproduzieren, in gewisser Beziehung doch als gleich oder ähnlich erscheinen. Wir sagen von solchen Reihen, sie seien von gleicher oder ähnlicher Form, indem wir die abstrahierte Gleichheit Form nennen.

r. Von räumlichen Gestalten haben wir bereits ge: sprochen.

2. Wir nennen 2 Melodien gleich, wenn sie dieselbe Folge von Tonhölenverhältnissen darbieten, die absolute Tonhöhe (die Tonart). mag noch só verschieden sein. Wir können die Melodien so wählen, daß nicht einmal zwei Partialtöne von Klängen 
in beiden gemeinschaftlich sind. Doch erkennen wir die Melodien als gleich. Ja wir merken uns die Melodieform sogàr leichter und erkennen sie leichter wieder, als die Tonart (die absolute Tonhöhe), in der sie gespielt wurde.

3. Wir erkennen an zwei Melodien den gleichen Rhythmus, die Melodien mögen sonst noch so verschieden sein. Wir merken und erkennen den Rhythmus sogar leichter als die absolute Zeitdauer (das . Tempo).

Diese Beispiele mögen genügen. In allen diesen und allen ähnlichen Fällen kann das Wiedererkennen und die Gleichheit nicht auf den Qualitäten der Vorstellungen beruhen, denn diese sind verschieden. Anderseits ist das Wiedererkennen, den Prinzipien der Psychologie zufolge, doch nur nach Vorstellungen. gleicher Qualität möglich. Also gibt es keinen andern Ausweg, als wir denken uns die qualitativ ungleichen Vorstellungen zweier Reihen notwendig mit irgend welchen qualitativ gleichen verbunden.

Wie in gleichen verschiedenfarbigen Gestalten g l e i c h e Muskelgefühle auftreten müssen, damit die Gestalten als gleich erkannt werden, so müssen auch allen Formen uiberhaupt, man könnte auch sagen, allen Abstraktionen, Vorstellungen von eigentümlicher Qualität zu Grunde liegen. Dies gilt für den Raum und die Gestalt so gut wie für die Zeit, den Rhythmus, die Tonhöhe, die Melodieform, die Intensität u. S. w. Aber woher soll die Psychologie alle diese Qualitäten nehmen? Keine Sorge darum! Sie werden sich alle so gut finden wie die Muskelempfindungen 
für die Raumtheorie. Der Organismus ist vorläufig noch reich genug, um nach dieser Richtung die Auslagen der Psychologie zu decken, und es wäre Zeit, mit der „körperlichen Resonnanz", welche die Psychologie so gern im Munde führt, einmal Ernst zu machen.

Verschiedene psychische Qualitäten scheinen untereinander in einem sehr engen Zusammenhange zu stehen. Spezielle Untersuchungen hierüber, sowie der Nachweis, daß diese Bemerkung sich für die Physik verwerten läßt, sollen später folgen.*)

*) Vgl. Mach, zur Theorie des Gehörorgans. Sitzungsber. der Wiener Akad. 1863. - Über einige Erscheinungen der physiolog. Akustik. Eben. daselbst 1864 . 


\section{Über wissenschaftliche Anwendungen der Photographie und Stereoskopie.*)}

Bei Gelegenheit einer Untersuchung über den Effekt räumlich verteilter Lichtreize auf die Netzhaut, deren.Resultate für die physiologische Optik und die Beleuchtungs. Konstruktionen der darstellenden Geometrie rerwertbar sind, fühlte ich das Bedürfnis, mir unveränderliche Flächen $z u$ verschaffen, deren Lichtintensität von Stelle zu Stelle nach einem beliebigen Gesetz variiert. Ich erhielt dieselben, indem ich mit schwarzen und weißen Sectoren von beliebiger Form bemalte Scheiben und Cylinder in der Rotation photographierte, nachdem ich durch photometrische Bestimmungen mich zuvor überzeugt, daß solche rotierende Körper auf das photographische Papier nach demselben Gesetz wirken, welches Plateau für ihre Wirkung auf die Netzhaut aufgestellt hat.*;)

") Dieser Artikel, welcher aus den Sitzungsberichten der Wiener Akademie math,-naturw. KI. II. Abt., Juni 2866 abgedruckt ist, dient zur Erläuterung des
Artikels VI.

In der Tat wurde ich durch diese theoretischen Betrachtungen zu meinen Viersuchen geführt, bevor mir noch die hierher gehörigen Erfahrungen bekannt waren, die sich den praktischen Photographen natirlich leicht zufälig präsentieren mufsten. 
Der photographische Effekt an irgend einer Stelle der präparierten Platte hängt hiernach nur von der Bestrahlungszeit und von der Bestrahlungs-Intensität $a b$, und ist beiden nahezu proportional. Man kann also schon a priori erwarten, dab mehrere Bilder, welche nacheinander auf dieselbe Patte fallen, so lange noch kein Punkt vollständig ausgewertet ist, sich einfach summieren und übereinander legen werden wie elementare Bewegungen.*) Das Auge vermag in gewissen Fällen, deren nähere Bezeichnung nicht hierher gehört, diese Bilder getrennt wahrzunehmen. Namentlich sind es Linearzeichnungen von verschiedener Farbe oder Helligkeit, welche selbst dann noch gut unterschieden werden, wenn sie in eine Ebene fallen.

Die angeführten Bemerkungen bilden die wissenschaftliche Grundlage für das Verfahren, welches man zur photographischen Darstellung der sogenannten Geistererscheinungen anwendet.

Ich verfiel noch auf eine andere Anwendung, die ich trotzden, daß sie sehr nahe liegt, für neu halten muß, da ich weder in der Litteratur noch durch mündliche Nachfragen bei Sachverständigen, darüber etwas erfahren konnte. Ich photographiere einen Körper, z. B. einen Würfel, stereoskopisch und stelle während der Operation einen andern, z. B. ein Tetraëder, an den Ort des Würfels. Dann sehe ich im Stereoskopbilde beide Körper durchsichtig und sich durchdringend.

*) Auf diese Weise könnte man auch schöne Musterflächen für die Beleuchtungskonstruktionen der darstellenden Geonetrie theoretisch konstruieren. 
Man kann diesen Erfolg des Experimentes wieder von vornherein erwarten. Denn es ist bekannt, daß man durch ein unbelegtes Planglas, welches man zwischen zwei Körper, Würfel und Tetraëder z. B. bringt, scheinbar den Effekt hervorbringen kann, als ob beide Körper durchsichtig wären und sich durchdringen würden. Selbst die feinsten Details beider Körper stören sich also nicht in ihrer Wirkung auf das Auge, sobald ihre Netzhautbilder nur verschiedenen Raumpunkten entsprechen. Für die Photographie ist es nun einerlei, ob die beiden Bilder nach einander oder gleichzeitig auf dieselbe Platte fallen, immer summieren sie sich. Das Verhalten der Augen aber einem solchen Stereoskopbilde gegenüber erklärt sich einfach aus dem Wettstreit der Sehfelder. Die beiden Bilder des momentan fixierten Raumpunktes überwiegen alle anderen, weil sie sich sehr ähnlich sind und $\mathrm{zu}$ keinem Wettstreit Veranlassung geben.

Die Unterstützung, welche solche Stereoskopbilder bei dem Studium der Stereometrie, der deskriptiven und der STEINER'schen Geometrie gewähren, ist unmittelbar klar. Das dreiseitige Prisma, welches sich in drei gleiche Pyramiden zerfällen läßt, kann weder durch eine Planzeichnung, noch durch ein Modell so anschaulich gemacht werden, wie durch ein durchsichtiges Stereoskopbild. Um die sich durchdringenden Kegel, Cylinder und windschiefen Flächen für die Zwecke der deskriptiven Geometrie darzustellen, hätte man einfach Fäden oder Drähte vor dem StereoskopApparate so zu bewegen, daß die sämtlichen Flächen, die sich durchdringen sollen, nach einander beschrieben werden. 
Sehr nette Resultate erhält man, wenn man den bewegten Faden in einem dunklen Raume mit intermittierendem Licht beleuchtet. Das Zimmer wird verfinstert und vor der Öffnung des Fensterladens eine mit Ausschnitten versehene rotierende Scheibe aufgestellt.

Vorzüglich eignet sich die Methode zur Darstellung von Maschinenansichten. Man nimmt eine Maschine stereoskopisch auf, unterbricht die Operation, entfernt einige Maschinenteile, welche andere verdecken, und photographiert dann auf derselben unveränderten Platte weiter. Eine solche Ansicht leistet oft mehr als eine Perspektivzeichnung oder Projektionen oder selbst ein Modell. Daß man auch rotierende Körper̉ stereoskopisch aufnehmen könne, versteht sich nach dem vorigen von selbst.

Die Versuche, die ich bisher ausgeführt, fielen sämtlich so schön und nett aus, daß man erwarten kann, die Methode werde auch bei Darstellung anatomischer Präparate gute Dienste leisten."*) Nehmen wir z. B. das S̈chläfenbein auf und setzen während der Operation des Photographierens einen Abguß der Höhlen des Gehörorgans an die passende Stelle, so sehen wir in dem Stereoskopbilde das Schläfenbein durchsichtig und in demselben die Höhlen des Gehörorgans. - Durch mehrmalige Aufnahme ließe sich wohl ein Stereoskopbild einer Extremität herstellen, in welchem man die Knochen, die Nerven, die Blutgefäße und die Muskel durchsichtig, sich durchdringend, und von

*) Ich habe während des Druckes dieser Notiz erfahren, dafs Brewster stereoskopische Geistererscheinungen dargestellt hat. Dagegen scheint noch niemand anatomische Präparate in dieser Art photographiert zu haben. (Brewster, the stereoscope. P. 175, 205.)

\section{Digitized by Microsoft ${ }^{\circledR}$}


einer durchsichtigen Haut überkleidet erblicken würde. So viel kann kein Präparat bieten. Ja selbst ein durchsichtiges Modell bleibt hier zuruick, weil die Lichtbrechung der Medien störend ins Spiel tritt. Kurz, es würde gar nichts geben, was dem Chirurgen ein so unauslöschliches Bild einprägen könnte, wie die stereoskopische Darstellung.

Diese vielleicht etwas idyllisch erscheinenden Er. wartungen werden fast noch übertroffen durch den Erfolg des einzigen Versuches, den ich bisher mit einem anatomischen Präparate ausführen konnte. Ein menschlicher Schädel mit abgesägtem Schädeldach wurde photographiert mit und.ohne Dach. Im Stereoskopbilde sieht man nun durch das durchsichtige Schädeldach, an dem gleichwohl alle Details sehr deutlich und plastisch sind, hindurch auf die eben so deutliche Schädelbasis. Der Anblick ist wahrhaft klassisch. Ich beehre mich gleichzeitig der holien k. Akademie dieses Bild vorzulegen.:

Eine Anwendung des Stereoskops, welche selir nahe liegt und bisher noch nicht ausgeführt ist, wäre die zur Schätzung oder Messung von Raumgrößen. Bringt man einen beliebigen Körper und etwa das Drathmodell eines Kubikfußes, der in Kubikzoll abgeteilt ist, neben einander und dazwischen ein unbelegtes Planglas, so scheint der Kubikfuß den Körper zu durchdringen und es ist nicht schwer, Schätzungen oder Messungen an dem Körper auf diese Weise vorzunehmen.

Ähnlich muß es nun sein, wenn man durch ein solches

*, Seither habe ich auch eine sehr schöne und instruktive stereoskopische Durchsicht des gesamten Gehörorgans durch vier Aufnahmen dargestelit. 
kubisches Netz, welches stereoskopisch auf Glas abgebildet ist, in den Raum hinaussieht. Es werden dann die Gegenstände einfach von diesem Netz durchdrungen. Es hat dies eine kleine Schwierigkeit, die übrigens gehoben werden kann. Die Linsen des Stereoskop-Apparates sollen nämlich nur die Netzzeichnung, nicht aber die Gegenstände im Raum affizieren. Dies kann erreicht werden durch eine Disposition, die durch nebenstehende Zeichnung erläutert wird.

Zwei unbelegte Plangläser werden durch $a b$ und $a c$ im Durchschnitt dargestellt, $b d$ und $e c$ sind Linsen, die sich an die Kästchen $b h i d$ und $c g f e$ anschließen, welche mit den beiden, die stereoskopischen Netzzeichnungen

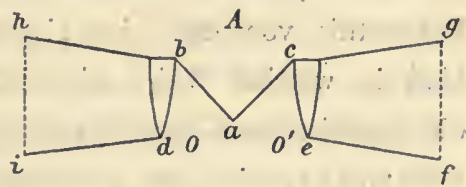

Fig. 28. tragenden Glastafeln $h i$ und $g f$ endigen. Sehen nun die beiden Augen $O$ und $O^{\prime}$ durch die Plangläser $a b$ und $a c$ in den Raum $A$ hinüber, so spiegeln sich in diesen gleichzeitig die Linsen und die Stereoskopbilder und der Effekt ist ganz derselbe, als ob zwar die Stereoskopbilder nicht aber die Gegenstände im Raum $A$ durch die Linsen gesehen würden. Die Verbindung mit dem Telestereoskop wäre für manche Fälle zweckmäbig.*)

*) [Es hat über dreifsig Jahre gewährt, bevor die hier mit voller Deutlichkeit ausgesprochene Idee in der Technik Verwendung gefunden hat. - Auch die Durchsichtsstereoskopien, deren Herstellung in manchen Fällen durch Röntgetis grolse Entdeckung so sehr erleichtert wjrd, haben kaum noch ausgiebige Anwendung gefunden. Vgl, meinen Artikel "On the stereoscopic application of Roentgens rays". (The Monist, April 1896 ) Deutsch, mit Verbesserung der Übersetzungsfehler, im Jahrgang 1896 der Wiener elektrotechnischen Zeitschrift. 1902.] 
X.

\section{Bemerkungen über wissenschaftliche An- wendungen der Photographie.*)}

Es wird nicht bestritten, daß alle wissenschaftliche Erkenntnis von der sinnlichen Anschauung ausgeht. Und in welcher Weise die sinnliche Anschauung durch die graphischen Künste überhaupt, insbesondere durch die Photographie (mit Einschluß der Stereoskopie) unterstützt wird, braucht hier ebenfalls nicht weiter auseinander gesetzt zu werden.

Aber die $\mathrm{Kr}$ aft der sinnlichen Anschauung kann durch die graphischen Künste noch sehr gesteiger $t$ und der Spielraum derselben noch bedeutend erweitert werden. Wenn wir eine große Anzahl physikalischer Beobachtungsdaten gesammelt haben, so haben wir dieselben allerdings aus der direkten sinnlichen Anschauung geschöpft, allein dieselbe mußte am Einzelnen haften bleiben. Wie groß ist dagegen der Reichtum, die Weite, die Verdichtung der Anschauung, wenn wir die Gesamtheit der Beobachtungsdaten durch eine Kurve darstellen!

\%) Aus Eders Jahrbuch für Photographie (1888) zur Erläuterung der Artikel $V$ und VI abgedruckt. 
Und wie selhr wird hierdurch die intellektuelle Verwertung erleichtert! Registrierapparate und Registriermethoden werden in der Physik, in der Meteorologie, ja fast in allen Naturwissenschaften angewandt und vielfach findet die Photographie hierbei ihre Verwertung. Wie viel insbesondere MAREY zur Entwicklung der Registriermethoden beigetragen hat, ist allgemein bekannt.

Selbst in Fällen, in welchen die unmittelbare sinnliche Anschauung gar nichts zu leisten vermag, können für dieselbe und für die graphischen Ktinste durch entsprechende Mittel neue Gebiete eröffnet werden. Das Mikroskop und seine Leistungen, welche wesentlich auf dem Prinzip der Raumviergrößer ung beruhen, werden allgemein bewundert. Seltener denkt man daran, wie wichtig auch das entgegengesetzte Prinzip ist, das der Raumverkl e in er ung. $\mathrm{Zu}$ einer klaren Vorstellung der Verteilung von Land und Meer auf unserer Erde, würden wir wohl durch unmittelbare sinnliche Anschauung, durch die weitesten Reisen niemals gelangen, einfach weil das Objekt für unser Gesichtsfeld zu groß, stets eine nur schwerfällige intellektuelle Zusammenfassung der einzelnen Teile zu einem Ganzen zuläßt. Die Karte drängt das Bild der ganzen Erde in unser Gesichtsfeld zusammen. Was ist die geographische Beschreibung.Libyens durch einen Augenzeugen, durch HERODOT, gegen die Vorstellung eines Schulknaben, der die Karte von Afrika gegenwärtig hat!

Die einzelnen Phasen einer Bewegung, die für unsere unmittelbare Anschauung $z \mathrm{u}$ rasch verläuft, fixieren wir durch Momentphotographie und können dann die-

$$
\text { Digitized by Microsoft }{ }^{2 *}
$$


selben in beliebig langsamer Folge unserer Anschauung vorführen. Die Leistungen von ANschutz, die Analyse des Vogelflugs durch Marey, die Momentbilder von fliegenden Projektilen samt den eingeleiteten Luftbewegungen, sind passende-Beispiele und erläutern das Prinzip der Zeit vergrö Berung, welches in diesen Fällen zur Anwendung kommt.

Hat man mit periodischen Bewegungen zu tun, so kann man die sogenannte stroboskopische Methode anwenden, welche ebenfalls auf dem Prinzip der Zeitvergrößerung beruht und selbstverständlich auch Verwertung der Photographie zuläßt. Die Bewegungen einer schwingenden Stimmgabel $G$ von z. B. roo Schwingungen per Sekunde lassen sich wegen der zu großen Geschwindigkeit nicht direkt beobachten. Blicken wir aber auf die Gabel durch eine rotierende Scheibe $S$, welche roo Spalten per Sekunde vor dem Auge vorbeiführt, so sehen wir die Gabel immer nach Ablauf einer Schwingung immer in derselben Phase, also scheinbar ruhig. Gehen aber nur 99 Spalten per Sekunde am Auge vorbei, so führt die Gabel, während I und 2 ihren Platz tauschen, eine Schwingung; , und fast noch $1 / 100$ mehr (genau $1 / 98$ ) aus. Beim Blick durch die Spalte 3 ist die Gabel um \%/99 einer Schwingung vorgeschritten u. s. w., so daß nach dem Vorbeigang von 99 Spalten (die erste nicht gerechnet), also in einer Sekunde, die Stimmgabel genau eine schein: bare Schwingung ausgeführt hat, während sje in Wirklichkeit too vollführt hat. Die $\mathrm{Zeit}$ ist also für den Beobachter roo mal vergrößert. Es ist dem Fachmann 
gegenüber unnötig auseinänder zusetzen, wie nach dem stroboskopischen Verfahren Momentbilder gewonnen werden können, die in einer stroboskopischen Trommel zur langsamen Reproduktion einer ihrer Schnelligkeít wegen direkt unwahrnehmbaren Bewegung verwendbar sind. (Vergl.

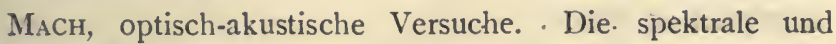
stroboskopische Untersuchung tönender Körper. Prag, Calve 1873.$)$

Sollte nicht auch das Prinzip der Ze itverk le in e r ung von Wert sein? In der Tat, denken wir uns die Wachs. tumsstadien einer Pflanze, ${ }^{*}$ ) die Entwicklungsstadien eines Embryo, die Glieder des DarwiNschen Stammbaumes der Tierreihe photographisch fixiert und in einer raschen Folge sich verdrängender „Nebelbilder“ vorgefuhrt! Welchen auch intellektuell stärkenden Eindruck

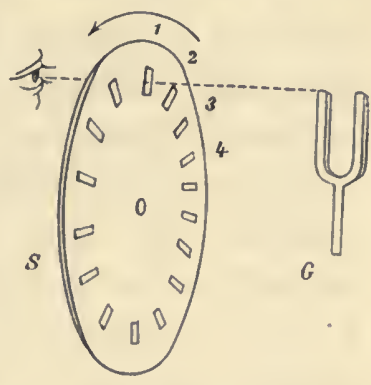

Fig. 29. müBte das hervorbringen! Die Bilder eines 'Menschen von der Wiege an, in seiner aufsteigenden Entwicklung und dann in seinem Verfall bis ins Greisenalter in wenigen Sekunden so vorgeführt, müßten ästhetisch und ethisch großartig wirken.

$\mathrm{DaB}$ uns dabei auch neue Einsichten aufleuchten würden, ist kaum zu bezweifeln. Wäre denn ein KEPLER nötig

*) Praktisch ausgeführt wurde der Versuch, das Wachstum einer Pflanze in dieser Weise darzustellen, von meinem Sohne Med. Dr. Ludwig Mach. Vgl. dessen Artikel: Über das Priscip der Zeitverkürzung in der Serienphotographie". (Scoliks photogr. Rundschau, April 1893.) - 1902.] 
gewesen, zu erraten, daß die Planeten in Ellipsen um die Sonne sich bewegen, wenn diese Bewegung räumlich und zeitlich verkleinert, sozusagen im Modell, anschaulich vorgelegen hätte? Freilich war diese Erkenntnis schwieriger aus einzelnen Beobachtungsdaten stückweise intellektuell zusammen zu setzen.

Vielleicht tragen diese Bemerkungen dazu bei, die Überzeugung $z \mathrm{u}$ befestigen, daß die hier berührten Fragen nicht allein von praktischem und industriellem, sondern auch von philosophischem Interesse sind. 


\section{XI.}

\section{Über die Grundbegriffe der Elektrostatik (Menge, Potential, Capazität u. s. w.) *)}

Es wurde mir die Aufgabe zu teil, vor Ihnen die quantitativen Grundbegriffe der Elektrostatik: „Elektrizitätsmenge“, „Potential“, „Capazität" in allgemein verständlicher Weise zu entwickeln. Es wäre nicht schwierig, selbst in dem Rahmen einer Stunde, die Augen durch zahlreiche schöne Experimente zu beschäftigen, und die Phantasie mit mannigfaltigen Vorstellungen $\mathrm{zu}$ erfüllen. Allein von einer klaren und mühelosen Übersicht der Tatsachen wären wir dann noch weit entfernt. Noch würde uns das Mittel fehlen, die Tatsachen in Gedanken genau nachzubilden, was für den Theoretiker und Praktiker von gleicher Wichtigkeit ist. Dieses Mittel sind eben die Maßbegriffe der Elektrizitätslehre.

So lange nur wenige vereinzelte Forscher sich mit einem Gebiete beschäftigen, so lange jeder Versuch noch leicht wiederholt werden kann, genügt wohl eine Fixierung der gesammelten Erfahrungen durch eine oberflächliche

*) Vortrag, gehalten auf der internationalen Elektrizitäts-Ausstellung zu Wien ain 4 . September $x 88_{3}$. 
Beschreibung. Anders verhält es sich, wenn jeder die Erfahrungen vieler verwerten muß, wie dies der Fall ist, sobald die Wissenschaft eine breite Basis gewonnen hat, und noch mehr, sobald sie anfängt, einem wichtigen $\mathrm{Zweige}$ der Technik Nahrung zu geben und umgekehrt aus dem praktischen Leben wieder in großartiger Weise Erfahrungen zu schöpfen. Dann müssen die Tatsachen so beschrieben sürden, daß jeder und allerorten dieselben aus wenigen leicht zu beschaffenden Elementen in Gedanken genau zusammensetzen, und nach dieser Beschreibung reproduzieren kann; dies geschieht mit Hilfe der Maßbegriffe und der internationalen Maße.

Die in dieser Richtung in der Periode der rein wissen. schaftlichen Entwicklung namentlich durch CouLOMB ( 7784 ), Gauss ( 1833 ) und Weber begonnene Arbeit wurde mächtig gefördert durch die Bedürfnisse der großen technischen Unternehmungen, die sich besonders seit der Legung des ersten transatlantischen Kabels fühlbar machten, und wurde glanzroll der Vollendung entgegengeführt durch die Arbeiten der British Association (I86r) und des Pariser Kongresses (I88I), namentlich durch die Bemühungen von Sir WiLliaM Thomson. (Lord Kelvin.)

Es versteht sich, daß ich Sie in der mir zugemessenen Zeit nicht alle die langen und gewundenen Pfade führen kann, welche die Wissenschaft wirklich eingeschlagen hat, daß es nicht möglich ist, bei jedem Schritt an alle die kleinen Vorsichten zur Vermeidung von Fehltritten zu erinnern, welche die früheren Schritte uns gelehrt haben. Ich muß mich vielmehr mit den einfachsten und rohesten 
Mitteln behelfen:- Die kürzesten Wege von "den 'Tatsachen zu den Begriffen will ich Sie führen, - wobei es mir allerdings nicht möglich sein wird, allen, den Kreuz- und Quergedanken, die sich beim Anblick der Seitenwege einstellen können, ja einstellen müssen, zuvorzukommen.

Wir betrachten zwiei kleine, gleiche, leichte, frei aufgehängte Körperchen (Fig. 30), die wir entweder durch Reibung mit einem dritten Körper oder durch Berührung mit einem schon elektrischen Körper „elektrisieren." Sofort zeigt sich eine abstoßende Kraft, welche die beiden Körperchen von einander (der Wirkung der Schwere entgegen) entfernit. Diese Kraft vermöchte dieselbe mechanische Arbeit wieder zu leisten, durch deren Aufwendung sie entstanden ist. ${ }^{*}$ )

CouLoms hat sich nun durch sehr umständliche Versuche mit Hilfe der Drehwage überzeugt, daß, wenn jene Körperchen bei einem. Abstande von $2 \mathrm{Cm}$. z. B. sich etwa mit derselben Kraft abstoßen, mit welcher ein Milligrammgewicht zur Erde zu fallen strebt, daß sie dann bei der Hälfte der Entfernung, bei I Cm., mit 4 Milligramm, und bei verdoppeltem Abstande, bei $4 \mathrm{Cm}$, mit nur $1 / 4$ Milligramm sich abstoßen. Er fand, daß die elektrische Kraft verkehrt proportional dem Quadrat der Entfernung wirkt.

Stellen wir uns nun vor, wir hätten ein Mittel, die elektrische Abstoßung durch Gewichte zu messen, welches

\$) Würden die beiden Körper ungleichnamig elektrisiert, so würden șie anziehend aufeinander wirken. 
einfache Mittel z. B. die elektrischen Pendel selbst sind, so können wir folgende Beobachtungen machen.

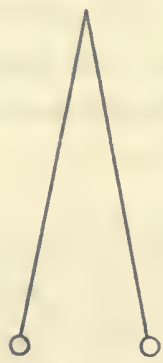

Fig. 30 .
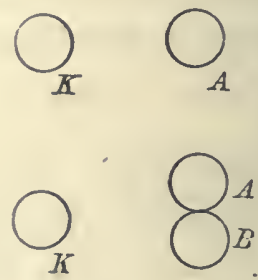

Fig. 3I.

Der Körper $A$ (Fig. 3I), wird von dem Körper $K$ bei $2 \mathrm{Cm}$. Entfernung etwa mit I Milligramm Druck abgestoßen. Berühren wir nun $A$ mit einem gleichen Körper $B$, so geht die Hälfte dieser Abstoßungskraft an denselben über. Sowohl $A$ als $B$ werden nun bei $2 \mathrm{Cm}$. Entfernung von $K$ nur mit je $1 / 2$ Milligramm, beide zusammen aber wieder mit I Milligramm abgestoßen. Die Teilung der elektrischen $\mathrm{K}$ raft unter die sich berührenden Körper ist eine $\mathrm{T}$ a ts a che. Eine keineswegs notwendige aber nuitzliche $\mathrm{Zutat}$ ist es, wenn wir uns vorstellen, in dem Körper $A$ sei eine elektrische $\mathrm{Flüssigkeit} \mathrm{vorhanden,} \mathrm{an} \mathrm{deren}$ Menge die elektrische Kraft gebunden ist, welche zur Hälfte nach $B$ überfließt. Denn an die Stelle der neuen physikalischen Vorstellung tritt hiermit eine uns längst geläufige, welche wie von selbst in den gewohnten Bahnen abläuft.

Entsprechend dieser Vorstellung bezeichnen wir als die Elektrizitätsmenge $\mathrm{E}$ in s nach dem sehr allgemein ange- 
nommenen Centimeter-Gramme-Sekundensystem (C.-G.-S.) diejenige, welche auf eine gleiche Menge in der Entfernung von I Cm., mit der Krafteinheit, d. h. mit einer Kraft abstoßend wirkt, welche der Masse von I Gr. in der Sekunde einen Geschwindigkeitszuwachs von I $\mathrm{Cm}$. erteilt. $\mathrm{Da}$ eine Grammmasse durch die Erdschwere einen Geschwindigkeitszuwachs von etwa $98 \mathrm{I} \mathrm{Cm}$. in der Sekunde erhält, so wird sie hiernach mit 98 I $\mathrm{Cm}$. (oder rund I 000 ) Krafteinheiten des Centimeter-Gramme - Sekundensystems angezogen, und ein Milligrammgewicht strebt ungefähr mit einer Krafteinheit dieses Systems zur Erde zu fallen.

Hiernach kann man sich leicht eine anschauliche Vorstellung von der Einheit der Elektrizitätsmenge verschaffen. Zwei je ein Gramm schwere kleine Körperchen $K$ sollen an $5 \mathrm{M}$. langen, fast gewichtslosen vertikalen Fäden so aufgehängt sein, daß sie sich beriihren. Werden beide gleich stark elektrisch, und entfernen sie sich hierbei um I $\mathrm{Cm}$. von einander, so entspricht die Ladung eines jeden der elektrostatischen Einheit der Elektrizitätsmenge; denn die Abstoßung hält dann der Schwerkraft-Komponente von rund I Milligramm das Gleichgewicht, welche die Körperchen einander zu nähern strebt.

Vertikal unter einem an einer Wage äquilibrierten, sehr kleinen Kügelchen befindet sich ein zweites in $\mathrm{I} \mathrm{Cm}$. Entfernung. Werden beide gleich elektrisiert, so wird das Kügelchen an der Wage durch die Abstoßung scheinbar leichter. Stellt ein Zuleggewicht von I Milligramm das Gleichgewicht her, so enthält jedes Kügelchen rund die elektrostatische Einheit der Elektrizitätsmenge. 
( : Mif Rücksicht darauf, daß' dieselben elektrischen Körper in verschiedener Entfernung verschiedene Kräfte aufeinandèr ausübèn, könnte man an dem dargelegten $\mathrm{MaB}$ der Menge Anstoß nehmen: "Was ist.das für eine Menge, die bald mehr, bald weniger wiegt, wenn man sn sagen darf? Allein diese schéinbare Abweichung von der gewöhnlichen Mengenbestimmung im bürgerlichen Ieben durch das .Gewicht ist vielmehr, genau betrachtet, eine Übereinstimmung. Auch eine schwere Masse wird auf einem hohen Berg schwächer - zur Erde gezogen als im Meeresniveau, und wir können von einer Bestimmung des Niveạus nur deshalb Umgang nehmen, weil wir den Körper mit dem Gewichtssatz olnnehin immer nur in de mselben Niveau vergleichen.

Würden wir aber von den beiden gleichen Gewichten, welche sich an einer Wage das Gleichgewicht halten, das eine dem Erdmittelpunkte merklich nähern, indem wir dasselbe an einem sehr langen Faden aufhängen, wie dies Prof. v. JOLLY in München ausgedacht hat, so würden wir diesem letztereren ein entsprechendes Übergewicht verschaffen.

Denken wir uns zwei verschiedene elektrische Flüssigkeiten, die positive und die negative, von derartiger Beschaffenheit, daß die Teile dieser beiden Flüssigkeiten sich gegenseitig verkehrt quadratisch anziehen, jene derselben Flüssigkeit aber nach demselben Gesetz gegenseitig ab. stoßen, denken wir uns in unelektrischen Körpern beide Flüssigkeiten in gleichen Mengen gleichmäßig verteilt, dagegen in elektrischen Körpern die eine der beiden im 
Überschuß, denken wir uns ferner in Leitern die Flüssigkeiten frei beweglich, in Nichtleitern unbeweglich, so haben wir die von Coulosi zu mathematischer Schärfe entwickelte Vorstellung. Wir brauchen uns nur.dieser Vor: stellung hinzugeben, so sehen wir im Geiste die Flüssigkeits: teilchen eines etwa positiv geladenèn Leiters, sich möglichst ron einander entfernend, alle nach der Oberfläche des Leiters wandern, dort die vorspringenden Teile und Spitzen aufsuchen, bis hierbei die größtmögliche Arbeit geleistet ist. Bei Vergrößerung der Oberfläche sehen wir eine Zerstreuung, bei Verkleinerung derselben eine Verdichtung der Teilchen. In einem zweiten, dem ersteren angenäherten unelektrischen Leiter, sehen wir sofort die beiden Fluissigkeiten sich trennen, die positive auf der abgekehrten, die negative auf der zugekehrten Seite der Oberfläche sich sammeln. Darin, daß diese Vorstellung alle nach und nach durch mühsame Beobachtung gefundenen Tatsachen anschaulich und wie von selbst reproduziert, liegt ihr Vorteil und ihr wissenschaftlicher Wert. Allerdings ist hiermit auch ihr Wert erschöpft, und wir dürften nicht etwa nach den beiden hypothetischen Flüssigkeiten, die wir ja nur hinzugedacht haben, in der Natur suchen, ohne auf Abwege zu geraten. Die Coulombsche Vorstellung kann durch eine gänzlich andere, wie z. B. die Faradaysche, ersetzt werden. Und das Richtıgste bleibt es immer, nachdem die Übersicht gewonnen ist, auf das Tatsächliche, auf die elektrischen Kräfte zurückzugehen.

Wir wollen uns nun zunächst mit der Vorstellung der Elektrizitätsmenge und der Art, dieselbe bequem zu messen oder zu schätzen, vertraut machen.

\section{Digitized by Microsoft ${ }^{\circledR}$}


Wir denken uns eine gewöhnliche Leydener-Flasche, Fig. 32, deren innere und äußere Belegung mit leitenden, etwa I Cm. von einander abstehenden Funkenkugeln verbunden ist. Ladet man die innere Belegung mit der Elcktrizitătsmenge $+q$, so tritt auf der äußeren Belegung durch das Glas hindurch eine Verteilung ein. Eine der Menge $+q$ fast gleiche*) positive Menge Hießt in die Erde $a b$, während die entsprechende $-q$ auf der äußeren Belegung bleibt. Die Funkenkugeln enthalten von diesen Mengen ihren Anteil, und wenn die Menge $q$ eben groß genug ist, tritt eine Durchbrechung der isolierenden Luft zwischen.den Kugeln und eine Selbstentladung der Flasche ein. Zur Selbstentladung der Flasche bei bestimmter Distanz und Größe der Funkenkugeln gehört jedesmal die Ladung durch die bestimmte Elektrizitäts-Menge $q$.

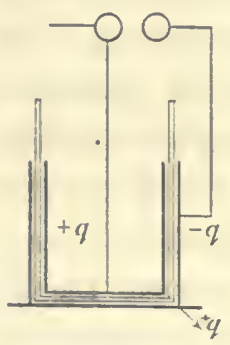

Fig. 32.

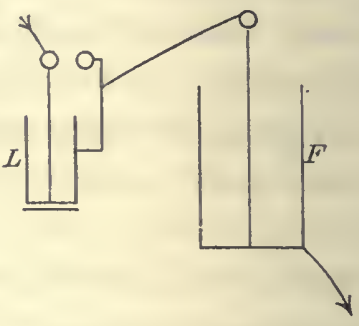

Fig. 33.

Isolieren wir nun die äußere Belegung der eben beschriebenen LaxEschen Maßflasche $L$, und setzen dieselbe

*) Die ahfliefsende Menge ist tatsächlich etwas kleiner als $q$. Sie wäre der Menge $q$ nur dann gleich, wenn die innere Belegung der Flasche von der àufsem ganz eingeschlossen wäre. 
menge zu fassen vermag wie $L$, daß sie die fünffache: Kaparität hat.*)

Wir wollen nun die Maßflasche $L$, mit welcher wir sozusagen in die Flasche $F$ einmessen, durch eine Franklinsche Tafel aus zwei parallelen ebenen Metallplatten ersetzen (Fig. 35), welche nur durch Luft getrennt sind. Genügen nun beispielsweise 30 Selbstentladungen der 'Tafel, um die Flasche zu fuillen, so sind hierzu etwa ro Entladungen hinreichend, wenn man den Luftraum zwischen den beiden Platten durch einen eingeschobenen Schwefelküchen ausfüllt. Die Kapazität der Frankuisschen Tafel aus Schwefel ist also etwa dreimal größer, als jene eines gleich geformten und gleich großen Luftkondensators oder, wie man sich auszudrücken pflegt, das spezifische Induktionsvermögen des Schwefels (jenes der Luft als Einheit genommen) ist etwa $3^{* *}$ ) Wir sind hier auf eine sehr einfache Tatsache gestoßen,

4) Genau ist dies allerdings nicht richtig. Zunächst ist zu bemerken, dafs sich die Flasche $L$ zugleich mit der Maschinenelektrode entladen murs. Die Flasche $F$ hingegen wird immer zugleich mit der äufseren Belegung der Flasche $L$ entladen. Nennt man also die Kapazität der Maschinenelektrode $E$, die der Mafsflasche $L$, die Kapazität der äufseren Belegung von $L$ aber $A$, und jene der Hauptflasche $F$, so würde dem Beispiel im Text die Gleichung entsprechen: $\frac{F+A}{L+E}=5$. Eine weitere Störung der Genauigkeit bringen die Entladungsrückstände mit sich.

\$t) Mit Rücksicht auf die in Anmerkung ${ }^{*}$ ) angedeuteten Korrektionen erhielt ich für die Dielektrizitäts-Konstante des Schwefels die Zahl 3.2, welche mit den durch feinere Methoden gewonnenen Zahlen genügend übereinstimmt. Genau genommen müfste man eigentlich die beiden Kondensatorplatten einmal ganz in Luft, das anderemal ganz in Schwefel versenken, wenn das Kapazitäts-Verhältnis der Dielektrizitäts.Konstante entsprechen sollte. In Wirklichkeit ist aber der Fehler, der dadurch entsieht, dars man nur eine Schwefelplatte einschiebt, welche den Raum zwischen den beiden Platten genau ausfült, nicht von Belang. 
welche uns die Bedeutung der Zahl, die man Dielektri$z$ it ät $\mathrm{s}-\mathrm{K}$ onst a n te oder spezifisches Induktionsvermögen

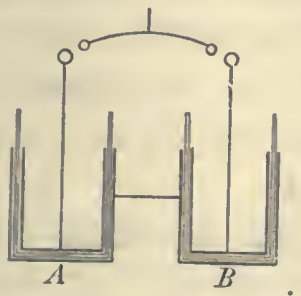

Fig. 36 .

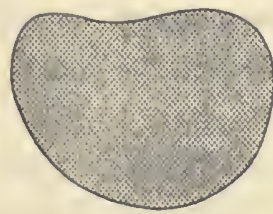

Fig. 37 .

nennt, und deren Kenntnis für die Theoric unterseeischer Kabel so wichtig ist, nahe legt.

Wir betrachten eine Flasche $A$, welche mit einer gewissen Elcktrizitätsmenge geladen ist. Wir können die Flasche direkt entladen. Wir können aber auch die Flasche $A$ (Fig. $3^{6}$ ) teilweise in eine Flasche $B$ entladen, indem wir die gleichnamigen Belegungen mit einander verbinden. Ein Teil der Elektrizitätsmenge geht hierbei unter Funkenbildung in die Flasche $B$ über und wir finden nun beide Flaschen geladen.

$\mathrm{DaB}$ die Vorstellung einer unveränderlichen Elektrizitätsmenge als Ausdruck einer reinen Tatsache betrachtet werden kann, sehen wir auf folgende Art. IVir denken uns einen beliebigen elektrischen Leiter, Fig. 37, der isoliert ist, zerschneiden ihn in eine große Anzahl kleiner Stückchen und bringen dieselben mit einer isolierten Zange auf I $\mathrm{Cm}$. Entfernung von einem elektrischen Körper, der auf einen gleichen, gleich beschaffenen in derselben Distanz die Krafteinheit austibt. Die Kräfte, 
welche der letztere Körper auf die einzelnen Leiterstiicke ausübt, zählen wir zusammen. Diese Kraftsumme ist nichts anderes als die Elektrizitätsmenge des ganzen Leiters. Sie bleibt immer dieselbe, ob wir die Form und Größe des Leiters ändern, ob wir ihn einem andern elektrischen Leiter nähern oder entfernen, so lange wir nur den Leiter isoliert lassen, d. h. nicht entladen.

Auch von einer anderen Seite her scheint sich für die Vorstellung der Elektrizitätsmenge eine reelle Basis zu ergeben. Wenn durch eine Säule von angesäuertem Wasser ein Strom, also nach unserer Vorstellung eine bestimmte Elektrizitätsmenge per Sekunde hindurchgeht, so wird mit dem positiven Strom Wasserstoff, gegen den Strom Sauerstoff an den Enden der Säule ausgeschieden. Für eine bestimmte Elektrizitätsmenge erscheint eine bestimmte Sauerstoffmenge. Man kann sich die Wassersäule als eine Wasserstoffsäule und eine Sauerstoffsäule denken, die sich durch einander hindurch schieben, und kann sagen, der elektrische Strom ist ein chemischer Strom und umgekehrt. Wenngleich diese Vorstellung im Gebiete der statischen Elektrizität und bei nicht zersetzbaren Leitern schwerer festzuhalten ist, so ist ihre weitere Entwicklung doch keineswegs aussichtslos.

Die Vorstellung der Elektrizitätsmenge ist also keineswegs eine so luftige, wie es scheinen könnte, sondern dieselbe vermag uns mit Sicherheit durch die Mannigfaltigkeit der Erscheinungen zu leiten, und wird uns durch die Tatsachen in beinahe greifbarer Weise nahegelegt. Wir können die elektrische Kraft ein einem Körper auf- 
sammeln, mit einem Körper dem anderen zumessen, aus einem Körper in den anderen überführen, sowie wir Flüssigkeit in einem Gefäß aufsammeln, mit einem Gefäß in ein anderes einmessen, aus einem in das andere ubergießen können.

Zur Beurteilung mechanischer Vorgänge hat sich an der Hand der Erfahrung ein Maßbegriff als vorteilhaft erwiesen, der mit dem Namen Arbeit bezeichnet wird. Eine Maschine gerät nur dann in Bewegung, wenn die an derselben wirksamen Kräfte Arbeit leisten können.

Betrachten wir z. B. ein Wellrad (Fig. 38) mit den Halbmessern $x$ und 2 M., an welchen beziehungsweise die Gewichte 2 und I Kilo angebracht sind. Drehen wir

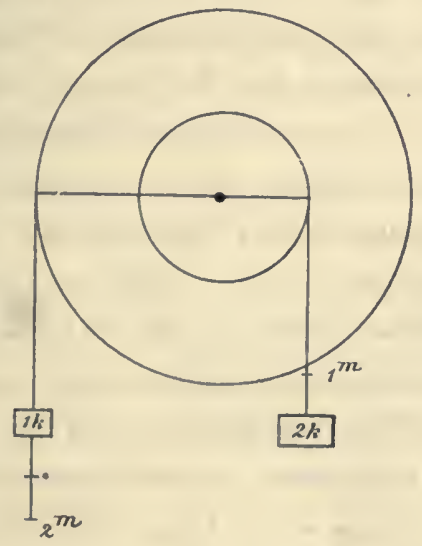

Fig. 38 . 
das Wellrad, so sehen wir etwa das Kilogewicht um 2 M. sinken, während das Zweikilogewicht um I M. steigt. Es ist auf beiden Seiten das Produkt

$$
\begin{aligned}
& \text { Kgr. M. Kgr. M. } \\
& \text { I } \times 2=2 \times \text { I }
\end{aligned}
$$

gleich. So lange dieseș Produkt beiderseits gleich ist, bewegt sich das Wellrad nicht von selbst. Wählen wir aber die Belastungen oder dic Halbmesser so, daß das Produkt Kilo $\times$ Meter bei einer Verschiebung auf der einen Seite einen Überschuß erhält, so wird diese Seite sinken. Das Produkt ist also charakterist is ch für den mechanischen Vorgang, und ist eben deshalb mit einem besonderen Namen belegt, Arbeit genannt worden.

Bei allen mechanischen Vorgängen, und da alle physikalischen Vorgänge eine mechanische Seite darbieten, bei allen physikalischen Prozessen, spielt die Arbeit eine maßgebende Rolle. Auch die elektrischen Kräfte bringen nur solche Veränderungen hervor, bei welchen Arbeit geleistet wird. Insofern bei den elektrischen Erscheinungen Kräfte ins Spiel kommen, reichen sie ja, mögen sie sonst was immer sein, ins Gebiet der Mechanik hinein und fügen sich den in diesem Gebiete geltenden Gesetzen. Als Maß der Arbeit betrachtet man also das Produkt aus der Kraft in den Wirkungsweg derselben, und in dem C.-G.-S.System gilt als Arbeitseinheit die Wirkung einer Kraft, welche einer Grammmasse in der Sekunde einen Geschwindigkeitszuwachs von I $\mathrm{Cm}$. erteilt auf I Cm. Wegstrecke, also rund etwa die Wirkung eines MilligrammGewichtsdruckes auf I Cm. Wegstrecke. 
Von einem positiv geladenen Körper wird Elektrizität, den Abstoßungskräften folgend und Arbeit leistend, wenn eine leitende Verbindung besteht, zur Erde abfließen. An einen negativ geladenen Körper gibt umgekehrt unter denselben Umständen die Erde positive Elektrizität ab. Die elektrische Arbeit, welche bei der Wechselwirkung eines Körpers mit der Erde möglich ist, charakterisiert den elektrischen Zustand des ersteren. Wir wollen die Arbeit, welche wir auf die Einheit der positiven Elektrizitätsmenge aufwenden, wenn wir dieselbe von der Erde zu dem Körper $K$ hinaufschaffen, das Potential des Körpers $K$ nennen. $\left.{ }^{*}\right)$

Wir schreiben dem Körper $K$ im C. G.-S.-System das Potential + I zu, wenn wir die Arbeitseinheit aufwenden müssen, um die positive elektrostatische Einheit der Elektrizitätsmenge von der Erde zu ihm hinaufzuschaffen, das Potential - I, wenn wir bei derselben Prozedur die Arbeitseinheit gewinnen, das Potential o, wenn hierbei keine Arbeit geleistet wird.

Den verschiedenen Teilen desselben im elektrischen Gleichgewicht befindlichen Leiters entspricht dasselbe

\$) Da diese Definition in ihrer einfachen Form zu Mlifsverständnissen An. lafs geben kann, werden derselben gewöhnlich noch Erläuterungen hinzugefügt. Es ist nämlich klar, dafs man keine Elektrizitätsmenge auf $K$ hinaufschaffen kann, ohne die Verteilung auf $K$ und das Potential auf $K$ zu ändern, Man hat sich demnach die Ladungen an $K$ festgehalten zu denken und eine so kleine Menge hinaufzuführen, dafs durch dieselbe keine merkliche Änderung entsteht. Nimmt man die aufgewendete Arbeit so vielmal als jene kleine Mlenge in der Einheit aufgeht, so erhält man das Potential. - Kurz und scharf läfst sich das Potential eines Körpers $K$ in folgender Weise definieren. Wendet man das Arbeitselement $d W$ auf, um das Element $d Q$ der positiven Menge von der Erde auf den Leiter zu fördern, so ist das Potential des Leiters $K$ gegeben durch $V=\frac{d W}{d Q}$ 
Potential, denn andernfalls würde die Elektrizität, Arbeit leistend in diesem Leiter sich bewegen und es bestünde noch kein Gleichgewicht. Verschiedene Leiter von gleichem I'otential, in leitende Verbindung gebracht, bieten keinen Austausch von Elektrizität dar, ebensowenig als bei sich berührenden Körpern von gleicher Temperatur ein Wärmeaustausch oder bei verbundenen Gefäßen von gleichem Flüssigkeitsdruck ein Flüssigkeitsaustausch stattfindet.

Nur zwischen Leitern verschiedenen Potentials findet cin Austausch der Elektrizität statt, und bei Leitern von gegebener Form und Lage ist eine bestimmte Potentialdifferenz notwendig, damit zwischen denselben ein die isolierende Luft durchbrechender Funke überspringt.

Je zwei verbundene Leiter nehmen sofort dasselbe Potential an, und hiermit ist das Mittel gegeben, das Potential eines Leiters mit Hilfe eines anderen hierzu geeigneten, eines sogenannten Elektrometers, ebenso zu bestimmen, wie man die Temperatur eines Körpers mit dem Thermometer bestimmt. Die auf diese Weise gewonnenen Potentialwerte der Körper erleichtern, wie dies nach dem Besprochenen einleuchtet, ungemein das Urteil iiber deren elektrisches Verhalten.

Denken wir uns einen positiv geladenen-Leiter. Verdoppeln wir alle elektrischen Kräfte, welche derselbe auf einen mit der Einheit geladenen Punkt ausübt, d. h. rerdoppeln wir an jeder Stelle die Menge, verdoppeln wir also auch die Gesamtladung, so besteht ersichtlich das Gleichgewicht fort. Führen wir aber nun die positive elektrostatische Einheit dem Leiter $z u$, so haben wir

\section{Digitized by Microsoft ${ }^{\circledR}$}


überall die doppelten Abstoßungskräfte zu überwinden wie zuvor, wir haben die doppelte Arbeit aufzuwenden, das Potential hat sich mit der Ladung des Leiters verdoppelt, Ladung und Potential sind einander proportional. Wir können also die gesamte Menge der Elektrizität eines Leiters mit $Q$, das Potential desselben mit $V$ bezeichnend, schreiben: $Q=C V$, wobei also $C$ eine Konstante bedeutet, deren Bedeutung sich ergibt, wenn wir bedenken, daß $C=\frac{Q}{V}$ ist. Dividieren wir aber die Anzahl der Mengeneinheiten eines Leiters durch die Anzahl seiner Potentialeinheiten, so erfahren wir, welche Menge auf die Einheit des Potentials entfallt. Wir nennen nun die betreffende Zahl $C$ die $\mathrm{K}$ apazität des Leiters, und haben somit an Stelle der relativen eine absolute Bestimmung der Kapazität gesetzt.*)

In einfachen Fällen läßt sich nun der Zusammenhang zwischen Ladung, Potential und Kapazität ohne Schwierigkeit ermitteln. Der Leiter sei z. B. eine Kugel vom Radius $r$ frei in einem großen Luftraum. Dann verteilt

*) Zwischen den Begriffen „Wärmekapazität" und „,elektrische Kapazität" besteht eine gewisse Übereinstimmung, doch darf auch der Unterschied beider Begriffe nicht aufser acht gelassen werden. Die Wärmekapazität eines Körpers hängt nur von ihm selbst ab. Die elektrische Kapazität eines Körpers $K^{\beta}$ wird aber durch alle Nachbarkörper beeinflufst, indem auch die Ladung dieser Körper das Potential von $K$ ändern kann. Um demnach dem Begriff Kapazität (C) des Körpers $K$ einen unzweideutigen $\operatorname{Sinn} z u$ geben, versteht man unter $C$ das Verhältnis $\underset{V}{V}$ für den Körper $K$ bei einer gegebenen Iage aller Nachbarkörper und Ableitung aller benachbarten Leiter zur Erde. In den für die Praxis wichtigen Fällen gestaltet sich die Sache viel einfacher. Die Kapazität einer Flasche z. B., deren innere Belegung durch die äufsere abgeleitete fast umschlossen ist, wird duroh geladene oder ungeladere Nebenleiter nicht merklich beeinflufst. 
sich die Ladung $q$, da keine anderen Leiter in der Nähe sind, gleichmäßig auf ihrer Oberfläche, und einfache geometrische Betrachtungen ergeben für das Potential den Ausdruck $V=\frac{q}{r}$. Hiernach ist also $\frac{q}{V}=r$, d. h. die Kapazität wird durch den Radius, und zwar im C.-G.-S.System in Centimetern gemessen. $\left.{ }^{*}\right)$ Es ist auch klar, da ein Potential eine Menge durch eine Länge dividiert ist, so muß eine Menge, durch ein Potential dividiert, eine Länge sein.

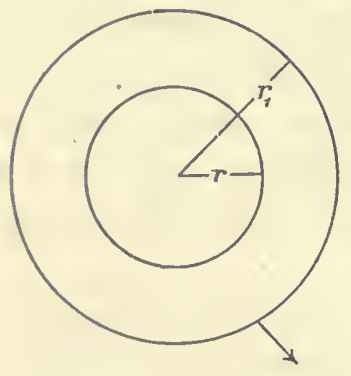

Fig. 39 .

Denken wir uns (Fig. 39) eine Flasche aus zwei konzentrischen leitenden Kugelflächen von den Radien $r$ und $r_{1}$ gebildet, welche nur Luft zwischen sich enthalten. Leitet man die äußere Kugel zur Erde ab, und ladet die innere durch einen dünnen durch die erstere isoliert hindurchgeführten Draht mit der Menge $Q$, so ist $V=\frac{r_{1}-r}{r_{1} r} Q$, und die Kapazität in diesem Falle $\frac{r_{1} r}{r_{1}-r}$, also wenn z. B. $r=\mathrm{I} 6, r_{1}=\mathrm{I9}$, nahe $=$ I $о \circ \mathrm{Cm}$.

*) Diese Formeln ergeben sich sehr leicht aus dem Newtonschen Satze, dafs eine homogene Kugelschicht, deren Elemente verkehrt quadratisch wirken, auf einen inneren Punkt gar keine Kraft ausibb, auf einen äufseren aber wie die im Kugelmittelpunkt vereinigte Masse wirkt. Aus demselben Satz fliefsen auch noch die zunächst folgenden Formeln. Eine elementare Ableitung findet sich bei M a ch, Leitfaden der Physik. Prag r8gr. S. 198. 
Diese einfachen Fälle wollen wir nun benützen, um das Prinzip der Kapazitätsbestimmung und der Potentialbestimmung zu erläutern. Zunächst ist klar, daß wir die Flasche aus konzentrischen Kugeln von bekannter Kapazität als Maßfiasche benutzen, und mit Hilfe derselben in der bereits dargelegten Weise die Kapazität einer vorgelegten Flasche $F$.ermitteln können. Wir finden z. B., daß 37 Entladungen dieser Maßflasche von der Kapazität

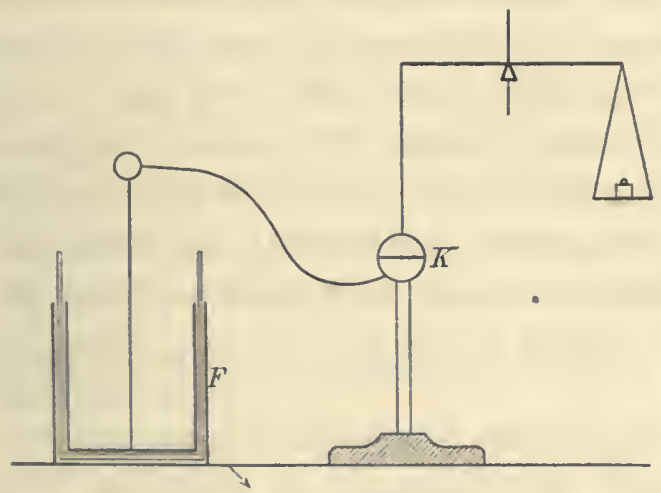

Fig. 40.

Ioo die vorliegende Flasche zu gleicher Schlagweite, das ist $\mathrm{zu}$ gleichem Potential laden. Demnach ist die Kapazität der vorliegenden Flasche $3700 \mathrm{Cm}$. Die große Batterie des Prager physikalischen Institutes, welche aus I 6 solchen nahe gleichen Flaschen besteht, hat demnach eine Kapazität von etwas mehr als $50000 \mathrm{Cm}$, also dieselbe Kapazität wie eine frei im Luftraum schwebende Kugel von mehr als I $\mathrm{Km}$. Durchmesser. Diese Bemerkung kann uns den großen Vorteil nahe legen, welchen Leydener- 
Flaschen bei Aufspeicherung von Elektrizität gewöhnlichen Konduktoren gegenüber gewähren. In der Tat unterscheiden sich Flaschen von einfachen Konduktoren, wie schon FARADAY wußte, wesentlich nur durch die große Kapazität.

Zum Zwecke der Potentialbestimmung denken wir uns die innere Belegung einer Flasche $F$, deren äußere Belegung abgeleitet ist, durch einen dünnen langen Draht mit einer leitenden Kugel $K$ verbunden, welche in einem Luftraume frei aufgestellt ist, gegen dessen Dimensionen der Kugelradius verschwindet. (Fig. 40.) Die Flasche und die.Kugel nehmen sofort gleiches Potential an. Auf der Kugeloberfläche aber befindet sich, wenn dieselbe von allen anderen Leitern weit genug entfernt ist, eine gleichmäßige Schicht von Elektrizität. Enthält die Kugel vom Radius $r$ die Ladung $q$, so ist $V=\frac{q}{r}$ ihr Potential. Ist nun die obere Kugelhälfte abgeschnitten und an einer Wage, an deren Balken sie mit Seidenfäden befestigt ist, äquilibriert, so wird die obere Hälfte von der unteren mit der Kraft $P=\frac{q^{2}}{8 r^{2}}=\frac{\mathrm{I}}{8} V^{2}$ abgestoßen. Diese Abstoßung $P$ kann durch ein Zuleggewicht ausgeglichen und folglich bestimmt werden. Das Potential ist dann $\left.V=\sqrt{8 P^{*}}{ }^{*}\right)$

*) Die Energie einer mit der Menge $Q$ geladenen Kugel vorn Halbmesser $r$ ist $\frac{1}{2} \cdot \frac{q^{2}}{r}$. Dehnt sich der Radius um $d r$, so findet hierbei ein Energieverlust statt, und die geleistete Arbeit ist $\frac{I}{2} \cdot \frac{q^{2}}{r} d r$. Nenntman $p$ dengleichmäfsigen elektrischen Druck auf die Oberfächeneinheit der Kugel, so ist die betreffende 
Daß das Potential der Wurzel aus der Kraft proportional geht, ist leicht einzusehen. Bei doppeltem oder dreifachem Potential ist die Ladung aller 'Teile verdoppelt oder verdreifacht, demnach ihre gegenseitige Abstoßungswirkung schon vervierfacht, verneunfacht.

Betrachten wir ein besonderes Beispiel. Ich will auf der Kugel das Potential 40 herstellen. Welches Übergewicht muß ich der Kugelhälfte in Grammen geben, damit der Abstoßungskraft eben das Gleichgewicht gehalten wird? Da ein Grammgewicht etwa Iooo Krafteinheiten entspricht, so haben wir folgende einfache Rechnung $40 \times 40=8 \times 1000 \cdot x$, wobei $x$ die Anzahl der Gramme bedeutet. Es ist rund $x=0.2$ Gramme. Ich lade die Flasche. Es erfolgt der Ausschlag, ich habe das Potential 40 erreicht oder eigentlich überschritten und Sie sehen, wenn ich die Flasche entlade, den zugehörigen Funken. ${ }^{*}$ )

Die Schlagweite zwischen den Funkenkugeln einer Maschine wächst mit der Potentialdifferenz, wenn auch

Arbeit auch $4 r^{2} \pi \beta d r$, demnach $\beta=\frac{1}{8} \cdot \frac{q^{2}}{r^{2} \pi r^{2}}$. Die Halbkugel, von allen Seiten demselben Oberfächendruck etwa in einer Flüssigkeit ausgesetzt, wäre im Gleichgewicht. Demnach haben wir den Druck $p$ auf die Fläche des gröfsten Kreises wirken zu lassen, um die Wirkung auf die Wage zu erhalten, welche ist $r^{2} \tau p=\frac{1}{8} \cdot \frac{q^{2}}{r^{2}}=\frac{1}{8} V^{2}$.

") Die eben angegebene Disposition ist aus mehreren Gründen zur wirklichen Messung des Potentials nicht geeignet. Das Thomsonsche absolute Elektrometer beruht auf einer sinnreichen Modifikation der elektrischen Wage von Harris und Volta. Von zwei grofsen planparallelen Platten ist die eine zur Erde abgeleitet, die andere auf das zu messende Potential gebracht. Ein kleines bewegliches Flächenstück $f$ der letzteren hängt an der Wage zur Bestimmung der Attraktion $P$. Bei dem Plattenabstand $D$ ergibt sich

$$
r=D \sqrt{\frac{8 \pi P}{f}} .
$$


nicht proportional derselben. Die Schlagweite wächst rascher als die Potentialdifferenz. Bei einem Abstand der Funkenkugeln von I $\mathrm{Cm}$. an dieser Maschine ist die Potentialdifferenz I Io. Man kann sie leicht auf das Zehnfache bringen. Und welche bedeutende Potentialdifferenzen in der Natur vorkommen, sieht man daraus, daß die Sclulagweite der Blitze bei Gewittern nach Kilometern zählt. Die Potentialdifferenzen bei galvanischen Batterien sind bedeutend kleiner, als jene an unserer Maschine, denn erst einige hundert Elemente geben einen Funken von mikroskopischer Schlagweite.

Wir wollen nun die gewonnenen Begriffe benützen, un eine andere wichtige Beziehung der elektrischen und mechanischen Vorgänge zu beleuchten. Wir wollen untersuchen, welche potentielle Energie oder welcher Arbeitsvorrat in einem geladenen Leiter, z. B. in einer Flasche, enthalten ist.

Schafft man eine Elektrizitätsmenge auf einen Leiter, oder ohne Bild gesprochen, erzeugt man durch Arbeit elektrische Kraft an einem Leiter, so vermag diese Kraft die Arbeit wiederzugeben, durch welche sie entstanden ist. Wie groß ist nun die Energie oder Arbeitsfähigkeit eines Leiters von bekannter Ladung $Q$ und bekanntem Potential $V$ ?

Wir denken uns die genannte Ladung $Q$ in sehr kleine Teile $q, q_{1}, q_{3} \ldots$ geteilt, und dieselben nach einander auf den Leiter geschafft. Die erste sehr kleine 
Menge $q$ gelangt ohne merkliche Arbeit hinauf, erzeugt aber ein kleines Potential $V_{1}$. Zur Förderung der zweiten Menge brauchen wir dann schon die Arbeit $q_{1} V_{1}$ und analog für die folgenden Mengen die Ärbeiten $q_{2} V_{2}$, $q_{3} V_{\S}$ u. s. f. $\mathrm{Da}$ nun das Potential den zugeführten Mengen selbst proportional bis $V$ ansteigt, so ergibt sich entsprechend unserer graphischen Darstellung (Fig. 4I) die Gesamtarbeit

$$
W=\frac{I}{2} Q V
$$

welche der gesamten Energie des geladenen Leiters entspricht. Mit Rücksicht auf die Gleichung $Q=C V$, worin $C$ die Kapazität bedeutet, können wir auch sagen

$$
W=\frac{\mathrm{I}}{2} C V^{2} \text { oder } W=\frac{Q^{2}}{2} C \text {. }
$$

Es wird vielleicht nützlich sein, den ausgeführten Gedanken noch durch eine Analogie aus dem Gebiete der

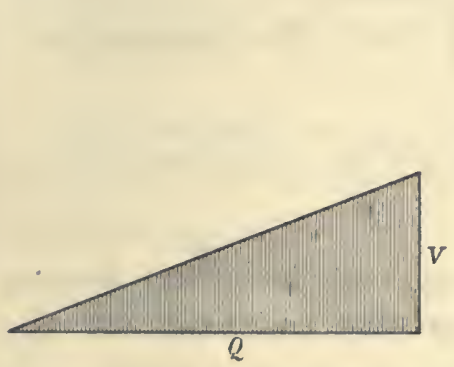

Fig. 41 .

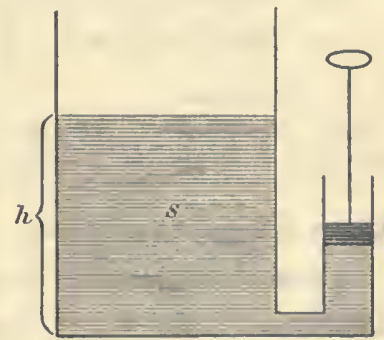

Fig. 42.

Mechanik zu erläutern. Wenn wir eine Flüssigkeitsmenge $Q$ allmählich in ein zylindrisches Gefäß pumpen (Fig. 42), so steigt in diesen das Niveau ebenso allmählich. Je 
mehr wir schon eingepumpt haben, mit desto größerem Druck müssen wir weiter pumpen, oder auf ein desto höheres Niveau müssen wir die Flüssigkeit heben. Die aufgespeicherte Arbeit wird wieder verwendbar, wenn das Flüssigkeitsgewicht $Q$, welches bis zum Niveau $h$ reicht, wieder ausfließt. Diese Arbeit $W$ entspricht dem Fall des ganzen Flüssigkeitsgewichts $Q$ um die mittlere Höhe $h$ $\frac{h}{2}$, oder um die Schwerpunktshöhe. . Es ist

$$
W=\frac{1}{2} Q h \text {. }
$$

Und weil $Q=K h$, d. h. weil das Flüssigkeitsgewicht und die Höhe $h$ proportional sind, ist auch

$$
W=\frac{I}{2} K h^{2} \text { und } W=\frac{Q^{2}}{2} \bar{K} \text {. }
$$

Betrachten wir als spezielles Beispiel unsere Flasche. Die Kapazität ist $C=3700$,

das Potential $V=$ I 1 o, demnach

die Menge $Q=C V=407.000$ elektrostatische Einheiten,

und die Energie $W=\frac{1}{2} Q V=22,385,000 \quad$ C.-G.-S.Arbeitseinheiten.

Diese Arbeitseinheit des C.-G.-S.-System liegt unserm Gefuhl fern, und ist für uns wenig anschaulich, da wir gewohnt sind, mit Gewichten zu operieren. Nehmen wir demnach als Arbeitseinheit ein Grammcentimeter, welche dem Druck eines Grammgewichtes auf die Wegstrecke von $1 \mathrm{~cm}$ entspricht, und welche rund I ooo mal größer ist als die vorher zu Grunde gelegte Einheit, so wird unsere 
Zahl rund 1000 mal kleiner. Und übergehen wir zu dem praktisch so geläufigen Kilogrammmeter als Arbeitseinheit, so ist dies wegen der roomal größeren Wegstrecke und dem rooo nal größeren Gewicht, das wir nun zu Grunde legen, I $00.000 \mathrm{mal}$ größer. Die Zahl für die Arbeit fällt also roo.000 mal kleiner aus, und wird rund 0.22 Kilogrammmeter. Wir können uns von dieser Arbeit sofort eine anschauliche Vorstellung verschaffen, wenn wir ein Kilogrammgewicht $22 \mathrm{~cm}$ tief fallen lassen.

Diese Arbeit wird also bei Ladung der Flasche geleistet, und kommt bei Entladung derselben nach Umständen teils als Schall, teils als mechanische Durchbrechung von Isolatoren, teils als Licht und Wärme u. s. w. zum Vorschein.

Die erwähnte große Batterie des physikalischen Institutes aus I 6 Flaschen zu gleichem Potential geladen, liefert, obgleich der Entladungseffekt imposant ist, doch nur eine Gesamtarbeit von etwa 3 Kilogrammmeter.

Bei Entwicklung der eben dargelegten Gedanken sind wir durchaus nicht auf den von uns eingeschlagenen Weg beschränkt, welcher nur als ein zur Orientierung vorzugsweise geeigneter gewählt wurde. Der Zusammenhang unter den physikalischen Erscheinungen ist vielmehr ein so mannigfacher, daß man derselben Sache auf sehr verschiedene Weise beikommen kann. Namentlich hängen die elektrischen Erscheinungen mit allen übrigen so innig zusammen, daß man die Elektrizitätslehre billig die Lehre vom Zusammenhang der physikalischen Erscheinungen

\section{Digitized by Microsoft ${ }^{\circledR}$}


nennen könnte, was Ihnen die folgenden Vorträge olne Zweifel recht nahe legen werden.

Was insbesondere das Prinzip der Erhaltung der Finergie betrifit, welches die elektrischen mit den mechanischen Erscheinungen verknüpft, so möchte ich noch kurz auf zwei Wege aufmerksam machen, diesen Zusammenhang zu verfolgen.

Professor RosetTI hat vor einigen Jahren an einer durch Gewicht betriebenen Influenzmaschine, die er abwechselnd in elektrischem und unelektrischem Zustande mit gleicher Geschwindigkeit in Gang setzte, in beiden Fällen die aufgewendete mechanische Arbeit bestimmt, und war dadurch in den Stand gesetzt, die nach Abzug der Reibungsarbeit rein auf Elektrizitätsentwicklung entfallende mechanische Arbeit zu ermitteln.

Ich selbst habe den Versuch in modifizierter, und wie ich glaube, in vorteilhafter Form angestellt. Anstatt nämlich die Reibungsarbeit besonders zu bestimmen, habe ich den Apparat so eingerichtet, daß sie bei der Messung von selbst ausfällt, und gar nicht beachtet $\mathrm{zu}$ werden braucht. Die sogenannte fixe Scheibe der Maschine, deren Rotationsaxe vertikal steht, ist ähnlich wie ein Kronleuchter an drei gleich langen vertikalen Fäden von der Länge $l$ und dem Axenabstand $r$ aufgehängt. Nur wenn die Maschine erregt ist, erhält diese Scheibe, welche einen Proxyschen Zaum vorstellt, durch die Wechselwirkung mit der rotierenden Scheibe eine Ablenkung $a$ und ein Drehungsmoment, welches durch $D=\frac{P r^{2}}{l} a$ ausgedrückt ist, wenn $P$ das 
Scheibengewicht ist.*) Der Winkel $a$ wird durch einen auf die Scheibe gesetzten Spiegel bestimmt. Die bei $n$ Umdrehungen aufgewendete Arbeit ist durch $2 n \pi D$ gegeben.

Schließt man die Maschine in sich, wie es RoseTtI getan hat, so erhält man einen kontinuierlichen Strom, der alle Eigenschaften eines sehr schwachen galvanischen Stromes hat, z. B. an einem eingeschalteten Multiplikator einen Ausschlag erzeugt u. s. w. Man kann nun direkt die zur Instandhaltung dieses Stromes aufgewendete mechanische Arbeit ermitteln.

Ladet man mit Hilfe der Maschine eine Flasche, so entspricht die Energie derselben, welche zur Funkenbildung, zur Durchbrechung von Isolatoren u. s. w. verwendet werden kann, nur einem Teil der aufgewendeten mechanischen Arbeit, indem ein anderer Teil im Schließungsbogen verbraucht wird. Es ist ein Bild der Kraft- oder richtiger der Arbeitsübertragung, welches diese Maschine mit eingeschalteter Flasche im Kleinen darbietet. Und in der Tat gelten hier ähnliche Gesetze für den ökonomischen Koëfficienten, wie sie für die großen Dynamo. maschinen platzgreifen.**;

*) Dieses Drehungsmoment murs noch wegen der elektrischen Attraktion der erregten Scheiben korrigiert werden. Dies erreicht man, indem man das Scheibengewicht durch Zuleggewichte ändert, und noch eine Winkel. ablesung macht.

*) In unserm Experiment verhält sich die Flasche wie ein Akkunulator, der durch eine Dynamomaschine geladen wird. Welches Verhältuis zwischen der aufgewendeten und uutzbaren Arbeit besteht, wird durch folgende einfache Darstellung ersichtlich. Die $\mathrm{H} o l \mathrm{tz}$ sche Maschine $H$, Fig. 43, lade eine Mafs. flasche $L$, welche nach $n$ Entladungen mit der Menge $q$ und dem Potential $v$, 
Ein anderes Mittel zur Untersuchung der elektrischen Knergie ist die Umwandlung derselben. in Wärme. Riess hat derartige Versuche mit Hilfe seines elektrischen Luft"Thermometers ausgefuihrt, und zwar vor langer Zeit schon (1838), als die mechanische Wärmetheorie noch nicht so populär war wie heute.

Wird die Entladung durch einen durch die Kugel des I.uft-Thermometers gezogenen feinen Draht geleitet, so läßt sich eine Wärmeentwicklung nachweisen, welche dem schon erwähnten Ausdruck $W=\frac{\mathrm{r}}{2} Q V$ proportional geht. Wenn es nun auch noch nicht gelungen ist, die gesamte Energie auf diese Weise in meßbare Wärme umzuwandeln, weil ein Teil in dem Funken in der Luft außerhalb des Thermometers verbleibt, so spricht doch alles dafür, daß die gesamte in allen Leiterteilen und

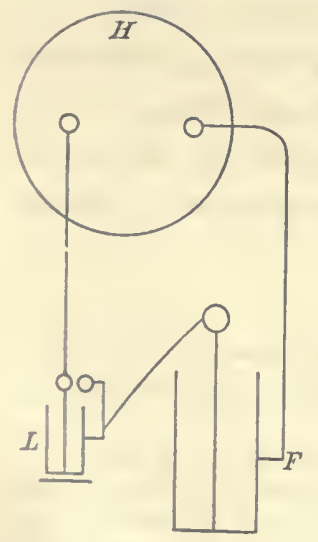

Fig. 43. die Flasche $F$ mit der Menge $Q$ zum Potential $V$ geladen hat. Die Energie der MafsflaschenEntladungen ist verloren, und jene der Flasche $F$ allein übrig. Demnach ist das Verhältnis der nutzbaren zur überhaupt aufgewendeten Arbeit:

$\frac{\frac{I}{2} Q V}{\frac{I}{2} Q V+\frac{n}{2} q v}$ und, weil $Q=n q$, auch $\frac{V}{V+v}$ Schaltet man nun auch keine Mafsflasche ein, so sind doch die Maschinenteile und Zuleitungsdrähte selbst solche Mafsflaschen und es besteht die Formel fort $\frac{V}{V+\Sigma v}$, in welcher $\Sigma v$ die Summe aller hintereinander geschalteten Potentialdifferenzen im Schliefsungskreise bedeutet. 
Entladungswegen schließlich entwickelte Wärme das Äquivalent der Arbeit $\frac{\mathrm{I}}{2} Q V$ sei

Es kommt hierbei auch gar nicht darauf an, ob die elektrische Energie auf einmal oder teilweise, nach und nach, umgewandelt wird. Wenn z. B. von zwei gleichen Flaschen die eine mit der Menge $Q$ zum Potential $V$ geladen ist, so ist die vorhandene Energie $\frac{\mathbf{I}}{2} Q V$. Entladet man die Flasche in die andere, so sinkt wegen der doppelten Kapazität $V$ auf $\frac{V}{2}$. Es verbleibt also die Energie $\frac{I}{4} Q V$, während $\frac{I}{4} Q V$ im Entladungsfunken in Wärme umgewandelt wurde. Der Rest ist aber in beiden Flaschen gleich verteilt, so daß jede bei ihrer Entladung noch $\frac{1}{8} Q V$ in Wärme umzusetzen vermag.

Wir haben die Elektrizität in der beschränkten Erscheinungsform besprochen, welche den Forschern vor Volta allein bekannt war und die man, vielleicht nicht ganz glücklich, statische Elektrizität oder Spannungselektrizität genannt hat. Es versteht sich aber, daß die Natur der Elektrizität überall eine und dieselbe ist, daß ein wesentlicher Unterschied zwischen statischer und galvanischer Elektrizität nicht besteht. Nur die quantitativen Umstände - sind in beiden Gebieten so sehr verschieden, daß in dem zweiten ganz neue Seiten der Erscheinung, wie z. B. die magnetischen Wirkungen deutlich hervortreten können, 
welche in dem ersten unbemerkt blieben, während umgekehrt wieder die statischen Anziehungen und Abstoßungen in dem zweiten Gebicte fast verschwinden. In der Tat kann man die magnetische Wirkung des Entladungsstromes einer Infuenzmaschine leicht am Multiplikator nachweisen, doch hätte man schwerlich an diesem Strome die magnetische Wirkung entdecken können. Die statischen Fernwirkungen der Poldrähte eines galvanischen Elementes wären ebenfalls kaum zu beobachten, wenn die Erscheinung nicht schon von anderer Seite her in auffallender Form bekannt wäre.

Wollte man die beiden Gebiete in den Hauptzügen charakterisieren, so würde man sagen, daß in dem ersteren hohe Potentiale und kleine Mengen, in dem letzteren kleine Potentiale und große Mengen ins Spiel kommen. Eine sich entladende Flasche und ein galvanisches Element verhalten sich etwa wie eine Windbüchse und ein Orgelblasebalg. Erstere gibt plötzlich unter sehr hohem Druck eine kleine Luftquantität, letzterer allmählich unter sehr geringem Druck eine große Luftquantität frei.

Es würde zwar prinzipiell nichts im Wege stehen, auch im Gebiet der galvanischen Elektrizität die elektrostatischen Maße festzuhalten, und z. B. die Stromstärke zu messen durch die Zahl der elektrostatischen Einheiten, welche in der Sekunde den Querschnitt passieren, allein dies wäre in doppelter Hinsicht unpraktisch. Erstens würde man die magnetischen Anhaltspunkte der Messung, welche der Strom bequem darbietet, unbeachtet lassen, und dafür eine Messung setzen, die sich an dem Strom nur schwer und 
mit geringer Genauigkeit ausführen läßt. Zweitens würde man eine viel $\mathrm{zu}$ kleine Einheit anwenden und dadurch in dieselbe Verlegenheit kommen, wie ein Astronom, der die Himmelsräume in Netern, statt in Erdradien und Erdbahnhalbmessern ausmessen wollte, denn der Strom, welcher nach magnetischem Maße (in C.-G.-S.) die Einheit darstellt, fördert etwa $30.000,000.000$ (30 Tausend Millionen) elektrostatischer Einheiten in der Sekunde durch den Querschnitt. Deshalb müssen hier andere Maße zu Grunde gelegt werden. Dies auseinanderzusetzen gehört aber nicht mehr zu meiner Aufgabe. *)

\#) [Es liegt die Bemerkung nahe, dafs man mit jedem der Begriffe $Q$ $V$, IV unmittelbar an die Beobachtung anknüpfen kann. Die beiden andern Begriffe lassen sich dann durch den als Fundamentalbegriff gewählten und die nötigen Konstanten ausdrücken. Coul omb geht von dem Mengenbegriff, Cavendihs von dem Potentialbegriff aus, während $\mathrm{Riefs}$ (allerdings nicht mit vollem. Bewufstsein) an den Energiebegriff anknüpt. Des letzteren Luftthermometer ist eigentlich ein Funkenka lorimeter, welches sich mit Vorteil in die Form des Bu n senschen Eiskalometers bringen liefse, und das dann wohl noch zu andern Untersuchungen (Schmelz- und Dampfwärme der Metalle usw.) dienen könnte. Man befreit sich von Zufälligkeiten der Auffassung, indem man sich die Folgen einer Änderung der historischen Reihenfolge von einander unab. hängiger Entdeckungen vergegenwärtigt. Vgl, „Erhaltung der Arbeit", "Mechanik" und den folgenden Artikel XII. - rgo2.] 
XII.

\section{Über das Prinzip der Erhaltung der Energie.")}

In einem durch seine liebenswürdige Einfachheit und Klarheit ausgezeichneten populären Vortrag, den Joule im Jahre I 847 gehalten hat, ${ }^{*}$ ) setzt dieser berühmte Physiker auseinander, daß die lebendige Kraft, die ein schwerer Körper im Fall durch eine gewisse Höhe erlangt hat, welche derselbe in Form der beibehaltenen Geschwindigkeit mit sich führt, das $\ddot{A} q u$ ivalent der Attraktion durch den Fallraum ist, und daß es ,absurd“ wäre anzunehmen, jene lebendige Kraft könnte zerstört werden, ohne dieses Äquivalent wieder zu erstatten. Er fügt dann hinzu: You will therefore be surprised to hear that until very recently the universal opinion has been that living force could be absolutely and irrevocably destroyed at any one's option." Nehmen wir hinzu, daß heute, nach 47 Jahren, das Gesetz der Erhaltung der Energie, so weit die Kultur reicht, als

9) Dieser Artikel, eins freie Bearbeitung eines Teiles meiner Schrift über, ,Erhaltung der Arbeit", erschien zuerst englisch in "The Monist". Vol. V. p. 22.

On Matter, Living Force, and Heat. Joule, Scientific Papers. London 1884. I. p. 265 . 
eine vollkommen ausgemachte Wahrheit gilt, und auf allen Gebieten der Naturwissenschaft die reichsten Anwendungen erfährt.

Das Schicksal aller bedeutenden Aufklärungen ist ein sehr ähnliches. Beim ersten Auftreten werden dieselben von der Mehrzahl der Menschen für Irrtümer gehalten. So wurde J. R. MAYERS Arbeit ïber das Energieprinzip (1842) von dem ersten physikalischen Journal Deutschlands zurückgewiesen, HémHoltz' Abhandlung erging es (I 847 ) nicht besser, und auch Joule scheint nach einer Andeutung von Playfair mit seiner ersten Publikation (1843) auf Schwierigkeiten gestoßen zu sein. Allmählich aber erkennt man, daß die neue Ansicht längst wohl vorbereitet und spruchreif war, nur daß wenige bevorzugte Geister das weit früher wahrgenommen hatten, als die andern, wodurch sich eben die Opposition der Majorität ergab. Mit dem Nachweis der Fruchtbarkeit der neuen Ansicht, mit ihrem Erfolg, wächst das Vertrauen zu derselben. Die Majorität der Menschen, welche die Ansicht verwendet, $k$ ann auf das gründliche Studium derselben nicht eingehen; sie nimmt den Erfolg für die Begründung. So kann es geschehen, daß eine Ansicht, welche die bedeutendsten Entdeckungen herbeigeführt hat, wie die Blacksche Wärmestofftheorie, zu einer spätern Zeit auf einem Gebiet, wo sie nicht zutrifft, ein Hemmnis des Fortschrittes wird, indem dieselbe die Menschen geradezu blind machit gegen Tatsachen, welche der beliebten Theorie nicht entsprechen. Soll eine Theorie vor dieser zweifelhaften Rolle bewahrt werden, so müssen von Zeit zu Zeit 
die Gründe und Motive ihrer Entwicklung und ihres Bestehens auf das Genaueste untersucht werden.

Durch mechanische Arbeit können die verschiedensten physikalischen (thermischen, elektrischen, chemischen u. s. w.) Veränderungen eingeleitet werden. Werden dieselben rückgängig, so erstatten sie die mechanische Arbeit wieder, genau in dem.Betrage, welcher zur Erzeugung des rückgängig gewordenen Teiles nötig war. Darin besteht der Satz der Érhaltung der Energie. Für das unzerstörbare Etwas, als dessen $\mathrm{Maß}$ die mechanische Arbeit gilt, ist allmählich der Name Energie in Gebrauch gekommen.*) Wie sind wir zu dieser Einsicht gelangt? Aus welchen Quellen haben wir dieselbe geschöpft ? Diese Frage ist nicht nur an sich von dem höchsten Interesse, sondern auch aus dem oben berührten Grunde.

Die Meinungen über die Grundlagen des Energiegesetzes gehen heute noch sehr weit auseinander. Manche führen den Energiesatz auf die Unmöglichkeit eines per petuum mobile zurück, welche sie entweder als durch die Erfahrung hinlänglich erwiesen oder gar als selbst v e r s tä n dlic h betrachten. Im Gebiete der bloßen Mechanik ist die Unmöglichkeit des perpetuum mobile, d. h. der fortwährenden Produktion v on Arbeit ohne bleibende Veränderung leicht darzuthun. Geht man also von der Ansicht aus, daß alle physikalischen Vorgänge lediglich mechanische Vorgänge, Bewegungen der Moleküle und Atome sind, so begreift man, auf Grund dieser me -

*) Derselbe scheint zuerst von Th. Youug auf dem Gebiete der Me. chanik eingefihrt zu sein. 
chanischen Auffassung der Physik, auch die Unmöglichkeit des perpetuum mobile in dem ganzen physikalischen Gebiet. Diese Auffassung zählt gegenwärtig wohl die meisten Anhänger. Andere Forscher lassen wieder nur eine durchaus experimentelle Begründung des Energiegesetzes gelten.

Es wird sich in dem Folgenden zeigen, daB alle berührten Momente bei Entwicklung der fraglichen Ansicht tatsächlich mitgewirkt haben, daß aber dabei außerdem ein bisher wenig beachtetes $\mathrm{log}$ is ches und ein rein for males Bedürfnis eine ganz wesentliche Rolle gespielt hat.

\section{Der Satz vom ausgeschlossenen perpetuum mobile.}

Das Energiegesetz in seiner modernen Form ist zwar mit dem Satze vom ausgeschlossenen perpetuum mobile nicht identisch, doch steht es $z u$ demselben in naher Beziehung. Letzterer Satz aber ist keineswegs neu, denn er hat auf mechanischem Gebiet schon vor Jahrhunderten die bedeutendsten Denker bei ihren Forschungen geleitet. Es sei gestattet, dies durch einige historische Beispiele $\mathrm{zu}$ begründen :

S. STEvixus, hypomnemata mathematica Tom. IV de statica. LEyDEx I605 p. 34 beschäftigt sich mit dem Gleichgewicht auf der schiefen Ebene.

An einem dreiseitigen Prisma $A B C$ (Fig. 44 im Durchschnitte dargestellt), dessen eine Seite $A B$ horizontal ist, hängt eine geschlossene Schnur, an welcher sich I 4 gleich schwere Kugeln gleichförmig verteilt befinden. $\mathrm{Da}$ man sich den untern symmetrischen Teil der Schnur $A D C$ 
wegdenken kann, so schließt Stevis, daß die vier Kugeln auf $A B$ den zwei Kugeln auf $A C$ das Gleichgewicht halten. Denn wäre das Gleich-

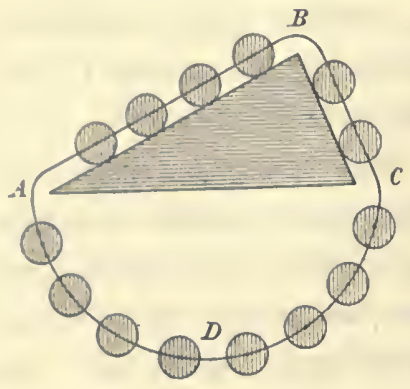

Fig. 44 . gewicht in einem Momente gestört, so könnte es nie bestehen, die Schnur müßte immer in demselben Sinne kreisen, wir hätten ein perpetuum mobile.

"Und gesetzt es sei dies, so wïrde die Reihe der Kugeln oder der Kranz (die Kette) dieselbe Lage haben wie zuvor, und aus demselben Grunde wïrden die acht Kugeln links gewichtiger sein, als jene sechs rechts; deshalb würden wieder jene acht sinken, jene sechs steigen, und diese Kugeln würden von selbst eine ewige Bewegung bewirken, was falsch ist.“*)

Hieraus leitet nun STEvin leicht die Gleichgewichtsgesetze für die schiefe Ebene und sehr viele andere fruchtbare Folgerungen ab.

In dem Abschnitt Hydrostatik desselben Werkes p. I I 4 stellt Stevin den Satz auf:

„Eine gegebene Wassermasse behält ihren gegebenen Ort innerhalb des Wassers. "\%)

Dieser Satz wird an Fig. 45 so bewiesen:

*) „Atqui hoc si sit, globorum series sive corona eundem situm cum priore habebit, eademque de causa octo globi sinistri ponderosiores erunt sex dextris, ideoque rursus octo illi descendent, sex illi ascendent, istique globi ex sese continuum et aeternum motum efficient, quod est falsum."

for "Aquam datam, datum sibi intra aquam locum servare." 
" $A$ also (wenn dies auf irgend eine natürliche Weise geschehen könnte) behalte den eingeräumten Ort nicht, sondern falle nach $D$; dies angenommen sinkt das $A$ nachfolgende Wasser vermöge derselben Ursache nach $D$, und dasselbe wird wieder von anderem vertrieben, und so wird dieses Wasser (da dieselbe Ursache fortbesteht) eine beständige Bewegung eingehen, was absurd wäre."

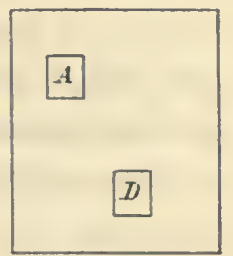

Fig. 45.

Hieraus werden nun sämtliche Sätze der Hydrostatik abgeleitet. Bei dieser Gelegenheit entwickelt Strevix auch zuerst den für die moderne analytische Mechanik so fruchtbaren Gedanken, nach welchem das Gleichgewicht eines Systems durch Hinzufigung fester Verbindungen nicht gestört wird. Bekanntlich leitet man heute z. B. den Satz der Erhaltung des Schwerpuuktes aus dem D'Alember'Tschen Prinzipe mit Hilfe jener Bemerkung her.

Wenn wir gegenwärtig die STEvisschen Demonstrationen reproduzieren wïrden, so müßten wir sie freilich etwas verändern. Uns macht es keine Schwierigkeit bei hinweggedachten Widerständen die Kette auf seinem Prisma in endloser gleichförmiger Bewegung vorzustellen. Dagegen würden wir gegen die Annahme einer beschleunigten Bewegung oder auch gegen die einer gleichförmigen bei nicht beseitigten Widerständen protestieren. Auch ließe sich zur größeren Schärfe des Beweises die Kugelkette

*) "A igitur, (si ullo modo per naturam fieri possit) locum sibi tributum non servato, ac delabatur in $D$; quibus positis aqua quae ipsi. $A$ succedit eandem ob causan deffluet in $D$, eademque ab alia instinc expelletur, atque ades aqua haec (cum ubique eadem ratio sit) motum instituet perpetuum, quod absurdum fuerit." 
durch eine schwere gleichförmige vollkommen biegsame Schnur ersetzen.

Dies ändert nichts an dem historischen Wert der STEvisschen Betrachtungen. Es ist Tatsache, Stevin leitet anscheinend viel einfachere Wahrheiten aus dem Prinzip des unmöglichen perpetuum mobile ab.

In dem Gedankengang, welcher GAl.JLEI zu seinen Entdeckungen führt, spielt der Satz eine bedeutende Rolle, daß ein Körper durch die im Falle erlangte Geschwindigkeit gerade so hoch steigen kann, als er herabgefallen ist. Dieser Satz, der bei GaliLer oft und mit großer Klarheit auftritt,. ist doch nur eine andere Form des Prinzips vom ausgeschossenen perpetuum mobile, wie wir dies bei Huygens sehen werden.

GaLiLei hat bekanntlich das Gesetz der gleichförmig beschleunigten Fallbewegung durch Spekulation als das „einfachste und natürlichste“ gefunden, nachdem er zuvor ein anderes angenommen und wieder fallen gelassen hatte. Um aber sein Fallgesetz zu prüfen, stellte er Versuche über den Fall auf der schiefen Ebene an, wobei er die Fallzeiten durch die Gewichte des aus einem Gefäße in feinem Strahle ansfließenden Wassers bestimmte. Hierbei nimmt er nun als Grundsatz an, daß die auf der schiefen Ebene erlangte Geschwindigkeit immer der vertikalen Fallhöhe entspricht, was für ihn daraus hervorgeht, daß der auf einer schiefen Ebene gefallene Körper auf einer andern beliebig geneigten mit seiner Geschwindigkeit immer nur zur gleichen Vertikalhöhe aufsteigen kann. Der Satz über die Steighöhe hat ihn, wie es scheint, auch auf das 
Trägheitsgesetz geführt. Hören wir seine eigene geistrolle Auseinandersetzung im dialogo terzo. Opere. Padova I 744 Tom. III.

S. 96 heißt es :

"Ich nehme an, die Geschwindigkeiten, welche dasselbe Bewegliche in Fall auf schiefen Ebenen verschiedener Neigung erreicht, seien gleich, wenn die vertikalen Fallhöhen gleich sind.“\%)

Hierzu läßt er Salviatr im Dialog bemerken:

„Ihr sprecht sehr überzeugend, aber über die Wahrscheinlichkeit hinaus will ich durch ein Experiment die Überzeugung so steigern, daß wenig $z u$ einem strengen Beweis fehlen soll. Denkt Euch, dieses Blatt sei eine vertikale Wand, und an einem daselbst befestigten Nagel hänge an einem vertikalen Faden $A B$ von 2 oder 3 Ellen eine Bleikugel von I oder 2 Unzen, und an der Wand zeichnet eine zu dem von der Wand unge. fähr 2 Zolle entfernten $A B$ senkrechte (horizontale) Gerade, fuihrt Ihr dann den Faden $A B$ mit der Kugel nach $A C$ und laßt die Kugel frei, so seht Ihr dieselbe

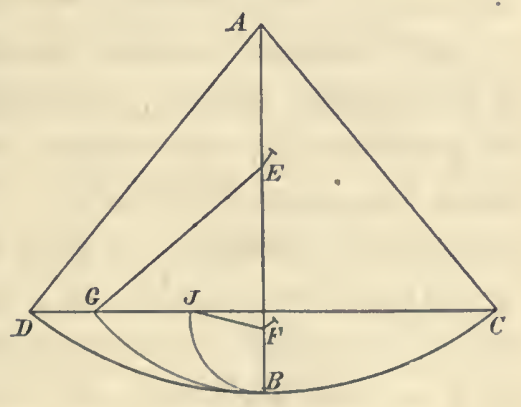

Fig. 46 .

*) Accipio, gradus velocitatis ejusdem mobilis super diversas planorun inclinationes acquisitos tunc esse aequales, cum eorundem planorum elevationes aequales sint." 
zunächst fallen, den Bogen $C B D$ beschreibend, und so viel die Grenze $B$ überschreiten, daß durch den Bogen $B D$ laufend dieselbe fast zur Geraden $C D$ aufsteigt, indem ein kleiner Zwischenraum übrig bleibt, so viel als vom lïiderstand der Luft und des Fadens herrührt. Hieraus können wir schließen, daß der durch den Fall im Punkte $B$ erlangte Schwung genügend sei, um durch einen gleichen Bogen zur selben Höhe aufzusteigen; nach wiederholter Ausführung des Versuches wollen wir in der Wand bei. $E$ einen Nagel einschlagen, oder bei $F, 5$ oder 6 Finger breit nach vorn, damit der Faden $A C$, wenn er mit der Kugel wieder nach $C B$ kommt und $B$ erreicht, beim Nagel $E$ festgehalten, und die Kugel genötigt werde, den Bogen $B C$ um $E$ zu beschreiben, wobei wir sehen werden, was dieselbe Geschwindigkeit leistet, die vorher denselben Körper durch den Bogen $B D$ zur Horizontalen $C D$ beförderte. Nun, meine Herren, werdet Ihr mit Vergnügen bemerken, daß die Kugel im Punkte $G$ den Horizont erreicht, und dasselbe geschieht, wenn das Hindernis sich tiefer befindet, wie bei $F$, wobei die Kugel den Bogen $B J$ beschreibt, den Aufstieg stets im Horizont $C D$ beendend, und wenn der hemmende Nagel so tief läge, daß der Rest des Fadens nicht mehr den Horizont $C D$ erreichen kann (was eintritt, wenn er näher an $B$ als am Durchschnitt von $A B$ mit $C D$ liegt), so uiberhüpft der Faden den Nagel und wickelt sich herum. Dieser Versuch läßt keinen Zweifel über die Wahrheit des aufgestellten Satzes. Denn, da die Bögen $C B, D B$ einander gleich sind und symmetrisch liegen, so wird das beim 
Fall durch den Bogen $C B$ erlangte Moment ebenso groß sein, wie die Wirkung durch den Bogen $D B$; aber das in $B$ erlangte, durch $C B$ hindurch erzeugte Moment vermag denselben Körper durch den Bogen $B D$ zu heben; folglich wird auch das beim Sinken durch $D B$ erzeugte Moment gleich sein demjenigen, welches denselben Körper vorher von $B$ bis $D$ führen konnte, so daß allgemein jedes beim Sinken erzeugte Moment gleich demjenigen ist, welches den Körper durch denselben Bogen zu erheben im stande ist: aber alle Momente, die den Körper durch die Bögen $B D, B G, B J$ heben konnten, sind einander gleich, da sie stets im Fall durch $C B$ entstanden waren, wie der Versuch lehrt: folglich sind auch alle Momente, welche im Fall durch die Bögen $D B$, $G B, J B$ entstehen, einander gleich.“*)

\#) Voi molto probabilmente discorrete, ma oltre al veri simile voglio con una esperienza crescer tanto la probabilita, che poco gli manchi all' agguagliarsi ad una ben necessaria dimostrazione. Figuratevi questo foglio essere una parete eretta al orizzonte, e da un chiodo fitto in essa pendere una palla di piombo d'un'oncia, o due, sospesa dal sottil filo $A B$ lungo due, o tre braccia perpendicolare all' orizzonte, e nella parete segnate una linea orizzontale $D C$ segante a squadra il perpendicolo $A B$, il quale sia lontano dalla parete due dita in circa, trasferendo poi il filo $A B$ colla palla in $A C$, lasciata essa palla in libertà, la quale primieramente vedrete scendere descrivendo l'arco $C B D$, e di tanto trapassare il termine $B$, che scorrendo per l'arco $B D$, sormonterá fino quasi alla segnata parallela $C D$, restando di per vernirvi per piccolissimo intervallo toltogli il precisamente arrivarvi dall impedimento dell'aria, e del filo. Dal che possiamo veracemente concludere, che l'impeto acquistato nel punto $b^{\prime}$ dalla palla nello scendere per l'arco $C B$, fu tanto, che bastò a risospingersi per un simile arco $B D$ alla medesima altezza; fatta, e più volte reiterata cotale esperienza, voglio, che fiechiamo nella parete rasente al perpendicolo $A B$ un chiodo come in $E$ ovvero in $F$, che sporga in fuori cinque, o sei dita, e questo acciocchè il filo $A C$ tornando come prima a riportar la palla $C$ per l'arco $C D$, giunta che ella sia in $B$, intoppando il filo nel chiodo $E$, sia costretta a camminare per la circonferenza $B G$ descritta intorno al centro $E$, dal che vedremo quello, che potrà far quel medesimo impeto, che dianzi concepizo nel medesimo termine $B$, sospinse l'istesso mobile per l'arco $E D$ all'altezza dell'orizzontale $C D$. Ora, Signori, voi vedrete con gusto condursi la palla all'orizzontale nel junto $G$, e l'istesso' accadere, l'intoppo si metesse più basso come in $F$, dove 
Dic über das Pendel gemachte Bemerkung überträgt sich sofort auf dic schiefe Ebene und führt zum Trägheitsgesctz. Es heißt S. I 24:

„Es steht bereits fest, daß ein Bewegliches aus der Ruhe in $A$ durch $A B$ herabsteigend dem Zeitzuwachs

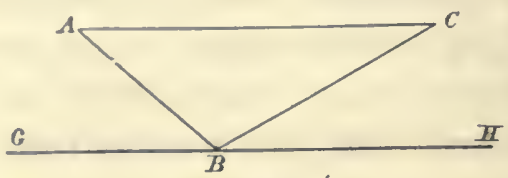

Fig. 47. entsprechende Geschwindigkeiten erlangt: daß aber der Geschwindigkeitsgrad in $B$ der größte und unveränderlich eingepflanzt sei, wenn nämlich die Ursache einer neuen Beschleunigung oder Verzögerung beseitigt ist: einer Beschleunigung, sage ich, wenn dasselbe weiter auf der ausgedehnten Ebene fortschreitet; einer Verzögerung aber, wenn es auf die ansteigende Ebene $B C$ abgeleitet wird: auf der Horizontalen $G H$ aber wird die gleichförmige Bewegung je nach der von $A$ nach $B$ erlangten Geschwindigkeit ins Unendliche fortbestehen. “*)

la palla descriverebbe l'arco $B J$, terminando sempre la sua salita precisamente nella linea $C D$, e quando l'intoppo del chiodo fusse tanto basso, che l'avanzo del filo sotto di lui non arivasse all' altezza di $C D$ (il che accaderebbe, quando fusse piu vicino al punto $B$, che al segamento dell' $A B$ coll orizzontale $C D$ ), allora il filo cavalcherebbe il chiodo, e segli avolgerebbe intorno. Questa es. perienza non lascia luogo di dubitare della veritá del supposto: imperocchè essendo li due archi $C B, D B$ equali e similmento posti, l'acquisto di momento fatto per la scesa nell'arco $C B$ é il medesimo, che il fatto per la scesa del. l'arco $D B$; ma il momento acquistato in $B$ per l'arco $C B$ è potente a risospingere in su il medesimo mobile per l'arco $B D$; adunque anco il momento acquistato nella scesa $D B$ e eguale a quello, che sospigne l'istesso mobile pel medesimo arco da $B$ in $\mathrm{D}$, sicche universalmente ogni momento acquistato per la scesa dun arco è eguale a quello, che può far risalire l'istesso mobile pel medisimo arco: ma $\mathrm{i}$ momenti tutti che fanno risalire per tutti gli archi $B D, B G, B J$ sono eguali, poichè son fatti dal istesso medesimo momento acquistato per la scesa $C B$, come mostra l'esperienza : adunque tutti i momenti, che si acquistano per le scese negli archi $J B, C B, J B$ sono eguali.

*) Constat jam, quod mobile ex quiete in $A$ descendens per $A B$, gradus acquirit velocitatis juxta temporis ipsius incrementum: gradum vero in $B$ esse 
Huygens, in allen Stücken ein Nachfolger Galileis, faßt das Trägheitsgesetz schärfer und verallgemeinert den für Galilei so fruchtbar gewordenen Satz über die Steighöhe. Letzteren verwendet er zur Lösung des Problems vom Schwingungsmittelpunkt und spricht sich darüber vollkommen klar aus, daß der Satz über die Steighöhe identisch sei mit dem Satze vom ausgeschlossenen perpetuum mobile.

Es folgen die wichtigen Stellen: Huygess, Horologium, zweiter Teil. Hypothesen:

„Wenn die Schwere nicht wäre, und wenn die Luft die Bewegung der Körper nicht hindern würde, würde. jeder derselben die einmal angenommene Bewegung mit gleich bleibender Geschwindigkeit längs einer geraden Linie fortsetzen." "*)

Horologium. Vierter Teil. Über den Schwingungsmittelpunkt:

„Wenn beliebige schwere Körper durch ihr Gewicht in Bewegung geraten, kann der gemeinsame Schwerpunkt derselben nicht höher steigen, als er zu Anfang sich befand."

„Wir werden zeigen, daß diese Voraussetzung, obgleich sie bedenklich scheinen könnte, nichts anderes besagt als das, was nie jemand bezweifelt hat, daß die schweren

maximum acquisitorum, et suapte natura imutabiliter impressum, sublatis scilicet causis accelerationis novae, aut retardationis: accelerationis inquam, si adhuc super extenso plano ulterius progrederetur; retardationis vero, dum super planum acclive $B C$ fit reflexio: in horizontali autem $G H$ aequabilis motus juxta gradum velocitatis ex $A$ in $B$ acquisitac in infinitum extenderetur.

\#) Si gravitas non esset, neque aër motui corporuın officeret, unumquodque eorum, acceptum semel motum continuaturum velocitate aequabili, secundum lineam rectam.

$\mathrm{Mach}$, Vorlesungen. 3. Aufl. 
Körper sich nicht (von selbst) aufwärts bewegen. - Und wenn dies die Erfinder neuer Konstruktionen zu benützen verständen, welche in irrigem Streben ein perpetuum mobile herzustellen suchen, wlirden sie leicht ihre Fehler erkeunen und einsehen, daß diese Sache auf mechanischem Wege nicht möglich sei.“*) .

Eine jesuitische reservatio mentalis ist vielleicht in den Worten „mechanica ratione" angedeutet. Man könnte hiemach glauben, daß Huygess ein nichtmechanisches perpetuum mobile für möglich hält.

Klarer wird die Verallgemeinerung des GaLILEIschen Satzes noch in Propos. IV desselben Abschnittes ausgesprochen :

"Wenn ein beliebiges aus mehreren schweren Körpern bestehendes Pendel aus der Ruhe freigelassen einen beliebigen Teil einer Schwingung ausgeführt hat, und man denkt sich nachher bei aufgelösten Verbindungen die Geschwindigkeiten aufwärts gekehrt, und die Körper so hoch als möglich aufgestiegen, so wird, nachdem dies geschehen, der gemeinsame Schwerpunkt so hoch gestiegen sein, als derselbe sich zu Anfang der Bewegung befand.“\%)

a) Horologii pars quarta. De centro oscillationis:

Sie pondera quotlibet, vi gravitatis suae, moveri incipiant; non posse centrum gravitatis ex ipsis compositae altius, quam ubi incipiente motu reperiebatur, ascendere.

lpsa vero hypothesis nostra quominus scrupulum moveat, nihil aliud sibi velle ostendemus, quam quod nemo unquam negavit, gravia nempe sursum non ferri. - Et sane, si hac eadem uti scirent novorum operum machinatores, qui motum perpetuum irrito conatu moliuntur, facile suos ipsi errores deprehenderent, intelligerentque rem eam mechanica ratione haud quaquam possibilem esse.

Si pendulum e pluribus ponderibus compositum, atque e quiete dimissum, partem quamcunque oscillationis integrae confecerit, atque inde porro intelligantur pondera ejus singula, relicto communi vinculo, celeritates acquisitas sursum convertere, ac quousque possunt ascendere; hoc facto centrum gravitatis ex 
Auf letzteren Satz nun, welcher eine Verallgemeinerung ist des von GaLILEI für eine Masse aufgestellten für ein System ron Massen, und den man nach der Huygessschen Erläuterung als das Prinzip des ausgeschlossenen perpetuum mobile erkennt, gründet Huygess die Theorie des Schwingungsmittelpunktes. Lagraxge nennt dieses Prinzip prekär und freut sich, daß es Jakob Berroulli $\mathbf{6} 68$ I gelungen sei, die Theorie des Schwingungsmittelpunktes auf die Hebelgesetze zurückzuführen, die ihm klarer scheinen. An demselben Problem versuchen sich fast alle bedeutenden Forscher des 17 . und I8. Jahrhunderts, und es führt zuletzt in Vereinigung mit dem Prinzip der virtuellen Geschwindigkeit zu dem von D'Alembert (traité de dynamique I 743) aufgestellten, vorher schon in etwas anderer Form von Euler und HERMANix verwendeten Prinzip.

Außerdem wird der Huygexssche Satz über die Steighöhe zur Grundlage des Gesetzes der Erhaltung der lebendigen Kraft und des Satzes der Erhaltung der.Kraft überhaupt, wie er ron ЈоH. und Dax. Bervoulli aufgestellt und namentlich von letzterem in seiner Hydrodynamik so fruchtbar verwendet wird. Diese BERxoulusschen Sätze unterscheidet sich nur in der Form des Ausdruckes von der späteren Lagraxgeschen Aufstellung.

Die Art, wie Torricelli sein berühmtes Ausflußtheorem für Flüssigkeiten gefunden hat, führt wieder auf denselben Satz. TORRicelul nahm an, daß die aus der Bodenöffnung

omnibus compositae, ad eandem altitudinem reversum erit, quam ante inceptam oscillationem obtinebat. 
des Gefäßes strömende Flüssigkeit vermöge ihrér Ausflußgeschwindigkeit nicht höher steigen könne, als sie im Gefábe steht.

Betrachten wir noch einen der reinen Mechanik angehörigen Punkt, die Geschichte des Prinzips der virtuellen Bewegung. Das Prinzip wurde nicht, wie man gewöhnlich sagt, und wie auch LAGRANGE behauptet, von GALILEI, sondern jedenfalls schon früher von STEviN aufgestellt. In seiner Trochleostatica des oben zitierten Werkes p. I72 sagt er: "Fis sei bemerkt, daß hier das statische Axiom gelte: Wic der Weg des Wirkenden zum Weg des Leidenden, So die Kraft des Leidenden zur Kraft des Wirkenden.“*)

Galiler bemerkt, wie bekannt, die Giltigkeit des Prinzipes bei Betrachtung der einfachen Maschinen und leitet auch die Gleichgewichtsgesetze der Flüssigkeiten aus demselben $a b$.

Torricelli führt das Prinzip auf Schwerpunkteigenschaften zurück. Soll an einer einfachen Maschine, an welcher wir uns Kraft und Last durch angehängte Gewichte vertreten denken, Gleichgewicht bestehen, so darf der gemeinsame Schwerpunkt der aufgelegten Lasten nicht sinken. Umgekehrt, wenn der Schwerpunkt nicht sinken kann, besteht Gleichgewicht, weil die schweren Körper nicht von selbst aufwärts steigen. In dieser Form ist also das Prinzip der virtuellen Geschwindigkeit identisch mit dem Huygexsschen Prinzip der Unmöglichkeit des Perpetuum mobile.

*) „Notare auten hic illud staticun axioma etiam locum habere:

„Ut spatium agentis ad spatium patientis

Sic potentia patientis ad potentiam agentis." 
JOH. BerNovlul erkennt zuerst 1717 in einem Briefe an VARIGxon die allgemeine Bedeutung des Prinzipes der virtuellen Bewegung für beliebige Systeme.

LAGRANGE endlich gibt einen allgemeinen Beweis des Prinzipes und griindet darauf seine ganze analytische Mechanik. Aber dieser allgemeine Beweis stützt sich im Grunde doch nur auf die Huygenssche und Torricíluische Bemerkung.

LAGRANGE denkt sich bekanntlich in den Richtungen der am System wirksamen Kräfte eine Art einfacher Flaschenzüge, windet eine Schnur durch alle diese Flaschenzüge durch, und hängt schließlich am Ende derselben einẹ Last an, welche ein gemeinschaftliches Maß sämtlicher am System wirksamer Kräfte ist. 'Die Elementenzahl jedes einzelnen Flaschenzuges kann nun leicht so gewählt werden; daß die betreffende Kraft in der Tat durch denselben ersetzt wird. Dann ist es klar, daß, wenn die angehängte End: last nicht sinken kann, Gleichgewicht besteht, weil schwere Körper nicht von selbst aufwärts steigen.

Wenn man nicht so weit'geht, sondern der TORk1CELLIschen Betrachtung näher bleiben will, so kann man sich jede Einzelkraft des Systems durch eine besondere Last ersetzt denken, die an einer Schnur hängt, welche über eine in der Richtung der Kraft liegende Rolle führt und am Angriffspunkte der Kraft befestigt ist. Gleịch: gewicht besteht dann; wenn der gemeinsame Schwerpunkt der sämtlichen Lasten nicht sinken kann. Die Grund: annahme dieses Beweises ist offenbar die Unmöglichkeit des perpetuum mobile.

\section{Digitized by Microsoft ${ }^{\circledR}$}


LAGRANGE hat sich vielfach bemührt, einen von fremdartigen Flementen freien und vollständig befriedigenden Beweis zu liefern, ohne daß ihm dies ganz gelungen wäre. Auch andere nach ihm dürften nicht glücklicher gewesen sein.

So ruht nun die ganze Mechanik auf einem Gedanken, der, wenn auch nicht zweifelhaft, so doch fremdartig und den übrigen Grundsätzen und Axiomen der Mechanik nicht ebenbürtig scheint. Jeder, der Mechanik treibt, fühlt einmal die Unbehaglichkeit dieses Zustandes, jeder wünscht sie beseitigt, selten wird sie durch Worte ausgedriickt. Und so findet sich der strebsame Jünger der Wissenschaft hoch erfreut, wenn er einmal bei einem Meister wie Porssor in seiner „théorie général de l'équilibre et du mouvement des systèmes" folgende Stelle liest, in welcher er sich über die analytische Mechanik ausspricht:

„Indessen, da man in diesem Werke von Anfang an nur daran dachte, die schöne Entwicklung der Mechanik zu betrachten, welche ganz aus einer Formel zu fließen schien, glaubte man natürlich, daß die Wissenschaft fertig sei, und daß nichts übrig sei, als das Prinzip der virtuellen Geschwindigkeiten zu beweisen. Aber diese Untersuchung brachte alle Schwierigkeiten zurück, welche man eben durch das Prinzip überwunden hatte. Dieses allgemeine Gesetz, in welches sich verschwommene Ideen ron unendlich kleinen Bewegungen und Gleichgewichtsstörungen einmengen, verdunkelte sich gewissermaßen bei näherer Prüfung; und da das Buch von LAGRANGE keine Klarheit mehr zeigte als in dem Gang der Rechnungen, sah man bald, daß das Gewölke über den Entwicklungen 
nur darum gehoben schien, weil es gewissermaßen über den Anfängen dieser Wissenschaft gesammelt war."

„Der allgemeine Beweis des Prinzipes der virtuellen Geschwindigkeiten kommt eigentlich darauf hinaus, die ganze Mechanik auf einer andern Grundlage aufzubauen: Denn der Beweis eines Gesetzes, welches die ganze Wissenschaft umfaßt, kann nichts anderes sein, als die Zurückführung dieser Wissenschaft auf ein anderes ebenso allgemeines aber einleuchtendes oder wenigstens einfacheres Gesetz, welches also das erstere unnötig macht."*)

Das Prinzip der virtuellen Bewegung beweisen heißt also nach PoIssot die ganze Mechanik ne u machen.

Ein anderer dem Mathematiker unbehaglicher Umstand ist der, daß in dem historischen Zustande, in welchem sich die Mechanik gegenwärtig befiudet, die Dynamik sich auf die Statik gründet, während man doch wünschen muß, daß in einer Wissenschaft, die auf deduktive Vollendung Anspruch macht, die spezielleren statischen Sätze sich mit Leichtigkeit aus den allgemeineren dynamischen ableiten lassen.

*) "Cependant, comme dans cet ouvrage on ne fu: d'abord attentif qu'i considérer ce beau développement de la mécanique qui semblait sortir tout entière d'une seule et mène formule, on crut naturellement que la science était faite, et qu'il ne restait plus qu'ì chercher la démonstration du principe des vitesses virtuelles. Mais cette recherche ramena toutes les difficultés qu'on avait franchies par le principe même. Cette loi si générale, où se mêlent des idées vagues et étrangères de mouvements infinement petits et de perturbation d'équilihre, ne fit en quelque sorte que s'obsurcir á l'examen: et le livre de L a grange n'offrant plus alors rien de clair que la marche des calculs, on vit bien que les nuages n'avaient paru levé sur le cours de la mécanique que parce. qu'ils étaient, pour ainsi dire, rassemblés à l'origine même de cette science.

Une démonstration générale du principe des vitesses virtuelles devait au fond revenir à établir la mécanique entière sur une autre hase: car la démonstration d'une loi qui embrasse toute une science ne peut être autre chose que la réduction de cette science à une autre loi aussi générale, mais évidente, ou du moins plus simple que la première, et qui partant la rende inutile." 
Diesem Wunsche gibt auch wieder ein großer Meister, nämlich GAuss, Ausdruck bei Gelegenheit der Aufstellung seines Prinzipes des kleinsten Zwanges (Crelles Journal IV. Bd. S. 233) mit folgenden Worten: „So sehr es in der Ordnung ist, daß bei der allmählichen Ausbildung der Wissenschaft und bei der Belehrung des Individuums das Leichtere dem Schwerern, das Einfachere dem Verwickeltern, das Besondere dem Allgemeinen vorangeht, so fordert doch der Geist, einmal auf dem höhern Standpunkt angelangt, den umgekehrten Gang, wobei die ganze Statik nur als ein spezieller Fall der Mechanik erscheine." Das Gausssche Prinzip ist nun allerdings ein allgemeines; nur schade, daß es nicht unmittelbar einzusehen, und daß Gauss es wieder mit Hilfe des D'Alembertschen Prinzips abgeleitet hat, wodurch alles wieder beim Alten bleibt.

Woher kommt nun diese sonderbare Rolle, die das Prinzip der virtuellen Bewegung in der Mechanik spielt? Ich will vorläufig nur dies darauf antworten. Es würde mir schwer fallen, die Verschiedenheit des Eindruckes zu beschreiben, den der Lagrangesche Beweis des Prinzipes auf mich machte, als ich ihn das erstemal als Student, und als ich ihn später wieder vornahm, nachdem ich historische Studien gemacht hatte. Früher erschien mir der Beweis abgeschmackt, namentlich durch seine Rollen und Schnüre, die mir nicht in die mathematische Betrachtung paßten, und deren Wirkung ich lieber aus dem Prinzipe selbst erkannt hätte, statt sie als bekannt vorauszusetzen. Nachdem ich aber die Geschichte studiert, kann ich mir keine schönere Ableitung denken. 
In der Tat ist es durch die ganze Mechanik dasselbe Prinzip des ausgeschlossenen perpetuum mobile, welches fast alles verrichtet, das LAGRANGE mißfällt, und das er doch selbst bei seiner Ableitung wenigstens versteckt benützen muß. Geben wir diesem Prinzip seine richtige Stellung und Fassung, so wird das Paradoxe natürlich.

Das Prinzip des ausgeschlossenen perpetuum mobile ist also gewiß keine neue Entdeckung; es leitet seit 300 Jahren die größten Forscher. Das Prinzip kann sich aber auch nicht eigentlich auf mechanische Einsichten grü nden. Denn lange vor dem Ausbau der Mechanik besteht schon die Überzeugung von der Richtigkeit des: selben, und diese wirkt eben bei dem Ausbau mit. Diese überze ugende Kraft muB also allgemeinere und ticfere Wurzeln haben. Wir kommen auf diesen Punkt zurück.

\section{Die mechanische Physik.}

Es kann nicht in Abrede gestellt werden; daß von Demokrit an bis auf die neueste Zeit ein unverkenn: bares Streben nach einer mechanischen Erklärung aller physikalischen Vorgänge besteht. Sehen wir von älteren unklaren Äußerungen auch ganz ab, so lesen wir doch bei Hurgess *) folgendes:

„Man darf nicht daran zweifeln, daß das Licht in der Bewegung irgend eines Stoffes besteht. Denn sei es, daß man seine Entstehung betrachtet, so findet man, daß es hier auf Erden vorzüglich durch Feuer und Flamme erzeugt wird, welche ohne Zweifel Körper in heftiger

*) 'Traité de la lumière. A Leide 1690 p. 2. 
Bewegung enthalten, weil sie mehrere der härtesten Körper auflösen und schmelzen; sei es, daß man dessen Wirkungen betrachtet, so sieht man, daß das durch Hohlspiegel gesammelte Licht die Fähigkeit hat, wie Feuer zu brennen, d. h. daß es die Teile der Körper trennt, was sicherlich eine Bewegung andeutet, wenigstens in der wahren Philosophic, welche alle natürlichen Wirkungen auf mechanische Ursachen zurückfïhrt. Denn das muß nach meiner Meinung geschehen, wenn man nicht jede Hoffnung, etwas in der Physik zu begreifen, aufgeben will.“*)

S. Carnot, $\left.{ }^{* *}\right)$ indem er das Prinzip des ausgeschlossenen perpetuum mobile in die Wärmelehre einführt, entschuldigt sich folgendermaßen:

„Man wird vielleicht einwenden, daß das perpetuum mobile, welches nur für mechanische Vorgänge als unmöglich erwiesen ist, bei Anwendung von Wärme oder Elektrizität vielleicht möglich ist; aber kann man denn die Frscheinungen der Wärme oder der Elektrizität als etwas anderes auffassen, denn als Bewegungen gewisser Körper, und müssen sie als solche nicht den allgemeinen Gesetzen der Mechanik genügen ?«\%;

*) L'on ne sçaurait douter que la lumière ne consiste dans le mouve me n t de certaine matiere. Car soit qu'on regarde sa production, on trouve qu'içy sur la terre c'est principalement le feu et la flamme qui l'engendrent, lesquels contient sans doute des corps qui sont dans un mouvement rapide, puis qu'ils dissolvent et fondent plusieurs autres corps des plus solides: soit qu'on regarde ses effets, on voit que quand la lumière est ramassée, comme par des miroires concaves, elle a la vertu de brûler comme le feu, c'est-à-dire qu'elle desunit les parties des corps; ce qui marque assurément du möuvement, au moins dans la vraye Philosophie, dans laquelle on conçoit la cause de tous les effets naturels par des raisons de mechdnique. Ce qu'il faut faire à mon avis, ou bien renoncer à toute espérance de jamais rien comprendre dans la Physique.

*) Sur la puissance motrice du feu. Paris 1824 .

* $)$,On objectra peut-être ici que le mouvement perpétuel, démontré in- 
Diese Beispiele, welche sich durch Citate aus der. neuesten Zeit ins Endlose vermehren ließen, zeigen, daß ein Streben, alles mechanisch aufzufassen, wirklich besteht. Und dieses Streben ist auch erklärlich. Die mechanischen Vorgänge als einfache Bewegungen in Raum und Zeit sind der Beobachtung und Verfolgung mit Hilfe unserer höchst organisierten Sinne am besten $z u$ gänglich. Die mechanischen Vorgänge reproduzieren wir fast mühelos in unserer Phantasie. Der Druck als bewegungseinleitender Umstand ist uns aus täglicher Übung wohl bekannt. Alle Änderungen, welche das Individuum persönlich in seiner Umgebung, oder die Menschheit auf dem Wege der Technik in der Welt hervorbringt, sind durch $\mathrm{B}$ e w e g un g e n vermittelt. Wie sollte uns also die Bewegung nicht als der wichtigste physikalische Faktor erscheinen?

Es gelingt auch an allen physikalischen Vorgängen $\mathrm{mech}$ an is che Eigenschaften zu entdecken. Die tönende Glocke zittert, der erhitzte Körper dehnt sich aus, der elektrische Körper zieht andere an. Warum sollte man also nicht versuchen, alle Vorgänge bei der uns geläufigsten, der Beobachtung und Messung leichter zugänglichen mechanischen Seite zu fassen? Es ist auch nichts gegen den Versuch einzuwenden, die mechanischen Eigenschaften der physikalischen Vorgänge durch mechanische Ana$\log$ ien zu erläutern.

possible par les seules actions méca n iques, ne l'est peut-être pas lors. qu'on emploie l'influence soit de la $\mathrm{chal}$ eur, soit de l'électricité; mais peuton concevoir les phénoménes de la chaleur et de l'électricité comme dus á autre chose qu'à des mouvements quelconques des corps, et comme tels ne doivent-ils pas être soumis aux lois générales de la mécanique?" 
Die moderne Physik ist aber in dieser Richtung allerdings sehr we it gegangen. Der Standpunkt; den Wundr in seiner sehr ansprechenden Schrift „über die physikalischen Axiome" zum Ausdruck bringt, möchte wohl von der Mehrzahl der Physiker geteilt werden.

Wuxd führt folgende Axiome der Physik an:

I. Alle Ursachen in der Natur sind Bewegungsursachen.

2. Jede Bewegungsursache liègt außerhalb des Bewegten.

3. Alle Bewegungsursachen wirken in der Richtung der geraden Verbindungslinie.

4. Die Wirkung jeder. Ursache verharrt.

5. Jeder Wirkung entspricht eine gleiche Gegenwirkung

6. Jede IVirkung ist äquivalent der Ursache.

Man könnte sich mit diesen Sätzen als Grundsätzen der Mechanik befreunden. Wenn dieselben aber als Axiome der Physik aufgestellt werden, so entspricht dies eigentlich einer Negierung allèr Vorgänge. mit Ausnahme der Bewegung. Alle Veränderungen in der Natur sind nach WUNDT bloße Ortsveränderungen, alle Ursachen sind Bewegungsursachen (a. a. O. S. 26). Wollten wir auf die philosophische Begründung, die Wund für seine Ansicht gibt, eingehen, so würde úns dies tief in die Spekulationen der Eleaten und Herbartianer hineinführen. Die Ortsveränderung, meint WUNDT, sei die einzige Veränderung eines Dinges, wobei dieses identisch bleibt. Ändert-sich ein Ding qualitativ, so müßte man sich vielmehr vorstellen, daß ein Ding vergeht und ein anderes entsteht, was mit der Vorstellung von der Identität des beobachteten Wesens und von der Unzerstörbarkeit der Materie nicht 
zusammenzureimen ist. Wir brauchen uns aber nur zu erinnern, daß die Eleaten Schwierigkeiten ganz derselben Art in der Bewegung gefunden haben. Kann man denn nicht auch denken, daß ein Ding an einem Orte vergeht und an einem andern ein gleiches entsteht?

Wissen wir denn im Grunde genommen $\mathrm{mehr}$ davon, warum ein Körper einen Ort verläßt und an einem andern auftaucht, als wie so ein kalter Körper wa rm wird? Gesetzt auch, wir verstünden die mechanischen Vorgänge vollständig, könnten und dürften wir deshalb andere Vorgänge, die wir nicht verstehen, a us der W elt schaffen: Nach diesem Prinzipe wäre es wirklich das Einfachste, die Existenz der ganzen Welt zu leugnen. Die Eleaten sind eigentlich dahin gelangt, und die Herbartianer waren nicht weit von diesem Ziel.

Die Physik, in dieser Weise behandelt, liefert uns nun ein Schema, in dem wir die wirkliche Welt kaum wieder erkennen. Und in der That erscheint Menschen, welche sich dieser Ansicht durch einige Jahre hingegeben haben, die Sinnenwelt, von welcher, als einer wohl vertrauten Sache, sie ausgegangen waren, plötzlich als das größte - „Welträtsel."

So erklärlich es also auch ist, daß man bestrebt war, alle physikalischen Vorgänge ,auf Bewegungen der Atome zurückzuführen," so muß man doch sagen, daß dies ein chimärisches Ideal ist. Dasselbe hat in populären Vorlesungen oft als effektvolles Programm gedient. In dem Arbeitsraume des ernsten Forschers hat es kaum eine wesentliche Funktion gehabt. 
Was in mechanischer Physik wirklich geleistet worden ist, besteht entweder in Erläuterung physikalischer Vorgänge durch uns geläufigere mechanische Analogien, wofür die Theorien des Lichtes und der Elektrizität, oder in der genauen quantitativen Ermittelung des Zusammenhanges mechanischer Vorgänge mit andern physikalischen Prozessen, wofür die der Thermodynamik angehörigen Arbeiten Beispiele bieten.

\section{Das Energieprinzip in der Physik.}

Nur die Erfahrung kann uns darïber belehren, daß durch mechanische Vorgänge andere physikalische Vandlungen bedingt sind, und umgekehrt. Durch die Erfindung der Dampfmaschine und deren technische Bedeutung wurde die Aufmerksamkeit zuerst auf den Zusammenhang mechanischer Vorgänge (insbesondere der Arbeitsleistung) mit Wärmezustandsänderungen gelenkt. Das technische Interesse mit dem Bedürfnisse nach wissenschaftlicher Klarheit vereinigten sich in dem Kopfe von $\mathrm{S}$. CARNOT, und führten zu der merkwürdigen Entwickelung, deren Ergebnis die 'Thermodynamik ist. Es ist nur ein historischer $\mathrm{Zufall,} \mathrm{daß} \mathrm{diese} \mathrm{Gedankenentwickelung} \mathrm{nicht} \mathrm{an} \mathrm{die}$ Elektrotechnik anknüpfen konnte.

Bei der Untersuchung darüber, wie viel Arbeit im Maximum eine Wärmemaschine überhaupt, und eine Dampfmaschine insbesondere, mit einem bestimmten Aufwand an Verbrennungswärme leisten kann, läßt sich CaRxot durch mechanische Analogien leiten. Ein Körper kann Arbeit leisten, indem er sich durch Erwärmung 
unter Druck ausdehnt. Hierzu muß derselbe aber von einem wärmere n Körper Wärme empfangen. Die Wärme muß also, um Arbeit zu leisten, von einem wärmeren $\mathrm{zu}$ einem kälteren Körper übergehn, ebenso wie das Wasser von einem höheren Niveau auf ein tiefes sinken muß, um die Mühle in Bewegung zu setzen. 'Temperaturdifferenzen stellen also ebenso Arbeitskräfte vor wie Höhendifferenzen schwerer Körper.

CARsot erdenkt einen idealen ProzeB, bei welchem gar keine Wärme nutzlos (ohne Arbeitsleistung) abfließt. Dieser liefert also mit gegebenem Wärmeaufwand das Arbeitsmaximum. Das Analogon ist ein Mühlrad, welches auf einem höheren Niveau Wasser schöpft, das in demselben ohne einen Tropfen Verlust seh r la ngs a m auf ein tieferes Niveau herabsinkt. Der Prozeß hat das Eigentümliche, daß mit dem Aufwand derselben Arbeitsleistung das Wasser wieder genau auf die ursprüngliche Höhe geschafft werden kann. Diese Eigenschaft der Umkehrbarke it kommt auch dem Carsotscher Prozeß zu. Auch dieser kann bei Aufwand derselben Arbeitsleistung umgekehrt, und hierbei die Wärme wieder auf das ursprüngliche Temperaturniveau geschafft werden.

Würde es $z$ wei verschiedene umkehrbare Prozesse $A, B$ geben, derart, da $B$ in $A$ eine von der Temperatur $t_{1}$ auf die niedere Temperatur $t_{2}$ abfließende Wärmemenge $Q$ eine Arbeit $W$, in $B$ aber unter denselben Unständen eine gröBere Arbeit $W+W^{1}$ ergäbe, so könnte man $B$ im angegebenen Sinne und $A$ im umgekehrten Sinne zu e in e m Prozeb verbinden. Hierbei würde $A$ die durch 
$B$ herbeigeführte Wärmeänderung rückgängig machen, und einen sozusagen aus nichts gewonnenen Arbeitsüberschuß $W^{1}$ übrig lassen. Diese Kombination würde ein perpetuum mobile vorstellen.

In dem Gefuihl nun, daß wenig darauf ankommt, ob die mechanischen Gesetze unmittelbar oder auf einem Umwege (durch Wärmevorgänge) durchbrochen werden, in der Überzeugung ron dem allgemeinen gesetzmäßigen Naturzusammenhang, schließt hier CARNoT zum erstenmal auf dem Gebiet der allgemeinen Physik das perpetuum mobile aus. Dann aber kann die Arbeitsgröße $W$, welche durch Übergang von einer Wärmemenge $Q$ von $t_{1}$ auf $t_{2}$ ge wonnen werden kann, gar nichtvonder Natur der Stoffe und auch nicht von der Art des Prozesses (sofern derselbe nur verlustlos), sondern nur von den Temperaturen $t_{1}$ und $t_{2}$ abhängen.

Dieser wichtige Satz ist durch die Spezialuntersuchungen von Carnot selbst (I824), von Clapeyrox (1834) und von Willian Thosisox (I 849 ) aufs vollständigste bestätigt worden. Derselbe ist ohne irgend eine Annahme über die Natur der Wärme durch Ausschluß des perpetuum mobile gewonnen. САRNot hat allerdings die BLACKsche Ansicht festgehalten, nach welcher die gesamte Wärmemenge unveränderlich ist, doch ist, soweit die Untersuchung bisher betrachtet wurde, die Entscheidung hierüber belanglos. Schon der Carnotsche Satz hat zu den merkwürdigsten Ergebnissen geführt. 
W. Thomson (Lord Kelvis) ( 1848 ) hat auf denselben den genialen Gedanken einer absoluten (allgemein vergleichbaren) Temperaturskala gegründet. JAMEs Thomson (I 849) hat sich einen CaRnotschen Prozeß mit unter Druck frierendem und daher Arbeit leistendem Wasser vorgestellt. Er hat hierbei erkannt, daß durch den Druck je einer Atmosphäre der Gefrierpunkt um $0.0075^{\circ}$ Celsius erniedrigt wird. Dies sei nur als Beispiel erwähnt. Zwei Dezennien nach CARnots Publikation wurde durch J. R. Mayer und J. P. Joule ein weiterer Fortschritt herbeigeführt. MAYER beobachtete als Arzt in holländischen Diensten bei Gelegenheit von Aderlässen auf Java eine auffallende Röte des venösen Blutes. Er brachte dies nach LıEBIGs Theorie der animalen Wärme mit dem geringeren Wärmeverlust in dem wärmeren Klima und mit dem geringeren Verbrauch an organischem Brennstoff in Zusammenhang. Die gesamte Wärmeausgabe eines sich ruhig verhaltenden Menschen mußte der gesamten Verbrennungswärme entsprechen. Da aber alle organischen Leistungen, auch die mecha * $\mathrm{n}$ ischen, auf Rechnung der Verbrennungswärme gesetzt werden mußten, so mußte eine Beziehung zwischen mechanischer Leistung und Wärmeverbrauch bestehen.

Joule ging von ganz ähnlichen Überlegungen über die galvanische Batterie aus. Die dem Zinkverbrauch entsprechende Verbindungswärme kann in der galvanischen Zelle zum Vorschein kommen. Kommt ein Stroin zu stande, so tritt ein Teil dieser Wärme in dem Stromleiter 
auf. Fin eingeschalteter Wasserzersetzungsapparat bringt einen Teil dieser Wärme zum Verschwinden; dieselbe kommt aber bei Verbrennung des gebildeten Knallgases wieder zum Vorschein. Treibt der Strom einen Elektromotor, so verschwindet wieder ein Teil der Wärme, der aber bei Aufzehrung der Arbeit durch Reibung wieder zum Vorschein kommt. Auch Joule erscheint also sowohl die erzeugte $\mathrm{W}$ ärme als auch die erzeugte $\mathrm{Arbeit}$ an einen Stoffverbrauch gebunden. Es liegt demnach sowohl Mayer als Joule nahe, Wärme und Arbeit als gleichartige Größen anzusehen, welche so zusammenhängen, daß stets in der einen Form zum Vorschein kommt, was in der andern verschwindet. Es geht daraus eine $\mathrm{sub}$ stanzielle Auffassung der Wärme und der Arbeit hervor, und schließlich eine substanzielle Auffassung der Energie iberhaupt. Hierbei wird als Energie jede physikalische Zustandsänderung angesehen, deren Vernichtung Arbeit (oder äquivalente Wärme) erzeugt. Elektrische Ladung z. B. ist Energie.

MAYer hat (1842) aus den damals allgemein bekannten physikalischen Zahlen berechnet, daß durch das Ver$\mathrm{schwinden}$ einer $\mathrm{Kilogrammkalorie} 365 \mathrm{Kilo}$ grammmeter Arbeit erzeugt werden können, und umgekehrt. Joule hingegen hat durch eine große Reihe feiner und mannigfaltiger Versuche, die I 843 beginnt, das mechanische Äquivalent der Kilogrammkalorie schließlich viel genauer zu $425 \mathrm{Kilogramm}$. meter bestimmt.

Schätzt man jede physikalische Zustandsänderung nach 
der mechanischen Arbeit, welche beim Ver. schwinden derselben geleistet werden kann, und nennt dieses Maß Energie, so kann man alle physikalischen Zustandsänderungen, so verschiedenartig dieselben sein mögen, mit demselben gemeinsamen $M a ß$ messen und sagen: Die Summe aller Energien bleibt konstant. Dies ist die Form, welche das Prinzip vom ausgeschlossenen perpetuum mobile bei seiner Erweiterung über die ganze Physik durch Mayer, Joule, Helshotlz und IV. Thosson (Lord KeLvis) angenommen hat.

Nachdem nachgewiesen war, daß Wärme verschwinden muB, wenn auf Kosten derselben mecha$\mathrm{nische}$ Arbeit geleistet werden soll, konnte der CARNOTsche Satz nicht mehr als ein vollständiger Ausdruck der Tatsachen angesehen werden. Die Vervollständigung desselben hat zuerst Cuausius (I 850) Tromson folgte $185 \mathrm{I}$ nach - angegeben. Dieselbe lautet: Wenn eine Wärmemenge $Q^{\prime}$ bei einem umkehrbaren Proze $B$ in Arbeit verwandelt wird, so sinkt eine andere Wärmemenge $Q$ von der absoluten *) Temperatur $T_{1}$ auf die absolute Temperatur $T_{2}$. Hierbei hängt $Q^{\prime}$ nur von $Q, T_{1}, T_{2}$ ab, ist dagegen von den angewendeten Stoffen und von der Art des Prozesses (sofern derselbe überhaupt verlustlos) un ab hängig. Infolge des letzteren Umstandes genügt es, die Beziehung für e inen physikalisch wohlbekannten Stoff (z. B. ein Gas) und einen bestimmten beliebig einfachen Prozeß zu bestimmen. Dieselbe ist

") Darunter versteht man die Celsiustemperatur von 273 unter dem Eispunkt gerechnet.

Digitized by Microsoft ${ }^{13^{*}}$ 
zugleich die allgemein giltige. Auf diesem Wege findet man

$$
\frac{Q^{\prime}}{Q^{\prime}+Q}=\frac{T_{1}-T_{2}}{T_{1}} \ldots . \text {. .) }
$$

d. h. der Quotient aus der in Arbeit verwandelten (nutzbaren) Wärme $Q^{\prime}$ und der Summe der verwandelten und übergeführten (der gesamten verbrauchten) Wärme, der sogenannte ökonomische Koëffizient des Prozesses ist: $\frac{T_{1}-T_{2}}{T_{1}}$.

\section{Die Vorstellungen über die Wärme.}

Wenn ein kalter Körper mit einem warmen Körper in Berührung kommt, bemerkt man, daß der erstere sich erwärmt, der letztere sich abkühlt. Man kann sagen, daß der eine Körper auf Kosten des andern sich erwärmt. Dies legt die Vorstellung von einem Etwas, von einem Wärmestoff nahe, welcher aus dem einen Körper in den andern übergeht. Kommen zwei Wassermassen $m$ und $m^{\prime}$ von ungleicher Temperatur mit einander in Berührung, so zeigt es sich, daß bei raschem Temperaturausgleich deren gegenseitige Temperaturän derungen $u$ und $u^{\prime}$ den Massen umgekehrt proportioniert, und von entgegengesetztem Zeichen sind, so daß die algebraische Summe der Produkte ist

$$
m u+m^{\prime} u^{\prime}=0
$$

BLACK hat die für die Beurteilung des Vorganges maßgebenden Produkte $m u, m^{\prime} u^{\prime}$ IVärmemengen genannt. Man kann sich dieselben mit BLACK sehr anschaulich als Maße von Stoffmengen vorstellen. Wesentlich ist 
aber nicht dieses Bild, sondern wesentlich ist die Unveränderlichkeit jener Produktensummen bei bloßen Leitungsvorgängen. Wenn irgendwo eine Wärmemenge verschwindet, erscheint anderswo dafür eine gleich große. Das Festhalten dieser Vorstellung führt zur Entdeckung der spezifischen Wärme. Schließlich erkennt BLACK, daß für eine verschwundene Wärmemenge auch etwas anderes, nämlich Schmelzung oder Ver. dampfung einer gewissen Stoffmenge erscheinen kann. Er hält die liebgewordene Vorstellung hier mit einer gewissen Freiheit noch fest, und betrachtet die verschwundene Wärmemenge als noch vorhanden, aber als latent.

Die allgemein geläufige Vorstellung vom Wärmestoff wurde durch die Arbeiten von MAYER und Joule mächtig erschüttert. Wenn die Wärmemenge vermehrt und vermindert werden kann, sagte man, kann die Wärme kein St off, sondern sie muß Bewegung sein. Dieser nebensächliche Satz ist viel populärer geworden als die ganze übrige Energielehre. Wir können uns jedoch überzeugen, daß die Bewegungsvorstellung der Wärme gegenwärtig so unwesentlich ist, als es vorher die S toffvorstellung war.

Die beiden Vorstellungen sind lediglich durch zufällige historische Umstände gefördert oder gehemmt worden. Daraus, daß der Wärmemenge ein mecha$\mathrm{n}$ isches Äquivalent entspricht, folgt noch nicht, daß die Wärme kein Stoff ist.

Dies wollen wir uns durch folgende Frage, die aufgeweckte Anfänger zuweilen an mich gerichtet haben, 
deutlich machen. Gibt es ein mechanisches Äquivalent der Elektrizität, so wie es ein mechanisches Äquivalent der Wärme gibt? Ja und nein! Es gibt kein mechanisches Äquivalent der Elektrizitätsmenge, wie es ein Äquivalent der Wärmemenge gibt, weil dieselbe Elektrizitätsmenge einen sehr verschiedenen Arbeitswert hat, je nach den Umständen, unter welchen sie erscheint; es gibt aber ein mechanisches Äquivalent der elektrischen Energie.

Fügen wir noch eine Frage hinzu. Gibt es ein mechanisches Äquivalent des Wassers? Ein Äquivalent der Wassermenge nicht, wohl aber des Wassergewichtes $\chi$ Fallhöhe desselben.

Wenn eine Leydnerflasche entladen wird und dabei Arbeit leistet, so stellen wir uns nicht vor, daß die Elektrizitätsmenge verschwindet, indem sie Arbeit leistet, wir nehmen vielmehr an, daß die Elektrizitäten nur in eine andere Lage kommen, indem sich gleiche Quantitäten positiver und negativer mit einander vereinigen.

Woher kommt nun diese Verschiedenheit unserer Vorstellung bei der Wärme und bei der Elektrizität? Sie hat lediglich historische Gründe, ist vollständig konventionell, ja was noch mehr besagt, vollständig gleichgiltig. Es sei mir erlaubt, dies zu begründen.

Coulomb konstruierte ${ }^{1} 785$ seine Drehwage, durch welche er in den Stand gesetzt wurde, die Abstoßung elektrisierter Körper zu messen. Gesetzt, wir hätten zwei kleine Kugeln $A$ und $B$, welche durchaus gleichförmig elektrisch sind. Diese werden bei einer bestimmten Entfernung $r$ ihrer Mittelpunkte eine gewisse Abstoßung $p$ 
aufeinander ausüben. Wir bringen nun mit $B$ einen Körper $C$ in Berührung, lassen beide gleichförmig elektrisch werden und messen dann die Abstoßung von $B$ gegen $A$ und von $C$ gegen $A$ bei derselben Distanz $r$. Die Summe dieser Abstoßungen wird nun wieder $p$ sein. Es ist also etwas bei dieser Teilung konstant geblieben, die Abstoßung. Schreiben wir nun diese Wirkung einem Agens, einem Stoff $z u$, so schließen wir ungezwungen auf die Konstanz desselben.

RiEsS konstruierte I 838 sein elektrisches Luftthermometer. Dasselbe gibt ein Maß für die durch eine Flaschenentladung produzierte Wärmemenge. Diese Wärmemenge ist nicht der nach Coulombschem Maß in der Flasche enthaltenen Elektrizitätsmenge proportional, sondern wenn $q$ diese Menge und $s$ ein von der Oberfläche, Form und Glasdicke der Flasche abhängiger Faktor ist, proportional $\frac{q^{2}}{s}$, oder kurz proportional der Energie der geladenen Flasche. Wenn wir nun eine Flasche einmal vollständig durch das Thermometer entladen, so erhalten wir eine gewisse Wärmemenge $W$. Entladen wir aber durch das Thermometer in eine andere Flasche, so erhalten wir weniger als $W$. Den Rest können wir aber noch erhalten, wenn wir nun beide Flaschen vollständig durch das Luftthermometer entladen, und er wird wieder proportional sein der Energie dieser beiden Flaschen. Bei der ersten unvollständigen Entladung ist also ein 'Teil der Wirkungsfähigkeit der Elektrizität verloren gegangen.

Wenn eine Flaschenladung Wärme produziert, so 
ändert sich ihre Energie und ihr Wert nach dem Riessschen Thermometer nimmt ab. Die Menge nach dem Coulomischen Maße jedoch bleibt unverändert.

- Nun stellen wir uns einmal vor, das RiEsssche Thermometer wäre früher erfunden worden, als die Coulombsche Drehwage, was uns nicht schwer fallen kann, da ja beide Erfindungen von einander unabhängig sind. Was wäre natürlicher gewesen, als daß man die Menge der in einer Flasche enthaltenen Elektrizität nach der im Thermometer produzierten Wärme geschätzt hätte? Dann würde aber diese sogenannte Elektrizitätsmenge sich vermindern bei Produktion von Wärme oder Arbeitsleistung, während sie jetzt unverändert bleibt; dann würde also die Elektrizität kein Stoff, sondern Bewegung sein, während sie jetzt noch ein Stoff ist. Es hat also bloß einen historischen und ganz zufälligen konventionellen Grund, wenn wir über die Elektrizität anders denken als über die Wärme.

So ist es auch mit andern physikalischen Dingen. Das Wasser verschwindet nicht bei Arbeitsleistungen. Warum? Weil wir die Menge des Wassers mit der Wage messen, ähnlich wie die Elektrizität. Denken wir aber, der.Arbeitswert des Wassers würde Menge genannt, und müßte also, etwa mit der Mühle, statt mit der Wage gemessen werden, so würde diese Menge in dem Maße verschwinden, als sie Arbeit leistet. - Nun wird man sich leicht vorstellen können, daß mancher Stoff nicht so leicht greifbar wäre wie das Wasser. Wir würden dann die eine Art der Messung mit der Wage gar nicht ausführen können, während uns manche andere MeBweisen unbenommen blieben. Bei der 
Wärme ist nun das historisch festgesetzte Maß der "Menge" zufällig der Arbeitswert der Wärme. Daher verschwindet er auch, wenn Arbeit geleistet wird. $\mathrm{DaB}$ die Wärme kein Stoff sei, folgt hieraus ebensowenig wie das Gegenteil.

Hätte jemand Lust, sich auch heute noch die Wärme als Stoff zu denken, so könnte man ihm dieses Vergnügen immerhin gestatten. Er brauchte ja nur zu denken, daß dasjenige, was wir Wärmemenge nennen, die Energie eines Stoffes sei, dessen Menge unverändert bleibt, während die Energie sich ändert. In der Tat würden wir nach der Analogie der übrigen physikalischen Bezeichnungen viel besser Wärmeenergie anstatt Wärmemenge sagen.

Wenn wir also die Entdeckung anstaunen, daß Wärme Bewegung sei, so staunen wir etwas an, was nie entdeckt worden ist. Es ist vollständig gleichgiltig und hat nicht den geringsten wissenschaftlichen Wert, ob wir uns die Wärme als einen Stoff denken oder nicht.

Die Wärme verhält sich eben in manchen Beziehungen wie ein Stoff, in andern wieder nicht. Die Wärme ist im Dampf so latent, wie der Sauerstoff im Wasser.

\section{Die Konformitāt im Verhalten der Energien.}

Die vorausgehenden Betrachtungen gewinnen an Klarheit durch Beachtung der Konformität im Verhalten aller Energien, auf welche ich vor langer Zeit aufmerksam gemacht habe. $\left.{ }^{*}\right)$ Ein Gewicht $P$ auf einer Höhe $H_{1}$

\#) Ich habe zuerst hierauf hingewiesen in meiner Schrift „Utber die Er. haltung der Arbeit" Prag 1872. - Auf die Analogie von mechanischer und thermischer Energie hatte schon vorher Zeuner aufmesksam gemacht. Weitere Ausfihrungen habe ich gegeben in: Geschichte und Kritik des Carnot. schen Wärmegesetzes. Sitzungsberichte der Wiener Akademie. Dezember 1892. - 
stellt eine Energie $W_{1}=P H_{1}$ vor. Lassen wir dasselbe auf die kleinere Höhe $H_{2}$ sinken, wobei Arbeit geleistet und diese zur Erzeugung von lebendiger Kraft, Wärme, elektrischer L.adung u. s. w. verwendet, kurz umgewandelt wird, so ist noch die Energie $W_{2}=F H_{2}$ übrig. Es besteht nun die Gleichung

$$
\frac{W_{1}}{H_{1}}=\frac{W_{2}}{H_{2}} \ldots .2 .
$$

Oder wenn man die umgewandelte Energie mit $W^{\prime}=W_{1}-W_{2}$, die auf das niedere Niveau überge führte mit $W=W_{2}$ bezeichnet

$$
\frac{W^{\prime}}{W^{\prime}+W}=\frac{H_{1}-H_{2}}{H_{1}} \ldots . .3 \text {, }
$$

eine Gleichung, welche I (auf S. I96) ganz analog ist. Die betreffende Eigenschaft ist also durchaus nicht der Wärme eigentümlich. Die Gleichung 2 gibt die Beziehung der dem höheren Niveau entnommenen, und der an das tiefere Niveau abgegebenen (zurückbleibenden) Energie; sie besagt, daß diese Energien den Nivea uhöhen proportional sind. Eine der Gleichung 2 analoge läßt sich für jede Energieform aufstellen, und demnach läßt sich auch die der Gleichung 3, beziehungsweise I entsprechende für jede Form als gültig ansehen. Für die Elektrizität z. B. bedeuten $H_{1}, H_{2}$ die Potentiale. Wenn man zum erstenmal die hier dargelegte Übereinstimmung in dem Umwandlungsgesetz der Energien bemerkt, so erscheint dieselbe überraschend und un erwartet, da man den Grund derselben nicht sofort Man vergl, auch die Ausführungen der modernen ,Energetiker": Helm, Ostwald u. A. 
sieht. Demjenigen aber, der das vergleichend-historische Verfahren befolgt, kann dieser Grund nicht lange verborgen bleiben.

Die mechanische Arbeit ist seit GallLeI, wenngleich lange ohne den jetzt gebräuchlichen Namen, ein Grund. begriff der Mechanik und ein wichtiger Begriff der Technik. Die gegenseitige Umwandlung von Arbeit in lebendige Kraft, und umgekehrt, legt die Energieauffassung nahe, welche Huygexs zuerst in ausgibiger Weise verwendet, obgleich erst TH. Young den Namen Energie gebraucht. Nimmt man die Unveränderlichkeit des Gewichtes (eigentlich der Masse) hinzu, so liegt es in Bezug auf die mechạnische Energie schon in der Definition, daß die Arbeitsfähigkeit oder (potentielle) Energie eines Gewichtes proportional der Niveauhöhe (im geometrischen Sinne) ist, und daß dieselbe beim Sinken, bei der Umwandlung, proportional der Niveauhöhe abnimmt. Das Nullniveau ist hierbei ganz willkürlich. Hiermit ist also die Gleichung 2, aus welcher die übrigen Formen folgen, gegeben.

Bedenkt man den großen Vorsprung der Entwicklung, den die Mechanik vor den übrigen Gebieten der Physik hatte, so ist es nicht wunderbar, daß man die Begriffe der ersteren überall, wo es anging, anzuwenden suchte. So wurde z. B. der Begriff der $\mathbf{M}$ asse in dem Begriff der Elektrizitätsmenge von Coulons nachgebildet. Bei weiterer Entwicklung der Elektrizitätslehre. wurde ebenso in der Potentialtheorie der Arbeitsbegriff sofort angewendet, und es wurde die elektrische Niveau- 
höhe durch die Arbeit der auf dieselbe gebrachten Mengeneinheit gemessen. Damit ist nun auch für die elektrische Energie ebenfalls die obige Gleichung mit allen Konsequenzen gegeben. Ähnlich ging es mit den anderen Energien.

Als besonderer Fall erscheint jedoch die Wärmeenergie. Daß die Wärme eine Energie ist, konnte nur durch die eigenartigen besprochenen Erfahrungen gefunden werden. Das Maß dieser Energie durch die Blacksche Wärme menge hängt aber an zufälligen Umständen. Zunächst bedingt die zufällige geringe Veränderlichkeit der Wärmekapazität $c$ mit der Temperatur und die zufällige geringe Abiweichung der gebräuchlichen Thermometerskalen von der Gasspannungsskala, daß der Begriff Wärmemenge aufgestellt werden kann, und daß die einer Temperaturdifferenz $t$ entsprechende Wärme men g e $c t$ der Wärmeenergie wirklich nahezu proportional ist. Es ist ein ganz zufälliger historischer Umstand, daß Amontons auf den Einfall kam, die Temperatur durch die Gasspannung zu messen. An die Arbeit der Wärme dachte er hierbei gewiß nicht:*) Hierdurch werden aber die Temperaturzahlen den Gasspannungen, also den Gasarbeiten, bei sonst gleichen Volumänderungen, proportional. So kommt es, daß die Temperaturhöhen und die Arbeits n iveauhöhen einander wieder proportioniert sind.

Wären von den Gasspannungen stark abweichende Merkmale des Wärmezustandes gewählt worden, so hätte

\$) Mit Bewufstsein ist die Überstimmung zwischen Temperatur und Arbeitsniveau erst durch W. Thoms on $(1848,185 \mathrm{r})$ hergestellt worden. 
dies Verhältnis sehr kompliziert ausfallen können, und die eingangs betrachtete Übereinstimmung zwischen der Wärme und den andern Energien würde $\mathrm{nicht}$ bestehen. Es ist sehr lehrreich, dies zu überlegen.

So liegt also in der Konformität des Verhaltens der Energien kein Naturgesetz, sondern dieselbe ist vielmehr durch die Gleichförmigkeit unserer Auffassung bedingt, und teilweise auch Glücksache.

\section{Die Unterschiede der Energien und die Grenzen des Energieprinzipes.}

Von jeder Wärmemenge $Q$, welche bei einem umkehrbaren (verlustlosen) Prozeß zwischen den absoluten Temperaturen $T_{1}, T_{2}$ Arbeit leistet, wird nur der Bruchteil $\frac{T_{1}-T_{2}}{T_{1}}$ in Arbeit verwandelt, während der Rest auf das niedere Temperaturniveau $T_{2}$ übergeführt wird. Dieser übergeführte Teil kann mit dem Aufwand der geleisteten Arbeit durch Umkehrung des Prozesses wieder auf das Niveau $T_{1}$ hinaufgeschafft werden. Ist jedoch der Prozeß nicht umkehrbar, so fließt mehr Wärme als im vorigen Fall auf das niedere Niveau über, und der Mehrbetrag kann nicht mehr obne einen besonderen Aufwand auf $T_{2}$ geschafft werden. W. THossos hat deshalb darauf aufmerksam gemacht, daß bei allen nicht umkehrbaren, also bei allen wirklich en Wärmeprozessen Wärmemengen für die mechanische Arbeit verloren gehen, daß also eine Zerstreuung oder Verwüstung von mecha $\mathrm{n}$ is cher Energie stattfindet. Wärme wird immer nur teil. 
we ise in Arbeit, Arbeit aber oft ganz in Wärme umgewandelt. Es besteht also eine $\mathrm{T}$ e n de $\mathrm{nz}$ zur Verminderung der mechanischen Energie und zur Vermehrung der Wärmeenergie in der Welt.

Für einen einfachen verlustlosen geschlossenen Kreisprozeß, bei welchem die Wärmemenge $Q_{1}$ dem Niveau $T_{1}$ entzogen und dem Niveau $T_{2}$ die Menge $Q_{2}$ abgegeben wird, besteht entsprechend der Gleichung 2 die Beziehung $\frac{-Q_{1}}{T_{1}}+\frac{Q_{2}}{T_{2}}=$ o.

Für beliebig zusammengesetzte umkehrbare Kreisprozesse findet Clausius analog die algebraische Summe

$$
\Sigma \frac{Q}{T}=0
$$

und wenn die Temperatur sich kontinuierlich ändert

$$
\int \frac{d Q}{T}=0 \ldots .4 \text {. }
$$

Hierbei werden die einem Niveau entzogenen Wärmemengenelemente negativ, die mitgeteilten positiv gerechnet. Ist der Prozeß nicht umkehrbar, so wä chst bei demselben der Ausdruck 4, welchen Clausius Entropie nennt. In Wirklichkeit ist dies immer der Fall, und Clausius sieht sich zu dem Ausspruch gedrängt:

I. Die Energie der Welt bleibt konstant.

2. Die En tropie der We l t strebt einem Maximum zu.

Hat man die Konformität im Verhalten verschiedener Energien erkannt, so muß die hier erwähnte Eigenheit der Wärmeenergie auffallen. Woher kommt dieselbe, da doch jede Energie im allgemeinen nur teilweise in eine 
andere Form übergeht, gerade so wie die Wärmeenergie? Die Aufklärung liegt in folgendem:

Jede Umwandlung einer Energieart $A$ ist an einen Potentialfall dieser Energieart gebunden, auch für die Wärme. Während aber für die andern Energiearten mit dem Potentialfall auch umgekehrt eine Umwandlung und daher ein Verlust an Energie der im Potential sinkenden Energieart verbunden ist, verhält sich die Wärme anders. Die Wärme kann einen Potentialfall erleiden, ohne wenigstens nach der üblichen Schätzung - einen Energieverlust zu erfahren. Sinkt ein Gewicht, so muß es notwendig kinetisçhe Energie, oder Wärme oder eine andere Energie erzeugen. Auch eine elektrische Ladung kann einen Potentialfall nicht ohne Energieverlust, d. h. ohne Umwandlung erfahren. Die Wärme hingegen kann mit Temperaturfall auf einen Körper von größerer Kapazität übergehen und dieselbe Wärmeenergie bleiben, so lange man nämlich jede Wärmemenge als Energie betrachtet. Das ist es, was der Wärme neben ihrer Energieeigenschaft in vielen Fällen den Charakter eines (materiellen) St offes, einer Menge gibt.

Betrachtet man die Sache unbefangen, so muß man sich fragen, ob es überhaupt einen wissenschaft lichen Sinn und $\mathrm{Zweck}$ hat, eine Wärmemenge, die man nicht mehr in mechanische Arbeit verwandeln kann (z. B. die Wärme eines abgeschlossenen durchaus gleichmäßig temperierten Körpersystems), noch als eine Energie anzusehen. Sicherlich spielt in diesem Fall das Energieprinzip eine ganz müßige Rolle, die ihm nur 
durch die Gewohnheit zugeteilt wird. Trotz der Anerkennung der Zerstreuung oder Verwüstung der mechanischen Energie, trotz der Entropievermehrung das Energieprinzip aufrecht halten, heißt also ungefähr sich dieselbe Freiheit erlauben, die BLACK sich gestattet hat, indem er die Schmelzwärme als noch vorhanden, aber als la tent ansah.

Es sei noch gestattet zu bemerken, daß die Ausdrücke „Energie der Welt" und „Entropie der Welt" etwas von Scholastik an sich haben. Energie ụnd Entropie sind $\mathrm{Ma}$ B begriffe. Welchen Sinn kann es haben, diese Begriffe auf einen Fall anzuwenden, auf welchen dieselben eben $\mathrm{nicht}$ a $\mathrm{nw}$ e $\mathrm{ndb}$ ar, in welchem deren Werte unbestimmbar sind?

Könnte man die Entropie der We lt wirklich bestimmen, so würde dieselbe das eigentliche absolute $Z$ e it ma $B$ vorstellen. Es wird so am besten ersichtlich, daß es nur eine Tautologie ist, wenn man sagt: Die Entropie der Welt wächst mit der Zeit. Daß gewisse Veränderungen nur in einem bestimmten Sinne stattfinden, und die Tatsache der Zeit, fällt eben in Eins zusammen.

\section{Die Quellen des Energieprinzipes.}

Wir sind nun vorbereitet, um die Frage nach den Quellen des Energieprinzips zu beantworten. Alle Naturerkenntnis stammt in letzter Linie aus der Erfahrung. In diesem Sinne haben also diejenigen Recht, welche auch das Energieprinzip als ein Ergebnis der Erfahrung ansehen;

Die Erfahrung lehrt, daß die sinnlichen Elemente $\alpha, \beta, \gamma, \delta \ldots$, in welche die Welt zerlegt werden kann, der Veränderung unterworfen sind, und sie lehrt ferner, 
daß gewisse dieser, Flemente an ándere Elemente g e bundè n sind; so daß sie miteinander auftreten und ver, schwinden, oder daß das Auftretèn der Elemente der einen Art an das Verschwinden der Flemente der andern Art geknüpft ist. Wir wollen hier die Begriffe Ursache und Wirkung ihrer Verschwommenheit.und Vieldeutigkeit wegen vermeiden. :Das Ergebnis der Erfahrung : läßt sich $1 \mathrm{so}_{\text {। }}$ ausdrücken, daß man ságt: Di.e sinnlichèn Elemente der Welt. $(\alpha, \beta, \gamma, \delta \ldots)$ erweisein sich, als, ab: hängig von einander. Man denkt sich diese, gegenseitige. Abhängigkeit aml besten so, wie man sich in der Geometrie etwa die gègenseitige. Abhängigkeit der Seiten und Winkel eines Dreiéckes vorstellt; nur weitaus mannig: faltiger und kompliziertér.

Als Beispiel, mag "eine Gasmasse dienen, welche in einem Cylinder ẹn bestimmtés .Volum ( $\boldsymbol{\alpha}$.) einnimmt, das

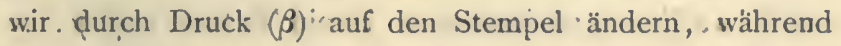
wir den Cylinder mit der'Hand befühlen und eine .Wärme, empfindung $(\gamma)$ ferhalten. Vergrößerung des Druckeśverkleinert das Volum: und steigert die Wärmeempfindung،

Die vetschiedenen Tatsachen der Erfahrung : gleichen sich nicht vollständig: ' Die gemeinsainen sinnlichen Flemente derselbén : treten durch einen Abstraktionsprozeß hervor und, prägen sich" der Erinnerung ein. Dadurch kommt. es zum Ausdruck des Übereinstimmenden ganzer Gruppen von Tatsachen. Schon der einfacliste Satz, den wir aussprecheh: können, ist. dem 'Wesen der.Sprache gemäß eine solché Abstrąktion. WAber auch den. Un tersch hieden verwahdter Tatsachen mmb Rechnung getragen

$\mathrm{Mach}$, Vorlesungen. 3. Aufl.

Digitized by Microsoft ${ }^{\circledR}$ 
werden. Tatsachen können sich so nahe stehen, daß sie dieselbe Art der $\alpha, \beta, \gamma \ldots$ enthalten, und da $\beta$ sich das $\alpha, \beta, \gamma$ der einen von jener der andern nur durch die $\mathrm{Zahl}$ der gleichen Teile unterscheidet, in die es zerlegt werden kann. Gelingt es dann Ableitungsregeln der M $\mathrm{B}$ zahlen der $\alpha, \beta, \gamma \ldots$ a useinander anzugeben, so hat man den allgemeinsten und zugleich den allen Un te r s c h i e d e n einer Gruppe von Tatsachen entsprechenden Ausdruck. Dies ist das Ziel der quantitativen Untersuchung.

Ist dieses Ziel erreicht, so hat man gefunden, daß zwischen den $\alpha, \beta, \gamma \ldots$ einer Gruppe von Tatsachen, beziehungsweise zwischen deren Maßzahlen eine Anzahl Gleichungen besteht. Die Tatsache der Veränderung bringt es mit sich, daß die $\mathrm{Zahl}$ dieser Gleichungen ge ringer sein muß als die Zahl der $\alpha, \beta, \gamma \ldots$ Ist erstere um $\mathrm{E}$ ins kleiner als letztere, so ist ein Teil der $\alpha, \beta, \gamma \ldots$ durch den andern eindeutig bestimmt.

Das Aufsuchen von Beziehungen der letzteren Art ist das wichtigste Ergebnis der experimentellen Spezialforschung, weil wir dadurch in den Stand gesetzt werden, teil we is e gegebene Tatsachen in Gedanken zu ergänzen. Es ist selbstverständlich, daß nur die Erfahrung darüber Aufschluß geben kann, daß zwischen den $\alpha, \beta, \gamma \ldots$ überhaupt Beziehungen bestehen und welcher Art dieselben sind.

Ferner kann nur die Erfahrung lehren, daßs solche Beziehungen zwischen den $\alpha, \beta, \gamma \ldots$ bestehen, da $\beta$ eingetretene Änderungen derselben wieder rückgängig 
werden können. Ohne diesen Umstand würde, wie leicht ersichtlich, jeder Anlaß zur Aufstellung des Energieprinzipes wegfallen. In der Erfahrung liegt also die letzte Quelle aller Naturerkenntnis und somit in diesem Sinne a uch jenedes Energieprinzipes.

Dies schließt aber nicht aus, daß das Energieprinzip auch eine logische Wurzel hat, wie sich dies sogleich zeigen wird. Nehmen wir auf Grund der Erfahrung an, eine Gruppe von sinnlichen Elementen $\alpha, \beta, \gamma \ldots$ bestimme eindeutig eine andere Gruppe $\lambda, \mu, \nu \ldots$ Die Erfahrung lehre ferner, daß Ändèrungen von $\alpha, \beta, \gamma \ldots$ wieder $\mathrm{r}$ ü $\mathrm{kg}$ ä $\mathrm{ng} \mathrm{ig}$ werden können. Dann ist es eine log is che Folge hiervon, daß jedesmal, wenn $\alpha, \beta, \gamma \ldots$ dieselben Werte annimmt, dies auch bei $\lambda, \mu, \nu \ldots$ der Fall ist, oder, daß bloß periodische Änderungen von $\alpha, \beta, \gamma \ldots$ keine bleibende Änderung von $\lambda, \mu, \nu \ldots$ zur Folge haben können. Ist die Gruppe $\lambda, \mu, \nu \ldots$ eine mechanische, so ist hiermit das perpetu um mobile a usgeschlossen.

Man wird sagen, das sei nur ein $Z$ irkelschluß, und dies sei ohne weiteres zugegeben. Allein ps y chologis $\mathrm{ch}$ ist die Situation doch eine wesentlich andere, ob ich nur an die eindeutige Bestimmtheit und Umkehrbarkeit der Vorgänge denke, oder ob ich das perpetuum mobile ausschließe. Die Aufmerksamkeit hat in beiden Fällen eine v.erschiedene Richtung und verbreitet Licht über ver schied ene Seiten der Sachẹ, die allerdings logisch notwendig zusammenhängen.

Sicherlich hat das feste logische Gefüge der Ge- 
dánken : der großen Fors̀cher (STEvin, 'GALILEI), welches bewiußt, oder instinktiv durch das feine Gefühl für die leisesten Widersprüche getragen wird, keineri andern Zweck, als den. Gedanken sozusagen e in en Grad der Freiheio und damit e in e Möglichkeit deș Irrtums su : benehmen. Hierınit ist also die $\log$ is che.Wurzel des Satzes vom ausgeschlossenen ' perpetuum mobile' angegeben, d. ii. jene, allgemeine Überżeugung, welche , selbst "vor dem Aưsbáu. der Mechanik bestand und bei demiselben mitwirkte.

$\because$ 'Es. ist eine natürliche Sache, daß das Prinzip des aus-: geschlossenen perpetuum mobile zuerst auf dem einfacheren Gebiet der reinén Mechanik..zur Anerkennung gelangt ist. Zur. Übertragung désselben auf das Gesamtgebiet der Physik hat allerdings, die.Vorstellung beigetràgen, 'daß alle physi-, kalischen Erscheinungen eigentlich mechanische Vorgängà seien. Dịe obige Entwickelung zeigt aber; wie. wenig wesentlich diese Vorstellung ist. Es kommt vielmehr auf die Erkenntnis des allgemeinen Naturzusammenh a n ges an. Ist dieser festgestellt, so sieht man (mit CARNOT), daß es nicht von Belahg ist, ob die męchanischen Gesetze unmittelbar oder auf einem. Umwege durchbrochen, werden. $\therefore \therefore$ Das Prinzip des ausgeschlossenen, perpetuum mobile steht.dem. modernen Energieprinżip zwar ${ }^{\circ}$ sehr nahe, es ist mit demselben aber ni.cht id e n.t is.ch, denn letzterés ergibt sich aus ersterem nur durch eine besondere for : mal.e - Auffassung. . Das / perpetuum - mabile - kainn man nach ..obiger Darlegung.. ausschließen, ..ohne den . Begriff Arbeit anzuwenden oder auch.. nur. zu.. kennen. Das nod.erne Energieprinzip. érgibt sich erst.. durch 
'eine substanzielle Auffassung' der Arbeit und ijeder physikalischen Zustandsänderung, welche; indem sie rückgängig wird, Arbeit erzeugt. Das starke Bedürfnis' nach eíner solchen Auffassung, welche durchaus $n \mathrm{i}, \mathrm{ch} \mathbf{t}$ not. wendig, áber formäl sehr bequem und an s'chaulich'ist,' tritt bei J. R. MAYer und Joule hervór. Es 'wurde' schón bemerkt, daß beidèn Forschern diese sAüfassing 'sehr nahe gelegt wurde durch die Bemerking, daß sowohl "die 'Wärmeerzeugung als : die mèchanische Arbeitsleistung an einen St of $\mathrm{fa} u \mathrm{f}$ w a $\mathrm{ndr}$ gebunden ist. MAYER sagt: "Ex nihilo nil fit", und an einer andern Stelle: Die 'Erschaffung "oder : Vernichtung" einer. Kraft (Arbeit) liegt außer dem. Bereich" mensschlichen Wirkens. - Bei Joule finden'wir die Stelle: „It is manifestly "absurd to suppose that the powers with which God has endowed matter can "bẹ destroyed." Man hat in isolchen Sätien den "Versuch" einer" "metaphys ischen -Begründiung der Energielehre sehen wollen. Ich: sèhe "in "den'selbeñ tediglich das formale Bëdürnnis nach. einer ärischà * lichen, übersichtlichen; einfachen̈ Rechnung, welches sich im praktischen Leben. entwickelt hat, und das man nun, so gut es geht, auf das Gebiet "der. Wissenschaft ubertrăgt. - In der Tat schreibt MÁYer an GRie'SINGER:" „Fragst Du mich endlich, wic ich:auf deñ ganzèn 'Handel gekommen; so ist die einfache' Antwort die:-' aúf meinèr Seèreise' mit dem Studium der Physiologie mich fast ausschließlich beschäftigend, fand ich die neue Liehre aus dem zureichenden Grunde, weil ich das bedü $\mathrm{r} \mathrm{n}$ is derselben lebhaft erkannte." ... 
Die substanzielle Auffassung der Arbeit (Energie) ist keineswegs eine notwendige, und es fehlt auch viel daran, daß mit dem Bedürfnis nach einer solchen Auffassung auch schon die Aufgabe gelöst wäre. Vielmehr sehen wir, wie MAYER sich bemüht, nach und nach seinem Bedürfnis zu entsprechen. Er hält zuerst die Bewe gungsquantität ( $m v$ ) für äquivalent der Arbeit, und verfällt erst später auf die lebendige $\mathrm{Kraft}$. Im Gebiete der Elektrizität vermag er den der Arbeit äquivalenten Ausdruck nicht anzugeben; dies geschieht erst später durch Helmholtz. Das formale Bedürfnis ist also zuerst vorhanden, und die Naturauffassung wird demselben erst allmählich angepaßt.

Die Bloßlegung der experimentellen, logis chen. und formalen Wurzel des heutigen Energieprinzipes dürfte wesentlich zur Beseitigung der Mystik beitragen, welche diesem Prinzip noch anhaftet. In Bezug auf unser formales Bedürfnis nach der einfachsten anschaulichsten substanziellen Auffassung der Vorgänge in unserer Umgebung bleibt es eine offene Frage, wie weit die Natur demselben entspricht, oder wie weit wir demselben entsprechen können. Nach einer der obigen Ausführungen scheint es, daß die Substanzauffassung des Energieprinzipes ebenso wie die Blacksche Substanzauffassung der Wärme ihre natürlichen Grenzen in den Tatsachen hat, über welche hinaus sie nur künstlich festgehalten werden kann. 
XIII.

\section{Die ökonomische Natur der physikalischen Forschung.*)}

Wenn das Denken mit seinen begrenzten Mitteln versucht, das reiche Leben der Welt wiederzuspiegeln, von dem es selbst nur ein kleiner Teil ist, und das $z u$ erschöpfen es niemals hoffen kann, so hat es alle Ursache, mit seinen Kräften sparsam umzugehen. Daher der Drang der Philosophie aller Zeiten, mit wenigen organisch gégliederten Gedanken die Grundzüge der Wirklichkeit zu umfassen. „Das Leben versteht den Tod nicht, und der "Tod versteht das Leben nicht." So spricht ein alter Philosoph. Gleichwohl war man, die Summe des Unbegreiflichen zu mindern, unablässig bemüht, den Tod durch das Leben und das Leben durch den Tod $z u$ verstehen.

Von menschlich enpfindenden Dämonen erfüllt finden wir die Natur bei den alten Kulturvölkern. Die an i mistische Naturansicht, wie sie der Kulturforscher TYLoR **) treffend und bezeichnend genannt hat, teilt der Fetischneger des heutigen Afrika im wesentlichen mit

\$) Vortrag gehalten in der feierlichen Sitzung der kaiserlichen Akademie der Wissenschaften zu Wien am 25. Mai 1882, - Vgl. „Exhaltung der Arbeit", ferner "Mechanik" und Artikel I, insbesondere S. $x 6$.

\$ڤ) Die Anfänge der Kultur. Leipzig. Winter. 1873 . 
den hochstehenden Völkern des Altertums. Nie hat sich diese Auffassung ganz verloren. Nicht der juidische, nicht der christliche Monotheismus haben sie jemals vollständig überwunden. Sie nimmt sogar drohende pathologische Dimensionen an im Hexen- und Aberglauben des 16. und 17 . Jahrhunderts, in der Zeit des Aufschwunges der Naturwissenschaft, - Während Stevin, 'KePLer und Galilei bedächtig Stein an Stein-fügen zu dem heutigen Bau der Naturwissenschaft, zieht man voll Grausamkeit und Entsetzen zu Felde, mit Folter und Feuerbrand, gegen die Ieufel, die uiberall hervorlugen, Ja auch heute noch, abgesehen von allen Überlebseln aus jener Zeit, abgesehen von allen Spuren des Fetischismus in unseren physikalischen Begriffen, *) leben diese, Vorstellungen noch fort; wenn auch halb latent und verschüchtert in dem wüsten Treiben der modernen Spiritisten.

... Neben dieser animistischen Anschauung erhebt sich zeitweilig in verschiedenen Formen, von Demokrit bis zur Gegenwart, mit dem gleichen. Anspruch, die Welt allein zu. begreifen, die Ansicht, die wir allgemeinverständich die physikalis ch-mechan ische nennen wollen. Daß̈ dieselbe heute die erste Stimme hat, daß sie die , Ideale und den Charakter unserer Zeit bestimmt, ., kann nicht zweifelhaft sein. . Es war e in e große ernüchternde Kultur: bewegung, durch welche die Menschheit im I 8 . Jahrhundert zur vollen Besinnung, kam: Sie schuf das leuchtende Vorbild eines menschenwürdigen Daseins zur Überwindung der alten Barbarei auf praktischem Gebiete; sie' schuf: die

*) Tylor, a. a: $\mathrm{O}$. 
Kritik dèr reineri Vernunft, welche' die begriflichen Truggestalten der alten Metaphysik ins Reich der Schatten verwies; sie drückte der physikalisch-mechanischen.Naturansicht die Zügel in die Hand, die sie heute führt.

Wie ein begeisterter Toast auf die wissenschaftlichë -Arbeit dë i 8 . Jahrhunderts klingen uns die oft angeführten Worte des großen LAPLACE*): „Eine Intelligenz, welcher für einen Augenblick alle Kräfte der Natur und die gegen'seitigen Lagen' aller Massen gegeben würden, wënn sie im übrigen umfassend genug wäre, diese Angaben der Analyse zu unterwerfen, könnte wit derselben Formel die Bewegung der größten Massen und der kleinsten Atome begreifen; nichts wäre ungëwiß für sie, die Zukunft und die Vergangenheit läge offen vor ihren Augen." LAPLACE. hat nachweislich bei seinen Worten auch an die'Atome des Gehirns gedacht. Ausdrücklicher noch haben dies mânche "seiner Nachfolger getan; und im ganzen möchte das Laplacesche Ideal - der liberwiegenden Mehrzahl der heutigen Naturforscher kaum fremd sein.

Freudig gönnen wir dem Schöpfer der mécanique céleste 'das'erhebende Gefühl, welches ihm die mächtig wachsende Aufklärung erregt, der auch wir unsere geistige Freiheit danken. Allein heute bei ruhigem Gemüt und vor neue Arbeit gestellt, ziemt es der physikalischen Forschung, sich durch Erkenntnis ihrer Natur vor Selbsttäuschung, zù schititzen, um dafuir aber desto sicherer ihre wahren Ziele i.

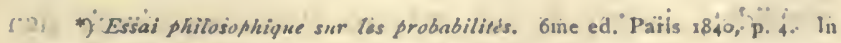
dieser Formulierung, fehle die notwendige, Berücksichtigung der Aufangsge: schwindigkeiten. 
verfolgen zu können. - Wenñ ich nun in der folgenden Frörterung, für die ich mir Ihre geneigte Aufinerksamkeit erbitte, zuweilen die engeren Grenzen meines Faches überschreite und auf befreundetes Nachbargebiet übertrete, so wird es mir gewiß zur Entschuldigung dienen, daß der St off allen Gebieten gemeinsain, und scharfe unverrückbare Marksteine überhaupt nicht gelegt sind.

Der Glaube an geheime Zaubermächte in der Natur ist allmählich geschwunden; dafuir hat sich aber ein neuer Glaube verbreitet, jener an die Zaubergewalt der Wissenschaft. Wirft doch diese, und nicht wie eine launische Fee nur dem Begünstigten, sondern der ganzen Menschheit, Schätze in den Schoß, wie sie kein Märchen erträumen konnte. Kein Wunder also, wenn ferner stehende Verehrer ihr zutrauen, daß sie im stande sei, unergründliche, unseren Sinnen unzugängliche Tiefen der Natur zu erschließen. Sie aber, die zur Erhellung in die Welt gekommen, kann jedes mystische Dunkel, jeden prunkvollen Schein, dessen sie zur Rechtfertigung ihrer Ziele und zum Schmucke ihrer offen daliegenden Leistungen nicht bedarf, ruhig von sich weisen.

Am besten werden die bescheidenen Anfänge der Wissenschaft uns deren einfaches, sich stets gleich bleibendes Wesen enthüllen. Halbbewußt und unwillkürlich erwirbt der Mensch seine ersten Naturerkenntnisse, indem er instinktiv die 'Tatsachen in Gedanken nachbildet und vorbildèt, indem er die trägere Erfahrung durch den schnelleren beweglichen Gedanken ergänzt, zunächst nur 
zu seinem materiellen Vorteile. Er konstruiert wie das Tier zum Geräusch im Gestrüppe den Feind, den er fürchtet, zur Schale den Kern der Frucht, welchen er sucht, nícht anders als wir zur Spektrallinie den Stoff, zur Reibung des Glases den elektrischen Funken in Gedanken vorbilden. Die Kenntnis der Kausalität in dieser Form reicht gewiß tief unter die Stufe, welche Schopenhauens Lieblingshund einnimmt, dem er diese Kenntnis zuschrieb. Sie reicht wohl durch die ganze Tierwelt und bestätigt das Wort des kräftigen Denkers von dem Willen, der sich den Intellekt für seine $\mathrm{Z}$ weckè schuf. Diese ersten psychischen Funktionen wurzeln in der Ökonomie des Organismus nicht minder.fest als. Bewegung und Verdauung. Daß wir in denselben auch die elementare Macht einer längst geübten logischen und physiologischen Handlung fühlen, die wir als Erbstück von unseren Vorfahren überkommen haben, wer wollte das leugnen?

Diese ersten Erkenntnisakte bilden auch heute noch die 'stärkste Gründlage alles wissenschaftlichen Denkens. Unsere instinktiven Kenntnisse, wie wir sie kurz nennen wollen, treten uns eben vermöge der Überzeugung, daß wir bewußt und willkürlich nichts zu denselben beigetragen haben, mit einer Autorität und logischen Gewalt entgegen, die bewußt und willkürlich erworbene Kenntnisse aus wohlbekannter Quelle und von leicht erprobter Fehlbarkeit niemals erreichen. Alle sogenannten Axiome sind solche instinktive Erkenntnisse. Nicht das mit Bewußtsein Erworbene allein, sondern der stärkste intellektuelle Instinkt, verbunden mit bedeutender begriftlicher Kraft, machen den 
großen Forscher aus. Die wichtigsten Fortschritte haben sich stets ergeben, wenn es gelang, instinktiv längst Erkanntes in klaré begriffliche', also mitteilbare Form zu úringen, und"so idem bleiberiden Eligentume der Mensch. heit hinzuzulégen. 'Durch NEwTons Satz'der' Gleichheit von Druck und Gegendruck, dessen Giltigkeit jedèr gefühlt, den aber vor ihm niemand begrifflich gefaßt hat, wurde die Mechanik mit einemmal auf eine höhère Stufe gehoben. Leicht ließe" sich die Behauptung nochi.an "den wissenschaftlichen Taten von Stevin, S. CARNot, FARAdar, J. R. MAYER u. a. historisch rechtfertigen.

Was wir besprochen, betrifft den Boden, dem die Wissenschaft entsprießt. Ihre eigentlichen'Aufänge treten erst auf in der Gesellschaft, und besonders im Handwerk, mit der Notwendigkeit der Mitteilung von Erfahrung. Erst da, wie dies mancher Autor schon' empfunden, ergibt sich der Zwang, die wichtigen und wesentlichen Züge einer Erfabrung zum Zwecke der Bezeichnung und Übertragung sich klar zum' Bewußtsein zu bringen. "Was ivir Unterricht nennen, bezweckt lediglich Ersparnis an Erfahrung eines Menschen durch jene eines anderen.

Die wunderbarste Ökonomie der Mitteilung liegt in der Sprachè. 'Dem gegossenen Letternsätze vergleichbar, welcher, die Wiederholung der Schriftżüge èrsparënd, den verschiedensten Zwecken diënt, “ dën 'wènigèn Lautën ähnlich, aus denen die verschiedensten Worte sich bilden, sind die Worte selbst. Mosaikartig setzt die Sprache und das mit/ihr in Wéchselbeziehung stehende begrifflichè Denken das -Wichtigste fixierend, das Gleichgiltige uber- 
sehend, die starren Bilder dèr flüssigen Welt zusammen, mit einem "Ópfer an Genauigkeit und Treué zwar, dafür; aber.mit Ersparnis an Mitteln und Arbeit. "Wie der, Klavierspieler :mit.. ein mal c.vorbereiteten Tönẹn, erregt, der Redner.im Hörer. e in mal für viele Fälle vorbereitete Gedariken, dièmit großer Geläufigkeit und geringer Mühe dem , Rufe folgen.

Die Grundsätze, welche der ausgezeichnete Wirtschaftsfors̀cher E. Herkmann für die Ökonomie der. Technik: als.giltig , betrachtet, sie finden auch volle Anwendung auf dem Gebiete der gemeinen und der , wissenschaftlichen. Begriffe. Gesteigert' ist natürlich die Ökonomie der Sprache in der wissenschaftlichen. Terminologie. Und was die Ökonomie der. schriftlichen Mitteilung betrifft, so ist kaum zu zweifeln, daß eben die Wissenschhaft den. schönen alten Traum der Philosophen von einer, internationalen Universalbegriffsschrift verwirklichen wird. Nicht mehr allzuferne liegt diese Zeit. '. Die Zahlenzeichen, die Zieichen 'der mathematischen Analyse, die ; chemischen Symbole, die musikalische Notenschrift, der sich eine entsprechende Farbenschrift leicht zur Seite stellen ließe, die BRUCKesche phonetische. Schrift sind wichtige Anfänge. Sie, werden, konsequent erweitert und: verbunden mit dem, was die schon vorhandene chineșische Begriffsschrift lehrt, jedes besondere Erfinnden und Dekretiẹren einer Universal-

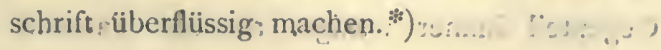

*) [Es versieht sich, dafs die Ausfiuhrung des L tibnizschen Gedankens einer Pasigráphie óder allgerheinen Jdeographie ein hinreichend klares und bea stimintes Begrifsystem von 'genígender. Entwicklung rur. Voraussetzung hat. Darin besteht eben die gröfste-Schwierigkeit. In dem Mafse als siols mit dem 
Die wissenschaftliche Mitteilung enthält stets die Beschreibung/d. i. die Nachbildung einer Erfahrung in Gedanken, welche Erfahrung ersetzen und demnach ersparen soll. Die Arbeit des Unterrichts und des I.crnens selbst wieder zu sparen, entsteht die $z$ usammenfás ende Beschreibung. Nichts anderes sind die Naturgesetze. Wenn wir uns etwa den Wert der Schwerebeschleunigung und das GaliLEIsche Fallgesetz merken, so besitzen wir eine sehr einfache und kompendiöse Anweisung, alle vorkommenden Fallbewegungen in Gedanken nachzubilden. Eine solche Formel ist ein vollständiger Ersatz für eine noch so ausgedehnte Tabelle, die vermöge der Formel jeden Augenblick in leichtester Weise hergestellt werden kann, ohne das Gedächtnis im geringsten $\mathrm{zu}$ belasten.

Die verschiedenen Fälle der Lichtbrechung könnte kein Gedächtnis fassen. Merken wir uns aber die Brechungsexponenten für die vorkommenden Paare von Medien und das bekannte Sinusgesetz, so können-wir jeden beliebigen Fall der Brechung ohne Schwierigkeit in Gedanken nachbilden oder ergänzen. Der Vorteil besteht in der Entlastung des Gedächtnisses, welche noch durch schriftliche Aufbewahrung der Konstanten unterstützt wird. Mehr als den umfassenden und verdichteten Bericht über Tatsachen enthält ein solches Naturgesetz nicht. Ja, es enthält im Gegenteil immer weniger als die Tatsache

Wachstum der Wissenschaft diese Voraussetzung erfüllt, wird die Pasigraphie ausführbar. Und in der Tat hat G. Peano in Turin für das Gebiet der Mlathematik eine Ideographie begründet. Vgl. hierüber den Bericht von L. Couturat im Bulletin des Sciences Mathematiques - Ig02.] 
selbst, weil dasselbe nicht die ganze Tatsache, sondern nur die für uns wichtige Seite derselben nachbildet, indem absichtlich oder notgedrungen von Vollständigkeit abgesehen wird. Die Naturgesetze sind intellektuellen, teils beweglichen, teils stereotypen Letternsätzen höherer Ordnung vergleichbar, welche letztere bei neuen Auflagen von Erfahrung oft auch hinderlich werden können.

Wenn wir ein Gebiet von Tatsachen zum erstenmal überschauen, erscheint es uns mannigfaltig, ungleichförmig, verworren und widerspruchsvoll. Es gelingt zunächst nur, jede einzelne Tatsache ohne Zusammenhang mit den übrigen festzuhalten. Das Gebiet ist uns, wie wir sagen, unklar. Nach und nach finden wir die einfachen sich gleich bleibenden Elemente der Mosaik, aus welchen sich das 'ganze Gebiet in Gedanken zusammensetzen läßst. Sind wir nun soweit gelangt, überall in der Mánnigfaltig. keit dieselben Tatsachen wieder zu erkennen, so fühlen wir uns in dem Gebiete nicht mehr fremd, wir überschauen es ohne Anstrengung, es ist für uns erklärt.

Erlauben Sie mir eine Erläuterung durch ein Beispiel. Kaum haben wir die geradlinige Fortpflanzung des Lichtes erfaßt, stößt sich der gewohnte Lauf der Gedanken an der. Brechung und Beugung. Kaum glauben wir mit e in e m Brechungsexponenten auszukommen; so sehen wir, daß für jede Farbe ein besonderer nötig ist. Haben wir uns daran gewöhnt, daß Licht zu Licht gefügt die Helligkeit vergrößert, bemerken wir plötzlich einen Fall der Verdunkelung. Schlieblich erkennt man aber in der überwältigenden Mannigfaltigkeit der Lichterscheinungen überall 
die Tatsache der räumlichen und zeitlichen Periodicität: des Lichtes und dessen von dem Stoffe und der Periode. abhängige Fortpflanzungsgeschwindigkeit. Dieses Ziel, ein: Gebiet mit dem geringsten Aufwand zu überschaiuen - und alle Tatsachen durch e in e n Gedankenprozeß nachzubildén, kann mit vollem Recht ein ökonomisches genannt werden.

Am. meisten; ausgebildet ist 'die Gedankenökonomie in jener Wissenschaft, welche die höchśte formelle Entwicklung erlangt lıat, welche auch die Naturwissenschaft so häufig zur. Hilfe heranzieht, in der Mathematik. : So sonderbar es klingen- mag, die Stärke der Mathematik beruht àuf der Vermeidung aller unnötigen Gedanken, auf..der größten Sparsamkeit der Denkoperationen. Schon 'die Ordnungszeichen, welche wir Zahlen nennen, bilden ein System von, wunderbarer Einfachheit und Sparsamkeit. Wenn wir beim Multiplizieren einer melırstelligen Zahl .durch Benützung des Einmaleins, die. Resultate schon ausgeftihrter Zähloperationen verwenden, statt sie jedesmal zu : wièderholen, wenn wir bei Gebrauch von .Logarithmentafeln: neu aus: zufuihrende Zähloperationen durch längst ausgeführte ersetzen und ersparen, wenn wir Determinanten vèrwenden, statt die Lösung eines Gleichungssystems "immer von neuem zu, beginnen, wenn wir neue. Integralausdruicke in altbe: kannte zerlegen, $:$ so sehen wir hierin nur ein schwaches Abbild der geistigen Tätigkeit eines Lagrange: oder Cauciy; der mit.dem. Scharfblick eines Feldherrn ,für neu auszuführende Operationen ganze Scharen schon .: ausgeführter eintreten läßt. is Man; wird keinen Widerspruch erheben, wenn.wir:sagen, die elementarste wie die :höchste. Mathes 
matik sei ökonomisch geordnete, für den Gebrauch bereit liegende $\mathrm{Z}$ ählerfahrung.

In der Algebra führen wir so weit als möglich formgleiche Zähloperationen ein für allemal aus, so daß nur ein Rest von Arbeit für jeden besonderen Fall uibrig bleibt. Die Verwendung der algebraischen und analytischen Zeichen, die nur Symbole von auszufuhrenden Operationen sind, entsteht durch die Bemerkung, daß man den Kopf entlasten, für wichtigere, schwierigere Funktionen sparen, und einen Teil der sich mechanisch wiederholenden Arbeit der Hand übertragen kann. Nur eine Konsequenz dieser Methode, welche den ökonomischen Charakter derselben bezeichnet, ist die Konstruktion von Rechenmaschinen. Der Erfinder einer solchen, der Mathematiker BabBaGE, war wohl der erste, der dies Verhältnis klar erkannt und, wenn auch nur fitichtig, in seinem Werke iiber Maschinenund Fabrikenwesen berihrt hat.

Wer Mathematik treibt, den kann zuweilen das unbehagliche (iefühl überkommen, als ob seine Wisserıschaft, ja sein Schreibstift, ihn selbst an Klugheit überträfe, ein Eindruck, dessen selbst der große Eulfr nach seinem Geständnisse sich nicht immer erwehren konnte. Eine gewisse Berechtigung hat dieses Gefuhl, wenn wir bedenken, mit wie vielen fremden oft vor Jahrhunderten gefabten Gedanken wir in geläufigster Weise operieren. Es ist wirklich teilweise eine fremde Intelligenz, dic uns in der Wissenschaft gegenübersteht. Mit der Erkenntnis dieses Sachverhaltes erlischt aber wieder das Mystische und Magische des Eindruckes, zumal wir jeden der

Mach, Vorlesungen. 3. Auf. 
fremden Gedanken, sobald wir nur wollen, nachzudenken vermögen.

Physik ist ökonomisch geordnete Erfahrung. Nicht nur die Übersicht des schon Erworbenen wird durch diese Ordnung ermöglicht, auch die Lücken und wünschenswerten Ergänzungen treten wie in einer guten Wirtschaft klar hervor. Die Physik teilt mit der Mathematik die zusammenfassende Beschreibung, die kurze kompendiöse, doch jede Verwechslung ausschließende Bezeichnung der Begriffe, deren mancher wieder viele andere enthält, ohne daß unser Kopf dadurch belästigt erscheint. Jeden Augenblick aber kann der reiche Inhalt hervorgeholt, und bis zu voller sinnlicher Klarheit entwickelt werden. Welche Menge geordneter, zum Gebrauch bereit liegender Gedanken faßt z. B. der Begriff Potential in sich. Kein Wunder also, daß mit Begriffen, die so viele fertige Arbeit schon enthalten, schließlich einfach zu operieren ist. Aus der Ökonomie der Selbsterhaltung wachsen also die ersten 'Erkenntnisse hervor. Die Mitteilung häuft die Erfahrungen vieler Individuen, die aber irgend einmal wirklich gemacht werden mußten, in e in e m auf. Sowohl die Mitteilung als das Bedürfnis des Einzelnen, seive Erfahrungssumme mit dem kleinsten Gedankenaufwand zu beherrschen, zwingt zu ökonomischer Ordnung. Hiermit ist aber auch die ganze rätselhafte Macht der Wissenschaft erschöpft. Im einzelnen vermag sie uns nichts $z u$ bieten, was nicht jeder in genügend langer Zeit auch ohne alle Methode finden könnte. Jede mathematische Aufgabe könnte durch direktes Zählen gelöst werden. 
Es gibt aber Zähloperationen, die gegenwärtig in wenigen Minuten vollführt werden, welche aber ohne Methode vorzunehmen die Lebensdauer eines Menschen bei weitem nicht reichen würde. So wie ein Mensch allein auf seine Arbeit angewiesen, niemals ein merkliches Vermögen sammeln würde, sondern die Ansanmlung der Arbeit vieler Menschen in einer Hand die Bedingung von Reichtum und Macht ist, so kann auch in endlicher Zeit und bei endlicher Kraft nur durch ausgesuchte Sparsamkeit in Gedanken, durch Häufung der ökonomisch geordneten Erfahrung Tausender in einem Kopfe ein nennenswertes Wissen erlangt werden. So ist also alles, was Zauberei scheinen könnte, wie es ja genügend oft im bürgerlichen Leben auch vorkommt, nichts als vortreff liche Wirtschaft. Die Wirtschaft der Wissenschaft hat aber vor jeder andern das voraus, daß durch Häufung ihrer Reichtümer niemand den geringsten Verlust erleidet. Darin liegt ihr Segen, ihre befreiende, erlösende Kraft.

Die Erkenntnis der ökonomischen Natur der Wissenschaft im allgemeinen mag uns nun behilflich sein, einige physikalische Begriffe leichter zu würdigen.

Was wir Ursache und Wirkung nennen, sind hervorstechende Merkmale einer Erfahrung, die für unsere Gedankennachbildung wichtig sind. Ihre Bedeutung blaßt $a b$, und geht auf andere neue Merkmale über, sobald eine Erfahrung geläufig wird. Tritt uns die Verbindung solcher Merkmale mit dem Eindruck der Notwendigkeit entgegen, so liegt dies nur daran, daß uns die Einschaltung längst 
bekannter Zwischenglieder, die also eine höhere Autorität für uns haben, oft gelungen ist. Die fertige Erfahrung im Setzen der Gedankenmosaik, mit welcher wir jedem neuen Fall entgegenkommen, hat KAxT einen angeborenen Verstandesbegriff genannt.

Die imposantesten Sätze der Physik, lösen wir sie in ihre Elemente auf, unterscheiden sich in nichts von den beschreibenden Sätzen des Naturhistorikers. Die Frage nach dem „warum", die überall zweckmäßig ist, wo es sich um Aufklärung eines Widerspruchs handelt, kann wie jede zweckmäßige Gewohnheit auch über den Zweck hinausgehen, und gestellt werden, wo nichts mehr zu verstehen ist.

Wollten wir der Natur die Eigenschaft zuschreiben, unter gleichen Umständen gleiche Erfolge hervorzubringen, so wüßten wir diese gleichen Umstände nicht zu finden. Die Natur ist nur einmal da. Nur unser schematisches Nachbilden erzeugt gleiche Fälle. Nur in diesem existiert also die Abhängigkeit gewisser Merkmale von einander.

Alle unsere Bemühungen, die. Welt in Gedanken abzuspiegeln wären fruchtlos, wenn es nicht gelänge, in dem bunten Wechsel Bleibendes zu finden. Daher das Drängen nacin dem Substanzbegriff, dessen Quelle von jener der modernen'Ideen über die Erhaltung der Energie nicht verschieden ist. Die Geschichte der Physik liefert für diesen Trieb auf fast allen Gebieten zahlreiche Beispiele, und die liebenswürdigen Äußerungen derselben lassen sich bis in die/ Kinderstube verfolgen. „Wo kommt das Licht hin, wenn es gelöscht wird und nicht melır in der Stube ist?" So frägt das Kind. Das plötzliche 
Schrumpfen eines Wasserstoffballons ist dem Kinde unfaßbar; es sucht iiberall nach dem großen Körper, der eben noch da war. "Wo kommt die Wärme her ?" „Wo kommt die Wärme hin?" Solche Kinderfragen im Munde reifer Manner bestimmen Charakter des Jahrhunderts.

Wenn wir in Gedanken einen Körper lostrennen von der wechselnden Umgebung, in welcher sich derselbe bewegt, so scheiden wir eigentlich nur eine Empfindungs. gruppe von verhältnismäßig größerer Beständigkeit, an welche wir unser Denken anklammern, aus dem Gewoge der Empfindungen aus. Eine absolute Unveränderlichkeit hat diese Gruppe nicht. Bald dieses, bald jenes Glied derselben verschwindet und kommt, erscheint verändert, und kehrt eigentlich in voller Gleichheit niemals wieder. Doch ist die Summe der bleibenden Glieder gegenüber den veränderlichen, namentlich wenn wir auf die Stetigkeit des Übergangs achten, immer so groß, daß sie uns zur Anerkennung des Körpers als desselben vorerst genügend erscheint. Weil wir aus der Gruppe jedes einzelne Glied ausscheidèn können, ohne daß der Körper aufhört, für uns derselbe zu sein, können wir leicht glauben, daß auch bei Ausscheidung aller noch etwas übrig bliebe, außer jenen Glicdern. So kann es kommen, daß wir den Gedanken einer von ihren Merkmalen verschiedenen Substanz, eines „Dinges an sich“, fassen, für dessen Eigenschaften die Empfindungen Symbole sein sollen. Umgekehrt müssen wir vielmehr sagen, daß Körper oder Dinge abkürzende Gedankensymbole für Gruppen von Empfindungen sind, Symbole, die außerhalb unseres Denkens nicht existieren. 
So wird auch jeder Kaufmann dic Etiquette einer Kiste als Symbol des Wareninhaltes betrachten und nicht umgekehrt. Er wird dem Inhalt, nicht aber der Etiquette realen Wert beilegen. Dieselbe Sparsamkeit, die uns veranlaßt, eine Gruppe aufzulösen und für deren auch in andern Gruppen enthaltene Bestandteile besondere Symbole zu setzen, kann uns auch treiben, durch ein Symbol die ganze Gruppe zu bezeichnen.

Auf den alten ägyptischen Monumenten sehen wir Abbildungen, die nicht einer Gesichtswahrnehmung entsprechen, sondern aus verschiedenen Wahrnehmungen zusammengesetzt sind. Die Köpfe und die Beine der Figuren erscheinen im Profil, die Kopfbedeckung und die Brust von vorn gesehen $u$. s. w. Es ist sozusagen ein mittlerer Anblick, in welchem der Künstler das ihm Wichtige festgehalten, das Gleichgiltige vernachlässigt hat. Wir können den auf den 'Tempelwänden versteinerten Vorgang bei den Zeichnungen unserer Kinder lebendig wahrnehmen und das Analogon desselben bei der Begriffsbildung in unseren Köpfen beobachten. Nur in dieser Geläufigkeit des Übersehens dürfen wir von ein e.m Körper sprechen. Sagen wir von einem Würfel, wir hätten dessen Ecken abgestutzt, obgleich er nun kein Würfel mehr ist, so berubt dies auf der natïrlichen Sparsamkeit, welche es vorzieht, der fertigen geläufigen Vorstellung eine Korrektur hinzuzufügen, statt eine gänzlich neue zu bilden. Alles Urteilen beruht auf diesem Vorgang.

Die Malerei der Ägypter und Kinder kann dem kritischen Blicke nicht standhalten. Dasselbe begegnet der rohen 
Vorstellung eines Körpers. Der Physiker, welcher einen Körper sich biegen, ausdehnen, sclımelzen und verdampfen sieht, zerlegt ihn in kleinere bleibende Teile, der Chemiker spaltet ihn in Elemente. Allein auch ein solches Element, wie das Natrium, ist nicht unveränderlich. Aus der weichen, silberglänzenden Masse wird bei Erwärmung eine flüssige, die bei größerer Hitze unter Luftabschluß in einen vor der Natriumlampe violetten Dampf sich verwandelt, und bei weiterer Erwärmung selbst mit gelbem Licht glüht. Wenn immer noch der Name Natrium festgehalten wird, so geschieht dies wegen der Stetigkeit des Überganges und aus notwendiger Sparsamkeit. Der Dampf kann sich kondensieren, und das weiße Metall ist wieder da. Ja, sogar nachdem das Metall, auf Wasser gelegt, in Natriumhydroxid übergegangen, können bei geeigneter Behandlung die gänzlich verschwundenen Eigenschaften wieder zum Vorschein kommen, wie ein Körper, der bei der Bewegung eine Zeitlang hinter einer Säule verborgen war, wieder sichtbar werden kann. Fs ist nun ohne Zweifel sehr zweckmäßig, den Namen und Gedanken für eine Gruppe von Eigenschaften, wo dieselben hervortreten können, stets bereit $\mathrm{zu}$ halten. Mehr als ein ökonomisch abkürzendes Symbol für alle jene Erscheirungen ist aber dieser Name und Gedanke nicht. Es wäre ein leeres Wort für jenen, dem er nicht eine ganze Reihe wohlgeordneter sinnlicher Eindrücke wachriefe. Und Ähnliches gilt von den Molekülen und Atomen, in welche das chemische Element noch zerlegt wird.

Zwar pflegt man die Erhaltung des Gewichtes oder 
genauer die Frhaltung der Masse als einen direkten Nachweis der Beständigkeit der Materie anzusehen. Allein dieser Nachweis verflüchtigt sich, wenn wir auf den Grund gehen, in eine solche Menge ron instrumentalen und intellektuellen Operationen, daß er gewissermaßen nur eine Gleichung konstatiert, welcher unsere Vorstellungen, Tatsachen nachbildend, zu genügen haben. Den dunklen Klumpen, den wir unwillkürlich hinzudenken, suchen wir vergebens außerhalb unseres Denkens. *;)

So ist es also uberall der rohe Substanzbegriff, der sich unbemerkt in die Wissenschaft einschleicht, der sich immer als unzulänglich erweist und sich auf immer kleinere Teile der Welt zurückziehen muß. Die niedere Stufe wird eben nicht entbehrlich durch die höhere, welche auf dieselbe gebaut ist, sowie durch die großartigsten Transportmittel die einfachste Lokomotion, das Gehen, nicht überflüssig geworden ist. Dem Physiker muß der Körper als eine durch Raumempfindungen verknüpfte Summe von Licht- und Tastempfindungen, wenn er nach demselben greifen will, so geläufig sein als dem Tiere, welches seine Beute hascht. Der Jünger der Erkenntnistheorie darf aber, wie der Geologe und Astronom von den Bildungen, die vor seinen Augen forgehen, zurückschließen auf jené, die er fertig vorfindet.

Alle physikalischen Sätze und Begriffe sind gekürzte Anweisungen, die oft selbst wieder andere Anweisungen

") Unter dem Schlagwort: ,Uberwindung des wissenschaftlichen Materialismus" wurden später verwandte Gedanken von W. Ostwald dargelegt. 
eingeschlossen enthalten, auf ökonomisch geordnete, zum Gebrauch bereit liegende Frfahrungen. Dic Kürze kann solchen Anweisungen, deren Inhalt nur selten vollkommen hervorgeholt wird, zuweilen den Anschein von selbständigen Wesen geben. Mit den poetischen Mythen, wie sic z. B. über die alles gebärende und alles wieder verschlingende Zeit bestehen, wollen wir uns hier natürlich nicht beschärtigen. Wir wollen uns nur erinnern, daß Newros nocl von einer absoluten, von allen Erscheinungen unabhängigen Zeit, wie auch von einem absoluten Raum spricht, über welche Anschauungen selbst KANT nicht hinausgekommen ist, und die heute noch zuweilen ernstlich erörtert werden. Für den Naturforscher ist jede zeitliche Bestimmung die abgekürzte Bezeichnung der Abhängigkeit einer Erscheinung von einer andern, und durchaus nichts weiter. Wenn wir sagen, die Beschleunigung eines frei fallenden Körpers betrage 9,8 I 0 Meter in der Sekunde, so heißt das, die Geschwindigkeit des Körpers gegen den Erdnittelpunkt ist um 9,8 I o Meter größer, wenn die Frde 1/s0400 ihrer Umdrehung mehr vollführt hat, was selbst wieder nur durch ihre Beziehung zu andern Himmelskörpern erkannt werden kann. In der Geschwindigkeit liegt wieder nur eine Beziehung der Lage des Körpers, zur Lage der Erde.*) Wir können alle Erscheinungen statt auf die Frde auf eine Uhr oder selbst auf unsere innere Zeitempfindung bezichen. Weil nun ein Zusammenhang aller besteht, und jede das Maß der übrigen sein kann, entsteht leicht dic

Es wird hierdurch klar, dafs alle sogenannten Elementargeseıze doch immer eine Beziehung auf das Ganze enthalten. 
'Täuschung, als ob die Zeit unabhängig von allen noch einen Sinn hätte.*)

Unser Forschen geht nach den Gleichungen, welche zwischen den Elementen der Erscheinungen bestehen. Die Gleichung der Ellipse drückt die allgemeinere denkbare Beziehung zwischen den Koordinaten aus, von welchen nur die reellen Werte einen geometrischen Sinn haben. So drüicken auch die Gleichungen zwischen den Erscheinungselementen eine allgemeinere mathematisch denkbare Beziehung aus; allein nur ein bestimmter Sinn der Änderung mancher Werte ist physikalisch zulässig. So wie in der Ellipse nur gewisse der Gleichung entsprechende Werte, so kommen in der Welt nur gewisse Wertänderungen vor. Die Körper werden stets gegen die Erde beschleunigt, die Temperaturdifferenzen werden, sich selbst überlassen, stets kleiner u. s. w. Auch in Bezug auf den uns gegebenen Raum haben bekanntlich mathematische und physiologische Untersuchungen gelehrt, daß derselbe ein wirklicher unter vielen den $\mathrm{k}$ baren Fällen ist, über dessen Eigentümlichkeiten nur die Erfahrung aus belehren kann. Die aufklärende Kraft dieses Gedankens kann nicht in Abrede gestellt werden, so monströs auch die Anwendungen sein mögen, die von demselben gemacht worden sind.

Versuchen wir nun die Ergebnisse unserer Umschau

*) Würde man einwenden, dafs wir es bemerken könnten, und das Zeitmaf́s nicht verlieren müfsten, sondern etwa die Schwingungsdauer der Natriumlichtwellen an die Stelle setzen könnten, wenn die Rotationsgeschwindigkeit der Erde Schwankungnn unterläge, so wäre damit nur dargetan, dafs wir aus praktischen Gründen diejenige Erscheinung wählen, wolche als einfachstes gemeinschaftiches Mấs der übrigen dienen kann. 
zusammenzufassen. In dem ökonomischen Schematisieren der Wissenschaft liegt die Stärke, aber auch der Mangel derselben. Die Tatsachen werden immer mit einem Opfer an Vollständigkeit dargestellt, nicht genauer, als dies unsern augenblicklichen Bedürfnissen entspricht. Die Inkongruenz zwischen Denken und Erfahrung wird also fortbestehen, so lange beide nebeneinander hergehen; sie wird nur stetig vermindert.

In Wirklichkeit handelt es sich immer nur um die Ergänzung einer teilweise vorliegenden Erfahrung, um Ableitung eines Erscheinungsteiles aus einem andern. Unsere Vorstellungen müssen sich hierbei direkt auf Empfindungen stützen. Wir nennen dies Messen. So wie die Entstehung, so ist auch die Anwendung der Wissenschaft an eine große Beständigkeit unserer Umgebung gebunden. Was sie uns lehrt, ist gegensẹitige Abhängigkeit. Absolute Prophezeiungen haben also keinen wissenschaftlichen Sinn. Mit großen Veränderungen im Himmelsraum würden wir unser Raum- und Zeitkoordinatensystem zugleich verlieren.

Wenn der Geometer die Form einer Kurve erfassen will, so zerlegt er sie zuvor in kleine geradlinige Elemente. Er weiß aber wohl, daß dieselben nur ein vorübergehendes willkürliches Mittel sind, stückweise zu erfassen, was auf einmal nicht gelingen will. Ist das Gesetz der Kurve gefunden, denkt er nicht mehr an ihre Elemente. So würde es auch der Naturwissenschaft nicht ziemen, in ihren selbstgeschaffenen veränderlichen ökonomischen Mitteln, den Molekülen und Atomen, Reali- 
täten linter den Erscheinungen zu sehen, vergessend der jüngst erworbenen weisen Besonnenneit ihrer kühneren Schwester, der Philosophie, eine me chanis che Mythologie zu setzen an die Stelle der animistischen oder metaphysischen, und damit vermeintliche Probleme zu schaffen. Das Atom mag immerhin ein Mittel bleiben, die Frscheinungen darzustellen, wie die Funktionen der Mathematik. Allmählich aber mit dem Wachsen der intellektuellen Erziehung an ihrem Stoff, verläßt die Naturwissenschaft das Mosaikspiel mit Steinchen und sucht die Grenzen und Formen des Bettes zu erfassen, in welchem der lebendige Strom der Erscheinungen fließt. Den spar samsten, einfachsten begrifflichen Ausdruck der Tatsachen erkennt sie als ihr Ziel.

Nun stellen wir uns noch die Frage, ob dieselbe Methode der Forschung, welche wir bisher stillschweigend als auf die physikalische Welt beschränkt angesehen haben, auch an das Gebiet des Psychischen hinanreicht. Dem Naturforscher erscheint diese Frage unnötig. Die physikalischen und die psychologischen Lehren entspringen in ganz gleicher Weise instinktiven Erkenntnissen. Wir lesen aus den Handlungen und Mienen der Menschen ihre Gedanken $a b$, ohne zu wissen wie. So wie wir das Benehmen einer Magnetnadel dem Strom gegenüber vorbilden, indem wir uns den Ampèreschen Schwimmer in demselben denken, so bilden wir die Handlungen der Menschen in Gedanken vor, indem wir mit ihrem Körper verbunden Empfindungen, Gefuihle und Willen ähnlich 
den unsrigen annehmen. Was wir da instinktiv treiben, miißte uns als der feinste wissenschaftliche Kunstgriff erscheinen, welcher an Bedeutung und genialer Konzeption die Ampèresche Schwimmerregel weit hinter sich ließe, wenn nicht jedes Kind unbewußt ihn finden würde. Es kann sich also nur darum handeln, wissenschaftlich $d$. h. begrifflich zu fassen, was/uns ohnehin geläufig ist. Und darin ist allerdings sehr viel $z u$ tun. Fine ganze Kette von Tatsachen ist zu enthüllen zwischen der Physik der Miene und Bewegung einerseits, der Empfindung und dem Gedanken anderseits.

"Wie sollte es aber möglich sein, aus den Atombewegungen des Hirns die Empfindung zu erklären ?" So hören wir fragen. Gewiß wird dies nie gelingen, so wenig als aus dem Brechungsgesetz jemals das Leuchten und Wärmen des Lichtes folgen wird. Wir brauchen eben das Fehlen einer sinnreichen Antwort auf solche Fragen nicht zu bedauern. Es liegt gar kein Problem vor. Mit Erstaunen bemerkt das Kind, welches über die Brüstung der Stadtmauer in den tiefen Wallgraben hinabblickt, unten die Menschen, und den verbindenden Torweg nicht kennend, begreift es nicht, wie sie von der hohen Mauer da herabkommen konnten. So ist es auch mit den physikalischen Begriffen. An unsern Abstraktionen können wir in die Psychologie zwar nicht hinauf - wohl aber hinunterklettern.

Sehen wir uns den Sachverhalt unbefangen an. Die Welt besteht aus Farben, Tönen, Wärmen, Drïcken, Räumen, Zeiten u. s. w., die wir jetzt nicht Empfindungen und nicht Er sche in unge n nennen wollen, weil in beiden 
Namen schon eine einseitige, willkürliche Theorie liegt. Wir nennen sie einfach Elemente. Die Erfassung des Flusses dieser Elemente, ob mittelbar oder unmittelbar, ist das eigentliche Ziel der Naturwissenschaft. So lange wir uns, den eigenen Körper nicht beachtend, mit der ge g e nseitigen Abhängigkeit jener Gruppen von Elementen beschäftigen, welche die fremden Körper, Menschen und Tiere eingeschlossen, ausmachen, bleiben wir Physiker. Wir untersuchen z. B. die Änderung der roten Farbe eines Körpers durch Änderung der Beleuchtung. Sobald wir aber den besonderen Einfluß jener Elemente auf dieses Rot betrachten, welche unsern Körper ausmachen, der sich durch die bekannte Perspektive mit unsichtbarem Kopf auszeichnet, sind wir im Gebiete der physiologischen Psychologie. Wir schließen die Augen, und das Rot mit der ganzen sichtbaren Welt ist weg. So liegt in dem Wahrnehmungsfelde eines jeden Sinnes ein Teil, welcher auf alle übrigen einen anderen und stärkeren Einfluß übt, als jene aufeinander. Hiermit ist aber auch alles gesagt. Mit Rücksicht darauf bezeichnen wir alle Elemente, sofern wir sie als abhängig von jenem besondern Teil (unserem Körper) betrachten, als Ėmp findungen. Daß die Welt unsere Empfindung sei, ist in diesem Sinne nicht zweifelhaft. Außer dieser vorübergehenden Auffassung aber ein System fürs Leben zu machen, dessen Sklaven wir bleiben, werden wir so wenig nötig haben, als der Mathematiker, wenn er eine vorher konstant gesetzte Reihe von Variablen einer Funktion nun variabel werden läßt, oder wenn er die unabhängig Variablen 
tauscht, obgleich ihm dies mitunter überraschende Ansichten verschafft.*)

Sieht man die Sache so naiv an, so erscheint es nicht zweifelhaft, daß die Methode der psychologischen Physiologie nur die physikalische sein kann, ja daß diese Wissenschaft selbst zu einem Teil der Physik wird. Der Stoff dieser Wissenschaft ist von jenem der Physik nicht verschieden. Sie wird die Beziehung der Empfindungen zur Physik unseres Körpers zweifellos ermitteln. Schon haben wir durch ein Mitglied dieser Akademie erfahren, daß der sechsfachen Mannigfaltigkeit der Farbenempfindungen aller Wahrscheinlichkeit nach eine sechsfache Mannigfaltigkeit des chemischen Prozesses der Sehsinnsubstanz, der dreifachen Mannigfaltigkeit der Raumempfindungen eine dreifache Mannigfaltigkeit des physiologischen Prozesses entspricht. Die Bahnen der Reflexe und des Willens werden verfolgt und aufgedeckt; welche Gegend des Hirns der Sprache, welche der Lokomotion dient, wird ermittelt. Was dann noch an unserm Körper hängt, die Gedanken, wird schon eine prinzipiell neue Schwierigkeit nicht mehr schaffen. Wird einmal die Erfahrung diese Tatsachen klargelegt und die Wissenschaft sie ökonomisch übersichtlich geordnet haben, dann ist nicht zu zweifeln, daß wir

\$) Den hier dargelegten Standpunkt nehme ich seit etwa 2 Dezennien ein, und habe ihn in verschiedenen Schriften (,Erhaltung der Arbeit, 1872", "Ciestalten der Flüssigkeit, $187^{\prime \prime}$, , Bewegungsempfindungen, $1875^{\prime \prime}$ ) festgehalten. Er liegt nicht den Philosuphen, wohl aber der Mehrzahl der Naturforscher recht fern. Umsomehr bedaure ich, dafs Titel und Verfasser einer kleinen Schrift, welche mit meinen Ansichten sogar in vielen Einzelnheiten zusanmentraf, und die ich in einer Zeit stürmischer Beschäftigung (1879-1880) flüchtig gesehen zu haben glaube, meinem Gedächtnis so entschwunden sind, dafs alle Versuche, sie wieder zu ermitteln, bisher erfolglos blieben. 
sie auch verstehen werden. Denn ein anderes Verstehen, als Beherrschung des Tatsächlichen in Gedanken hat es nie gegeben. Die Wissenschaft $\mathrm{sch}$ afft nicht eine 'Tatsache aus der andern, sie or dnet aber die bekannten.

Betrachten wir nun noch etwas näher die psychologișchphysiologische Forschung. Wir haben eine ganz klare Vorstellung davon, wie ein Körper sich im Raume seiner Umgebung bewegt. Unser optisches Gesichtsfeld ist uns sehr geläufig. Wir wissen aber gewöhnlich nicht anzugeben, wie wir zu einem Gedanken gekommen, aus welcher Ecke des intellektuellen Gesichtsfeldes er hereingebrochen, noch durch welche Stelle der Impuls zu einer Bewegung hinausgesendet worden. Dieses geistige Gesichtsfeld werden wir auch durch Selbstbeobachtung allein nie kennen lernen. Die Selbstbeobachtung im Verein mit der physiologischen Forschung, welche den physikalischen Zusammenhängen nachgeht, kann dieses Gesichtsfeld klar vor uns legen, und wird damit unsern innern Menschen erst eigentlich offenbaren.

Die Naturwissenschaft oder die Physik im weitesten Sinne lehrt uns die stärksten Zusammenhänge von Gruppen von Elementen kennen. Auf die einzelnen Bestandteile dieser Gruppen dürfen wir vorerst nicht zuviel achten, wenn wir ein faßbares Ganzes behalten wollen. Die Physik gibt, weil ihr dies leichter wird, statt der Gleichungen zwischen den Urvariablen, Gleichungen zwischen Funktionen derselben. Die psychologische Physiologie lehrt von dem Körper das Sichtbare, Hörbare, Tastbare absondern, wobei sie, von der Physik kräftig unterstützt, 
dieses wieder reichlich vergilt, wie schon aus der Einteilung der physikalischen Kapitel zu ersehen ist. Das Sichtbare löst die Physiologie weiter in Licht- und Raumempfindungen, erstere wieder in die Farben, letztere ebenfalls in ihre Bestandteile; die Geräusche löst sie in Klänge, diese in Töne auf u. s. w. Ohne Zweifel kann diese Analyse noch sehr viel weiter geführt werden, als es schon geschehen ist. Es wird schließlich sogar möglich sein, das Gemeinsame, welches sehr abstrakten und doch bestimmten logischen Handlungen von gleicher Form zu Grunde liegt, das der scharfsinnige Jurist und Mathematiker mit solcher Sicherheit herausfühlt, w่o der Unkundige nur leere Worte hört, ebenfalls aufzuweisen. Die Physiologie wird uns mit einem Worte die eigentlichen realen Elemente der Welt aufschließen. Die physiologische Psychologie verhält sich also zur Physik im weitesten Sinne ähnlich wie die Chemie zur Physik im engeren Sinne. Weitaus größer als die gegenseitige Unterstützung der Physik und Chemie wird jene sein, welche Naturwissenschaft und Psychologie sich leisten werden, und die aus diesem Wechselverkehr sich ergebenden Aufschlüsse werden jene der heutigen mechanischen Physik wohl weit hinter sich lassen.

Mit welchen Begriffen wir die Welt umfassen werden, wenn der geschlossene Ring der physikalischen und psychologischen Tatsachen vor uns liegen wird, von dem wir gegenwärtig nur zwei getrennte Stücke sehen, läßt sich zu Anfang der Arbeit natïlich nicht sagen. Die Männer werden sich finden, die das Recht erkennen, und den Mut haben werden, statt die verschlungenen Pfade des 
logischen historischen Zufalls nachzuwandeln, die geraden Wege zu den Höhen einzuschlagen, von welchen aus der ganze Strom der Tatsachen sich überschauen läßt. $\mathrm{Ob}$ dann der Begriff, den wir heute Materie nennen, über den gewöhnlichen Handgebrauch hinaus noch eine wissen. schaftliche Bedeutung haben wird, wissen wir nicht. Gewiß wird man sich aber wundern, wie uns Farben und Töne, die uns doch am nächsten liegen, in unserer physikalischen Welt von Atomen plötzlich abhanden kommen konnten, wie wir auf einmal erstaunt sein konnten, daß das, was da draußen so trocken klappert und pocht, drinnen im Kopfe leuchtet und singt, wie wir fragen konnten, wieso die Materie e m p find en kann, d. h. also, wieso ein Gedankensymbol für eine Gruppe von Empfindungen empfindet?

In scharfen Linien vermögen wir die Wissenschaft der Zukunft nicht zu zeichnen. Allein ahnen können wir, daß dann die harte Scheidewand zwischen dem Menschen und der Welt allmählich verschwinden wird, daß die Menschen nicht nur sich, sondern der ganzen organischen und auch der sogenannten leblosen Natur mit weniger Selbstsucht und einem wärmeren Gefühl gegenüberstehen werden. Eine solche Ahnung mochte wohl vor 2000 Jahren den großen chinesischen Philosophen Licius ergreifen, als er auf altes menschliches Gebein deutend, in dem durch die Begriffsschrift diktierten Lapidarstil zu seinen Schülern die Worte sprach: „Nur diese und ich haben die Erkenntnis, daß wir weder leben noch tot sind." 


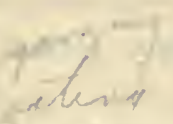 \\ XIV.}

\section{Über Umbildung und Anpassung im naturwissenschaftlichen Denken. *)}

Als Galilei zu Ende des r6. Jahrhunderts, mit vornehmer Nichtachtung der dialektischen Künste und der sophistischen Feinheiten der Gelehrtenschulen dieser Zeit, sein helles Auge der Natur zuwandte, um von ih ro seine Gedanken umbilden zu lassen, anstatt sie in die Fesseln seiner Vorurteile schlagen zu wollen, da fühlte man alsbald auch in fachlich fernstehenden Kreisen, ja in Schichten der Gesellschaft, welche sonst nur in negativer Weise auf die Wissenschaft Rücksicht zu nehmen pflegen, die gewaltige Veränderung, welche sich hiermit im menschlichen Denken vollzog.

*) Rede gehalten bei Antritt des Rektorates der deutschen Universität Prag am 18. Oktober ${ }_{1883}$. - Vgl. Artikel V. und "Mechanik".

Der in den folgenden Zeilen dargelegte Gedanke ist im wesentlichen weder neu noch fernliegend. Ich selbst habe ihn schon 1866 und auch später mehrmals berïhrt, ohne ihn jedoch zum 1Hauptthema einer Untersuchung zu machen. (Vgl. Artikel V.) Auch von anderen ist diese Idee jedenfalls schon behandelt worden; sie liegt eben in der luft. Da aber manche meiner Detailausführungen auch in der unvollständigen Form, in welcher sie durch den Vortrag und die Tageblätter bekannt geworden sind, einigen Anklang gefunden haben, so habe jch mich, gegen meine anfängliche Absicht, doch zur Publikation entschlossen. Auf das Gebiet der Biologie wünsche ich hiermit nicht überzugreifen. Man sehe in meinen Worten nur den Ausdruck des Umstandes, dafs dem Einflusse einer bedeutenden und weittragenden Idee sich niemand zu entziehen vermag. 
Und groß genug war diese Veränderung! Teils als unmittelbare Folge der GaLiLEIschen Gedanken, teils als Frgebnis des eben auflebenden frischen Sinnes für Naturbeobachtung, der GALILEI gelehrt hatte, an der Betrachtung des fallenden Steines selbst seine Begriffe über den Fall zu bilden, sehen wir von $1600-1700$, im Keime wenigstens, fast alles entstehen, was in unserer Naturwissenschaft und Technik eine Rolle spielt, was in den beiden folgenden Jahrhunderten die Physiognomie der Erde so bedeutend umgestaltet hat, was heute sich so mächtig fortentwickelt. Während GALILEI noch ohne ein nennenswertes Werkzeug seine Untersuchungen beginnt, in einfachster Weise durch ausfließendes Wasser die Zeit mißt, "sehen wir alsbald das Fernrohr, das Mikroskop, das Barometer, das Thermometer, die Luftpumpe, die Dampfmaschine, die Pendeluhr, die Elektrisiermaschine in voller Tätigkeit. Die grundlegenden Sätze der Dynamik, der Optik, der Wärme- und Elektrizitätslehre, alle enthüllen sich in dem einen Jahrhundert nach GaLILEI.

Dürfen wir unserem Gefühl trauen, so ist die Bewegung, welche durch die bedeutenden Biologen der letzten hundert Jahre vorbereitet, und durch den kürzlich verstorbenen großen Forscher DARIVIN wachgerufen wurde, kaum von geringerer Bedeutung. GaLiLeI schärfte den Sinn für die einfacheren Erscheinungsformen der unorganischen Natur. Mit gleicher Schlichtheit und Unbefangenheit wie GaLILEI, ohne Aufwand technisch-wissenschaftlicher Mittel, ohne Mikroskop, ohne physikalisches und chemisches Experiment, nur durch die Kraft des 
Gedankens und der Beobachtung erfaßt DARwin eine neue Eigenschaft der organischen Natur, die wir kurz deren Plastizität*) nennen wollen. Mit gleicher Energie wie GaLiLEI verfolgt er seinen Weg, mit gleicher Aufrichtigkeit und Wahrheitsliebe zeigt er die Stärke und den Mangel seiner Beweise, mit taktvoller Ruhe vermeidet er jede außerwissenschaftliche Diskussion, und erwirbt sich die Achtung der Anhänger sowohl als der Gegner.

Noch sind keine drei*) Decennien verflossen, seit DARWIN die Grundzüge seiner Entwicklungslehre ausgesprochen hat, und schon sehen wir diesen Gedanken auf allen, selbst fernliegenden Gebieten Wurzel fassen. Überall,

*) Auf den ersten Blick scheinen sich die gleichzeitigen Annahmen der Vererbungs- und Anpassungsfähigkeit zu widersprechen, und wirklich schliefst eine starke Tendenz zur Vererbung eine grofse Fähigkeit der Anpassung aus. Denkt man sich aber den Organismus ähnlich wie eine plastische Masse, welche die von früheren Einwirkungen herrührende Form so lange beibehält, bis neue Einwirkungen dieselbe abändern, so stellt die eine Eigenschaft der Plastizität sowohl die Vererbungs- als die Anpassungsfähigkeit dar. Ähnlich verhält sich ein Stahlstück von bedeutender magnetischer Koërzitivkraft, indem es seinen Magnetismus so lange beibehält, bis eine neue Kraft denselben verändert, ähn. lich auch eine beivegte Masse, welche die vom vorigen Zeitteilchen ererbte Geschwindigkeit beibehält, wenn dieselbe nicht durch eine augenblickliche Beschleunigung abgeändert wird. In Bezug auf das letztere Beispiel schien die A bänderung selbstverständlich, und die Auffindung der Trägheit war das Überraschende, während umgekehrt im $D_{a}$ rwinschen Falle die Vererbung als selbstverständlich angesehen wurde, und die $\mathrm{Abänderung} \mathrm{als} \mathrm{das} \mathrm{Neue}$ erschien.

Vollkommen zutreffende Ansichten können natürlich nur durch das Studium der von Darwin betonten Tatsachen selbst, und nicht durch diese Analogien allein gewonnen werden, von welchen ich die auf die Bewegung bezügliche, wenn ich nicht irre, zuerst von meinem Freunde Ingenieur J. Popper (in Wien) im Gespräche gehört habe.

Viele Forscher betrachten die Stabilität der Art als etwas Ausgemachtes, und stellen derselben die Darwinsche "Theorie" gegenüber. Doch ist die Stabilität der Art eben auch eine ,Theorie". Wie wesentlichen Umwandlungen übrigens die $\mathrm{D}$ a rw in schen Ansichten entgegen gehen, sehen wir an den Arbeiten von Wallace und besonders an der Schrift von W. H. Rolph (Biologische Probleme. Leipzig r882!. Leider zählt der letztere geniale Forscher nicht mehr zu den Lebenden.

4 $188_{3}$ geschrieben, 1895.] 
in den historischen, in den Sprachwissenschaften, selbst in den physikalischen Wissenschaften hören wir die Schlagworte: Vererbung, Anpassung, Auslese. Man spriclit vom Kampf ums Dasein unter den Himmelskörpern, vom Kampf ums Dasein unter den Molekülen. *)

Wie von GaLlLEI nach allen Richtungen Anregungen ausstrahlten, z. B. von seinem Schüler BoRElu die exakte medizinische Schule begründet wurde, aus welcher selbst bedeutende Mathematiker hervorgingen, so belebt jetzt der DARwinsche Gedanke alle Forschungsgebiete. Zwar besteht die Natur nicht aus zwei getrennten Stücken, dem organischen und dem unorganischen, die etwa nach gänzlich verschiedener Methode behandelt werden müßten, aber viele Seiten hat die Natur. Sie ist wie ein mannigfaltig zu einem Knoten verschlungener Faden, dessen Verlauf bald von dieser, bald von jener bloßliegenden Schlinge aus verfolgt werden kann, und nie darf man glauben - dies haben auf beschränkterem Gebiet die Physiker von FARADAY und J. R. MAYER gelernt - daß das Fortschreiten auf einmal eingeschlagener Bahn allein alle Aufklärung bedingt.

$\mathrm{Ob}$ nun von den DaRwiNschen Gedanken auf den verschiedenen Gebieten viel oder wenig haltbar und fruchtbar bleiben wird, werden die Spezialforscher der betreffenden Fächer in Zukunft zu prüfen und zu entscheiden haben. Mir mag es nur erlaubt sein, an dieser Stätte, welche der universitas literarum angehört, die ja in die Förderung des freieren Wechselverkehrs der Wissenschaften mit Recht

*) Vgl, Pfaundler, Pogg. Ann. Jubelband. S. r8r. 
ihren Stolz setzt, das Wachstum der Naturerkenntnis im Lichte der Entwicklungslehre zu betrachten. Denn die Erkenntnis ist eine Äußerung der organischen Natur. Und wenn auch Gedanken in ihrer Eigenart sich nicht in jeder Beziehung wie gesonderte Lebewesen verhalten können, wenn auch jede gewaltsame Vergleichung hier vermieden werden soll, der allgemeine Zug der Entwicklung und Umbildung mub, sofern DARWIN einen richtigen Blick getan, auch an ihnen hervortreten.

Von dem reichhaltigen Thema der Vererbung von Gedanken, oder vielmehr der Vererbung der Stimmung für bestimmte Vorstellungen, will ich hier (absehen. ${ }^{*}$ ) Es würde mir auch nicht zukommen, Betrachtungen über die psychische Entwicklung überhaupt anzustellen, wie sie SPENCER ${ }^{* * ;}$ ) und manche moderne Zoopsychologen mit mehr oder weniger Glück weitläufig ausgeführt haben. Ebenso soll der Kampf und die natürliche Auslese, die unter den wissenschaftlichen Theorien in der Literatur Platz greift, ${ }^{*}$ ) unberücksichtigt bleiben. Nur Um. bildungsprozesse solcher Art wollen wir in Augenschein nehmen, wie sie jeder Lernende leicht an sich selbst beobachten kann.

$$
\text { * * *. }
$$

Wenn ein Sohn der Wildnis, der mit feinen Sinnen die Fährten seiner Jagdtiere aufzuspüren und zu unter-

क) Schöne Ausfuhrungen über diesen Punkt finden sich bei Hering, "über das Gedächtnis als eine allgemeine Funktion der organisierten Materie". Almanach der Wiener Akademie, 1870. - Vgl. Dubois, Über die Übung. Berlin 188x.

Shencer, The principles of psychology. London 1872 .

A家市) V gl. Artikel V. besonders S. 72-75. 
scheiden, der mit Schlauheit seinen Feind $z u$ überlisten weiß, der sich in seinem Kreise vortrefflich zurecht findet, einer ungewöhnlichen Naturerscheinung oder einem Erzeugnis unserer technischen Kultur begegnet, so steht er diesen Dingen machtlos und ratlos gegenüber. Er versteht sie nicht. Versucht er sie zu begreifen, so mißdeutet er sie. Der verfinsterte Mond wird ihm von einem Dämon geplagt; die pustende Lokomotive ist ihm ein lebendes Ungeheuer; das einer Sendung beigegebene Begleitschreiben, welches seine Naschhaftigkeit verriet, ist ihm ein bewußtes Wesen, das unter einẹ Stein gelegt wird, wenn es gilt, eine neue Missetat unbeobachtet auszuführen. Das Rechnen erscheint ihm, wie selbst norh in den arabischen Märchen, als Punktierkunst, *) die alle Geheimnisse zu enthüllen vermag. Und in unsere sozialen Verhältnisse versetzt, führt er, wie VolTAIREs ,ingénu“, nach unseren Begriffen vollends die tollsten Streiche aus.

Anders der Mensch, welcher die moderne Kultur in sich aufgenommen hat, Er sieht den Mond in seiner Bahn zeitweilig in den Erdschatten eintreten. Er fühlt in Gedanken die Erwärmung des Wassers im Kessel der Lokomotive, er fühlt zugleich die wachsende Spannung, welche den Kolben ${ }^{*}$ fortschiebt. Wo er nicht unmittelbar folgen kann, greift er nach Maßstab und Logarithmentafel, die seine Gedanken stützen und entlasten, ohne sie zu beherrschen. Die Meinungen der Menschen, welchen er nicht zustimmen kann, sind ihm doch bekannt, und er weiß ihnen zu begegnen.

*) Vgl. z. B. G. Weil, Tausend und eine Nacht. 2. Ausgabe III, S. 154. 
Worin besteht nun der Unterschied zwischen beiden Menschen? Der Gedankenlauf des ersteren entspricht nicht den Dingen, die er sieht. Er wird auf Schritt und Tritt überrascht. Die Gedanken des zweiten folgen den Erscheinungen, und eilen ihnen voraus, sie sind dem größeren Beobachtungs- und Wirkungskreis angepaBt, er denkt sich die Dinge wie sie sind. Wie sollte auch ein Wesen, dessen Sinne immer nach dem Feinde spähen müssen, dessen ganze Aufmerksamkeit und Kraft durch das Beschaffen der Nahrung in Anspruch genommen wird, den Blick in die Ferne richten können? Dies wird erst möglich, wenn uns unsere Mitmenschen einen Teil der Sorge ums Dasein abnehmen. Dann gewinnen wir die Freiheit der Beobachtung, und leider auch oft jene Einseitigkeit, welche uns die Hilfe der Gesellschaft mißachten lehrt.

Wenn wir in einem bestimmten Kreise von Tatsachen uns bewegen, welche mit Gleichförmigkeit wiederkehren', so passen sich unsere Gedanken alsbald, der Umgebung so an, daß sie dieselbe unwillkürlich ábbilden. Der auf die Hand drückende Stein fällt, losgelassen, nicht nur wirklich, sondern auch in Gedanken zu Boden, das Eisen fliegt auch in der Vorstellung dem Magnete zu, erwärmt sich auch in der Phantasie am Feuer.

Der Trieb kur Vervollständigung der halbbeobachteten Tatsache in Gedanken entspringt, wie wir wohl fühlen, nicht der einzelnen Tatsache, er liegt, wie wir ebenfalls wissen, auch nicht in unserem Willen, er scheint uns vielmehr als eine fremde Macht, als ein Gesetz gegenüber zu stehen, welches Gedanken, und Tatsachen treibt. 
Daß wir mit Hilfe eines solchen Gesetzes prophezeien können, beweist eigentlich nur die für eine derartige Gedankenanpassung hinreichende Gleichförmigkeit unserer Umgebung. In dem Zwange, der die Gedanken treibt, und in der Möglichkeit der Prophezeiung liegt ja durchaus noch nicht die Notwendigkeit des Zutreffens. In der Tat müssen wir ja jedesmal das Eintreffen einer Prophezeiung erst abwarten. Und Mängel derselben werden immer bemerklich, nur sind sie klein in Gebieten von so großer Stabilität, wie etwa die Astronomie.

Wo unsere Gedanken den Tatsachen mit Leichtigkeit folgen, wo wir den Verlauf einer Erscheinung vorausfihlen, ist es natürlich, zu glauben, daß letztere sich nach den Gedanken richten müsse. Der Glaube an die geheimnisrolle Macht, $\mathrm{K}$ a usalität genannt, welche Gedanken und Tatsachen in Übereinstimmung hält, wird aber bei dem sehr erschiuttert, der zum erstenmal ein neues Erfahrungsgebiet betritt, z. B. die sonderbare Wechselwirkung elektrischer Ströme und Magnete, oder die Wechselwirkung von Strömen wahrnimmt, die so aller Mechanik zu spotten scheint. Er fühlt sich von seiner Prophetengabe sofort verlassen, und nimmt in dieses neue Gebiet nichts mit, als die Hoffnung, auch diesem seine Gedanken bald anzupassen. Wenn jemand zu einem Knochen mit dem Gefühl der größten Sicherheit den Rest des Skelettes, oder zu einem teilweise verdeckten Schmetterlingsflitgel eben den verdeckten Teil errät, so sehen wir darin nichts Metaphysisches, während die Gedankenanpassungen des Physikers an den dynamisch-zeitlichen Verlauf der Tat- 
sachen, die doch ganz von derselben Art sind, wohl nur ihres hohen praktischen Wertes wegen, einen besonderen metaphysischen Nimbus erhalten.*)

Überlegen wir nun was vorgeht, wenn der Beobachtungskreis, dem unsere Gedanken angepaßt sind, sich erweitert. Wir sahen oft die schweren Körper, wenn die Unterlage wich, sinken; wir sahen wohl auch, daß ein schwerer sinkender Körper einen leichteren in die Höhe drängte. Nun werden wir plötzlich gewahr, wie ein leichter Körper, etwa an einem Hebel, einen anderen von viel größerem Gewichte hebt. Die gewohnten Gedanken fordern ihr Recht, die neue Tatsache fordert es auch. In diesem Wiederstreite der Gedanken und Tatsachen entsteht das Problem, aus dieser teilweisen Inkongruenz entspringt die Frage: „warum?" Mit der neuerlichen Anpassung an den erweiterten Beobachtungskreis, in unserem Beispiele mit der Annahme der Gewohnheit, in allen Fällen auf die mechanische Arbeit zu achten, verschwindet das Problem, d. h. es ist gelöst.

Das Kind, dessen Sinne eben erwachen, kennt kein Problem. Die farbige Blume, die klingende Glocke, alles ist ihm neu, und doch wird es durch nichts überrascht. Der vollendete Philister, der nur an seine gewohnte Be-

\$) Ich weifs wohl, dafs dem Streben, sich bei der Naturforschung auf das Tatsächliche zu beschränken, der Vorwurf einer übertriebenen Furcht vor "metaphysischen Gespenstern" entgegengehalten wird. Ich möchte aber nicht unbemerkt lassen, dafs unter allen Gespenstern, nach dem Unheil zu ur. teilen, das sie angerichtet haben, die metaphysischen allein keine Fabel sind. Es soll ibrigens nicht in Abrede gestellt werden, dafs manche Denkformen nicht erst vom Individuum erworben, sondern durch die Entwicklung der Art vorgebildet oder doch vorbereitet sind, in dem Sinne wie dies Spencer, $\mathrm{Häckel}$, Hering u. a. sich vorgestellt haben, und wie ich selbst gelegentlich angedeutet habe. 
schäftigung denkt, hat auch kein Problem. Alles geht ja seinen bestimmten Lauf, und was etwa einmal verkehrt geht, ist höchstens ein Curiosum, nicht wert, daß man es beachtet. Wirklich hat, wo die Tatsachen uns nach allen Seiten geläufig werden, die Frage "warum" ihr Recht verloren. Der entwicklungsfähige junge Mensch aber, der eine Summe von Denkgewohnheit in sich aufgenommen hat, und der stets noch Neues und Ungewohntes wahrnimmt, hat den Kopf voll von Problemen, und des Fragens nach dem „warum" ist kein Ende.

Was also das naturwissenschaftliche Denken am meisten fördert, ist die allmähliche Erweiterung der Erfahrung. Das Gewohnte bemerken wir kaum, es erhält seinen intellektuellen Wert eigentlich erst im Gegensatze zu dem Neuen. WVas wir zu Hause kaum sehen, entzuickt uns in wenig veränderter Gestalt auf der Reise. Die Sonne scheint da heller, die Blumen blühen frischer, die Menschen blicken fröhlicher. Und zurückgekehrt finden wir auch unsere Heimat wieder bemerkenswerter.

Von dem Neuen, von dem Ungewöhnlichen, von dem Unverstandenen geht aller Reiz zur Umbildung der Gedanken aus. Wunderbar erscheint das Neue dem, dessen ganzes Denken hierdurch erschüttert wird und in gefährliches Schwanken gerät. Allein das Wunder liegt niemals in der Tatsache, sondern immer nur im Beobachter. Der stärkere intellektuelle Charakter strebt sofort nach einer entsprechenden Umbildung der Gedanken, ohne dieselben ganz aus ihrer Bahn drängen zu lassen. So wird die Wissenschaft zur natürlichen Feindin des Wunderbaren, 
und das erregte Erstaunen weicht bald einer ruhigen Aufklärung und Enttäuschung.

Betrachten wir nun einen solchen Umwandlungsprozeß der Gedanken im einzelnen. Das Sinken der schweren Körper erscheint als gewöhnlich und selbstverständlich. Bemerkt man aber, daß das $\mathrm{Holz}$ auf dem Wasser schwimmt, die Flamme, der Rauch in der Luft aufsteigen, so wirkt der Gegensatz dieser Tatsachen. Eine alte Lehre sucht dieselben zu erfassen, indem sie das dem Menschen Geläufigste, den Willen, in die Körper verlegt, und sagt, daß jedes Ding seinen Ort suche, das schwere unten, das leichte oben. Bald zeigt es sich aber, daß selbst der Rauch ein Cewicht hat, daß auch er seinen Ort unten sucht, daß er von der abwärts strebenden Luft nur aufwärts gedrängt wird, wie das Holz vom Wasser, weil dieses stärker ist.

Wir sehen nun einen geworfenen Körper. Er steigt auf. Wie kommt es, dab er seinen Ort nicht mehr sucht? Warum nimmt die Geschwindigkeit seiner "gewaltsamen" Bewegung ab, während jene des „natürlichen“ Falles zunimmt? Folgen wir aufmerksam beiden Tatsachen, so löst sich das Problem von selbst. Wir sehen mit GaLilei in beiden Fällen d i e s e l b e Geschwindigkeitszunahme gegen die Erde. Also nicht ein Ort, sondern eine Beschleu. nigung gegen die Erde ist dem Körper angewiesen.

Durch diesen Gedanken werden die Bewegungen schwerer Körpér vollkommen geläufig. "Die neue Denkgewohnheit festhaltend, sieht nun Nsiwros den Mond und die Planeten ähnlich geworfenen Körpern sich bewegen, 
aber doch, mit Eigentümlichkeiten, die ihn nötigen, diese Denkgewohnheit abermals - etwas abzuändern. Die Weltkörper, oder vielmehr deren Teile, halten keine kon. stânte Beschleunigung gegen einander ein, sie ,ziehen sich an" im verkehrt quadratischen Verhältnisse der Entfermung und im direkten der Massen.

Diese Vorstellung, welche jene der irdischen schweren Körper als besonderen Fäll enthält, ist nun schon sehr verschieden von der, von welcher wir ausgingen. Wie beschränkt war jene, und welcher Fülle von Tatsachen ist diese angepaßt. Und doch steckt in der "Anziehung“ noch etwas von dem „Suchen des Ortes". Und töricht wäre es, diese „Anziehungsvorstellung“, welche unsere Gedanken in so längst geläufige Bahnen leitet, welche wie die historische Wurzel der NewToxschen Anschauung anhaftet, als müßte dieselbe eine Andeutung ihres Stammbaumes bei sich führen, ängstlich vermeiden zu wollen. So fallen die genialsten Gedanken nicht vom Himmel, sie entstehen vielmehr aus schon vorhandenen.

Ähnlich ist der Lichtstrahl zuerst eine unterschiedslose Gerade. Er wird dann zur Projektilbahn, zu einem Bündel von Bahnen unzähliger verschiedener Projektilarten. Er wird periodisch, erhält zuletzt verschiedene Seiten, und verliert schließlich sogar wieder die geradlinige Bewegung.

Der elektrische Strom ist zunächst der Strom einer hypothetischen Flüssigkeit. Bald verknüpft sich mit dieser Vorstellung jene eines chemischen Stromes, eines an die Strombahn gebundenen elektrischen, magnetischen und anisotropen optischen Feldes. Und je reicher die Vor- 
stellung den Tatsachen folgen wird, desto geeigneter ist sie auch, ihnen gelegentlich voraus zu eilen.

Derartige Anpassungsprozesse haben keinen nachweisbaren Anfang, denn jedes Problem, welches den Reiz zu neuer Anpassung liefert, setzt schon eine feste Denkgewohnheit voraus. Sie haben aber auch kein absehbares Ende, sofern die Erfahrung kein solches hat. So steht also die Wissenschaft mitten in dem EntwicklungsprozeB, den sie zweckmäßig zu leiten und zu fördern, aber nicht zu ersetzen vermag. Eine Wissenschaft, nach deren Prinzipien der Unerfahrene die Welt der Erfahrung, ohne sie zu kennen, konstruieren könnte, ist undenkbar. Ebenso wohl könnte man erwarten, mit Hilfe der bloßen Theorie, und ohne musikalische Erfahrung, ein großer Musiker oder, nach Anleitung eines Lehrbuches, ein Maler zu werden.

Lassen wir die Geschichte eines schon geläufigen Gedankens an uns vorbeiziehen, so können wir den ganzen Wert seines Wachstumes nicht mehr richtig abschätzen. Wie wesentliche organische Umwandlungen stattgefunden haben, erkennen wir nur an der erschütternden Beschränktheit, mit welcher zuweilen gleichzeitig lebende große Forscher einander gegenüberstehen. Huygens' optische Wellenlehre ist einem NEwTnN, und NEwTons Ansicht der allgemeinen Schwere einem HuYGENS unfaßbar. Und nach einem Jahrhundert haben beide gelernt, sich selbst in unbedeutenden Köpfen zu vertragen.

Die freiwillig wachsenden Gedankenneubildungen bahnbrechender Menschen, welche mit kindlicher Naivetät die Reife des Mannes verbinden, nehmen eben keine fremde 
Dressur an, und sind nicht mit dem Denken zu vergleichen, das hypnotisch den Schatten folgt, welche das fremde Wort in unser Bewußtsein, wirft.

pver. A. '

Eben die Ideen, welche durch die ältere Erfahrung am geläufigsten geworden sind drängen sich, nach Selbsterhaltung ringend, in die Auffassung jeder neuen Erfahrung ein, und eben sie werden von der notwendigen Umwandlung ergriffen. Die Methode, neue, unverstandene Erscheinungen durch Hypothesen zu erklären, beruht gänzlich auf diesem Vorgang. Indem wir, statt ganz neue Vorstellungen über die Bewegung der Himmelskörper, über das Flutphänomen zu bilden, uns die Teile der Weltkörper gegen einander schwer denken, indem wir ferner ebenso die elektrischen Körper mit sich anziehenden und abstoßenden Flüssigkeiten beladen, oder den isolierenden Raum zwischen denselben in elastischer Spannung uns denken, ersetzen wir, soweit als möglich, die neuen Vorstellungen durch anschauliche, längst geläufige, welche teilweise mühelos in ihren Bahnen ablaufen, teilweise allerdings sich umgestalten müssen. So kann auch das Tier für jede neue Funktion, die ihm sein Schicksal aufträgt, nicht neue Glieder bilden, es muß vielmehr die vorhandenen benützen. Dem Wirbeltiere, welches fliegen oder schwimmen lernen will, wächst kein neues drittes Extremitätenpaar für diesen Zweck; es wird im Gegenteil eines der vorhandenen hierzu umgestaltet.

Die Hypothesenbildung ist also nicht das Ergebnis einer künstlichen wissenschaftlichen Methode, sie geht vielmehr ganz unbewußt schon in der Kindheit der Wissen- 
schaft vor sich. Hypothesen werden auch später erst nachteilig und dem Fortschritte gefährlich, sobald man ihnen mehr traut, als den Tatsachen selbst, und ihren Inhalt für realer hält, als diese, sobald man, dieselben starr festhaltend, die erworbenen Gedanken gegen die noch zu erwerbenden überschätzt.

Die Erweiterung des Gesichtskreises, mag die Natur wirklich.ihr Antlitz ändern, und uns neue Tatsachen darbieten, oder mag dieselbe auch nur von einer absichtlichen oder unwillkürlichen Wendung des Blickes herrühren, treibt die Gedanken zur Umbildung. In der Tat lassen sich die mannigfaltigen von JoHN STUART MiLL aufgezählten Methoden der Naturforschung, der absichtlichen Gedankenanpassung, jene der Beobachtung sowohl, als jene des Experimentes, als Formen einer Grundmethode, der $\mathrm{M}$ e $\mathrm{th}$ o d e der Veränderung erkennen. Durch Veränderung der Umstände lernt der Naturforscher. Die Methode ist aber keineswegs auf den eigentlichen Naturforscher beschränkt. Auch der Historiker, der Philosoph, der Jurist, der Mathematiker, der Ästhetiker*), der Künstler klärt und entwickelt seine Ideen, indem er aus dem reichen Schatze der Erinnerung gleichartige und doch verschiedene Fälle hervorhebt, indem er in Gedanken beobachtet und experimentiert. Selbst wenn alle sinnliche Erfahrung plötzlich ein Ende hätte, würden die Erlebnisse früherer Tage in wechselnder Stellung in unserem Bewußtsein sich begegnen, und es würde der Prozeß fortdauern, welcher im Gegensatze

") Vgl. 2. B. Schiller, "Zerstreute Betrachtungen über verschiedene - ästhetische Gegenstände."

Mach, Vorlesungen, 3. Auf. 
zur Anpassung der Gedanken an die Tatsachen der eigentlichen Theorie angehört, die Anp̧assung der Gedanken a ne in ander.

Die Methode der Veränderung führt uns gleichartige Fälle von Tatsachen vor, welche teilweise gemeinschaftliche, teilweise verschiedene Bestandteile enthalten. Nur bei Vergleichung verschiedener Fälle der Lichtbrechung mit wechselnden Einfallswinkeln kann das Gemeinsame, die Konstanz des Brechungsexponenten hervortreten, und nur bei Vergleichung der Brechung verschiedener Farben kann auch der Unterschied, die Ungleichheit der Brechungsexponenten die Aufmerksamkeit auf sich ziehen. Die durch die Veränderung bedingte Vergleichung leitet die Aufmerksamkeit zu den höchsten Abstraktionen und zu den feinsten Distinktionen zugleich.

Ohne Zweifel vermag auch das Tier das Gleichartige und Verschiedene zweier Fälle zu erkennen. Durch ein Geräusch wird sein Bewußtsein geweckt, und sein Bewegungszentrum stellt sich in Bereitschaft. Der Anblick des geräuscherregenden Wesens wird. wahrscheinlich je nach seiner Größe Flucht oder Verfolgung auslösen, und die feineren Unterschiede im letzteren Falle werden die Art des Angriffes bestimmen. Nur der Mensch aber erlangt die Fertigkeit der willkürlichen und bewußten Vergleichung, dab er mit seiner Abstraktion einerseits bis zum Satze der Erhaltung der Masse und der Erhaltung der Energie sich erheben, und anderseits im nächsten Augenblick die Gruppierung der Eisenlinien im Spektrum beobachten kann. Indem er die Objekte seines Vor- 
stellungslebens so behandelt, wachsen seine Begriffe dem Nervensystem selbst entsprechend zu einem weit verzweigten, organisch gegliederten Baume aus, an welchem er jeden Ast in seine feinsten Ausläufer verfolgen kann, um nach Bedürfnis von da an wieder zum Stamme zurückzukehren.

Der englische Forscher WHEwELL hat behauptet, daß zur Entwicklung der Naturwissenschaft zwei Faktoren zusammenwirken müßten: Ideen und Beobachtungen. Ideen allein verflüchtigen sich zur Spekulation, Beobachtungen allein liefern kein organisches Wissen. In der Tat sehen wir, wie es auf die Fähigkeit ankommt, vorhandene Ideen neuen Beobachtungen anzupassen. $\mathrm{Zu}$ große Nachgibigkeit gegen jede neue Tatsache läßt gar keine feste Denkgewohnheit aufkommen. Zu starre Denkgewohnheiten werden der freien Beobachtung hinderlich. Im Kampfe, im Kompromiß des Urteiles mit dem Vorurteile, wenn man so sagen darf, wächst unsere Einsicht.

Ein gewohntes Urteil, ohne vorausgegangene Prüfung auf einen neuen Fall angewandt, nennen wir Vorurteil. Wer kennt nicht dessen furchtbare Gewalt! Seltener denken wir daran, wie wichtig und nützlich das Vorurteil sein kann. So wie niemand physisch bestehen könnte, wenn er die Blutbewegung, die Atmung, die Verdauung seines Körpers durch willkürliche, vorbedachte Handlungen einleiten und im stande halten müßte, so könnte auch niemand intellektuell bestehen, wenn er genötigt wäre, alles was ihm vorkommt $z$ beurteilen, anstatt sich vielfach durch sein Vorurteil leiten zu lassen. Das Vorurteil ist eine Art Reflexbewegung im Gebiete der Intelligenz. 
Auf Vorurteilen, d. h. auf nicht jedesmal auf ihre Anwendbarkeit geprüften Gewohnheitsurteilen, beruht ein guter Teil der Überlegungen und Handgriffe des Naturforschers, auf Vorurteilen beruht die Mehrzahl der Handlungen der Gesellschaft. Mit dem plötzlichen Erlöschen aller Vorurteile würde sie selbst sich ratlos auflösen. Und eine tiefe Kenntnis der Macht der intellektuellen Gewohnheit hat jener Fürst verraten, der seine den rückständigen Sold ungestüm fordernde Leibgarde durch das übliche Kommandowort zum Abzuge zwang, wohl wissend, daß sie. diesem nicht widerstehen wïrde.

Erst wenn die Divergenz zwischen dem gewohnten Urteile und den Tatsachen zu groß wird, verfällt der Forscher einer empfindlichen Täuschung. Im praktischen Leben des Einzelnen und der Gesellschaft treten dann jene tragischen Verwicklungen und Katastrophen ein, in welchen der Mensch, die Gewohnheit über das Leben statt in den Dienst desselben stellend, ein Opfer seines Irrtums wird. Es kann eben dieselbe Macht, welche uns geistig fördert, nährt und erhält, unter andern Umständen uns wieder täuschen und vernichten.

$$
\because \quad *
$$

Die Gedanken sind nicht das ganze Leben. Sie sind nur wie eine flüchtige leuchtende Blüte, bestimmt, die Wege des Willens zu erhellen. Aber das feinste Reagens auf unsere organische Entwicklung sind unsere Gedanken. Und die Umwandlung, die wir durch dieselbèn an uns gewahr werden, wird uns keine Theorie bestreiten können, 
noch haben wir nötig, uns dieselbe erst beweisen $\mathrm{zu}$ lassen. Sie ist uns unmittelbar gewiß.

So erscheint uns die Gedankenumwandlung, die wir betrachtet haben, als ein Teil der allgemeinen Lebensentwicklung, der Anpassung an einen wachsenden Wirkungskreis. Ein Felsstuick strebt zur Erde. Es muß Jahrtausende warten, bis die Unterlage weicht. Ein Strauch, der an dessen Fuße wächst, richtet sich schon nach Sommer und Winter. Der Fuchs, welcher der Schwere entgegen bergan schleicht, weil er oben Beute wittert, wirkt freier schon als beide. Unser Arm reicht noch viel weiter, und an uns geht umgekehrt kaum etwas spurlos vorüber, was Wichtiges in Asien oder Aftika sich ereignet. Wie viel von dem Leben anderer Menschen, von ihrer Lust und ihrem Schmerz, ihrem Glück und ihrem Elend, spielt in uns hinein, wenn wir nur um uns blicken, wenn wir nur auf moderne Lektüre uns beschränken. Wie viel mehr erleben wir, wenn wir mit Herodot das alte Ägypten bereisen, durch die Straßen von Pompeoji wandern, uns in die düstere Zeit der Kreuzzüge und Kinderfahrten, in die heitere Blütezeit der italienischen Kunst versetzen, jetzt mit einem MoLiereschen Arzt und darauf mit Diderot und D'Alembert Bekanntschaft machen. Wie viel fremdes Leben, wie viel Stimmung, wie viel Willen nehmen wir durch Dichtung und Musik auf. Und wenn auch alles dies die Saiten unserer Leidenschaften nur leise berührt, wie den Greis die Erinnerung der Jugend anweht, teilweise haben wirs doch mit erlebt. Wie erweitert sich hierbei das Ich, und wie klein wird 
doch die Person! Die egoistischen Systeme des Optimis. mus und Pessimismus sehen wir zugleich mit ihrem kleinlichen Stimmungsmaßstab versinken. Wir fühlen, daß im wechselnden Inhalt des Bewußtseins die wahren Perlen des Daseins liegen, und daß die Person nur ist wie ein gleichgiltiger symbolischer Faden, an dem sie aufgereiht sind. *)

So wollen wir uns und jeden unserer Begriffe als ein Ergebnis und als ein Objekt zugleich der allgemeinen Entwicklung betrachten, um rüstig und unbehindert fortzuschreiten auf den Wegen, welche die Zukunft uns eröffnen wird. $\%$ )

*). Wir dürfen uns nicht darüber täuschen, dafs das Glück anderer Menschen ein sehr bedeutender und wesentlicher Teil des unserigen ist. Es ist ein ge. meinschaftliches Kapital, das von dem Einzelnen nicht geschaffen werden kann, und mit ihm nicht stirbt. Die schematische Abgrenzung des Ich, welche nur für die rohesten praktischen $Z$ wecke notwendig ist -und ausreicht, lärst sich hier

- nicht aufrecht halten. Die ganze Menschheit ist wie ein Polypenstock. Die materiellen organischen Verbindungen der lıdividuen, welche die Freiheit der Bewegung und Entwicklung nur gehindert hätten, sind zwar a b g erissen, allein ihr $Z$ weck, der psychische Zusammenhang, ist durch die hierdurch ermöglichte reichere Ausbildung in viel höherem Mafse erreicht worden.

\$) C. E. von Baer, der nachmalige Gegner Darwins und Häckels, hat in zwei wunderbaren Reden (,Das allgemeinste Gesetz der Natur in aller Entwicklung " und ,Welche Auffassung der lebenden Natur ist die richtige, und wie ist diese Auffassung auf die Entomologie anzuwenden ?') die Beschränktheit der Ansicht dargelegt, welche das Tier in seinem momentanen Zustand als ein Abgeschlosseues, Fertiges auffalst, anstatt dasselbe als eine Phase in der Reihe seiner Entwicklungsformen, uud die Art selbst als eine Phase der Entwicklung der Tierwelt überhaupt zu betrachten. 


\section{XV.}

\section{Über das Prinzip der Vergleichung in der Physik.*)}

Als Kirchioff vor 20 Jahren die Aufgabe der Mechanik dahin feststellte: "die in der Natur vor sich gehenden Bewegungen vollständig und auf die einfachste Weise zu beschreiben", brachte er mit diesem Ausspruch eine eigentümliche Wirkung hervor. Noch I4 Jahre später konnte Boltzirann in dem lebensvollen Bilde, das er von dem großen Forscher gezeichnet hat, von dem allgemeinen Staunen ${ }^{*}$ ) über diese neue Behandlungsweise der Mechanik sprechen, und noch heute erscheinen erkenntniskritische Abhandlungen, welche dęutlich zeigen,

*) Vortrag gehalten auf der Naturforscherversammlung zu Wien 1894 .

\$4 Ich konnte mich an jenem Staunen nicht beteiligen, denn ich hatte schon in meiner 1872 erschienenen Schrift "Über die Erhaltung der Arbeit" die Ansicht vertreten, dafs es der Naturforschung durchaus nur auf den ökonomischen Ausdruck des Tatsächlichen ankommt. Aber neu war dieser Satz auch damals nicht. Denn wenn wir auch von der praktischen Betätigung dieser Ansicht bei Galilei und von Newtons Wort: "hypotheses non fingo" absehen wollen, so sagt doch J. R. Mayer ausdrücklich: ,Ist einmal eine Tatsache nach allen ihren Seiten hin bekannt, so ist sie eben damit erklärt, und die Aufgabe der Wissenschaft ist beendigt" (1850). Wie sehr aber schon Adam Smith im 18. Jahrhundert in seinen Gedanken über die Wissenschaft sich in verwandten Bahnen bewegt hat, hat kürzlich Mc. Cormack gezeigt. (An Episode in the history of Philosophy. The Open Court. 1895 No. 397) [1895]. Vgl, auch: Die Mechanik in ihrer Entwicklung. 4. Aufl. rgor und Artikel XIII. 
wie schwer man sich mit diesem Standpunkte abfindet. Doch gab es eine bescheidene kleine Zahl von Naturforschern, welchen sich KIRCHHOFF mit jenen wenigen Worten sofort als ein willkommener und mächtiger Bundesgenosse auf erkenntniskritischem Gebiet offenbarte.

Woran mag es nun liegen, daß man dem philosophischen Gedanken des Forschers so widerstrebend nachgibt, dessen naturwissenschaftlichen Erfolgen niemand die freudige Bewunderung versagen kann? Wohl liegt es zunächst daran, daß in der rastlosen Tagesarbeit, die auf Erwerbung neuer Wissensschätze ausgeht, nur wenige Forscher Zeit und Muße finden, den gewaltigen psychischen Prozeß selbst, durch welchen die Wissenschaft wächst, genauer zu erörtern. Dann aber ist es auch unvermeidlich, daB in den lapidaren KIRCHHOFFschen Ausdruck nicht manches hineingelegt wird, was derselbe nicht meint, und $\mathrm{da} ß$ anderseits nicht manches in demselben vermißt wird, was bisher als ein wesentliches Merkmal der wissenschaftlichen Erkenntnis gegolten hat. Was soll uns eine bloße Beschreibung? Wo bleibt die Erklärung, die Einsicht in den kausalen Zusammenhang?

Gestatten Sie mir für einen Augenblick, nicht die Ergebnisse der Wissenschaft, sondern die Art ihres Wachstums schlicht und unbefangen zu betrachten. Wir kennen eine einzige Quelle unmittelbarer Offenbarung von naturwissenschaftlichen Tatsachen - unsere Sinne. Wie wenig aber das zu bedeuten hätte, was der Einzelne auf diesem Wege allein in Erfahrung bringen 
könnte, wäre er auf sich angewiesen, und müßte jeder von vorn beginnen, davon kann uns kaum jene Naturwissenschaft eine genug demütigende Vorstellung geben, die wir in einem abgelegenen Negerdorfe Centralafrikas antreffen möchten, denn dort ist schon jenes wirkliche Wunder der Gedankenübertragung tätig, gegen welches das Spiritistenwunder nur eine Spottgeburt ist, die s pr a ch liche Mitteilung. Nehmen wir hinzu, daß wir mit Hilfe der bekannten Zauberzeichen, welche unsere Biblio: theken bewahren, über Jahrzehnte, Jahrhunderte und Jahrtausende hinweg, von Faraday bis Galilei und Archimedes unsere großen Toten zitieren können, die uns nicht mit zweifelhaften, höhnenden Orakelsprüchen abfertigen, sondern das Beste sagen, was sie wissen, so fühlen wir, welch gewaltiger, wesentlicher Faktor beim Aufbau der Wissenschaft die Mitteilung ist. Nicht das, was der feine Naturbeobachter oder Menschenkenner an halbbewußten Konjekturen in seinem Innern birgt, sondern nur was er klar genug besitzt, um es mitteilen zu können, gehört der Wissenschaft an.

Wie aber fangen wir das an, eine neugewonnene Frfahrung, eine eben beobachtete Tatsache mitzuteilen? So wie der deutlich unterscheidbare Lockruf, Warnungsruf, Angriffsruf der Herdentiere ein unwillkürlich entstandenes Zeichen für eine übereinstimmende gemeinsame Beobachtung oder Tätigkeit trotz der Mannigfaltigkeit des Anlasses ist, der hiermit schon den Keim des Begriffes enthält, so sind auch die Worte der nur viel weiter spezialisierten Menschensprache Namen oder Zeichen fuir allgemein bekannte, ge- 
meinsam beobachtbare und beobachtete Tatsachen. Folgt also die Vorstellung zunächst passiv der neuen Tatsache, so muß letztere alsbald selbsttätig in Gedanken aus bereits allgemein bekannten, gemeinsam beobachteten Tatsachen aufgebaut oder dargestellt werden. Die Erinnerung ist stets bereit, solche bekannte Tatsachen, welche der neuen ähnlich sind, d. h. in gewissen Merkmalen mit derselben übereinstimmen, zur V e r gl e i c h un g darzubieten, und ermöglicht so zunächst das elementare innere Urteil, dem bald das ausgesprochene folgt.

Die Vergleichung ist es, welche, indem sie die Mitteilung überhaupt ermöglicht, zugleich das mächtigste innere Lebenselement der Wissenschaft darstellt. Der Zoologe sieht in den Knochen der Flughaut der Fledermaus Finger, vergleicht die Schädelknochen mit Wirbeln, die Embryonen verschiedener Organismen mit einander, und die Entwicklungsstadien desselben Organismus unter einander. Der Geograph erblickt in dem Gardasee einen Fjord, in dem Aralsee eine im Vertrocknen begriffene Lake. Der Sprachforscher vergleicht verschiedene Sprachen und die Gebilde derselben Sprache. Wenn es nicht üblich ist, von vergleichender Physik zu sprechen, wie man von vergleichender Anatomie spricht, so liegt dies nur daran, daß bei einer mehr aktiven experimentellen Wissenschaft die Aufmerksamkeit von dem kontemplativen Element allzusehr abgelenkt wird. Die Physik lebt und wächst aber, wie jede andere Wissenschaft, durch die Vergleichung. 
Die Art, in welcher das Ergebnis der Ver. gleichung in der Mitteilung Ausdruck findet, ist allerdings eine sehr verschiedene: Wenn wir sagen, die Farben des Spektrums seien rot, gelb, grün, blau, violett, so mögen diese Bezeichnungen von der 'Technik des Tätowierens herstammen, oder sie mögen später die Bedeutung gewonnen haben, die Farben seien jene der Rose, Citrone, des Blattes, der Korblume, des Veilchens. Durch die häufige Anwendung solcher Vergleichungen unter mannigfaltigen Umständen haben sich aber den übere instimmenden Merkmalen gegenüber die wechselnden so verwischt, daß erstere eine selbständige, von jedem Objekt, jeder Verbindung, unabhängige, wie man sagt, abstrakte oder begriffliche Bedeutung gewonnen haben. Niemand denkt mehr bei dem Worte "rot" an eine andere Übereinstimmung mit der Rose als jene der Farbe, bei dem Worte "gerade" an eine andere Eigen. schaft der gespannten Schnur, als die durchaus gleiche Richtung. So sind auch die $\mathrm{Zahlen}$, ursprünglich die Namen der Finger, Hände und Füße, welche als Ordnungszeichen der mannigfaltigsten Objekte benützt wurden, zu abstrakten Begriffen geworden. Eine sprachliche Mitteilung über eine Tatsache, die nur diese rein begrifflichen Mittel verwendet, wollen wir eine direkte Beschreibung nennen.

Die direkte Beschreibung einer etwas umfangreicheren Tatsache ist eine mühsame Arbeit, selbst dann, wenn die hierzu nötigen Begriffe bereits volk entwickelt sind. Welche Erleichterung muß es also gewähren, wenn man einfach

\section{Digitized by Microsoft ${ }^{\circledR}$}


sagen kann, eine in Betracht gezogene Tatsache $A$ verhalte sich nicht in einem einzelnen Merkmal, sondern in vielen oder allen Stücken wie eine bereits bekannte Tatsache $B$. Der Mond verhält sich wie ein gegen die Erde schwerer Körper, das Licht wie eine Wellenbewegung oder elektrische Schwingung, der Magnet wie mit gravitierenden Flüssigkeiten beladen u. s. w. Wir nennen eine solche Beschreibung, in welcher wir uns gewissermaßen auf eine bereits anderwärts gegebene oder auch erst genauer auszuführende berufen, naturgemäß eine indirekte Beschreibung. Es bleibt uns unbenommen, dieselbe allmählich durch eine direkte zu ergänzen, zu korrigieren oder ganz zu ersetzen. Man sieht unschwer, daß das, was wir eine Theorie oder eine theoretische Idee nennen, in die Kategorie der indirekten Beschreibung fällt.

Was ist nun eine theoretische Idee? Woher haben wir sie? Was leistet sie uns? Warum scheint sie uns höher zu stehen, als die bloße Festhaltung einer Tatsache, einer Beobachtung? Auch hier ist einfach Erinnerung und Vergleichung im Spiel. Nur tritt uns hier aus unserer Erinnerung, statt eines einzelnen Zuges von Ähnlichkeit, ein ganzes System von Zügen, eine wohlbekannte Physiognomie entgegen, durch welche die neue Tatsache uns plötzlich zu einer wohlvertrauten wird. Ja die Idee kann mehr bieten, als wir in der neuen Tatsache augenblicklich noch sehen, sie kann dieselbe erweitern und bereichern mit Zügen, welche erst zu suchen wir veranlaßt werden, und die sich oft wirk-

\section{Digitized by Microsoft ${ }^{\circledR}$}


lich finden. Diese Rapidität der Wissenserweiterung ist es, welche der Theorie einen quantitativen Vorzug vor der einfachen Beobachtung gibt, während jene sich von dieser qualitativ weder in der Art der Entstehung noch in dem Endergebnis wesentlich unterscheidet.

Aber die Annahme einer Theorie schließt immer auch eine Gefahr ein. Denn die Theorie setzt in Gedanken an die Stelle einer Tatsache $A$ doch immer eine andere, einfachere oder uns geläufigere $B$, welche die erstere gedanklich in gewisser Beziehung vertreten kann, aber eben weil sie eine andere ist, in anderer Beziehung doch wieder gewiß nicht vertreten kann. Wird nun darauf, wie es leicht geschieht, nicht genug geachtet, so kann die fruchtbarste Theorie gelegentlich auch ein Hemmnis der Forschung werden. So hat die Emissionstheorie, indem sie den Physiker gewöhnte, die Projektilbahn der „Lichtteilchen“ als unterschiedslose Gerade zu fassen, die Erkenntnis der Periodizität des Lichtes nachweislich erschwert. Indem Huygens an die Stelle des Lichtes in der Vorstellung den ihm vertrauteren Schall treten läßt, - erscheint ihm das Licht vielfach als ein Bekanntes, jedoch als ein doppelt Fremdes in Bezug auf die Polarisation, welche den ihm allein bekannten longitudinalen Schallwellen fehlt. So vermag er die Tatsache der Polarisation, die ihm vor Augen liegt, nicht begrifflich zu fassen, während NewtoN, seine Gedanken einfach der Beobachtung anpassend, die Frage stellt: „Annon radionum hminis diversa sunt latera " mit welcher die Polarisation ein Jahrhundert vor Malus begrifflich gefaßt oder direkt beschrieben ist. - 
Reicht hingegen die Übereinstimmung zwischen einer Tatsache und der dieselbe theoretisch vertretenden we it er als der Theoretiker anfänglich voraussetzte, so kann er hierdurch zu unerwarteten Entdeckungen geführt werden, wofür die konische Refraktion, die Cirkularpolarisation durch Totalreflexion, die HerTzschen Schwingungen naheliegende Beispiele liefern, welche $z u$ den obigen im Gegensatz stehen.

Vielleicht gewinnen wir noch an Einblick in diese Verhältnisse, wenn wir die Entwicklung einer oder der andern Theorie mehr im einzelnen verfolgen. Betrachten wir ein magnetisches Stahlstück neben einem sonst gleich beschaffènen unmagnetischen. Während letzteres sich gegen Eisenfeile gleichgiltig verhält, zieht ersteres dieselbe an. Auch wenn die Eisenfeile $\mathrm{n}$ ich $\mathrm{t}$ vorhanden ist, müssen wir uns das magnetische Stück in einem andern Zustand denken, als das unmagnetische. Denn daß das bloße Hinzubringen der Eisenfeile nicht die Erscheinung der Anziehung bedingt, zeigt ja das andere unmagnetische Stück. Der naive Mensch, dem sich zur Vergleichung sein eigener Wille als bekannteste Kraftquelle darbietet, denkt sich in dem Magnet eine Art Geist. Das Verhalten eines heiBen oder eines elektrischen Körpers legt ähnliche Gedanken nahe. Dies ist der Standpunkt der ältesten Theorie, des F e t is c h is m us, den die Forscher des fruhen Mittelalters noch nicht überwunden hatten, und der mit seinen letzten Spuren; mit der Vorstellung von den Kräften, noch in unsere heutige Physik herüberragt. Das dramatische Element braucht also, wie wir sehen, 
in einer naturwissenschaftlichen Beschreibung eben so wenig zu fehlen, wie in einem spannenden Roman.

Wird bei weiterer Beobachtung etwa bemerkt, daß ein kalter Körper an einem heißen sich sozusagen a u f K o ste $n$ des letzteren erwärmt, daß ferner bei gleichartigen Körpern der kältere, etwa von doppelter Masse, nur halb soviel Temperaturgrade gewinnt, als der heißere von einfacher Masse verliert, so entsteht ein ganz neuer Eindruck. Der dämonische Charakter der Tatsache verschwindet, denn der vermeintliche Geist wirkt nicht nach Willkür, sondern nach festen Gesetzen. Dafür tritt aber instinktiv der Eindruck eines Stoffes hervor, der teilweise aus dem einen Körper in den andern überfließt, dessen Gesa m t . menge aber, darstellbar durch die Summe der Produkte der Massen und der zugehörigen Temperaturänderungen, konstant bleibt. BLACK ist zuerst von dieser Ähnlichkeit des Wärmevorganges mit einer Stoffbewegung $\mathfrak{i}$ ber wältigt worden, und hat unter Leitung derselben die spezifische Wärme, die Verflüssigungs- und Verdampfungswärme entdeckt. Allein durch diese Erfolge gestärkt, ist nun die Stoffvorstellung dem weiteren Fortschritt hemmend in den Weg getreten. Sie hat die Nachfolger Blacks geblendet und verhindert, die durch Anwendung des Feuerbohrers längst bekannte, offenkundige Tatsache zu sehen, daß Wärme durch Reibung e r ze ug $\mathrm{t}$ wird. Wie fruchtbar die Vorstellung für BLACK war, ein wie hilfreiches Bild sie auch heute noch jedem Lernenden auf dem BLAckschen Spezialgebiet ist, bleibende und allgemeine Giltigkeit als $\mathrm{T}$ he or ie konnte sie nicht in Anspruch nehmen. Das begrifilich 
Wesentliche derselben aber, die Konstanz der erwähnten Produktensumme, behält seinen Wert, und kann als d i r e k t e B e sch r eibung der BLAckschen 'Tatsachen angesehen werden.

Es ist eine natürliche Sache, daß jene Theorien, welche sich ganz ungesucht von selbst, sozusagen instinktiv, aufdrängen, am mächtigsten wirken, die Gedanken mit sich fortreißen und die stärkste Selbsterhaltung zeigen.*) Anderseits kann man auch beobachten, wie sehr dieselben an Kraft verlieren, sobald sie kritisch. durchschaut werden. Mit Stoff haben wir unausgesetzt zu tun, dessen Verhalten hat sich unserem Denken fest eingeprägt, unsere lebhaftesten anschaulichsten Erinnerungen knüpfen sich an denselben. So darf es uns nicht allzusehr wundern, daß Robert Mayer und Joule, welche die Blacksche Stoffvorstellung endgiltig vernichtet haben, dieselbe Stoffvorstellung in abstrakterer Form und modifiziert auf einem viel umfassenderen Gebiet wieder einführen.

Auch hier liegen die psychologischen Unstände klar vor uns, welche der neuen Vorstellung ihre Gewalt gegeben haben. Durch die auffallende Röte des venösen Blutes im tropischen Klima wird MAYER aufmerksam auf die geringere Ausgabe an Eigenwärme und den entsprechend geringeren $\mathrm{S}$ t of $\mathrm{fv}$ e r b r a u c h des Menschenleibes in diesem Klima. Allein da jede Leistung des Menschenleibes, auch die mechanische Arbeit, an Stoffverbrauch gebunden ist, und Arbeit durch Reibung Wärme entwickeln kann, so erscheinen Wärme und Arbeit als gle ichartig, und zwischen beiden muß eine Proportionalbeziehung be-

*) Vgl. V, S. 74 und XIV, S. 256. 
stehen. Zwar nicht jede einzelne Post, aber die passend gezählte Summe beider, als an einen proportionalen Stoffverbrauch gebunden, erscheint selbst substanziell.

Durch ganz analoge Betrachtungen, die an die Ökonomie des galvanischen Elementes anknüpfen, ist Joule zu seiner Auffassung gekommen; er findet auf experimentellem Wege die Summe der Stromwärme, der Verbrennungswärme des entwickelten Knallgases, der passend gezählten elektromagnetischen Stromarbeit, kurz aller Batterieleistungen an die proportionale Zinkkosumtion gebunden. Demnach hat diese Summe selbst substanziellen Charakter.

MAYER wurde von der gewonnenen Ansicht so ergriffen, daß ihm die Unzerstörbarkeit der $\mathrm{Kraft}$, nach . unserer Terminologie der Arbeit, a priori einleuchtend schien. „Die Erschaffung und die Vernichtung einer Kraft - sagt er - liegt außer dem Bereich menschlichen Denkens und Wirkens." Auch Joule äußert sich ähnlich und meint: „Es ist offenbar absurd, anzunehmen, daß die Kräfte, welche Gott der Materie verliehen hat, eher zerstört als geschaffen werden könnten." Man hat auf Grund solcher Äußerungen merkwïrdiger Weise zwar nicht JouLE, wohl aber Mayer zu einem Metaphysiker gestempelt. Wir können aber dessen wohl sicher sein, daß beide Männer halb unbewußt nur dem starken formalen Bedürfnis nach der neuen einfachen Auffassung Ausdruck gegeben haben, und daß beide recht betroffen gewesen wären, wenn man ihnen vorgeschlagen hätte, etwa durch einen Philosophenkongreß oder eine kirchliche Synode über die $\mathrm{Zu}$ lässigkeit ihres Prinzipes entscheiden zu, lassen. Diese 
beiden Männer verhielten sich übrigens bei aller Übereinstimmung höchst verschieden. Während MAYER das formale Bedürfnis mit der größten instinktiven Gewalt des Genies, man möchte sagen mit einer Art von Fanatismus, vertritt, wobei ihm auch die begriffliche $\mathrm{Kraft}$ nicht fehlt, vor allen anderen Forschern das mechanische Äquivalent der Wärme aus längst bekannten, allgemein zur Verfügung stehenden Zahlen zu berechnen und ein die ganze Physik und Physiologie umfassendes Programm für die neue Lehre aufzustellen, wendet sich JoulE der eingehenden Begründung derselben durch wunderbar angelegte und meisterhaft ausgeführte Experimente auf allen Gebieten der Physik-zu. Bald nimmt auch Helmholtz in seiner ganz selbständigen und eigenartigen Weise die Frage in Angriff. Nächst der fachlichen Virtuosität, mit welcher dieser alle noch unerledigten Punkte des Mayerschen Programms und noch andere Aufgaben zu bewältigen weiß, tritt uns hier die volle kritische Klarheit des 26 jährigen Mannes überraschend entgegen. Seiner Darstellung fehlt das Ungestüm, der Impetus der MaYerschen. Ihm ist das Prinzip der Energieerhaltung kein a priori einleuchtender Satz. Was folgt, wenn er besteht? In dieser hypothetischen Frageform bewältigt er seinen Stoff.

Ich muß gestehen, ich habe immer den ästhetischen und ethischen Geschmack mancher unserer Zeitgenossen bewundert, welche aus diesem Verhältnisse gehässige nationale und personale Fragen zu schmieden wuBten, anstatt das Glück zu preisen, das mehrere solche Menschen zugleich wirken ließ, und anstatt sich 
an der so lehrreichen und für uns so fruchtbringenden Verschiedenheit bedeutender intellektueller Individualitäten zu erfreuen.

Wir wissen, daß bei Entwicklung des Energieprinzipes nocl eine theoretische Vorstellung wirksam war, von der sich MAyER allerdings ganz frei zu halten wußte, nämlich die, daß die Wärme und auch die übrigen physikalischen Vorgänge auf Bewegung beruhen. Ist einmal das Energieprinzip gefunden, so spielen diese Hilfs- und Durchgangstheorien keine wesentliche Rolle mehr, und wir können das Prinzip, sowie das Blacksche, als einen Beitrag zur direkten" Beschreibung eines umfassenden Gebietes von Tatsachen ansehen.

Es möchte nach diesen Betrachtungen nicht nur ratsam, sondern sogar geboten erscheinen, ohne bei der Forschung die wirksame Hilfe theoretischer Ideen zu verschmähen, doch in dem Maße, als man mit den neuen Tatsachen vertraut wird, allmählich an die Stelle der indirekten die direkte Beschreibung treten zu lassen, welche nichts Unwesentliches mehr enthält ınd sich lediglich auf die begriffliche Fassung der Tatsachen beschränkt. Fast muß man sagen, daß die mit einem gewissen Anflug von Herablassung so genannten beschreibenden Naturwissenschaften an Wissenschaftlichkeit die noch kürzlich sehr üblichen physikalischen Darstellungen überholt haben. Allerdings ist hier mitunter aus der Not eine Tugend geworden. 
Wir müssen zugestehen, daß wir außer stande sind, jede Tatsache sofort direkt zu beschreiben. Wir müßten vielmehr mutlos zusammensinken, würde uns der ganze Reichtum der Tatsachen, den wir nach und nach kennen lernen, a $\mathrm{f}$ e inmal geboten. Glücklicherweise fällt uns zunächst nur Vereinzeltes, Ungewöhnliches auf, welches wir, mit dem Alläglichen vergleichend, uns näher bringen. Hierbei entwickeln sich die Begriffe der gewöhnlichen Verkehrssprache. Mannigfaltiger und zahlدeicher werden dann die Vergleich unge n, umfassender die verglichenen Tatsachengebiete, entsprechend allgemeiner und abstrakter die gewonnenen Begriffe, welche die direkte Beschreibung ermöglichen.

Erst wird uns der freie Fall der Körper vertraut. Die Begriffe Kraft, Masse, Arbeit werden in geeigneter Modifikation auf die elektrischen und magnetischen Erscheinungen übertragen. Der W a s e r strom soll Fourier das erste anschauliche Bild für den Wärmestrom geliefert haben. Ein besonderer, von TAYLOR untersuchter Fall der Saitenschwingung erklärt ihm einen besonderen Fall der Wärmeleitung. Ähnlich wie DAN. BERnoulli und EULER die mannigfaltigsten Saitenschwingungen aus TAYrorschen Fällen, setzt Fourier die mannigfaltigsten Wärmebewegungen analog aus einfachen Leitungsfällen zusammen, und diese Methode verbreitet sich über die ganze Physik. Orm bildet seine Vorstellung vom elektris chen Strom jener FouriERs nach. Dieser schließt sich auch Ficks Theorie der Diffusion an. In analoger Weise entwickelt sich eine Vorstellung vom magnetischen Strom. Alle 
Arten von stationären Strömungen lassen nun gemeinsame Züge erkennen, und selbst der volle Gleichgewichtszustand in einem ausgedehnten Medium teilt diese Züge mit dem dynamischen Gleichgewichtszustand, der stationären Strömung. So weit abliegende Dinge wie die magnetischen Kraftlinien eines elektrischen Stromes und die Stromlinien eines reibungslosen Flüssigkeitswirbels treten dadurch in ein eigentümliches Ähnlichkeitsverhältnis. Der Begriff Potential, ursprünglich für ein engbegrenztes Gebiet aufgestellt, nimmt eine umfassende Anwendbarkeit an. An sich so unähnliche Dinge wie Druck, Temperatur, elektromotorische Kraft zeigen nun doch eine Übereinstimmung in ihrem Verhältnis zu den daraus in bestimmter Weise abgeleiteten Begriffen: Druckgefälle, Temperaturgefälle, Potentialgefälle und zu den ferneren: Flüssigkeits-, Wärme-, elektrische Stromstärke. Eine solche Beziehung von Begriffssystemen, in welcher sowohl die Unähnlichkeit je zweier homologer Begriffe als auch die Übereinstimmung in den logischen Verhältnissen je zweier homologer Begriffspaare zum klaren Bewußtsein kommt, pflegen wir eine Analogie zu nennen. Dieselbe ist ein wirksames Mittel, heterogene Tatsachengebiete durch einheitliche Auffassung zu bewältigen. Es zeigt sich hier deutlich der Weg, auf dem sich eine allge me in e, alle Gebiete umfassende $\mathrm{phy}$ i k a lis che $\mathrm{Phänomen} \mathrm{ologie}$ entwickeln wird.

Bei dem geschilderten Vorgang gewinnen wir nun erst dasjenige, was zur direkten Beschreibung großer Tatsachengebiete unentbehrlich ist, den weitreichenden $a b$ strakten Begriff. Und da muß ich mir die schul- 
meisterliche, aber unerläßliche Frage erlauben: Was ist ein Begriff? Ist derselbe eine verschwommene, aber doch immer noch anschauliche Vorstellung? Nein! Nur in den einfachsten Fällen wird sich diese als Begleiterscheinung einstellen. Man denke etwa an den Begriff, "Se lbst ind uktionsk o effi ze n t" und suche nach der anschaulichen Vorstellung. Oder ist der Begriff etwa ein bloßes Wort? Die Annahme dieses verzweifelten Gedankens, der kürzlich von geachteter mathematischer Seite ${ }^{*}$ ) wirklich geäußert worden ist, würde uns nur um ein Jahrtausend zurück in die tiefste Scholastik stürzen. Wir müssen denselben also ablehnen.

Die Aufklärung liegt nahe. Wir -dürfen nicht denken, daß die Empfindung ein rein passiver Vorgang ist Die niedersten Organismen antworten auf dieselbe mit einer einfachen Reflexbewegung, indem sie die herankommende Beute verschlingen. Bei höheren Organismen findet der centripetale Rẹiz im Nervensystem Hemmungen und Förderungen, welche den centrifugalen Prozeß modifizieren. Bei noch höheren Organismen kann — bei Prüfung und Verfolgung der Beute - der berührte Prozeß eine ganze Reihe von Cirkelbewegungen durchlaufen, bevor derselbe zu einem relativen Stillstand gelangt. Auch unser Leben spielt sich in analogen Prozessen ab, und alles, was wir Wissenschaft nennen, können wir als Teile, als Zwischenglieder solcher Prozesse ansehen.

Es wird nun nicht mehr befremden, wenn ich sage:

\footnotetext{
क) Paul du Bois-Reymond, über die Grundlagen der Erkenntnis. Tübingen 1890, S. 80 .
} 
Die Definition eines Begriffes, und, falls sie geläufig ist, schon der Name des Begriffes, ist ein Impuls zu einer genau bestimmten, oft komplizierten, prüfenden, vergleichenden oder konstruierenden Tätigkeit, deren meist sinnliches Ergebn is ein Glied des Begriffsumfangs ist. Es kommt nicht darauf an, ob der Begriff nur die Aufmerksamkeit auf einen hestimmten Sinn (Gesicht) oder die Seite eines Sinnes (Farbe, Form) hinlenkt, oder eine umständliche Handlung auslöst, ferner auch nicht darauf, ob die 'lätigkeit (chemische, anatomische, mathematische Operation) muskulär, oder gar technisch, oder endlich nur in der Phantasie ausgeführt, oder gar nur angedeutet wird. Der Begriff ist für den Naturforscher, was die Note für den Klavierspieler. Der geübte Mathematiker oder Physiker liest eine Abhandlung so, wie der Musiker eine Partitur liest. So wie aber der Klavierspieler seine Finger einzeln und kombiniert erst bewegen lernen mub, um dann der Note fast unbewußt Folge zu leisten, so muß auch der Physiker und Mathematiker eine lange Lehrzeit durch. machen, bevor er die mannigfaltigen feinen Innervationen seiner Muskeln und seiner Phantasie, wenn ich so sagen darf, beherrscht. Wie oft führt der Anfänger in Mathematik oder Physik anderes, mehr oder weniger aus, als er soll, oder stellt sich anderes vor. Trifft er aber nach der nötigen Übung auf den „Selbstinduktions . koeffizienten", so weiß er sofort, was das Wort von ihm will. Wohlgeübte Tätigkeiten, die sich aus der Notwendigkeit der Vergleichung und Darstellung der Tatsachen durch einander ergeben haben, sind also der 
Kern der Begriffe. Will ja auch sowohl die positive wie die philosophische Sprachforschung gefunden haben, daß alle Wurzeln durchaus Begriffe, und ursprünglich durchaus nur muskuläre Tätigkeiten bedeuten. Und nun wird uns auch die zögernde Zustimmung der Physiker zu KirchHOFfs Satz verständlich. Die konnten ja fühlen, was alles an Einzelarbeit, Einzeltheorie und Fertigkeit erworben sein muß, bevor das Ideal der direkten Beschreibung verwirklicht werden kann.

Es sei nun das Ideal für ein Tatsachengebiet erreicht. Leistet die Beschreibung alles, was der Forscher verlangen kann? Ich glaube ja! Die Beschreibung ist ein Aufbau der Tatsachen in Gedanken, welcher in den experimentellen Wissenschaften oft die Möglichkeit einer wirklichen Darstellung begründet. Für den Physiker insbesondere sind die Maßeinheiten die Bausteine, die Begriffe die Bauanweisung, die Tatsachen das Bauergebnis. Unser Gedankengebilde ist uns ein fast vollständiger Ersatz der Tatsache, an welchem wir alle Eigenschaften derselben ermitteln können. Nicht am schlechtesten kennen wir das, was wir selbst herzustellen wissen.

Man verlangt von der Wissenschaft, daß sie zu prophezeien verstehe, und auch Hertz gebraucht diesen Ausdruck in seiner nachgelassenen Mechanik. Der Ausdruck, obgleich naheliegend, ist jedoch zu eng. Der Geologe, Paläontologe, zuweilen der Astronom, immer der Historiker, Kulturforscher, Sprachforscher prophezeien, sozusagen, nach rückwärts. Die deskriptiven Wissenschaften, 
ebenso wie die Geometrie, die Mathematik prophezeien nicht vor- und nicht rückwärts, sondern suchen zu den Bedingungen das Bedingte. Sagen wir lieber: Die Wissenschaft hat teilweise vorliegende Tat. sachen in Gedanken zu ergänzen. Dies wird durch die Beschreibung ermöglicht, denn diese setzt Abhängigkeit der beschreibenden Elemente von einander voraus, da ja sonst nichts beschrieben wäre.

Man sagt, daß die Beschreibung das Kausalitätsbedürfnis unbefriedigt läßt. Wirklich glaubt man Bewegungen besser zu verstehen, wenn man sich die ziehenden $\mathrm{Kr}$ äfte vorstellt, und doch leisten die tatsächlichen $\mathrm{Be}$ schleunigungen mehr, ohne Überflüssiges einzuführen. Ich hoffe, daB die kïnftige Naturwissenschaft die Begriffe Ursache und Wirkung, die woll nicht für mich allein einen starken Zug von Fetischismus haben, ihrer formalen Unklarheit wegen beseitigen wird. Es empfiehlt sich vielmehr, die begrifflichen Bestimmungselemente einer Tatsacheals abhängig von einander anzusehen, einfach in dem rein logischen Sinne, wie dies der Mathematiker, etwa der Geometer, tut. Die Kräfte treten uns ja durch Vergleich mit dem Willen näher; vielleicht wird aber der Wille noch klarer durch den Vergleich mit der Massenbeschleunigung.

Fragen wir uns aufs Gewissen, wann uns eine Tatsache klar ist, so müssen wir sagen, dann, wenn wir dieselbe durch recht e in fa che, uns geläufige Gedankenoperationen, etwa Bildung von Beschleunigungen, geometrische Summation derselben u. s. w., nachbilden können. Diese An- 
forderung an die Einfachheit ist selbstredend für den Sachkundigen eine andere, als für den Anfänger. Ersterem genügt die Beschreibung durch ein System von Differentialgleichungen, während letzterer den allmählichen Aufbau aus Elementargesetzen fordert. Ersterer durchschaut sofort den Zusammenhang beider Darstellungen. Es soll natürlich nicht in Abrede gestellt werden, daB, sozusagen, der künstlerische Wert sachlich gleichwertiger Beschreibungen ein sehr verschiedener sein kann.

Am schwersten werden Fernerstehende zu überzeugen sein, daß die großen allgemeinen Gesetze der Physik für beliebige Massensysteme, elektrische, magnetische Systeme u. s. w. ron Beschreibungen nicht wesentlich verschieden seien. Die Physik befindet sich da vielen Wissenschaften gegenüber in einem leicht darzulegenden Vorteil. Wenn z. B. ein Anatom, die ïbereinstimmenden und unterscheidenden Merkmale der Tiere aufsuchend, zu einer immer feineren und feineren Klassifikation gelangt, so sind die einzelnen Tatsachen, welche die letzten Glieder des Systems darstellen, doch so verschieden, $\mathrm{da} ß$ dieselben einzeln gemerkt werden müssen. Man denke z. B. an die gemeinsamen Merkmale der Wirbeltiere, die Klassencharaktere der Säuger und Vögel einerseits, der Fische anderseits, an den doppelten Blutkreislauf einerșeits, den einfachen anderseits. Es bleiben schließlich immer isolierte Tatsachen übrig, die unter einander nur eine gering e Ähnlichkeit aufweisen.

Eine der Physik viel verwandtere Wissenschaft, die Chemie, befindet sich oft in einer ähnlichen Lage. Die 
sprungweise Änderung der qualitativen Eigenschaften, die vielleicht durch die geringe Stabilität der Zwischenzustände bedingt ist, die geringe Ähnlichkeit der koordinierten Tatsachen der Chemie, erschweren die Behandlung. Körperpaare von verschiedenen qualitativen Eigenschaften verbinden sich in verschiedenen Massenverhältnissen; ein $\mathrm{Zu}-$ sammenhang zwischen ersteren und letzteren ist aber zunächst nicht wahrzunehmen.

Die Physik hingegen zeigt uns ganz große Gebiete qualitativ gleichartiger Tatsachen, die sich nur durch die Zahl der gleichen Teile, in welche deren Merkmale zerlegbar sind, also nur qua n tit a tiv unterscheiden. Auch wo wir mit Qualitäten (Farben und Tönen) zu tun haben, stehen uns quantitative Merkmale derselben zur Verfügung. Hier ist die Klassifikation eine so einfache Aufgabe, daß sie als solche meist gar nicht zum Bewußtsein kommt, und selbst bei unendlich feinen Abstufungen, bei einem Kontinuum von Tatsachen, liegt das Zahlensystem im voraus bereit, beliebig weit zu folgen. Die koordinierten Tatsachen sind hier sehr ähnlich und verwandt, ebenso deren Beschreibungen, welche in einer Bestimmung der Maßzahlen gewisser Merkmale durch jene anderer Merkmale mittels geläufiger Rechnungsoperationen, d. i. Ableitungsprozesse bestehen. Hier kann also das Gemeinsame aller Beschreibungen gefunden, damit eine zusammenfassende Beschreibung oder eine Herstellungsregel für alle Einzelbeschreibungen angegeben werden, die wir eben das Geset $z$ nennen. Allgemein bekannte Beispiele sind die Formeln für den 
freien Fall, den Wurf, die Centralbewegung u. s. w. Leistet also die Physik mit ihren Methoden scheinbar so viel mehr, als andere Wissenschaften, so müssen wir anderseits bedenken, daß dieselbe in gewissem Sinne auch weitaus einfachere Aufgaben vorfindet.

Die úbrigen Wissenschaften, deren Tatsachen ja auch eine physikalische Seite darbieten, werden die Physik um diese günstigere Stellung nicht zu beneiden haben, denn deren ganzer Erwerb kommt schließlich ihnen wieder zu gut. Aber auch auf andere Weise kann und soll sich dieses Leistungsverhältnis ändern. Die Chemie hat es ganz wohl verstanden, sich der Methoden der Physik in ihrer Art zu bemächtigen. Von älteren Versuchen abgesehen, sind die periodischen Reihen von L. MEyer und MendelejefF ein geniales und erfolgreiches Mittel, ein übersichtliches System von Tatsachen herzustellen, welches, sich allmählich vervollständigend, fast ein $\mathrm{K}$ ont in u u m von Tatsachen ersetzen wird. Und durch das Studium der Lösungen, der Dissoziation, überhaupt der Vorgänge, welche wirklich ein Kontinuum von Fällen darbieten, haben die Methoden der Thermodynamik Eingang in die Chemie gefunden. So dürfen wir auch hoffen, daß vielleicht einmal ein Mathematiker, welcher das Tatsachenkontinuum der Embryologie auf sich wirken läßt, dem die Paläontologen der Zukunft vielleicht mehr Schaltformen und Abzweigungsformen zwischen dem Saurier der Vorwelt und dem Vogel der Gegenwart vorführen können, als dies jetzt mit dem vereinzelten Pterodaktylus, Archaeopteryx, Ichthyornis u.s.w. geschieht, daß dieser uns durch Variation einiger Parameter 
wie in einem flüssigen Nebelbild die eine Form in die andere überführt, so wie wir einen Kegelschnitt in den andern umwandeln.*)

Denken wir nun an KIRChноFfs Worte zurück, so werden wir uns über deren Bedeutung leicht verständigen. Gebaut kann nicht werden ohne Bausteine, Mörtel, Gerüst und Baufertigkeit. Doch aber ist der Wunsch wohlbegründet, den fertigen, nun auf sich beruhenden Bau dem künftigen Geschlecht ohne Verunstaltung durch das Gerüst zu zeigen. Es ist der reine logisch-ästhetische Sinn des Mathematikers, der aus KIRCHHOFF spricht. Seinem Ideal streben neuere Darstellungen der Physik wirklich zu, und dasselbe ist auch uns verständlich. Ein schlechtes didaktisches Kunststïck aber wäre es allerdings, wollte man Baumeister bilden, indem man sagt: Sieh hier ẹinen Prachtbau, willst du auch bauen, so gehe hin, und tue desgleichen.

Die Schranken zwischen Fach und Fach, welche Arbeitsteilung und Vertiefung ermöglichen, und die uns doch so frostig und philisterhaft anmuten, werden allmählich schwinden. Brücke auf Brücke wird geschlagen. Inhalt und Methoden selbst der abliegendsten Fächer treten in Vergleichung. Wenn nach roo Jahren die Naturforscherversammlung einmal tagt, dürfen wir erwarten, daß sic in

\#) [Dieser Mathematiker hat sich recht bald in der Person des genialen, weit über sein Fach ausblickenden Astronomen Schiaparelli gefunden. Vgl. J. V. Schiaparelli, Studio comparativo tra le forme organiche uaturali e le forme geometriche pure. U. Hoepli. Milano 1898. - :902.] 
höherem Sinne als heute eine Einheit darstellen wird, nicht nur der Gesinnung und dem Ziele, sondern auch der Methode nach. Fördernd für diese Wandlung muß es aber sein, wenn wir uns die innere Verwandt. schaft aller Forschung gegenwärtig halten, welche KIRCHнOFF mit so klassischer Einfachheit zu bezeichnen wuBte. 
XVI.

\section{Über den Einfluis zufälliger Umstände auf die Entwicklung von Erfindungen und Entdeckungen. ${ }^{*}$ )}

Den naiven hoffnungsfrohen Anfängen des Denkens jugendlicher Völker und Menschen ist es eigentümlich, daß beim ersten Schein des Gelingens alle Probleme für lösbar und an der Wurzel faßbar gehalten werden. So glaubt der Weise von Milet, indem er die Pflanze dem Feuchten entkeimen sieht, die ganze Natur verstanden $z u$ haben; so meint auch der Denker von Samos, weil bestimmte Zahlen den Längen harmonischer Saiten entsprechen, mit den Zahlen das Wesen der Welt erschöpfen zu können. Philosophie und Wissenschaft sind in dieser Zeit nur Eins. Reichere Erfahrung deckt aber bald die Irrtümer auf, erzeugt die Kritik, und führt zur 'Teilung, Verzweigung der Wissenschaft.

Da nun aber gleichwohl eine allgemeine Umschau in der Welt dem Menschen Bedürfnis bleibt, so trennt sich, demselben zu entsprechen, die Philosophie von der Spezial-

*) Rede gehalten bei Übernahme der Professur für Philosophie (Ge. schichte und Theorie der induktiven Wissenschaft) an der Universität Wien am 21. Oktober 1895 . 
forschung. Noch öfter finden wir zwar beide in einer gewaltigen Persönlichkeit wie Descartes oder LeIBNIz vereinigt. Weiter und weiter gehen aber deren Wege im allgemeinen auseinander. Und kann sich zeitweilig die Philosophie so weit der Spezialforschung entfremden, daß sie meint, aus bloßen Kinderstubenerfahrungen die Welt aufbauen zu dürfen, so hält dagegen der Spezialforscher den Knoten des Welträtsels für lösbar von der einzigen Schlinge aus, vor der er steht, und die er in riesiger perspektivischer Vergrößerung vor sich sieht. Er hält jede weitere Umschau für umöglich oder gar für überflüssig, nicht eingedenk des VoLTAIREschen Wortes, das hier mehr als irgendwo zutrifft: "Le superflu-chose très nécessaire". Wahr ist $\mathrm{ja}$, daß wegen Unzulänglichkeit der Bausteine die Geschichte der Philosophie größtenteils eine Geschichte des Irrtums darstellt, und darstellen muß. Nicht undankbar aber sollen wir vergessen, daß die Keime der Gedanken, welche die Spezialforschung heute noch durchleuchten, wie die Lehre vom Irrationalen, die Erhaltungsideen, die Entwicklungslehre, die Idee der spezifischen Energien u. a. sich in weit entlegene Zeiten auf philosophische Quellen zurückverfolgen lassen. Es ist auch gar nicht gleichgiltig, ob ein Mensch den Versuch der Orientierung in der Welt mit Erkennt $\mathrm{n}$ is der Unzulänglichkeit der Mittel aufgeschoben, aufgegeben, oder ob er denselben gar nie unternommen hat. Diese Unterlassung rächt sich ja dadurch, daß der Spezialist auf seinem engern Gebiet in dieselben Fehler wieder verfällt, welche die Philosophie längt als solche erkannt hat. 
So finden wir wirklich in der Physik und Physiologie namentlich der ersten Hälfte unseres Jahrhunderts Gedankengebilde, welche an naiver Ungeniertheit jenen der Jonischen Schule, oder den Platonischen Ideen, oder dem berüchtigten ontologischen Beweis u. a. auf ein Haar gleichen.

Dies Verhältnis scheint sich nun allmählich doch ändern zu wollen. Hat sich die heutige Philosophie bescheidenere erreichbare Ziele gesetzt, steht sie der Spezialforschung nicht mehr abhold gegenüber, nimmt sie sogar eifrig an derselben Teil, so sind anderseits die Spezialwissenschaften, Mathematik und Physik nicht minder als die historischen, die Sprachwissenschaften sehr philosophisch geworden. Der vorgefundene Stoff wird nicht mehr kritiklos hingenommen; man sieht sich nach den Nachbargebieten um, aus welchen derselbe herrührt. Die einzelnen Spezialgebiete streben nach gegenseitigem Anschluß. So bricht sich allmählich auch unter den Philosophen die Überzeugung Bahn, daß alle Philosophie nur in einer gegenseitigen kritischen Ergänzung, Durchdringung und Vereinigung der Spezialwissenschaften zu einem einheitlichen Ganzen bestehen kann. Wie das Blut, den Leib zu nähren, sich in zahllose Kapillaren teilt, um dann aber doch wieder im Herzen sich zu sammeln, so wird auch in der Wissenschaft der Zukunft alles Wissen in einen einheitlichen Strom mehr und mehr zusammenfließen.

Diese der heutigen Generation nicht mehr fremde Auffassung denke ich zu vertreten. Hoffen Sie also nicht, oder furrchten Sie nicht, daß ich Systeme vor Ihnen bauen

Mach, Vorlesungen. 3. Auf.

Digitized by Microsoft ${ }^{B}$ 
werde. Ich bleibe Naturforscher. Erwarten Sie aber auch nicht, daß ich auch nur alle Gebiete der Naturforschung durchstreife. Nur auf dem mir vertrauten Gebiet kann ich ja versuchen, Führer zu sein, und nur da kann ich einen kleinen Teil der bezeichneten Arbeit fördern helfen. Wenn es mir gelingt, Ihnen die Beziehungen der Physik, Psychologie und Erkenntniskritik so nahe zu legen, daß Sie aus jedem dieser Gebiete für jedes Nutzen und $\mathrm{Zu}$ wachs an Klarheit gewinnen, werde ich meine Arbeit für keine vergebliche halten. Um aber an einem Beispiel zu zeigen, wie ich mir solche Untersuchungen meinen Vorstellungen und Kräften ${ }^{-}$gemäß geführt denke, bespreche icl heute, natürlich nur in Form einer Skizze, einen besondèren begrenzten Stoff: Den EinfluB zufälliger Umstände auf die Entwickelung von Erfindungen und Entdeckungen.

Wenn man von einem Menschen sagt, er habe das Pulver nicht erfunden, meint man damit seine Fähigkeiten in eine recht ungünstige Beleuchtung zu stellen. Der Ausdruck ist kaum glücklich gewählt, da wohl an keiner Erfindung das vorsorgliche Denken einen geringeren, und der glückliche Zufall einen größeren Anteil gehabt haben mag, als gerade an dieser. Dürfen wir aber die Leistung eines Erfinders überhaupt unterschätzen, weil ihm der $\mathrm{Zu}$ fall behilflich war? Huxgens, der so viel entdeckt und erfunden hat, daß wir ihm wohl ein Urteil in diesen Dingen zutrauen können, weist dem Zufall eine gewichtige Rolle $z u$, indem er sagt, daß er den für einen übermenschlichen Genius halten müßte, welcher das 
Fernrohr ohne Begünstigung durch den Zufall erfunden hatte. *)

Der mitten in die Kultur gestellte Mensch findet sich von einer Menge der wunderbarsten Erfindungen umgeben, wenn er nur die Mittel der Befriedigung der alltäglichen Bedürfnisse beachtet. Versetzt er sich in die Zeit vor Erfindung dieser Mittel, und versucht er deren Entstehung ernstlich zu begreifen, so müssen ihm die Geisteskräfte der Vorfahren, welche solches geschaffen haben, zunächst als unglaublich große, der antiken Sage gemäß als fast göttliche erscheinen. Sein Erstaunen wird aber beträchtlich gedämpft durch die ernüchternden, aufklärenden und die Vorzeit doch so poetisch durchleuchtenden Enthüllungen der Kulturforschung, welche vielfach nachzuweisen vermag, wie langsam, in wie unscheinbaren kleinen Schritten, jene Erfindungen entstanden sind.

Eine kleine Vertiefung im Boden, in welcher Feuer angemacht wird, ist der ursprüngliche Ofen. Das Fleisch des erlegten Tieres, mit Wasser in dessen Haut getan, wird durch eingelegte erhitzte Steine gekocht. Auch in Holzgefäßen wird dieses Steinkochen geübt. Ausgehöhlte Kürbisse werden durch Tonüberzug vor dem Verbrennen geschützt. So entsteht zufällig aus gebranntem Ton der umschließende Topf, welcher den Kürbis selbst überflüssig macht, der aber noch lange über den Kürbis, oder in ein Korbgeflecht hinein geformt wird, bevor die Töpfer-

") "Quod si quis tanta industria exstitisset, ut ex naturae principiis et geometria hanc rem eruere potuisset, eum ego supra mortalium sortem ingenio valuisse dicendum crederem. Sed hoc tantum abest, ut fortuito reperti artificii rationem non adhuc satis explicari potuerint viri doctissimi." Hugenii Dioptrica (de telescopiis). 
kunst endlich selbständig auftritt. Auch dann behält sie noch, gewissermaßen als Ursprungszeugnis, das geflecht-ähnliche Ornament bei. So lernt also der Mensch durch zufällige, d. h. außer seiner Absicht, Voraussicht und Macht liegende Umstände, allmählich vorteilhaftere Wege zur Befriedigung seiner Bedürfnisse kennen. Wie hätte auch ein Mensch ohne Hilfe des Zufalls voraussehen sollen, daß Ton, in der üblichen Weise behandelt, ein brauchbares Kochgefäß liefern würde ?

Die meisten der in die Kulturanfänge fallenden Erfindungen - Sprache, Schrift, Geld u. a. eingeschlossen - konnten schon deshalb nicht Ergebnis absichtlichen planmäßigen Nachdenkens sein, weil man von deren Wert und Bedeutung eben erst durch den Gebrauch eine Vorstellung gewinnen konnte. Die Erfindung der Brücke mag durch einen quer über den Gießbach gestürzten Baumstamm, jene des Werkzeugs durch einen beim Aufschlagen von Früchten zufällig in die Hand geratenen Stein eingeleitet worden sein. Auch der Gebrauch des Feuers wird wohl dort begonnen und von dort aus sich verbreitet haben, wo Vulkanausbrüche, heiße Quellen, brennende Gasausströmungen, Blitzschläge Gelegenheit boten, dessen Eigenschaften in ruhiger Beobachtung kennen und benuitzen zu lernen. Nun erst konnte der etwa beim Durchbohren eines Holzstückes gefundene Feuerbohrer in seiner Bedeutung als Zündvorrichtung gewürdigt werdèn. Phantastisch und unglaublich klingt ja die von einem großen Forscher geäußerte Ansicht, welche die Erfindung des Feuerbohrers durch eine religiöse Ceremonie entstehen läßt. Und so wenig werden wir von der Erfindung des Feuerbohrers 
erst den Gebrauch des Feuers ableiten wollen, wie etwa von der Erfindung der Zündhölzchen. Denn sicherlich entspricht nur der umgekehrte Weg der Wahrheit.**)

Ähnliche zum Teil noch in tiefes Dunkel gehüllte Vorgänge begründen den Übergang der Völker vom Jäger- zum Nomadenleben und zum Ackerbau.**) Wir wollen die Beispiele nicht häufen und nur noch bemerken, daß dieselben Erscheinungen in der historischen Zeit, in der Zeit der großen technischen Erfindungen wiederkehren, und daß auch über diese teilweise recht abenteuerliche Vorstellungen verbreitet sind, welche dem $\mathrm{Zu}$ fall einen ungebührlich übertriebenen, psychologisch unmöglichen Einfluß einräumen. Die Beobachtung des aus dem Theckessel entweichenden, mit dem Deckel klappernden Dampfes soll zu Erfindung der Dampfmaschine geführt haben. Man denke an den Abstand zwischen diesem Schauspiel und der Vorstellung einer großen Kraftleistung des Dampfes für einen Menschen, der die Dampfmaschine eben noch nicht kennt! Wenn aber ein Ingenieur, der schon Pumpen gebaut hat, eine zum Trocknen erhitztc noch mit Dampf erfüllte Flasche zufällig mit der Mündung ins Wasser taucht, und nun dieses heftig in die Flasche

\#) Dies schliefst nicht aus, dafs der Feuerbohrer nachher bei der Verehrung des Feuers oder der Sonne eine Rolle gespielt hat. - [Ich freue mich, meine auf Grund ps y chölogis cher Erwägungen gefafsten Ansichten über diese Dinge in Übereinstimmung zu finden mit den Ausführungen von $\mathrm{K}$ von den Steinen (,Unter den Naturvölkern Central-Brasiliens." Berlin 1897. S. 214-2r8.) Derselbe nimmt etwa folgende Stufen an: $t$. Benützung des zufallig in der Natur vorgefundenen Feuers, 2. Pflege und Erhaltung desselben, 3. Verbreitung und Übertragung desselben (durch Brände und glimmenden $Z$ under), 4. Frfindung des Feuerbohrers bei $B$ eschaffung des $Z$ unders. - Das genannte Buch tritt auch manchen anderen Vorurteilen wirksam entgegen. - 1902].

w) Vergl. hierüber die höchst interessante Mitteilung von Carus, The philosophy of the tool. Chicago 1893 . 
hineinstürzend sich erhebt, dann liegt wohl der Gedanke recht nahe, auf diesen Vorgang eine bequeme vorteilhafte Dampfsaugpumpe zu gründen, welche sich in psychologisch möglichen, ja naheliegenden unscheinbaren kleinen Schritten allmählich in die WATTsche Dampfmaschine umwandelt.

Wenn nun auch dem Menschen die wichtigsten Erfindungen in von ihm unbeabsichtigter Weise durch den Zufall recht nahe gelegt werden, so kann doch der $\mathrm{Zu}-$ fall allein keine Erfindung zu stande bringen. Der Mensch verhält sich hierbei keineswegs untätig. Auch der erste Töpfer im Urwald muß etwas von einem Genius in sich fühlen. Er muß die neue Tatsache beachten, die für ihn vorteilhafte Seite derselben erschauen und erkennen, und verstehen, dieselbe als Mittel zu seinem Zweck zu verwenden. Er muß das Neue unterscheiden, seinem Gedächtnis, einfügen, mit seinem übrigen Denken verbinden und verweben. Kurz er muß die Fähigkeit haben, Erfahrungen zu machen.

Man könnte die Fähigkeit, Erfahrungen zu machen, geradezu als das Ma $B$ der Intelligenz ansehen. Dieselbe ist beträchtlich verschieden bei Menschen desselben Stammes und wächst gewaltig, wenn wir, bei den niederen Tieren beginnend, dem Menschen uns nähern. Erstere sind fast ganz auf ihre mit der Organisation ererbten Reflextätigkeiten angewiesen, individueller Erfahrungen fast ganz unfähig, und bei ihren einfachen Lebensbedingungen derselben auch kaum bedürftig. Die Reusenschnecke nähert sich immer wieder der fleischfressenden Aktinie, so oft sie auch mit Nesselfäden beworfen zusammenzuckt, 
als ob sie kein Gedächtnis für den Schmerz hätte.*) D i e se lb e Spinne läßt sich wiederholt durch Berührung des Netzes mit der schwingenden Stimmgabel hervorlocken; die Motte fliegt wieder der Flamme zu, an welcher sie sich schon verbrannt hat; der Taubenschwanz stößt unzähligemal gegen die gemalten Rosen der Tapetenwand, **) ähnlich dem bedauerlichen verzweifelten Denker, der dasselbe unlösbare Sche in problem immer wieder in derselben Weise angreift. Fast so planlos wie Maxwellsche Gasmoleküle und fast ebenso unvernünftig kommen die Fliegen angeflogen, und bleiben, dem Lichten und Freien zustrebend, an der Glastafel des halb geöffneten Fensters gefangen, indem sie den Weg um den schmalen Rahmen herum nicht zu finden vermögen. Der Hecht aber, der im Aquarium von Ellritzen durch eine Glastafel getrennt ist, merkt doch schon nach einigen. Monaten, nachdem er sich halb zu Tode gestoßen, daß er diese Fische nicht ungestraft angreifen darf. Er läßt sie nunmehr auch nach Entfernung der Scheidewand in Ruhe, verschlingt aber sofort jeden fremden neu eingebrachten Fisch. Schon den Zugvögeln müssen wir ein bedeutendes Gedächtnis zuschreiben, welches wahrscheinlich wegen Wegfalls störender Gedanken so präcis wirkt wie jenes mancher Cretins. Allgemein bekannt ist aber die Abrichtungsfähigkeit der höheren Wirbeltiere, in welcher sich deren Fähigkeit, Erfahrungen zu machen, deutlich ausspricht.

Ein stark entwickeltes mechanisches Gedächtnis,

\$) Möbius, Naturwiss. Verein f. Schleswig.Holstein. Kiel 1873 . S. 113 ff.

Die Beobachtung uber den Taubenschwanz verdanke ich Herrn Prof. Hatschek. 
welches dagewesene Situationen lebhaft und treu wiederholend ins Bewußtsein zurückruft, wird genügen, eine be stimmte besondere Gefahr zu vermeiden, eine bestimmte besondere günstige Gelegenheit zu benuitzen. Zur Entwicklung einer Erfindung wird dasselbe nicht ausreichen. Hierzu gehören längere Vorstellungsreihen, die Erregung verschiedener Vorstellungsreihen durcheinander, ein stärkerer, vielfacher mannigfaltiger Zusammenhang des gesamten Gedächtnisinhaltes, ein durch den Gebrauch gesteigertes mächtigeres und empfindlicheres psychisches Leben. Der Mensch kommt an einen unüberschreitbaren Gießbach, der ihm ein schweres Hemmnis ist. Er erinnert sich, daß er einen solchen auf einem umgestürzten Baum schon überschritten hat. In der Nähe sind Bäume. Umgestuirzte Bäume hat er schon bewegt. Er hat auch Bäume schon gefällt, und sie waren dann beweglich. Zur Fällung hat er scharfe Steine benutzt. Er sucht einen solchen Stein, und indem er die in Erinnerung gekommenen Situationen, welche sämtlich durch das eine starke Interesse der Überschreitung des Gießbaches lebendig gehalten werden, in umgekehrter Ordnung herbeiführt, erfindet er die Brücke.

$\mathrm{Da}$ die höheren Wirbeltiere in bescheidenem Maße ihr Verhalten den Umständen anpassen, ist nicht zweifelhaft. Wenn sie keinen merklichen Fortschritt durch Aufsammlung von Erfindungen zeigen, so erklärt sich dies hinreichend durch einen Grad-oder Intensitätsunterschied ihrer Intelligenz dem Menschen gegenüber; die Annahme eines Artunterschiedes ist NEwTons Forschungsprinzip 
gemäß unnötig. Wer nur einen minimalen Betrag täglich erspart, hat demjenigen gegenüber einen unabsehbaren Vorteil, der denselben Betrag täglich verliert, oder auch den gewonnenen nur nicht dauernd zu erhalten vermag. Ein kleiner quantitativer Unterschied erklärt hier einen gewaltigen Unterschied des Aufschwungs.

Dasselbe, was für die vorhistorische Zeit gilt, gilt auch für die historische, und was von der Erfindung gesagt wurde, läßt sich fast wörtlich in Bezug auf die Ent. deckung wiederholen; denn beide unterscheiden sich nur durch den Gebrauch, der von einer neuen Erkenntnis gemacht wird. Immer handelt es sich um den ne u erschaten Zusammenhang neuer oder schon bekannter sinnlicher oder begrifflicher Eigenschaften. Es findet sich z. B., daB ein Stoff, der eine chemische Re. aktion $A$ gibt, auch eine Reaktion $B$ auslöst; dient dieser Fund lediglich zur Förderung der Einsicht, zur Erlösung von einer intellektuellen Unbehaglichkeit, so liegt eine Entdeckung vor, eine Erfindung hingegen, wenn wir den Stoff von der Reaktion $A$ benützen, um die gewünschte Reaktion $B$ zu praktischen $Z$ wecken herbeizuführen, zur Befreiung von einer materiellen Unbehaglichkeit. Der Ausdruck „Ne ua uffindung des Zusammenhanges von Reaktionen" ist umfassend genug, um Entdeckungen und Frfindungen auf allen Gebieten zu charakterisieren. Derselbe umfaßt den Pytha. goreischen Satz, welcher dic Verbindung einer geometrischen mit einer arithmetischen Reaktion enthält, die Newtossche Entdeckung des Zusammenhanges der KEPLER- 
schen Bewegung mit dem verkehrt quadratischen Gesetz ebenso gut, wie das Auffinden einer kleinen Konstruktionsänderung an einem Werkzeug oder einer zweckdienlichen Manipulationsänderung in der Färberei.

Die Erschließung neuer, bislang unbekannter Tatsachengebiete kann nur durch z u fäll i g e Umstände herbeigeführt werden, unter welchen eben die gewöhnlich unbemerkten Tatsachen merkli ch werden. Die Leistung des Entdeckers liegt hier in der scharfen Aufmerksamkeit, welche das Ungewöhnliche des Vorkommnisses und der bedingenden Umstände schon in den S p u r en wahrnimmt, ${ }^{*}$ ) und die Wege erkennt, auf welchen man zur vollen Beobachtung gelangt.

Hierher gehören die ersten Wahrnehmungen über die elektrischen und magnetischen Erscheinungen, die Interferenzbeobachtung Grimaldis, ARAGos Bemerkung der stärkern Dämpfung der in einer Kupferhülse schwingenden Magnetnadel gegenüber jener in einer Pappschachtel, Foucaults Beobachtung der stabilen Schwingungsebene eines auf der Drehbank rotierenden zufällig angestoßenen Stabes, MAyERS Beachtung der Röte des venösen Blutes in den Tropen, KiRCHHOFfs Beobachtung der Verstärkung der D-Linie des Sonnenspektrums durch eine vorgesetzte Kochsalzlampe, ScHönbeins Entdeckung des Ozons durch den Phosphorgeruch beim Durchschlagen von elektrischen Funken durch die Luft u. a. m. Alle diese Tatsachen, von welchen viele gewiß oft gesehen wurden, bevor man sie beachtete, sind Beispiele der Einleitung folgenschwerer Entdeckungen durch zufällige Umstände,

*) Vgl. Hoppe, Entdecken und Finden. 1870. 
und setzen zugleich die Bedeutung der gespannten Aufmerksamkeit in ein helles Licht.

Aber nicht nur bei Einleitung, sondern auch bei Fortfiihrung einer Untersuchung können ohne die Absicht des Forschers mitwirkende Umstände sehr einflußreich werden. Dufax erkẻnnt so die Existens $\mathrm{zweier}$ elektrischer $\mathrm{Zu}$ stände, während er das Verhalten des einen von ihm vorausgesetzten verfolgt. Fresnel findet durch Zufall, daß die auf einem matten Glas abgefaßten Interferenzstreifen weit besser in der freien Luft zu sehen sind. Die Beugungserscheinung zweier Spalten fällt beträchtlich anders aus als FraUnHOFER erwartet, und er wird in Verfolgung dieses Umstandes zur Entdeckung der wichtigen Gitterspektren geführt. Die FARADAYsche Induktionserscheinung weicht wesentlich ab von der Ausgangsvorstellung, die seine Versuche veranlaßt hat, und gerade diese Abweichung stellt die eigentliche Entdeckung vor.

Jeder hat schon über irgend etwas nachgedacht. Jeder kann diese großen Beispiele durch kleinere selbsterlebte vermehren. Ich will statt vieler nur eines anführen. $\mathrm{Zu}$ fällig einmal beim Durchfahren einer Eisenbahnkurve bemerkte ich die bedeutende scheinbare Schiefstellung der Häuser und Bäume. Dies belehrte mich, daß die Richtung der totalen physikalischen Massenbeschleunigung physiologisch als Vertikale reagiert. Indem ich zunächst nur dies in einem großen Rotationsapparat genauer erproben wollte, fuihrten mich die Nebenerscheinungen auf die Empfindung der Winkelbeschleunigung, den Drehschwindel, die FLourensschen Versuche der Durchschneidung 
der Bogengänge u. a., woraus sich allmählich die alsbald auch von BREUER und Brows vertretenen Vorstellungen über Orientierungsempfindungen ergaben, die, erst so vielfach bestritten, jetzt so vielfach als richtig anerkannt werden, und welche noch in letzter Zeit durch BREUERs Untersuchungen über die „macula acustica“ und KREIDLS Versuche mit magnetisch orientierbaren Krebsen in so interessanter Weise bereichert worden sind. Nicht Mißa c htung des Zufalls, sondern $z$ we ckmäBige und zi el. bewußte Benützung desselben wird der Forschung förderlich sein.

Je stärker der psychische Zusammenhang der gesamten Erinnerungsbilder je nach Individuum und Stimmung, desto fruchtbringender kann dieselbe zufällige Beobachtung werden. Galiler kennt das Gewicht der Luft, er kennt auch die „Resistenz des Vacuums“, sowohl in Gewicht als auch in der Höhe einer Wassersäule ausgedrückt. Allein diese Gedanken bleiben in seinem Kopfe nebeneinander. Erst Torricelli variiert das spezifische Gewicht der druckmessenden Flussigkeit, und dadurch erst tritt die Luft selbst in die Reihe der drückenden Flüssigkeiten ein. Die Umkehrung der Spektrallinien ist vor KIRCHHOFF wiederholt gesehen und auch mechanisch erklärt worden. Die Spur des Zusammenhanges mit Wärmefragen hat aber nur sein feiner Geist bemerkt, und ihm allein enthüllt sich in ausdauernder Arbeit die weitreichende Bedeutung der Tatsache für das bewegliche Gleichgewicht der Wärme. Nächst dem schon vorhandenen vielfachen organischen Zusammenhang 
des gesamten Gedächtnisinhaltes, welcher den Forscher kennzeichnet, wird es vor allem das starke Interesse für ein bestimmtes Ziel, für eine Idee sein, welche die $\mathrm{n}$ o ch n i ch t geknüpften günstigen Gedankenverbindungen schlägt, indem jene Idee bei allem sich hervordrängt, was tagsiuber gesehen und gedacht wird, zu allem in Beziehung tritt. So findet BradLey, lebhaft mit der Aberration beschäftigt, deren Erklärung durch ein ganz unscheinbares Erlebnis beim Übersetzen der Themse. Wir dürfen also wohl fragen, ob der Zufall dem Forscher, oder der Forscher dem Zufall zu Erfolg verhilft?

Niemand denke daran, ein größeres Problem zu lösen, von dem er nicht so ganz erfüllt ist, daß alles andere für ihn Nebensache wird. Bei einer flüchtigen Begegnung Mayers mit Jolly zu Heidelberg äußert letzterer zweifelnd, daß ja das Wasser durch Schütteln sich erwärmen müßte, wenn MAYERS Ansicht richtig wäre. MAYER entfernt sich ohne ein Wort zu sagen. Nach mehreren Wochen tritt er, von Jolly nicht mehr erkannt, bei diesem ein mit den Worten: „Es ischt aso!“ Erst durch einige Wechselreden erfährt Jolly, was MAYER sagen will. Der Vorfall bedarf keiner weiteren Erläuterung. *)

Auch wer von sinnlichen Eindrücken abgeschlossen nur seinen Gedanken nachhängt, kann einer Vorstellung begegnen, welche sein ganzes Denken in neue Bahnen leitet. Ein psychischer Zufall war es dann, ein Gedankenerlebnis im Gegensatz zum physischen, dem er diese sozusagen am Nachbild der Welt auf deduk-

*) Nach einer mündlichen, brieflich wiederholten Mitteilung Jollys.

Digitized by Microsoft ${ }^{\circledR}$ 
tivem Wege gemachte Entdeckung, anstatt einer experimentellen, verdankt. Eine rein experimentelle Forschung gibt es übrigens nicht, denn wir experimentieren, wie Gauss sagt, eigentlich immer mit unsern Gedanken. Und gerade der stetige, berichtigende Wechsel, die innige Berührung von Experiment und Deduktion, wie sie Galilei in den Dialogen, Newron in der Optik pflegt und ïbt, begründet die glückliche Fruchtbarkeit der modernen Naturforschung gegenüber der antiken, in welcher feine Beobachtung und starkes Denken zuweilen fast wie zwei Fremde nebeneinander herschreiten.

Den Eintritt eines günstigen physischen Zufalls müssen wir abwarten. Der Verlauf unserer Gedanken unterliegt dem Associationsgesetz. Bei sehr armer Erfahrung würde dieses nur eine einfache Reproduktion bestimmter sinnlicher Erlebnisse zur Folge haben. Ist aber durch reiche Erfahrung das psychische Leben stark und vielseitig in Anspruch genommen worden, so ist jedes Vorstellungselement mit so vielen andern so verknüpft, daß der wirkliche Verlauf der Gedanken durch ganz geringe zufällig ausschlaggebende, oft kaum bemerkte Nebenumstände beeinflußt und bestimmt wird. Nun kann der ProzeB, den wir als Phantasie bezeichnen, seine vielgestaltigen Gebilde von endloser Mannigfaltigkeit zu Tage fördern. Was können wir aber tun, um diesen Prozeß zu leiten, da wir doch das Verknüpfungsgesetz, der Vorstellungen nicht in der Hand haben? Fragen wir lieber: Welchen Einfluß kann eine starke, immer wiederkehrende Vorstellung auf den Verlauf der übrigen nehmen? 
Die Antwort liegt nach dem Vorigen schon in der Frage. Die Idee beherrscht eben das Denken des Forschers, niclit umgekehrt.

Versuchen wir nun, in den Vorgang der Entdeckung noch etwas nähern Einblick zu gewinnen. Der Zustand des Entdeckers ist, wie W. JAMEs treffend bemerkt, nicht unähnlich der Situation desjenigen, der sich auf etwas Vergessenes zu besinnen sucht. Beide fühlen eine Lücke, kennen aber nur ungefähr die Natur des Vermißten. Treffe ich z. B. in Gesellschaft einen wollbekannten freund. lichen Mann, dessen Namen mir entfallen, der aber die schreckliche Forderung ausspricht, ihn irgendivo vorzustellen, so suche ich nach Lichtenbergs Anweisung im Alphabet zuerst den Anfangsbuchstaben des Namens. Eine eigentümliche Sympathie hält mich beim $G$ fest. Probeweise füge ich den nächsten Buchstaben hinzu, und blẹibe beim e. Bevor ich den dritten Buchstaben $r$ noch wirklich versucht habe, tönt schon der Name "Gerson" voll in mein Ohr, und ich bin von meiner Pein befreit. Bei einem Ausgang hatte ich eine Begegnung und erhielt eine Mitteilung. $\mathrm{Zu}$ Hause angelangt hatte ich über Wichtigerem alles vergessen. Mißmutig und vergebens sinne ich hin und her. Endlich merke ich, dab ich in Gedanken meinen Weg nochmals gehe. An der betreffenden Straßenecke steht der Mann wieder vor mir, und wiederholt seine Mitteilung. Hier treten also naclı und nach alle Vorstellungen ins Bewußtsein, welche mit der vermißten verbunden sein können, und ziehen schließlich diese selbst ans Licht. Besonders in dem ersten Fall ist 
- wenn die Erfahrung einmal gemacht ist, und als bleibender methodischer Gewinn dem Denken sich eingeprägt hat ein systematisches Verfahren leicht ausfihrbar, da man schon weiß, daß ein Name aus einer gegebenen begrenzten Zahl von Lauten bestehen muß. Zugleich sieht man aber, daß doch die Kombinationsarbeit ins Ungeheure wachsen würde, wenn der Name etwas länger, und die Stimmung für denselben nur mehr schwach wäre.

Nicht ohne Grund pflegt man zu sagen, der Forscher habe ein Rätsel gelöst. Jede geometrische Konstruktionsaufgabe läßt sich in die Rätselform kleiden: „Was ist das für ein Ding $M$, welches die Eigenschaften $A, B, C$ hat ?:i „Was ist das für ein Kreis, der die Geraden $A, B$ und letztere in einem Punkt $C$ berïhrt? " Die beiden ersten Bedingungen führen unserer Phantasie die Schar der Kreise vor, deren Mittelpunkte in den Symmetralen von $A, B$ liegen. Die dritte Bedingung erinnert uns an die Kreise mit den Mittelpunkten in der durch $C$ auf $B$ errichteten Senkrechten. Das gemeinsame Glied oder die gemeinsamen Glieder dieser Vorstellungsreihen lösen das Räts e1, erfüllen die Aufgabe. Ein beliebiges Sach- oder Worträtsel leitet einen ähnlichen Prozeß ein, nur wird die Erinnerung in vielen Richtungen in Anspruch genommen, und reichere, weniger klar geordnete Gebietc von Vorstellungen sind zu überschauen. Der Unterschied zwischen der Situation des konstruierenden Geometers und jener des Technikers oder Naturforschers, welcher vor einem Problem steht, ist nur der, daß ersterer sich auf einem vollkommen bekannten Gebiet bewegt, während

\section{Digitized by Microsoft ${ }^{\circledR}$}


letztere sich mit diesem weit über das geivöhnliche Maß hinaus erst näher vertraut machen müssen. Der Techniker verfolgt hierbei mit gegebenen Mitteln wenigstens noch ein bestimintes Ziel, während selbst letzteres dem Naturforscher zuweilen nur in allgemeinen Umrissen vorschweben kann. Oft hat er sogar das Rätsel erst zu formulieren. Oft ergiht sich erst mit der Erreichung des Ziels die vollständigere Übersicht, welche ein systematisches Vorgehen ermöglicht hätte. Hier bleibt also dem Glück und Instinkt viel mehr überlassen.

Unwesentlich ist es für den bezeichneten Prozeß, ob derselbe in einem Kopfe rasch abläuft, oder im Laufe der Jahrhunderte durch eine lange Reihe von Denkerleben sich fortspinnt. Wie das ein Rätsel lösende Wort zu diesem, verhält sich die heutige Vorstellung vom Licht $\mathrm{zu}$ den von Grimaldi, Römer, Huygens, Newton, Young, Malus und Fressel gefundenen Tatsachen, und erst mit Hilfe dieser allmählich entwickelten Vorstellung vermögen wir das große Gebiet besser zu durchblicken.

$\mathrm{Zu}$ den Aufklärungen, welche Kulturforschung und vergleichende Psychologie uns liefern, bilden die Mitteilungen großer Forscher und Künstler eine willkommene Ergänzung. Forscher und Künstler dürfen wir sagen, denn Johannes Múller und Liebig haben es mutig ausgesprochen, daß ein tiefgehender Unterschied zwischen dem Wirken beider nicht besteht. Sollen wir LEONaRdo DA VINCI für einen Forscher oder für einen Künstler halten? Baut der Künstler aus wenigen Motiven sein Werk auf, so hat der Forscher die Motive zu erschauen, 
welche die Wirklichkeit durchdringen. Ist ein Forscher wie LAGRANGE oder FOURIER gewissermaßen Künstler in der Darstellung seiner Ergebnisse, so ist ein Künstler wie SHAKEspeare oder Ruysdael Forscher in dem Schauen, welches seinem Schaffen vorhergehen muß.

NewToN, über seine Arbeitsmethode befragt, wußte nichts zu sagen, als da $B$ er oft und oft uiber dieselbe Sache nachgedacht habe; ähnlich äußern sich D'AlEmberT, Helmholtz u. a. - Forscher und Künstler empfehlen die ausdauernde Arbeit. Wenn nun bei diesem wiederholten Überschauen eines Gebietes, welches dem günstigen Zufall Gelegenheit schafft, alles zur Stiminung oder herrschenden Idee Passende lebhafter geworden, alles Unpassende allmählich so in den Schatten gedrängt worden ist, daß es sich nicht mehr hervorwagt, dann kann unter den Gebilden, welche die frei sich .selbst überlassene hallucinatorische Phantasie in reichem Strome hervorzaubert, plötzlich einmal dasjenige hell aufleuchten, welches der herrschenden Idee, Stimmung oder Absicht vollkommen entspricht.;) Es gewinnt dann den Anschein, als ob dasjenige Ergebnis eines Schöpfungsaktes wäre, was sich in Wirklichkeit langsam durch eine allmähliche Auslese ergeben hat. So ist es wohl zu verstehen, wenn NEwTON, MOzART, R. WAGNER sagen, Gedanken, Melodien, Harmonien seien ihnen zugeströmt, und sie hätten einfach das Richtige behalten. Auch das Genie geht gewiß, bewußt oder instinktiv, uiberall systematisch vor, wo dies ausführbar ist; aber dasselbe

\#) [Die Rolle des Zufalls bei der künstlerischen Erfindung behandelt in vorzüglicher Weise P. Souriau, Theorie de l'Invention, Paris, I88r-rgoz.] 
wird in feinem Vorgefühl manche Arbeit gar nicht beginnen, oder nach flüchtigem 'Versuch aufgeben, mit welcher der Unbegabte fruchtlos sich abmüht. So bringt dasselbe in mäßiger Zeit zu stande, wofür das Leben des gewöhnlichen Menschen weitaus nicht reichen würde.*)

Wir werden kaum fehl gehen, wenn wir in dem Genie eine vielleicht nur geringe Abweichung von der mittleren menschlichen Begabung sehen — eine etwas größere Reaktionsempfindlichkeit und Reaktionsgeschwindigkeit des Hirns. Mögen dann derartige Menschen, welche ihrem Triebe folgend einer Idee so große Opfer bringen, statt ihren materiellen Vorteil zu suchen, dem Vollblutphilister immerhin als rechte Narren erscheinen, schwerlich werden wir mit Lombroso das Genie geradezu als eine Krankheit ansehen dürfen, wenn leider auch wahr bleiben wird, daß ein empfindlicheres Hirn, ein gebrechlicheres Gebilde, auch leichter einer Krankheit verfällt.

Was C. G. J. JACOBI von der mathematischen Wissenschaft sagt, daß dieselbe langsam wächst, und nur spät auf vielen Irrwegen und Umwegen zur Wahrheit gelangt, daß alles wohl vorbereitet sein muß, damit endlich zur bestimmten Zeit

*) Ich weifs nicht, ob Swifts Akademie der Projektenmacher in Lagado, in welcher durch eine Art Würfelspiel mit Worten grofse Entdeckungen und Erfindungen gemacht werden, eine Satire sein soll auf Francis Bacons Methode, mit Hilfe von (durch Schreiber angelegten) Übersichtstabellen Entdeckungen zu machen. Übel angebracht wäre dieselbe nicht. - E. Capitaines Schrift „Das Wesen des Erfindens", welche im Text nicht mehr berücksichtigt werden konute, sei hier erwähnt. Die Schrift zeugt von einem aufrichtigen Streben nach Aufklärung und enthält viel Gutes. Allerdings hätte sich der Verfasser durch weitere Umschau überzeugen können, dafs es un die Einsicht in den Vorgang pes Erfindens und um die Schärfe der wissenschaftlichen Begrife nicht so schlimm steht, als er annimmt. Die Leistungsfähigkeit systematischer und mechanischer Proceduren als Hilfsmittel der Erfindung dürfte aber der Verfasser sehr iberschätzen. 
die neue Wahrheit wie durch eine göttliche Notwendigkeit getrieben hervortritt ${ }^{*}$ ) - alles das gilt von jeder Wissenschaft. Wir staunen oft, wie zuweilen durch ein Jahrhundert die bedeutendsten Denker zusammenwirken müssen, um eine Einsicht zu gewinnen, die wir in wenigen Stunden uns aneignen können, und die, einmal bekannt, unter gliicklichen Umständen sehr leicht $z u$ gewinnen scheint. Gedemütigt lernen wir daraus, wie selbst der bedeutende Mensch mehr für das tägliche Leben als für die Forschung geschaffen ist. Wie viel auch er dem Zufall dankt, d. h. gerade jenem eigentümlichen Zusammentreffen des physischen und psychischen Lebens, in welchem eben die stets fortschreitende, unvollkommene, unvollendbare Anpassung des letztern an ersteres deutlich zum Ausdruck kommt, das haben wir heute betrachtet. JACOBIS poetischer Gedanke von einer in der Wissenschaft wirkenden göttlichen Notwendigkeit wird für uns nichts an Erhabenheit verlieren, wenn wir in dieser Notwendigkeit dieselbe erkennen, die alles Unhaltbare zerstört und alles Lebensfähige fördert. Denn größer, erhabener und auch poetischer als alle Dichtung ist die Wirklichkeit und die Wahrheit.

*) Crescunt disciplinae lente tardeque; per varios errores sero pervenitur ad veritatem. Omnia praeparata esse debent diuturno et assiduo labore ad introitum veritatis novae. Jam illa certo temporis momento divina quadam necessitate coảcta emerget." Citiert bei Simony, „In ein ringfömiges and einen Knoten zu machen." Wien $188 \mathrm{x}$. S. $4 \mathrm{x}$. 


\section{Über den relativen Bildungswert der phi- lologischen und der mathematisch-natur- wissenschaftlichen Unterrichtsfächer der höheren Schulen.*)}

$\mathrm{Zu}$ den wunderlichsten Vorschlägen, deren Ausführung Maupertuis, **) der bekannte Präsident der Berliner Akademie, seinen Zeitgenossen ans Herz gelegt hat, gehört wohl jener der Gründung einer Stadt, in welcher (zum Nutzen und zur Ausbildung der studierenden Jugend) ausschließlich lateinisch gesprochen werden sollte. Diese lateinische Stadt ist ein frommer Wunsch geblieben. Doch bestehen seit Jahrhunderten lateinisch-

kn Die nachfolgenden Ausfïhrungen sind im wesentlichen dem Entwurf eines Vortrages entnommen, welchen ich $\mathrm{x} 88 \mathrm{x}$ auf der Naturforscherversammlung zu Salzburg hätte halten sollen, der aber wegen Kollision mit der Pariser Aus. stellung nicht $\mathrm{zu}$ stande kam. In der Einleitung $\mathrm{zu}$ meinen $288_{3}$ gehaltenen Vorlesungen ,über den physikalischen Unterricht an der Mittelschule" kam ich nochmals auf denselben Stoff zurück, doch gab mir erst die freundliche Einladung des deutschen Realschulmännervereins Gelegenheit, meine Gedanken vor einem weiteren Kreise in der Versammlung zu Dortmund am r6. April 1886 darzulegen. Dieser äufsere Anlafs, ohne welchen es zu einer Publikation wohl nicht gekommen wäre, bringt es auch mit sich, dafs meine Ausführungen zunächst nur die deutschen Schulen betreffen, und dafs sie auf die öster. reichischen nicht ohne die übrigen naheliegenden Modifikationen zu übertragen sind.

Indem ich hier einer starken und vor langer Zeit gefafsten persönlichen 
griechische Häuser, in welchen unsere Kinder einen guten Teil ihrer Tage verbringen, und deren Atmosphäre sie auch außerhalb dieser Zeit unausgesetzt umgibt.

Seit Jahrhunderten wird der Unterricht in den antiken Sprachen gepflegt. Seit Jahrhunderten wird die Notwendigkeit desselben von e in er Seite behauptet, von der a n dern bestritten. Energischer als je erheben sich jetzt wieder bedeutende Stimmen gegen das Übergewicht des Unterrichtes in den alten Sprachen und für eine mehr zeitgemäße Erziehung, namentlich für eine ausgiebigere Berücksichtigung der Mathematik und der Naturwissenschaften.

Wenn ich nun, freundlicher und ehrenvoller Aufforderung folgend, hier über den relativen Bildungswert der philologischen und der mathematisch-naturwissenschaftlichen Unterrichtsfächer der höheren Schulen spreche, so sehe ich die Rechtfertigung hierfür in der Pflicht und der Notwendigkeit für jeden Lehrenden, sich nach se in e n Erfahrungen über diese wichtige Frage eine Meinung zu bilden, und ètwa noch in dem besonderen Umstande, $\mathrm{daB}$ ich selbst in meiner Jugend nur kurze Zeit (unmittel-

Überzeugung Ausdruck gebe, kann es mir nur willkommen sein, dafs dieselbe vielfach zu den Ansichten stimmt, die Paulsen (Geschichte des gelehrten Unterrichts, Leipzig 1885) und Frary (la question du latin, Paris Cerf. I885) in ihrer Weise dargelegt haben. Es kommt mir hier durchaus nicht darauf an, viel Neues zu sagen, sondern vielmehr darauf, nach meinen Kräften zur Einleitung der unausbleiblichen Bewegung auf dem Gebiete des Schulwesens beizutragen. Diese Bewegung wird nach der Ansicht erfahrener Schulmänuer zunächst dazu führen, das Griechische einerseits und die Mathematik anderseits für akultative Unterrichtsgegenstände der Oberklassen des Gymnasium s zu erklären. (Vergl. Anm. S. 343 die vorzüglichen Einrichtungen in Dänemark.) Die eigentliche Kluft zwischen dem humanistischen Gymnasium und dem (deutschen) Realgymnasium wäre hierdurch überbrückt, und die übrigen unvermeidlichen Wandlungen wïrden sich dann relativ ruhig und lautlos voll. ziehen, Prag, im Mai 1886.

Ma pertuis, Oeuvres. Dresden 1752 . S. 339. 
bar vor dem Übertritt auf die Universität) dem Einflusse einer öffentlichen Schule ausgesetzt war, somit die Wirkung sehr verschiedener Unterrichtsweisen an mir selbst beobachten konnte.

Indem wir nun daran gehen, zu überschauen, wa s die Vertreter des philologischen Unterrichtes zu gunsten desselben anfuhren, und was die naturwissenschaftlichen Fächer dagegen für sich geltend machen können, befinden wir uns den ersteren Argumenten gegenüber in einiger Verlegenheit. Denn sehr verschieden waren diese zu verschiedenen Zeiten, und auch heute sind sie sehr mannigfaltig, wie es nicht anders sein kann, wenn man für etwas Bestehendes, das man eben um jeden Preis halten will, alles anführt, was sich nur auftreiben läbt. Wir werden manches finden, was ersichtlich nur ausgesprochen wurde, um dem Nichtwissenden zu imponieren, manches wieder, was in redlichster Absicht vorgebracht, auch der tatsächlichen Begründung nicht ganz entbehrt. Eine leidliche Übersicht der berührten Argumente erhalten wir, wenn wir zuerst diejenigen betrachten, welche sich an die historischen Umstände der Einführung des philologischen Unterrichtes knüpfen, nachher jene, die sich wie zufällige spätere neue Funde hinzugesellten.

Der Lateinunterricht wurde, wie dies PAULSEN *) eingehend dargelegt hat, durch die römische Kirche mit dem christlichen Glauben eingeführt. Mit der lateinischen Sprache zugleich wurden die spärlichen und dürttigen

*) F. Paulsen, Geschichte des gelehrten Unterrichts. Leipzig 1885. 
Überreste der antiken Wissenschaft überliefert. Wer sich diese Bildung - damals die einzige nennenswerte erwerben wollte, für den war die lateinische Sprache das einzige und notwendige Mittel; er mu $\mathrm{Bte}$ lateinisch lernen, um zu den Gebildeten zu zählen.

Der große Einfluß der römischen Kirche hat mancherlei Wirkungen hervorgebracht. $\mathrm{Zu}$ den jedermann willkommenen Wirkungen rechnen wir wohl ohne Widerspruch die Herstellung einer gewisseu Uniformität unter den Völkern, eines internationalen Verkehrs durch die lateinische Sprache, der das Zusammenarbeiten der Völker an der gemeinsamen Kulturaufgabe im r5.-r8. Jahrhundert wesentlich gefördert hat. Lange war so die lateinische Sprache die Gelehrtensprache und der Latein unterricht der Weg zur allgemeinen Bildung, welches Schlagwort noch immer festgehalten wird, obgleich es längst nicht mehr paßt.

Für den Gelehrtenstand als solchen mag es bedauerlich bleiben, daß die lateinische Sprache aufgehört hat, das allgemeine internationale Verkehrsmittel zu sein. Wenn man aber die Unhaltbarkeit der lateinischen Sprache in dieser Funktion durch ihre Unfähigkeit zu erklären versucht, den vielen neuen Gedanken und Begriffen $z u$ folgen, welche im Entwicklungsgange der Wissenschaft sich ergeben haben, so halte ich diese Auffassung entschieden für falsch. Nicht leicht hat ein moderner Forscher die Naturwissenschaft mit so vielen neuen Begriffen bereichert wie Newton, und doch wußte er dieselben ganz korrekt und scharf in lateinischer Sprache zu bezeichnen. Wäre 
die erwähnte Auffassung richtig, so würde sie eben auch fuir jede lebende Sprache gelten. Jede Sprache muß sich neuen Ideen erst anpassen.

Viel eher dürfte die lateinische Sprache durch den Einfluß des Adels, der bequemen vornehmen Herren, aus der wissenschaftlichen Litteratur verdrängt worden sein. Indem diese Herren die Ergebnisse der schönen und wissenschaftlichen Litteratur mitgenießen wollten, ohne das schwerfällige Mittel der lateinischen Sprache, erwiesen sie aber auch dem Volke einen wesentlichen Dienst. Denn mit der Beschränkung der Kenntnis der gelehrten Litteratur auf eine $\mathrm{K}$ aste war es nun vorbei, und darin liegt vielleicht der wichtigste moderne Fortschritt. Niemand wird nun heute, nachdem der internationale Verkehr sich auch trotz der Mehrheit der modernen Kultursprachen erhalten und gesteigert hat, an Wiedereinführung der lateinischen Sprache denken. *)

Wie sehr auch die antiken Sprachen die Fähigkeit besitzen, neuen Begriften zu folgen, ergibt sich aus dem Umstande, daß die überwiegende Mehrzahl unserer wissenschaft $\mathrm{l}$ ichen Begriffe als Überlebsel aus jener Zeit des lateinischen internationalen Verkehrs lateinische

क) Es liegt eine eigentümliche Ironie des Schicksals darin, dafs, während Leibniz nach einem neuen universellen sprachlichen Verkehrsmittel suchte, die lateinische Sprache, welche diesem Zweck noch ambbesten genügte, mehr und mehr aufser Gebrauch kam, und dafs gerade Leibniz selbst nicht am wenigsten dazu beigetragen hat.

[Auf den wissenschaftlichen Kongressen, welche 1900 zu Paris getagt haben, ist das lebhafte Bedürfnis nach einem internationalen Verständigungsmittel lebhaft empfunden worden, und hat zur Bildung der "Délégation pour l'Adoption d'une langue auxiliaire internationale" gefuihrt, welche diese Aufgabe zu lösen hofft. Vgl. L. Couturat, ,iiber die internationale Hilfssprache" in Ostwalds Annalen der Naturphilosophie Bd. I rgon]. 
und griechische Bezeichnungen tragen, und noch vielfach neu erhalten. Wollte man aber aus der Existenz und dem Gebrauch solcher Termini die Notwendigkeit ableiten, auch heute noch lateinisch und griechisch zu lernen, für jeden, der sie gebraucht, so müßte diese Folgerung doch als eine sehr weitgehende erscheinen. Alle Bezeichnungen, ob sie passend oder unpassend sind - und es gibt in der Wissenschaft genug unpassende und ungeheuerliche - beruhen auf Übereinkunft. Daß man an das Zeichen genau die bezeichnete Vorstellung knüpfe, darauf kommt es an. Es wird wenig daran liegen, ob jemand das Wort: Telegraph, Tangente, Ellipse, Evolute u. s. w. philologisch richtig ableiten kann, wenn ihm nur beim Gebrauch des. Wortes der richtige Begriff gegenwärtig ist. Kennt er anderseits die Ableitung noch so gut, so nützt ihm dieselbe gar nichts ohne die richtige Vorstellung. Man versuche doch, sich von einem guten Durchschnittsphilologen einige Zeilen aus Newross „Prinzipien“ oder aus Huygens" „Horologium“ übersetzen zu lassen, und man wird sofort sehen, welche höchst untergeord. n e t e Rolle in diesen Dingen die bloß̣e Sprachkenntnis spielt. Jeder Name bleibt eben ein Schall ohne den zugehörigen Gedanken. Die Mode lateinische und griechische Termini $\mathrm{zu}$ verwenden - denn nicht anders kann man's nennen - hat ihren natürlichen historischen Grund, sie konnte auch nicht plötzlich verschwinden, ist aber schon sehr im Abnehmen begriffen. Die Bezeichnungen: Gas, Ohm, Ampère, Volt u. s. w. sind auch international, aber nicht mehr lateinisch und griechisch. Von einer Not- 
wendigkeit Lateinisch oder Griechisch zu lernen aus dem angeführten Grunde, noch dazu mit einem Zeitaufwand von 8-ro Jahren, kann doch nur der sprechen, welcher die gleichgültige und zufällige Hülle für wichtiger hält, als den sachlichen Inhalt. Kann denn über solche Dinge nicht ein Wörterbuch in wenigen Sekunden Aufschluß geben ?*)

Es kann kein Zweifel bestehen, daß unsere moderne Kultur an die antike angeknüpft hat, daß dies sogar mehrmals stattgefunden hat, daß vor Jahrhunderten die Überreste der antiken Kultur die einzige überhaupt in Europa vorhandene Kultur darstellten. Damals war gewiß die philologische Bildung die allgemeine Bildung, die höhere Bildung, die ideale Bildung, denn sie war die e inzige Bildung. Wenn aber jetzt für dieselbe noch der gleiche Anspruch erhoben wird, so nuß dieser als durchaus ungerechtfertigt mit aller Entschiedewheit zurückgewiesen werden. Denn unsere Kultur ist doch allmählich

*) Es wird überhaupt dadurch viel gesündigt, dars man das menschliche Hirn mifsbraucht, und mit Dingen belastet, welche viel zweckmäßsiger und besser in Büchern verwahrt bleiben, wo man sie jederzeit finden kann. - Herr Amtsrichter $\mathrm{Hartwich}$ (aus Düsseldorf) schrieb mir jügst: „Eine Menge Wörter sind sogar noch vollkommen lateinisch oder griechisch und werden von an und für sich sehr gebildeten Leuten, die aber zufällig die alten Sprachen nicht erlernt haben, mit vollem Verständnis angewandt: so z. B. das Wort „Dynastie" ..." Das Kind, respektive der Mensch, erlernt solche Wörter als Bestandteile des "Sprachschatzes", gleichsam als Teile der Muttersprache, gerade so wie die Worte "Vater, Mutter, Brot, Milch". Weifs denn ein gewöhnlicher Sterblicher die Etymologie dieser deutschen Worte? Bedurfte es nicht der fast unglaublichen Arbeitskraft der Gebrüder Grimm, um wenigstens einiges Licht in das Werden und Wachsen unserer Muttersprache zu bringen? - Und bedienen sich nicht jeden Augenblick unzählige sogenannte humanistisch Gebildete einer Menge von Fremlwörtern, deren Ursprung sie nicht kennen? Nur wenige halten es der Mühe wert, im Fremdwörterbuch nachzuschlagen, obgleich sie mit Vorliebe behaupten, man müfste die alten Sprachen „schon der Etymologie wegen" erlernen." 
cine ganz selbständige geworden; sie hat sich weit über die antike erhoben, und überhaupt eine ganz n e u e Richtung eingeschlagen. Ihr Schwerpunkt liegt in der mathematischnaturwissenschaftlichen Aufklärung, die nicht nur die Technik, sondern nach und nach alle Gebiete, selbst die philosophischen und historischen Wissenschaften, die Sozialund Sprachwissenschaften durchdringt. Was an Spuren antiker Anschauungen in der Philosophie, im Rechtsleben, in Kunst und Wissenschaft noch zu finden ist, wirkt mehr hemmend als fördernd, und wird sich gegenüber der Entwicklung unserer eigenen Ansichten auf die Dauer nicht halten können.

Es steht also den Philologen schlecht an, wenn sie sich noch immer für die vorzugsweise Gebildeten halten, wenn sie jeden, der nicht Lateinisch und Griechisch versteht, für ungebildet erklären, sich darïber beschweren, daß man mit ihm kein Gespräch führen könne u. s. w. Die ergötzlichsten Geschichten werden da als Beleg der mangelhaften Bildung mancher Naturforscher und Techniker in Umlauf gesetzt. Ein namhafter Naturforscher z. B. soll ein Collegium publicum mit der Bezeichnung "frustra" angekündigt, ein Insekten sammelnder Ingenieur erzählt haben, daß er „Etymologie" treibe. Es ist richtig, ähnliche Vorkommnisse verursachen uns, je nach Stimmung oder Naturell, eine Gänsehaut oder eine heftige Erschütterung der Lachmuskel. " Im nächsten Augenblicke müssen wir uns aber doch sagen, daB wir da nur einem kindischen Vorurteil unterlegen sind. Ein Mangel an Takt allerdings, nicht aber ein Mangel an Bildung, spricht sich in dem

\section{Digitized by Microsoft ${ }^{\circledR}$}


Gebrauch solcher halbverstandener Bezeichnungen aus. Jeder, der aufrichtig ist, wird eingestehen, da $B$ manches Gebiet existiert, über welches er besser schweigt. Wir wollen auch nicht so boshaft sein, den Spieß umzudrehen, und hier die Frage zu erörtern, welchen Eindruck etwa die' Philologen auf den Naturforscher oder Ingenieur machen, wenn von Naturwissenschaft die Rede ist? Ob sich da nicht manche sehr heitere Geschichte ergeben würde, zugleich von tief ernster Bedeutung, welche die mitgeteilten mehr als kompensierẹn möchte?

Diese gegenseitige Härte des Urteils, auf die wir da gestoßen sind, kann uns übrigens zum Bewußtsein bringen, wie wenig verbreitet noch eine wirkliche allgemeine Bildung ist. Es liegt in dieser Urteilsweise etwas von dem beschränkten mittelalterlichen Standesprotzentum, für welches je nach dem Standpunkt des Urteilenden der Mensch beim Gelehrten, beim Soldaten oder beim Baron anfängt. Ja, gestehen wir's, es liegt wenig Sinn für die gan ze Aufgabe der Menschheit, wenig Verständnis für die gegenseitige Hülfeleistung bei der Kulturarbeit, wenig freier Blick, wenig allgemeine Bildung darin!

Die Kenntnis des Lateinischen (und teilweise auch jene des Griechischen) bleibt ein Bedürf $\mathrm{n}$ is für die Angehörigen jener Berufszweige, welche noch stärker an die antike Kultur anknüpfen, also für Juristen, Theologen und Philologen, für Historiker, sowie überhaupt für die geringe Zahl derjenigen, zu welchen auch ich mich zeitweilig rechnen muß, die aus der lateinischen Litteratur der ver- 
flossenen Jahrhunderte schöpfen wollen.*) Daß aber deshalb unsere ga $\mathrm{nze}$ nach höherer Bildung strebende Jugend in so u n m äßiger Weise Lateinisch und Griechisch treiben muß, daß deshalb die angehenden Mediziner und Naturforscher mangelhaft gebildet, ja verbildet, an die Hochschule kommen müssen, daß sie nur von jener Schule kommen dürfen, welche ihnen $\mathrm{nicht}$ die nötige Vorbildung zu geben vermag, das sind doch etwas starke Folgerungen.

Nachdєm auch die Umstände, welche dem lateinischen und griechischen Unterricht seine hohe Bedeutung gegeben hatten, längst nicht mehr wirksam waren, wurde doch wie natürlich der einmal hergebrachte Unterricht festgehalten. Es konnte auch nicht fehlen, daß mancherlei Wirkungen dieses Unterrichtes, gute und schlimme, an die bei Einführung desselben niemand gedacht hatte, sich einstellten und beobachtet wurden. Ebenso natürlich betonten diejenigen, welche an der Erhaltung dieses Unterrichtes ein starkes Interesse hatten, weil sie nur diesen kannten, oder von demselben lebten, oder aus irgend einem anderen Grunde, die guten Wirkungen dieses Unterrichtes. Sie hoben dieselben so hervor, als wären sie mit Vorbedacht erzielt worden, und nur auf diesem Wege zu erzielen.

Ein wirklicher Vorteil, der sich durch den richtig

\#) Ich würde als Nichtjurist nicht gewagt haben, zu sagen, dafs das Studium des Griechischen für den Juristen unnötig sei; doch ist diese Ansicht bei der dem Vortrage folgenden Debatte von sehr sachverständiger Seite vertreten worden. Hiernach würde die auf einem (deutschen) Realgymnasium erworbene Vorbildung auch für den angehenden Juristen genügen, und nur für Theologen und Philologen unzureichend sein. 
geleiteten philologischen Unterricht für die Jugend ergeben $\mathrm{könnte,} \mathrm{würde} \mathrm{in} \mathrm{der} \mathrm{Erschließung} \mathrm{des} \mathrm{reichen} \mathrm{Inhaltes}$ der antiken Litteratur, in der Bekanntschaft mit der IV́eltanschauung zweier hochstehender Völker bestehen. Wer die griechischen und römischen Autoren gelesen und verstanden hat, hat mehr erlebt, als derjenige, der auf die Eindrücke der Gegenwart beschränkt bleibt. Er sieht, wie die Menschen unter anderen Umständen gan z anders iber dieselben Dinge urteilen, als heute. Er wird selbst freier urteilen. Ja die griechischen und römischen Autoren sind wirklich eine reiche Quelle der Erfrischung, der Aufklärung und des Genusses nach des Tages Arbeit, und stets wird der Einzelne, sowie die europäische Menschheit, denselben dankbar bleiben. Wer würde nicht gern der Irrfahrten des Odysseus sich erinnern, wer nicht gern der naiven Erzählung Herodots lauschen? Wer könnte es bereuen, Platons Dialoge kennen gelernt, oder Lucians göttlichen Humor verkostet zu haben? Wer wollte durch Ciceros Briefe, durch Plautus und Terentius nicht ins antike Privatleben geblickt haben? Wem wären Suetons Schilderungen nicht unvergeßlich? Ja wer wollte überhaupt ein Wissen von sich werfen, das er einmal erworben hat?

Aber wer nur aus diesen Quellen schöpft, wer nur diese Bildung kennt, hat allerdings ke in Recht über den Wert einer ander $\mathrm{n}$ abzusprechen. Als Forschungsobjekt für Einzelne ist ja diese Litteratur äußerst wertvoll, ob aber als fast einziges Unterrichtsmittel für die Jugend, das ist eine andere Frage. 
Gibt es nicht noch andere Völker, andere Litteraturen, von welchen wir zu lernen haben? Ist nicht die Natur selbst unsere höchste Lehrmeisterin? Sollen uns die Griechen mit ihrer beschränkten kleinstädtischen Anschauung, in welcher sie alles in "Griechen und Barbaren" einteilen, mit ihrem Aberglauben, mit ihrem ewigen Orakelbefragen immer die höchsten Muster bleiben? Aristoteles mit seiner Unfähigkeit von Tatsachen zu lernen, mit seiner Wortwissenschaft, Platon mit seinem schwerfälligen schleppenden Dialog, mit seiner unfruchtbaren, oft kindlichen Dialektik, sind sie unübertrefflich ?*)

Die Römer mit ihrer wort- und silbenreichen prahlenden prunkvollen Äußerlichkeit und Gefühllosigkeit, mit ihrer beschränkten Philisterphilosophie, mit ihrer wütenden Sinnlichkeit, mit ihrer in Tier- und Menschenhetzen schwelgenden grausamen Wollust, mit ihrem rücksichtslosen Mißbrauchen und Ausbeuten der Menschen, sind sie nachahmenswerte Muster? Oder soll vielleicht unsere Naturwissenschaft ạ Plinius sich erbauen, der Hebammen als Gewährsmänner zitiert, und der selbst auf ihrem Standpunkt steht?

*) Wenn ich an dieser Stelle die Schattenseiten der Schriften des Platoll und Aristoteles hervorhebe, die mir bei Lektüre vorzugsweise in de ut s cher Uhersetzung aufgefallen sind, - denn das Griechische ist mir nicht mehr geläufig genug - so denke ich natürlich nicht daran, hiermit die grofsen Verdienste und die hohe historische Bedeutung beider Männer herabsetzen zu wollen. Allerdings darf man die Bedeutung dieser Männer nicht nach dem Umstande messen, dafs unsere spekulative Philosophie sich noch zum grofsen Teil in ihren Gedankenbahnen bewegt. Vielleicht folgt daraus eher, dafs dieses Gebiet seit Jahrtausenden sehr geringe Fortschritte gemacht hat. War doch auch die Naturwissens chaft durch Jahrhunderte in Aristotelischen Gedanken befangen, und verdankt sie doch ihren Aufschwung wesentlich dem Abschütteln dieser Fesseln! 
Und wenn eine Bekanntschaft mit der antiken Welt wirklich erzielt würde, so möchte man sich mit dem philologischen Unterricht noch abfinden. Allein Worte und Formen sind es und Formen und Worte, die der Jugend immer wieder geboten werden. Und alles, was daneben noch getrieben werden kann, verfällt derselben trostlosen Methode, und wird zur Wissenschaft aus Worten, zum bloßen gehalt' osen Gedächtniskram.

Ja wirklich, man fühlt sich zurück versetzt um ein Jahrtausend, in die dumpfe Klosterzelle des Mittelalters! Das muß anders werden! Man kann die Anschauungen der Griechen und Römer auf einem kürzern Wege kennen lernen, als durch den Verstand betäubendes 8 bis I $\circ$ jähriges Deklinieren, Konjugieren, Analysieren und Extemporieren. Es gibt auch jetzt schon Gebildete genug, welche mit Hilfe guter Übersetzungen lebendigere, klarere und umfassendere Ansichten über das klassische Altertum erworben haben als unsere Gymnasialabiturienten.*)

Die Griechen und Römer sind für die moderne Zeit einfach zwei Objekte der Archäologie und Geschichtsforschung wie alle andern. Führt man sie der Jugend in frischer und anschaulicher Weise und nicht bloß in Worten und Silben vor, so wird die Wirkung nicht ausbleiben. Ganz anders genießt man auch die Griechen, wenn man nach dem Studium der modernen Kulturforschung an die-

*) Ich will durchaus nicht behaupten, dafs man ganz denselben Gewinn aus einem griechischen Autor zieht, ob man denselben im Original oder in der Übersetzung liest. Die Differenz aber, der Mehrgewinn im ersteren Fall, scheint mir, und wohl den meisten Menschen, welche nicht Fachphilologen werden wollen, mit einsm Zeitaufwand von 8 Jahren viel zu teuer erkauft.

$\mathrm{Mach}$, Vorlesungen. 3. Auf. 
selben herankommt. Anders liest man manches Kapitel im Herodot, wenn man mit Naturwissenschaft ausgerüstet, mit Kenntnissen über die Steinzeit und den Pfahlbau daran geht. Was die Philologie zu leisten vorgibt, das wird ein zureichender historischer Unterricht, der freilich nicht bloß Namen und Zahlen, patriotisch und confessionell gefärbte Dynastie- und Kriegsgeschichte bieten darf, sondern wahre Kulturgeschichte sein muß, der Jugend in viel ausgiebigerer Weise wirklich leisten.

Die Anschauung ist noch sehr verbreitet, daß alle "höhere ideale Bildung", alle Erweiterung der Weltanschauung durch philologische und etwa noch durch historische Studien gewonnen werde, daß dagegen die Mathematik und die Naturwissenschaften wegen ihres $\mathrm{Nutzens}$ nicht zu vernachlässigen seien. Ich kann dieser Ansicht durchaus nicht zustimmen. Es wäre auch sonderbar, wenn der Mensch aus einigen alten Topfscherben, besçhriebenen Steinen und Pergamentblättern, die doch auch nur ein Stückchen Natur sind, mehr lernen, mehr geistige Nahrung schöpfen könnte, als aus der ganzen übrigen Natur. Gewiß geht den Menschen zunächst der Mensch an, aber doch nicht allein.

Wenn wir den Menschen nicht als Mittelpunkt der Welt ansehen, wenn uns die Erde als ein um die Sonne geschwungener Kreisel erscheint, der mit dieser in unendliche Ferne fliegt, wenn wir in Fixsternweiten dieselben Stoffe antreffen wie auf der Erde, überall in der Natur denselben Vorgängen begegnen, von welchen das Leben 
des Menschen nur ein verschwindender gleichartiger Teil ist, so liegt hierin a u ch eine Erweiterung der Weltanschauung, auch eine Erhebung, auch eine Poesie! Vielleicht liegt hierin Größeres und Bedeutenderes, als in dem Brïllen des verwundeten Ares, in der reizenden Insel der Kalypso, dem Okeanos, der die Erde umfließt. Über den - relativen Wert beider Gedankengebiete, beider Poesien, darf nur der sprechen, der beide kennt!

Der "Nutzen" der Naturwissenschaft ist gewissermaßen nur ein Nebenprodukt des geistigen Aufschwungs, der sie erzeugt hat. Doch darf in niemand unterschätzen, der sich die Verwirklichung der orientalischen Märchenwelt durch unsere moderne Technik willig gefallen läßt, ain wenigsten derjenige, dem diese Schätze o hne sein Zutun, unverstanden, wie aus der ,vierten Dimension", zufallen.

Auch das darf man nicht glauben, dab die Naturwissenschaft etwa nur dem Techniker nützt. Ihr Einflub durchdringt alle unsere Verhältnisse, unser ganzes Leben, ihre Anschauungen werden also auch überall maßgebend. Wie ganz anders wird auch der Jurist, der Staatsmann, der Nationalökonom urteilen, welcher sich z. B. nur lebhaft gegenwärtig hält, daß eine Quadratmeile fruchbarsten Landes mit der alljährlich verbrauchten Sonnenwärme nur eine ganz bestimmte begrenzte Mensclienzahl zu ernähren vermag, welche durch keine Kunst, keine Wissenschaft weiter gesteigert werden kann. Gar manche volkswirtschaftliche Theorie, die mit luftigen Begriffen neue Bahnen bricht, natürlich wieder nur in der Luft, wird ihm vor dieser Einsicht hinfällig. 
Sehr gern betonen die Lobredner des philologischen Unterrichts die Geschmacksbildung; welche durch Beschäftigung mit den antiken Mustern erzielt wird. Ich gestehe aufrichtig, daß dies für mich etwas Empörendes hat. Also um den Geschmack zu bilden, muß die Jugend ein Decennium opfern! Der Luxus geht also dem Notwendigsten vor! Hat die künftige Generation angesichts der schwierigen Probleme, angesichts der sozialen Fragen, welchen sie an Verstand und Gemüt gekräftigt entgegen gehen sollte, wirklich nichts Wichtigeres zu tun?

Nehmen wir aber die Aufgabe an! Läßt sich der Geschmack nach Rezepten bilden? Ändert sich nicht das Schönheitsideal? Ist es nicht eine gewaltige Verkehrtheit, sich künstlich in die Bewunderung von Dingen hineinzuzwingen, die bei allem historischen Interesse, bei aller Schönheit im einzelnen, unserm übrigen Denken und Sinnen, wenn wir überhaupt ein e ig e n e s haben, doch vielfach fremd gegenüberstehen? Eine wirkliche Nation hat ihren e i g e n en Geschmack, und holt ihn nicht bei andern. Und jeder einzelne volle Mensch hat seinen eigene n Geschmack.*)

*) „Die Versuchung - schreibt Herr Amtsrichter Hartwich - den „Geschmack" der Alten für so ,erhaben" und „unübertrefflich" zu halten, scheint mir wesentlich darin ihren Grund zu haben, dafs die Alten in der Darstellung des Nackten allerdings unübertrefflich dastehen; erstens schufen sie durch unausgesetzte Pflege des menschlichen Körpers herrliche Modelle und zweitens hatten sie diese Modelle in ihren "Gymnasien“ und bei ihren Festspielen stets vor Augen; kein Wunder, dafs ihre Statuen noch heute unser Staunen erregen; denn die Form, das I deal des menschlichen Körpers, hat sich im Laufe der Jahrhunderte nicht verändert. Ganz anders steht es aber mit den geistigen Idealen; diese ändern sich von Jahrhundert zu Jahrhundert, ja von Jahrzehut zu Jahrzehnt! Es ist nun zu natürlich, dafs man das Anschaulichste, näm. lich die Werke der Bildhau erkunst, unbewufst als allgemeinen Mafsstab für den hochentwickelten Geschmack der Alten anlegt, ein Fehlschlufs, vor dem man nach meiner Ansicht nicht genug warnen kann." 
Und worauf kommt es bei dieser Geschmacksbildung hinaus? Auf Aneignung des persönlichen Stils einiger Autoren! Was würden wir nun von einem Volke halten, das etwa nach I 000 Jahren seine Jugend zwingen würde, sich durch vieljährige Übung in den geschraubten oder ïberladenen Stil eines gewandten Advokaten oder Reichstags-Abgeordneten der Gegenwart einzuleben? Würden wir ihm nicht mit Recht Geschmacklosigkeit vorwerfen?

Die üble Wirkung dieser vermeintlichen Gesclımacksbildung äußert sich auch oft genug. Wenn ein junger Gelehrter das Niederschreiben einer wissenschaftlichen Arbeit für ein Advokatenkunststück hält, statt einfach die Tatsachen und die Wahrheit unverhüllt darzulegen, so sitzt er unbewußt auf der Schulbank, und vertritt unbewußt den römischen Standpunkt, auf dem das Ausarbeiten von Reden als wissenschaftliche (!) Beschäftigung erscheint.

Nicht unterschätzen wollen wir die Entwicklung des Sprachgefühles und das gesteigerteVerständnis der Mut tersprache, welches durch philologische Studien erzielt wird. Durch die Beschäftigung mit einer fremden Sprache, namentlich mit einer von der Muttersprache sehr verschiedenen, ergibt sich eine Sonderung der sprachlichen Zeichen und Formen von dem bezeichneten Gedanken. Die sich am nächsten entsprechenden Worte verschiedener Sprachen koinzidieren nicht genau mit denselben Vorstellungen, sondern treffen etwas verschiedene Seiten derselben Sache, auf welche eben durch das Sprachstudium

\section{Digitized' by Microsoft ${ }^{\circledR}$}


die Aufmerksamkeit hingelenkt wird. Daß aber das Studium des Lateinischen und Griechischen das erfolgreichste und natürlichste oder gar das e in zige Mittel sei, diesen Zweck zu erreichen, dürfen wir deshalb noch nicht behaupten. Wer sich einmal das Vergnügen macht, in einer chinesischen Grammatik zu blättern, wer sich die Sprech- und Denkweise eines Volkes klar zu machen sucht, welches nicht bis zur Lautanalyse fortschreitet, sondern bei der Silbenanalyse stehen bleibt, welchem daher unsere Buchstabenschrift das merkwürdigste Rätsel ist, welches durch wenige Silben mit geänderter Betonung und Stellung alle seine reichen und tiefen Gedanken ausdrückt, de m gehen vielleicht noch andere Lichter auf über das Verhältnis von Sprechen und Denken. Soll aber vielleicht unsere Jugend deshalb $\mathrm{Chinesisch}$ treiben? Gewiß nicht! Aber auch mit dem Lateinischen soll sie wenigstens nicht in dem Maße belastet werden, als es geschieht.

Es ist ein sehr schönes Kunststück, einen lateinischeu Gedanken möglichst sinngetreu und sprachgetreu deutsch wiederzugeben - für den Übersetzer. Wir werden auch dem Übersetzer hierfür sehr dankbar sein, aber von jedem gebildeten Merischen dieses Kunststück zu verlangen, ohne Rücksicht auf die Opfer an Zeit und Mühe, ist unvernünftig. Eben deshalb wird, wie die Pädagogen selbst zugestehen, dieses Ziel auch nur unvollkommen erreicht, nur bei einzelnen Schülern, bei besonderer Anlage und andauernder Beschäftigung. 'Ohne also die hohe Wichtigkeit des Studiums der antiken Sprachen als Fach. studium in Abrede zu stellen, glauben wir doch, daß 
das zur allgemeinen Bildung gehörige Sprachbew $\mathrm{Bt}$. sein auf andere Art gewonnen werden kann, und ge. wonnen werden soll. Wären wir denn wirklich so ganz verloren, wenn etwa die Griechen gar nicht vor uns gelebt hätten?

Wir müssen ja mit unsern Forderungen sogar etwas weiter gehen, als die Vertreter der klassischen Philologie. Wir müssen wünschen, daß ein gebildeter Mensch sich eine dem Standpunkte der Wissenschaft einigermaßen entsprechende Vorstellung von dem Wesen und Wert der Sprache, von der Sprachbildung, von dem Bedeutungswechsel der Wurzeln, von dem Verfall ständiger Redensarten zu grammatischen Formen, kurz von den sehr auf. klärenden Ergebnissen der modernen vergleichenden Sprachwissenschaft aneigne. Man sollte meinen, daß dies durch ein vertieftes Studium der Muttersprache und der nächst verwandten Sprachen, nachher älterer Sprachen, von denen jene abstammen, zu erreichen wäre. Wer mir einwendet, $\mathrm{da} \beta$ dies $\mathrm{zu}$ schwierig ist, und $\mathrm{zu}$ weit führt, dem rate ich, neben eine deutsche Bibel einmal eine holländische, dänische und schwedische zu legen, und nur einge Zeilen $\mathrm{zu}$ vergleichen; er wird erstaunen über die Fülle von Anregungen. ${ }^{*}$ ) Ich bin sogar der Meinung, daß auf dieseın

*) Im Anfang schuf Gost Himmel und Erde. Und die Erde war wüste und leer, und es war finster auf der liefe; und der Geist Goltes schwebse auf dem Wasser. - (Holländisch.) In hes begin schiep God den hemel en de aarde. De aarde nu was woest en ledig, en duisternis was op den afgrond; en de Geest Gods zwefde op de wateren. - (Dänisch.) I Begyndelsen skabte Gud Himmelen og Jorden. $\mathrm{Og}$ Jorden var ode og og Guds Aand svoevede ovenover Vandene. - (Schwedisch.) I begyanelsen skapade Gud Himmel och Jord. Och Jorden war öde och tom, och mörker war pä djupet, och Guds Ande swäfde öfwer wattnet. 
Wege allein der Sprachunterricht zu einem wirklich förderlichen, fruchtbaren, vernünftigen und aufklärenden werden kann. Mancher meiner Zuhörer erinnert sich vielleicht noch aus seiner Jugend der aufheiternden erwärmenden Wirkung, ähnlich jener eines Sonnenblicks an trübem Tage, welche die spärlichen und schüchternen sprachvergleichenden Bemerkungen der CurTiusschen griechischen Grammatik in die öde geistlose Silbenstecherei brachten.

[Um jedem Mißverständnis zu begegnen, muß ich hier nochmals hervorheben, daß meine Ausführungen nicht gegen die philologische Forschung, sondern nur gegen die Gymnasialpädagogik und Gymnasialdidaktik gerichtet sind. Die Entzifferung der Hieroglypheninschrift von Rosette oder der Keilschrift von Behistun erscheint mir als eine ebenso große Geistestat, wie irgend eine bedeutende naturwissenschaftliche Entdeckung. Solche Leistungen sind aber überhaupt erst möglich geworden durch die Erziehung in der Schule der klassischen Philologie, abgesehen davon, daß die dort entwickelte Kunst der Entzifferung, die Kunst zwischen den Zeilen zu lesen, und aus den leisesten Andeutungen auf den psychischen Zustand des Schreibers Konjekturen $\mathrm{zu}^{\prime}$ machen, an sich in keiner Weise unterschätzt werden darf. - I895.]

Der wesentlichste Erfolg, welcher bei der gegenwärtigen Art, das Studium der antiken Sprachen zu treiben, wirklich noch erzielt wird, ist an die Beschäftigung mit der komplizierten Grammatik derselben gebunden. Er be- 
steht in der Schärfung der Aufmerksamkeit und in der Übung des Urteils durch Subsumieren besonderer Fälle unter allgemeine Regeln, und durch Unterscheiden verschiedener Fälle von einander. Selbstverständlich kann dasselbe Resultat auf mancherlei andere Art, z. B. durch irgend ein schwieriges Kartenspiel erreicht werden. J e de Wissenschaft, so auch die Mathematik und die Naturwissenschaften, leisten in Bezug auf Übung des Urteils dasselbe, wo nicht mehr. Hierzı kommt noch, daß der Stoff dieser Wissenschaften für die Jugend ein viel höheres Interesse hat, wodurch die Aufmerksamkeit von selbst gefesselt wird, und daß dieselben noch in andern Richtungen aufklärend und nützlich wirken, in welchen die Grammatik gar nichts leisten kann. Wem wäre es an sich nicht gänzlich gleichgiltig, ob man im Genitiv Pluralis "hominum" oder "hominorum" sagt, so interessant dies auch für den Sprachforscher sein mag. Und wer wollte es bestreiten, daß das Kausalitätsbedürfnis durch die Naturwissenschaften und nicht durch die Grammatik geweckt wird?

Den günstigen Einflub, den a uch das Studium der lateinischen und griechischen Grammatik auf die Schärfung des Urteils ausübt, stellen wir also durchaus nicht in Abrede. Insofern nun die Beschäftigung mit dem Wort an sich die Klarheit und Schärfe des Ausdrucks besonders fördern muß, insofern auch das Lateinische und Griechische für manche Berufszweige noch nicht ganz entbehrlich ist, räumen wir diesen Lehrstoffen gern einen Platz in der Schule ein, wünschen aber die ihnen ungebührlich 
zugemessene Zeit, welche sie in ganz ungerechtfertigter Weise andern fruchtbareren Disziplinen entziehen, schon jetzt bedeutend beschränkt. Daßß aber das Lateinische und Griechische als a llgemeine Bildungsmittel sich auf die Dauer nicht halten werden, davon sind wir iberzeugt. Sie werden sich in die Stube des Gelehrten, des Fach. philologen zurückziehen, und allmählich den modernen Sprachen und der modernen Sprachw issenschaft Platz machen.

Schon Locke hat die übertriebenen Vorstellungen von dem engen Zusammenhange von Denken und Sprechen, von Logik und Grammatik auf ihr richtiges Maß zurückgeführt und neuere Forscher haben seine Ansicht noch fester begründet. Wie wenig eine komplizierte Grammatik mit der Feinheit der Gedanken zu tun hat, beweisen die Italiener und Franzosen, welche, obgleich sie den grammatischen Luxus der Römer fast gänzlich abgeworfen haben, doch an Feinheit der Gedanken gegen dieselben nicht zurïckstehen, und deren poetische und namentlich wissenschaftliche Litteratur, wie wohl niemand bestreiten wird, sich mit der römischen messen kann.

Überblicken wir noch einmal die Argumente, welche für den Unterricht in den antiken Sprachen in die Wagschale geworfen werden, so müssen wir sagen, daß dieselben großenteils überhaupt $\mathrm{nicht}$, mehr gelten. Soweit aber die Ziele, welche dieser Unterricht verfolgen könnte, noch erstrebenswert sind, erscheinen sie uns als zu beschränkt, als eben so einseitig und beschränkt 
aber auch die Mittel, welche verwendet werden. Fast als einziges unbestreitbares Ergebnis dieses Unterrichts werden wir eine größere Gewandtheit und Genauigkeit im Ausdruck zu betrachten haben. Wollte man boshaft sein, so könnte man sagen, daß unsere Gymnasien erwachsene Menschen erziehen, die sprechen und schreiben können, aber leider nicht viel $\mathrm{zu}$ berichten wissen. Von dem freien umfassenden Blick, von der gerühmten all. gemeinen Bildung, welche dieser Unterricht erzeugen soll, werden wir kaum im Ernst sprechen können. Vielleicht würde diese Bildung richtiger die einseitige oder beschränkte heißen.

Wir haben schon bei Betrachtung des Sprachunterrichts einige Seitenblicke auf die Mathematik und auf die Naturwissenschaften geworfen. Stellen wir uns nun noch die Frage, ob diese als Unterrichtsfächer nicht manches leisten können, was auf keine andere Weise zu erzielen ist. Ich werde zunächst auf keinen Widerspruch stoßen, wenn ich sage, daß der Mensch ohne eine wenigstens elementare mathematische und naturwissenschaftliche Bildung ein Fremdling bleibt in der Welt, in welcher er lebt, ein Fremdling in der Kultur der Zeit, die ihn trägt. Was ihm in der Natur oder in der Technik begegnet, spricht ihn entweder gar nicht an, weil er kein Ohr und kein Auge dafür hat, oder es spricht zu ihm in einer unverständlichen Sprache.

Das sachliche Verständnis der Welt und der Kultur ist aber nicht die einzige Wirkung des Studiums 
der Mathematik und der Naturwissenschaften. Viel wichtiger für die Vorbereitungsschule ist die formale Bildung durch diese Fächer, die Kräftigung des Verstandes und Urteils, die Übung der Anschauung. Die Mathematik, die Physik, die Chemie und die sogenannten beschreibenden Naturwissenschaften verhalten sich in dieser Richtung so ähnlich, daß wir dieselben in der Betrachtung, einzelne Punkte abgerechnet, gar nicht zu trennen brauchen.

Die für ein ersprießliches Denken so notwendige Folgerichtigkeit und Stetigkeit der Vorstellungen wird vorzugsweise durch die Mathematik, die Fähigkeit mit den Vorstellungen den Tatsachen zu folgen, d. h. zu beobachten oder Erfahrungen zu sammeln, vorzugsweise durch die $\mathrm{Nat} u \mathrm{rw}$ issenschaften gefördert. Ob wir nun aber bemerken, daß die Seiten und Winkel eines Dreieckes in gewisser Weise von einander abhängen, daß ein gleichschenkliges Dreieck gewisse Symmetrieeigenschaften hat, oder ob. wir die Ablenkung der Magnetnadel durch den elektrischen Strom, die Auflösung des Zinks in verdünnter Schwefelsäure wahrnehmen, ob wir bemerken, daß die Flügel der Tagfalter unten, die Vorderflügel der Nachtfalter oben unscheinbar gefärbt sind, überall gehen wir von Beobachtungen, von intuitiven Erkenntnissen aus. Das Gebiet der Beobachtungen ist etwas kleiner und näher liegend in der Mathematik, etwas reicher und weiter, aber schwieriger zu durchmessen in den Naturwissenschaften. Doch müssen wir vor allem andern in 
jedem dieser Gebiete beobachten lernen. Die philosophische Frage ist hier für uns von keiner Bedeutung, ob etwa die intuitiven Erkenntnisse der Mathematik von besonderer Art seien. Gewiß kann nụn die Beobachtung auch an sprachlichem Stoffe geibt werden. Niemand wird aber bezweifeln, daß die konkreten lebendigen Bilder, welche in den vorher bezeichneten Gebieten auftreten, ganz anders anziehend auf den jugendlichen Geist wirken werden, als die abstrakten Schattengestalten, welche der sprachliche Stoff bietet, und denen die Aufmerksamkeit gewiß nicht so spontan und also nicht mit gleich großem Erfolg sich zuwenden wird. *)

Haben wir durch : Beobachtung verschiedene Eigenschaften etwa eines geometrischen oder eines Naturgebildes gefunden, so bemerken wir in vielen Fällen eine gegenseitige $A b h$ ängigkeit dieser Eigenschaften voneinander. In keinem Gebiete drängt sich nun diese Abhängigkeit (wie etwa Gleichschenkligkeit und Gleichheit der Winkel an der Grundlinie des Dreiecks, Zusammenhang von Druck und Bewegung) so deutlich auf, nirgends wird die Not. wendigkeit und Beständigkeit dieser Abhängigkeit so bemerklich, wie in den bezeichneten Gebieten. Daher die Stetigkeit und Folgerichtigkeit der Vorstellungen, welche man sich durch Beschäftigung mit diesen Gebieten erwirbt. Die relative Einf a chhe it und Über . sichtlichkeit geometrischer und physikalischer Verhältnisse wirkt hier sehr fördernd. Verhältnisse von ähn-

*) Vgl. die vortreffliche Ausführung von Herzen (de l'enseignement secondaire dans la suisse romande. Lausaune 1886). 
licher Einfachheit finden sich auf den Gebieten nicht, welche der sprachliche Unterricht zu erschließen vermag. -Mancher dürfte sich schon gewundert haben, wie wenig Achtung vor den.Begriffen Ursache und Wirkung und deren Verhältnis bei Vertretern der philologischen Fach. gruppe zuweilen gefunden wird: Die Erklärung mag wohl darin liegen, daß das ihnen geläufige analoge Verhältnis von Motiv und Handlung lange nicht die ubersichtliche Einfachheit und Bestimmtheit darbietet, wie das erstere.

Die vollständige Übersicht aller möglichen Fälle, die daraus hervorgehende ökonomische Ordnung und organische Verbindung der Gedanken, welche jedem, der sie einmal gekostet hat, zu einem bleibenden Bedürnnis wird, das er in jedem neuen Gebiet zu befriedigen strebt, kann sich $\mathrm{nur}$ bei der relativen Einfachheit des mathematischen und naturwissenschaftlichen Stoffes in gleichem Maße entwickeln.

Wenn eine Reihe von Tatsachen mit einer Reihe von anderen Tatsachen in scheinbaren Widerstreit gerät, und dadurch ein Problem auftritt, so besteht die Lösung gewöhnlich nur in einer verfeinerten Unterscheidung, in einer vervollständigten Übersicht der Tatsachen, wie dies 2. B. an der NEwTonschen Lösung des Dispersionsproblems sich sofort erläutern läßBt. Wenn eine neue mathematische oder naturwissenschaftliche Tatsache bewiesen oder erklärt wird, so beruht dies wieder nur auf der Darlegung des Zusammenhanges der neuen Tatsache mit schon bekannten. Daß z. B. der Kreisradius sechsmal in der Peripherie aufgetragen werden 
kann, wird erklärt oder bewiesen durch Zerlegung des dem Kreise eingeschriebenen regulären Sechseckes in gleichseitige Dreiecke. Daß die in einem Stromleiter in der Sekunde entwickelte Wärmemenge mit der Verdoppelung der Stromstärke sich vervierfacht, erklären wir durch das zur doppelten Stromstärke gehörige doppelte Potentialgefälle und die ebenfalls zugehörige doppelte durchfließende Menge, mit einem Wort durch die Vervierfachung der zugehörigen Arbeit. Erklärung und direkter Beweis sind nicht wesentlich voneinander verschieden.

Wer eine geometrische, physikalische oder technische A u fga be wissenschaftlich löst, bemerkt leicht, daß sein Verfahren ein durch die ökonomische Übersicht ermöglichtes methodisches Suchen in Gedanken ist, ein vereinfachtes zielbewuBtes Suchen, zum Unterschied von dem planlosen unwissenschaftlichen Probieren. Der Geometer z. B., der einen zwei gegebene Gerade berührenden Kreis zu konstruieren hat, überblickt die Symetrieverhältnisse der gesuchten Konstruktion, und sucht den Kreismittelpunkt nur mehr in der Symmetrielinie der gegebenen Geraden. Wer ein Dreieck mit $z$ we i gegebenen Winkeln und gegebener Seitensumme sucht, überblickt die Formbestimmtheit des Dreiecks, und sucht nur mehr in einer gewissen Reihe for $\mathrm{mgleicher}$ Dreiecke. So macht sich unter den verschiedensten Umständen die Einfachheit und Durchdringbarke.it des mathematisch-naturwissenschaftlichen Stoffes fühlbar, und fördert die Übung und das Selbstvertrauen im Gebrauch.des Verstandes. 
Ohne Zweifel wird sich durch den mathematischnaturwissenschaftlichen Unterricht noch viel mehr erreichen lassen, als jetzt schon erreicht wird, wenn noch eine etwas natülichere Methode in Gebrauch kommt. Hierzu gehört, daß die Jugend nicht durch verfrühte Abstraktion verdorben wird, sondern den Stoff durch die A n s c ha u ung kennen lernt, bevor sie mit demselben denkend $z u$ arbeiten hat. Eine zweckentsprechende Ansammlung von geometrischer Erfahrung würde z. B. durch das geometrische Zeichnen und durch das Herstellen von Modellen gewonnen. An die Stelle der unfruchtbaren nur für einen beschränkten Zweck passenden Eukuidesschen Methode muß eine freiere und mehr bewußte treten, wie dies schon HANkel betont hat.*) Werden nun etwa bei Wiederholung des geometrischen Stoffes, wenn dieser selbst keine Schwierigkeiten mehr bereitet, die allgemeineren Gesichtspunkte, die Grundsätze des wissenschaftlichen Verfahrens hervorgehoben, und zum Bewußtsein gebracht, wie dies v. NAGEL, $\left.{ }^{* *}\right)$ J. K. BECKER, züglicher Weise getan haben, so kann eine fruchtbringende Wirkung nicht ausbleiben. Ebenso muß auch der naturwissenschaftliche Lehrstoff durch Anschauung und Experiment bekannt sein, bevor eine tiefere denkende Erfassung desselben versucht wird. Auch hier werden die allgemeineren Gesichtspunkte zuletzt hervorzuheben sein.

4) Geschichte der Mathematik. Leipzig 1874.

*a) Geometrische Analysis. Ulm 1886.

(s) In seinen mathematischen Elementarbüchern.

absandlungen ans dem Gebiete der Mathematik. Würzburg $188_{3}$. 
In diesem 'Kreise habe ich' wohl nicht nötig, weiter darzulegen, daß Mathematik und Naturwissenschaften be rechtigte Bildungselemente sind, was ja selbst die Philologen, mit einigem Wiederstreben allerdings; schon zugeben. Hier kann ich vielleicht sogar auf Zustimmung rechnen, wenn ich sage, daß Mathematik und Naturwissenschaften als Unterrichtsfächer für sich allein eine a us gibigere materielle und formale Bildung, eine mehr zeitgemäße, eine allgemeinere Bildung .erzeugen, als die philologischen Fächer für sich allein.

Wie soll nun dieser Anschauung in dem Lehrplan der Mittelschulen Rechnung getragen werden? Mir scheint es unzweifelhaft, daß die Realschule und das Realgymnasium, welche den sprachlichen Unterricht nicht vernachlässigen, dem mittleren Menschen eine zweckmäßigere Bildung geben als das Gymnasium, wenn auch erstere als Vorbildungsschulen für angehende Theologen und Philologen zur Zeit nicht für zureichend gehalten werden. *) Die Gymnasien sind zu einseitig. An diesen ist zunächst zu modifizieren; mit diesen allein wollen wir uns.hier, um nicht weitläufig $\mathrm{zu}$ werden, einen Augenblick beschäftigen. Vielleicht möchte auch eine zweckmäßige Vorbereitungsschule allen Bedürfnissen genügen.

Sollen wir nun in den Gymnasien die Lehrstunden, welche wir zur Verfügung haben, oder welche wir etwa

*) Es ist hier nur von den deutschen Realschulen x. O. und von den deutschen Realgymnasien die Rede. Die österreichischen Realschulen, welche die antiken Sprachen gar nicht berücksichtigen, können selbstverständlich als Vorbildungsschulen für Juristen, Theologen u. s. w. nicht in Betracht kommen.

$\mathrm{Mach}$, Vorlesungen. 3. Aufl. 
den Philologen noch abringen können, mit möglichst viel und möglichst mannigfaltigem, mathematisch-naturwissenschaftlichem St off ausfüllen? Erwarten Sie keine solchen Vorschläge von mir. Niemand wird sie vorbringen, der sich selbst mit naturwissenschaftlichem Denken beschäftigt hat. Gedanken lassen sich anregen und befruchten, wie ein Feld durch Sonnenschein und Regen befruchtet wird. Gedanken lassen sich aber nicht durch Häufung von Stoff und Unterrichtsstunden, überhaupt nicht nach Rezepten heraushetzen und herausdressieren; sie wollen freiwillig wachsen. Gedanken lassen sich auch ebensowenig über ein gewisses $\mathrm{Maß}$ in e in e m Kopf anhäufen, als der Ertrag eines Feldes unbegrenzt gesteigert werden kann.

Ich glaube, daß der für eine zweckmäßige Bildung zureichende Lehrstoff, welcher allen Zöglingen einer Vorbereitungsschule gemeinsam geboten werden muß, sehr bescheiden ist. Hätte ich den nötigen Einfluß, so würde ich mit voller Beruhigung, und in der Überzeugung das Beste zu thun, zunächst in den Unterklassen den gesamten Unterrichtsstoff in den philologischhistorischen und in den mathematisch-naturwissenschaftlichen Fächern bedeutend reduzieren; ich würde die Zahl der Schulstunden und die Arbeitszeit außer der Schule bedeutend einschränken. Ich bin $\mathrm{n}$ icht mit vielen Schulmännern der Meinung, daß ro Arbeitsstunden täglich für einen Knaben nicht $\mathrm{zu}$ viel seien. Ich bin überzeugt, daß die reifen Männer, die so gelassen dieses Wort aussprechen, selbst nicht im stande 
sind $\mathrm{t} a ̈ \mathrm{glich}$ durch so lange Zeit einem ihnen neuen Stoff z. B. elementarer Mathematik oder Physik, die Aufmerksamkeit mit Erfolg zuzuwenden, und ich bitte jeden, der das Gegenteil glaubt, an sich die Probe zu machen. Das Lernen, sowie das Unterrichten, ist keine Bureauarbeit, die nach der schon geläufigen Schablone lange fortgesetzt werden kann. Und auch solche Arbeit ermüdet endlich. Soll der junge Mensch nicht abgestumpft und erschöpft auf die Hochschule kommen, soll er nicht in der Vorbereitungsschule seine Lebenskraft a usge be n, die er daselbst doch $\mathrm{zu}$ sammeln hat, so muß hier eine bedeutende Änderung eintreten. Sehe ich auch von den schädlichen Folgen der Überbürdung in leibliche $r$ Beziehung hier ganz ab, so erscheinen mir die Nachteile für den Verstand schon furchtbar.

Ich kenne nichts Schrecklicheres als die armen Menschen, die $\mathrm{zu}$ viel gelernt haben. Statt des gesunden kräftigen Urteils, welches sich vielleicht eingestellt hätte, wenn sie $\mathrm{nichts}$ gelernt hätten, schleichen ihre Gedanken ängstlich und hypnotisch einigen Worten, Sätzen und Formeln nach, immer auf denselben Wegen. Was sie besitzen, ist ein Spinnengewebe vơn Gedanken, zu schwach, um sich darauf zu stützen, aber kompliziert genug, um zu verwirren.

Wie soll nun aber eine bessere mathematisch-naturwissenschaftliche Erziehung mit Verminderung des Stoffes vereinigt werden? Ich glaube einfach durch Aufgeben des systematis chen Unterrichts, wenigstens soweit er für alle Zöglinge gemeinsam ist. Es scheint 
mir keine Notwendigkeit, daß aus der Mittelschule Menschen hervorgehen, welche kleine Philologen, $z$ u * gleich aber auch kleine Mathematiker, Physiker, Botaniker sind; ja ich sehe gar nicht die Möglichkeit eines solchen Ergebnisses. Ich sehe in dem Streben nach diesem Resultat, in welchem jeder für sein Fach allen andern gegenüber eine Ausnahmsstellung wünscht, den Hauptfehler unserer Schuleinrichtung. Ich wäre zufrieden, wenn jeder Jüngling einige wenige mathematische oder naturwissenschaftliche Entdeckungen so zu sagen mit erlebt, und in ihre weiteren Konsequenzen verfolgt hätte. Der Unterricht würde sich da vorzüglich und natürlich an die ausgewählte Lektüre der großen naturwissenschaftlichen Klassiker anschließen.*) Die wenigen kräftigen und klaren Ideen könnten in den Köpfen ablagern, gründlich verarbeitet werden, und die Jugend würde uns gewiß ein anderes Bild bieten.

Was soll z. B. die Belastung eines jungen Kopfes mit allen botanischen Einzelheiten? Wer nur unter Leitung des Lehrers einmal gesammelt hat, dem tritt statt Indiffe-

$\left.{ }^{2^{*}}\right)$ Ich denke hier an eine zweckmärsige Zusammenstellung von Lesestücken aus den Schriften von Galilei, Huygens, Newton u.s.w. Die Wahl läfst sich leicht so treffen, dafs von einer ernstlichen Schwierigkeit nicht die Rede sein kann. Der Inhalt würde mit den Schülern durchgesprochen und durchexperimentiert. Diesen Unterricht allein würden in den Oberklassen jene Schüler erhalten, welche auf einen systematischen Unterricht in den Naturwissenschaften nicht reflektieren. Diesen Reformvorschlag bringe ich hier nicht zum erstenmal vor. Ich zweifle uibrigens nicht, dafs man auf so radikale Änderungen nur langsam eingehen wird. - Mein vor Jahren ( 1876 ) gemachter Vorschlag, die mathematisch-naturwissenschaftlichen Klassiker durch neue Ausgaben zugänglicher zu machen, oder wenigstens durch eine Chrestomathie der Jugend zu erschliefsen, wurde von einer berühmten Verlagsbuchhandlung damals als buchhändlerisch gänzlich aussichtslos bezeichnet. Derselbe ist seither einer. seits durch die Ostwald schen Ausgaben, die Neudrucke von Mayer und Müller u. s. w., anderseits durch das Buch von $\mathrm{Da}$ n $\mathrm{n} \mathrm{m}$ an $\mathrm{n}$ verwirklicht worden. 
rentem überall Bekanntes oder Unbekanntes entgegen, wodurch er angeregt wird; er hat einen ble i be n d e n Gewinn. Ich spreche hier nur die Ansicht eines befreundeten sachverständigen Schulmannes aus. Es ist auch gar nicht nötig, daß alles, was in der Schule vorgebracht wurde, auch gelernt werde. Das Beste, was wir gelernt haben, und was uns fürs Leben geblieben ist, ist uns niemals abexaminiert worden. Wie kann der Verstand gedeihen, wenn Stoff auf Stoff gehäuft, und auf Unverdautes noch Neues aufgeladen wird? Es handelt sich ja gar nicht um Anhäufung von positivem Wissen, sondern vielmehr um geistige Übung. Es scheint ferner unnötig, daß in jeder Schule genau dasselbe getrieben werde. Ein philologisches, e in historisches, e in mathematisches und ein naturwissenschaftliches Fach als gemeinsame Unterrichtsgegenstände für alle Zöglinge können für die geistige Entwicklung alles leisten. Die gegenseitige Anregung müßte im Gegenteil durch eine größere Mannigfaltigkeit der positiven Bildung der Menschen wesentlich gefördert werden. Die Uniformierung paßt ja gewiß vortrefflich fürs Militär, für die Köpfe taugt sie aber gar nicht. Das hat schon Karl V. erfahren, und man hätte es nicht wieder vergessen sollen. Lehrer und Schüler bedürfen im Gegenteil eines beträchtlichen individuellen Spielraumes, wenn sie leistungsfähig sein sollen.

Ich bin mit JOH. KarL BECKer der Meinung, daß yon jedem Fache genau festgestellt werden muß, welchen Nutzen sein Studium gewährt, und wie viel von demselben für jeden nötig ist. Was über dieses Maß hinaus- 
geht, müßte, aus den Unterklassen wenigstens, unbedingt verbannt werden. In Bezug auf Mathematik scheint mir BECKer*) diese Aufgabe gelöst zu haben.

Etwas anders stellt sich die Forderung in Bezug auf die Oberklassen. Auch hier braucht der allen Zög. lingen $\mathrm{g}$ e meins a me Lehrstoff ein be scheidenes Maß nicht $z u$ überschreiten. Allein bei den vielen Kenntnissen, welche ein junger Mann heutzutage für seinen Beruf erwerben muß, geht es nicht mehr an, daß ein Dezennium der Jugend mit bloßen Präludien vergeudet werde. Die Oberklassen müssen eine wirkliche ausgiebige Vorbereitung für das Berufsstudium geben, und sollen nicht bloß nach den Bedürfnissen der künftigen Juristen, Theologen und Philologen zugeschnitten sein. Natürlich wäre es aber sinnlos und unmöglich, denselben Menschen z u gl e i ch für die verschiedensten Berufszweige ausgibig vorzubereiten. Die Schule würde da, wie schon Lichtenberg fürchtete, nichts erzielen, als eine Auslese der Abrichtungsfähigsten, und gerade die größten Spezialtalente, die sich nicht jede beliebige Dressur gefallen lassen, würden von der Wettbewerbung ausgeschlossen. Demnach muß in den Oberklassen notwendig eine gewisse Ler $\mathrm{n}$ freihe it eingeführt werden, vermöge welcher es jedem, der über die Wahl seines Berufes sich klar ist, freisteht, sich vorzugsweise dem Studium der philologisch-historischen oder der mathematisch-naturwissenschaftlichen Fächer zu widmen. Dann kann der gegenwärtig behandelte Stoff beibehalten, in manchen Fällen vielleicht noch zweckmäßig vermehrt

\$ ) Die Mathematik als Lehrgegenstand des Gymnasiums. Berlin 1883 . 
werden, ${ }^{*}$ ) ohne daß eine größere Belastung des Schülers durch viele Fächer oder eine Vermehrung der Stundenzahl nötig wird. Bei mehr homogener Arbeit steigt auch die Leistungsfähigkeit des Schülers, indem ein Teil der Arbeit den andern stiitzt, statt ihn zu behindern. Wählt aber ein junger Mann später noch einen anderen Beruf, dann ist es seine Sache, das ihm Fehlende nachzuholen. Der Gesellschaft wird es gewiß nicht schaden, und sie wird es nicht als Unglück empfinden, wenn etwa mathematisch gebildete Philologen und Juristen, oder philologisch gebildete Naturforscher auftauchen.**)

Die Einsicht ist schon sehr verbreitet, daß die late in isch-griechische Bildung längst nicht mehr dem allgemeinen Bedürfnis entspricht, daß es eine mehr zeitgemäße, eine allgemeinere Bildung gibt. Mit dem Namen allgemeine Bildung wird allerdings viel Mißbrauch getrieben. Eine wirkliche allgemeine Bildung ist gewiß sehr selten. Die Schule ist wohl

* So unzweckmärsig es ist, dafs auch die künftigen Mediziner und Naturforscher der Theologen und Philologen wegen mit dem Griechischen belastet werden, so unzweckmäfsig wäre es, die Theologen und Philologen der Mediziner wegen etwa zum Studium der analytischen Geometrie anzuhalten. Übrigens kann ich nicht glauben, dafs dem Mediziner, wenn er nur sonst im quantitativen Denken geübt ist, die Unkenntnis der analytischen Geometrie ernstlich hinderlich werden könnte. Einen besonderen Erfolg kann man an den Abiturienten der österreichischen Gymnasien, die ja alle analytische Geometrie getrieben haben, im allgemeinen nicht wahrnehmen.

**\$) Direktor Dr. Krumme in Braunschweig hat mich im Gespräch aufmerksam geinacht, dafs das hier vorgeschlagene Prinzip der beschränkten J.ernfreiheit an den dänischen Gelehrtenschulen, die unseren Gynınasien entsprechen, bereits mit bestem Erfolg durchgeführt ist. Die Dänischen Gelehrtenschulen sind sechsklassige Einheitsschulen mit Bifurkation der beiden oberen Klassen. Ich entnehme Krummes, „pädagogischem Archiv“ I883 S. 544 den Lehrplan der beiden oberen Klassen. In der folgenden Tabelle 
kaum im stande diese zu bieten; sie kann dem Schüler höchstens das Bedürfnis nach derselben ins Herz legen. Seine Sache ist es dann, sich je nach seinen Kräften eine mehr oder weniger allgemeine Bildung zu verschaffen. Es wäre wohl auch recht schwer, zur Zeit eine jedermann zufriedenstellende Definition der allgemeinen Bildung zu geben, noch schwerer eine solche, welche etwa für roo Jahre vorhalten würde. Das Bildungsideal ist eben sehr verschieden. Dem Einen scheint „selbst durch einen frühen Tod" die Kenntnis des klassischen Altertums nicht zu teuer erkauft. Wir haben auch nichts dagegen, daß Dieser und seine Gesinnungsgenossen ihr Ideal in ihrer Weise verfolgen. Dagegen wollen wir aber energisch protestieren, daß solche Bildungsideale an unsern $\mathrm{K}$ indern verwirklicht werden. Ein anderer, Platon z. B., stellt wieder in der Geometrie unwissende Menschen

bedeutet SG die sprachlich-geschichtliche, MN die mathematisch-naturwissenschaftliche Abteilung und $\mathrm{G}$ die beiden Abteilungen gemeinsamen Unterrichtsgegenstände.

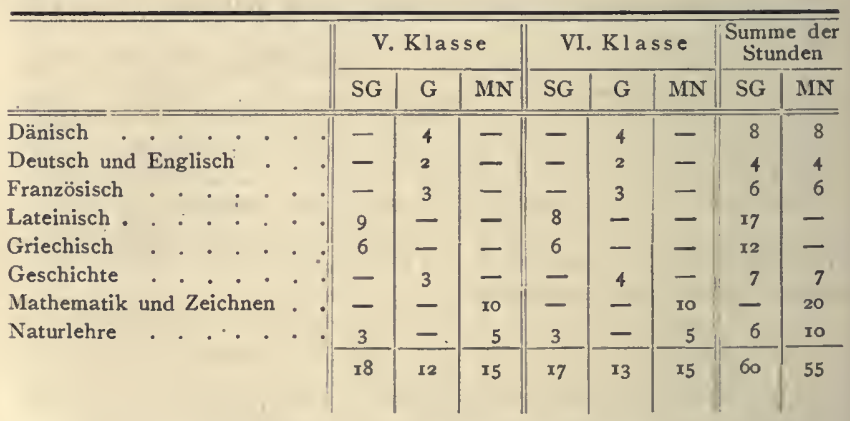

Die in derselben Richtung interessante Schulordnung in Norwegen ist etwas zu kompliziert, um sie hier kurz darzulegen. Näheres hieriiber im ,pädagog. Archiv". 1884. S. 497. 
auf die Stufe der Tiere. *) Hätten solche beschränkte Urteile die Macht der Zauberin Kirke, dann würde mancher, der sich vielleicht mit Recht für sehr gebildet hält, eine nicht sehr schmeichelhafte Verwandlung an sich verspüren. Suchen wir also mit unserem Unterrichtswesen den Bedürfnissen der Gegenwart gerecht $\mathrm{zu}$ werden, und schaffen wir keine Vorurteile für die Zukunft!

Wie kommt es doch, müssen wir uns fragen, daß etwas so Unzeitgemäßes, wie die Gymnasialeinrichtung, sich so lange gegen die öffentliche Meinung halten konnte? Die Antwort ist einfach. Die Schulen waren erst eine Unternehmung der Kirche, nachher, seit der Reformationszeit, eine Staatsunternehmung. Solche gr o B e Unternehmungen bieten manche Vorteile. Dem Unterricht können Mittel zugeführt werden, wie sie eine Privatunternehmung (wenigstens in Europa) kaum auftreiben würde. Es kann in vielen Schulen nach demselben Plan gearbeitet, und dadurch ein Experiment im Großen angestellt werden, das sonst wieder unmöglich wäre. Ein einzelner Mann, der eben Einfluß und Einsicht hat, kann unter diesen Umständen Bedeutendes in Förderung des Unterrichtes leisten.

Allein die Sache hat auch ihre Kehrseite. Die eben im Staate herrschende Partei arbeitet für sich, benutzt die Schule für sich. Jede Konkurrenz ist ausgeschlossen, ja jeder ausgibige Versuch einer Verbesserung ist unmöglich, wenn der Staat nicht selbst ihn unternimmt, oder

*) Vgl. M. Cantor, Geschichte der Mathematik. Leipzig r88o. I. Bd.S. 193. 
wenigstens duldet. Durch die Un iformität der Volkserziehung wird ein einmal geltendes Vorurteil in Permanenz erklärt. Die höchste Intelligenz und der kräftigste Wille vermöchte nicht, dasselbe auf einmal $\mathrm{zu}$ brechen. Ja, da alles dieser Anschauung angepaßt ist, so wäre eine plötzliche Wandlung auch materiell un. möglich. Eben die beiden, den Staat fast noch allein regierenden Stände, die Juristen und Theologen, kennen nur die einseitige, vorwiegend philologische Bildung, welche sie in der Staatsschule erworben haben, und wollen nur diese geachtet und geschätzt wissen. Andere nehmen aus Leichtgläubigkeit diese Meinung an. Andere beugen sich, ihren eigenen Wert für die Gesellschaft unterschätzend, vor der.Macht der herrschenden Meinung. Wieder andere affektieren die Meinung der herrschenden Stände, um mit diesen auf gleicher Stufe der Achtung zu bleiben, sogar gegen ihre bessere Überzeugung. Ich will keine Beschuldigung aussprechen, muß aber doch gestehen, daß mir das Verhalten der Ärzte gegenüber der Berechtigungsfrage der Realschulabiturienten zuweilen diesen Eindruck gemacht hat. Bedenken wir endlich, daß ein einflußreicher Staatsmann selbst innerhalb der Schranken, welche Gesetz und öffentliche Meinung ihm ziehen, dem Unterricht auch sehr schaden kann, indem er seine einseitige Ansicht für unfehlbar hält, und dieselbe in rïcksichtsloser, unduldsamer Weise zur Geltung bringt, was nicht nur geschehen kann, sondern wiederholt wirklich geschehen ist, $\%$ ) so sehen wir das Staatsmonopol doch mit etwas anderen Augen an

*) Vgl. Paulsen, a. a. O. S. 607.688.

\section{Digitized by Microsoft (B)}


Und darüber können wir nicht im Zweifel bleiben, daß die Gymnasien in ihrer gegenwärtigen Form längst nicht mehr bestehen würden, wenn der $\mathrm{Sta}$ at sie nicht gehalten hätte.

Diese Dinge müssen sich nun ändern. Sie werden sich nicht von selbst, nicht ohne unser kräftiges Zutun und jedenfalls nur langsam ändern. Der Weg ist aber vorgezeichnet. Die Volksvertretung muß auf die Schulgesetzgebung größeren und stärkeren Einfluß nelımen. Dazu müssen aber die hierher gehörigen Fragen vielfacls öffentlich und mit Freimut erörtert werden, damit sich die Ansichten klären. Alle die, welche die Unzulänglichkeit des Bestehenden erkennen, müssen sich zu einem großen Bunde vereinigen, damit ihre Meinung Nachdruck erhalte, und die einzelne Stimme nicht ungehört verhalle.

Meine Herren! kürzlich habe ich in einer vortrefflichen Reisebeschreibung gelesen, daß die $\mathrm{Ch}$ in ese n nur ungern von.Politik sprechen. Ein derartiges Gespräch wird gewöhnlich mit der Bemerkung abgebrochen: „Darum mögen sich diejenigen kümmern, die es angeht, und die dafür bezahlt sind." Es will mir nun scheinen, daß es nicht nur den Staat, sondern auch jeden von uns sehr stark angeht, wie unsere Kinder in den öffentlichen Schulen auf unsere Kosten erzogen werden.

\section{$\mathrm{N}$ achtrag.}

[Seit Abhaltung des vorstehenden Vortrages (1886) hat sich manches in erfreulicher Weise geändert. Die Vertreter der klassischen Philologie betonen zwar in Versammlungen noch immer durch Resolutionen ihren Standpunkt, allein die 
Logik der Tatsachen macht sich dennoch geltend, und drängt sogar Staatsmänner, auch gegen ihr Gefühl und gegen die Traditionen ihrer Erziehung, in öffentlichen Reden für die Förderung der Realschulen und technischen Hochschulen, kurz für die Wertschätzung der mathematisch-naturwissenschaftlichen Bildung einzutreten. Wenn wir auch dem $\mathrm{Zu}$ geständnis des Ingenieur- und Doktortitels an die Techniker keine zu große Bedeutung zuschreiben, eine abgerungene Anerkennung der Gleichwertigkeit aller Wissenschaft liegt $\mathrm{doc} h$ in demselben. Vielleicht dürfen wir auch erwarten, $\mathrm{da} ß$ in nicht $\mathrm{zu}$ ferner Zeit das mittelalterliche $\mathrm{Z} \mathrm{u} \mathrm{n} \mathrm{ft}$ w e s e $\mathrm{n}$, welches ja im Gewerbe glücklich überwunden ist, endlich auch aus dem wissenschaftichen Leben allmählich ganz verschwindet. Hoffentlich wird dann der Mensch nicht mehr nach einer abgesessenen Schulbank oder nach einem Diplom, sondern nach seinen Leistungen gelten. Hiermit werden auch die raffiniert ausgedachten Schranken fallen, durch welche wißbegierige begabte reifere Menschen, welche den systematischen Weg verfehlt haben, in barbarischer Weise von Bildungsmitteln, Bildungsstätten und gelehrter Berufen fern gehalten werden. Die ,University Extension` mit ihren unerwarteten Erfolgen ist ein kleiner Anfang hierzu.

In dem Vortrag durfte ich den Boden des Bestehenden nicht verlassen. Für weitere Ausblicke bot sich nur wenig Anla.ß. Ich möchte jedoch bei dieser Gelegenheit Farbe bekennen in Bezug auf meine Bildungs- und Unterrichtsideale, wenn auch die Verwirklichung derselben noch in ferner Zukunft liegt. Ich denke mir die künftigen Bildungsanstalten, von der niedersten bis zur höchsten, als 
vom Staate ganz unabhängige Privatunternehmungen. Dieselben werden vom Staate nicht erhalten, dieser verleiht ihnen auch keinerlei behördliche. Vollmachten, sie unterliegen dafür aber auch keinerlei Bevormundung. Ihr Erfolg hängt bei der freien Konkurrenz ganz von deren Leistung und der Gegenleistung des sie benützenden Publikums ab; sie werden höchstens, wie in Amerika, durch Stiftungen gefördert. $\mathrm{Da} \beta$ das Publikum die nötige Reife habe, und den Wert des Wissens schätzen könne, ist eine Voraussetzung, die sich endlich von selbst erfüllen muß. Der Zutritt zu diesen Anstalten steht jedem frei, und jeder hat für die nötige Vorbildung selbst zu sorgen. Dies schließt nicht aus, daß der Staat nach wie vor seine PrüfungsKommisionen aufstellt, um sich und seine Bürger vor Schaden zu schützen. Die geeignetsten Wege zur Erwerbung des Wissens und der Bildung zu en t d e c k e $\mathrm{n}$ kann aber nicht die Aufgabe der Staatsbehörde sein. Dies muß der freien Konkurrenz der Unterrichtenden vorbehalten bleiben.

Wichtig scheint es mir, daß die Fach- und Berufsbildung viel früher beginne, als es gegenwärtig üblich ist. Die Masse der für den Beruf zư erwerbenden Spezialkenntnisse, die eben nur in der Jugend leicht angeeignet wird, rechtfertigt dies hinreichend. Es muß aber auch wesentlich zur Charakterbildung beitragen, wenn der junge Mensch frühzeitig den Ernst und die Verantwortlichkeit des Lebens kennen lernt. Die Erwerbung einer umfassendern allgemeinen Bildung, für welche der Gymnasiast seinem physischen Alter nach nicht reif ist, da ihm das Wichtigste und Aufklärendste verschwiegen werden muß, fällt zweckmäßig demErwachsenen

\section{Digitized by Microsoft ${ }^{\circledR}$}


als eigene Angelegenheit zu. Der Erwachsene lernt ja bei den heutigen Behelfen manches spielend und sich unterhaltend, was demGymnasiasten lange Zeit und vielÜberwindung kostet.

Auch das Bildungsniveau und die Berufswahl der Frauen soll in keiner Weise beschränkt werden. Die Hindernisse, die man aus Besorgnis vor der Konkurrenz und dem Einfluß der Frauen hier auftürmt, werden auf die Dauer dem nivellierenden Zug der Zeit nicht widerstehen. Diese Bewegung kann man verzögern, aber nicht aufhalten, und niemand wird viel Ehre davon haben, der es versucht. Die Gefahr dieser Wandlung wird gewiß übertrieben und überschätzt. Was für ein Unglück soll daraus entstehen, wenn die Frauen, welche doch gewiß in der Konsumtion der Güter mit uns konkurrieren, auch an unserer Arbeit teilnehmen? Die Natur wird mit dem Problem des Gleichgewichts der Geschlechter schon zu stande kommen. Ohne bedeutenden Einfluß auf alle, selbst politische Verhältnisse ist die Frau auch jetzt nicht. Wer wollte aber den Einfluß einer Frau, welche den Ernst des Lebens und der Arbeit kennen gelernt hat, nicht jenem einer kulturell minderwertigen Frau vorziehen? Die unkultivirte Frau pflegt und bewahrt sorgfältig jede Art von hergebrachtem Aberglauben, bis zur Furcht vor der Zahl I 3 und vor dem verschütteten Salz, überträgt denselben gewissenhaft auf die künftige Generation, und ist auch jederzeit das dankbarste Angriffsobjekt für alle Rückschrittsbestrebungen. Wie soll die Menschheit sicher fortschreiten, so lange nicht einmal die Hälfte derselben auf erhellten Wegen wandelt! — I902.] 


\section{Über Erscheinungen an fliegenden Projektilen.*)}

Die Menschen fühlen sich heutzutage verpflichtet, zuweilen für recht fragwürdige Ziele und Ideale sich gegenseitig in kürzester Zeit möglichst viele Löcher in den Leib zu schießen. Und ein anderes Ideal, welches zu den vorgenannten meist in schärfstem Gegensatze steht, gebietet ihnen zugleich, diese Löcher von kleinstem Kaliber herzustellen, und die hergestellten möglichst rasch wieder zu stopfen und zu heilen.

Da unter diesen Umständen das Schießen, und was daran hängt, in unserem heutigen Leben eine sehr wichtige, wo nicht die wichtigste Sache ist, werden Sie vielleicht Ihr Interesse für eine Stunde einigen Versuchen zuwenden wollen, welche zwar nicht in kriegerischer, wohl aber in wissenschaftlicher Absicht unternommen worden sind, und welche über die Vorgänge beim Schießen einige Autklärung geben.

Die heutige Naturwissenschaft ist bestrebt, ihr Weltbild nicht auf Spekulationen, sondern nach Möglichkeit auf beobachtete Tatsachen aufzubauen: sie prüft ihre Kon-

*) Vortrag gehalten den ro. November 1897 im Wiener Verein zur Verbreitung naturwissenschaftlicher Kenntnisse. 
struktionen wieder durch die Beobachtung. Jede neu beobachtete Tatsache ergänzt dieses'Weltbild, und jede Abweichung einer Konstruktion von der Beobachtung macht auf eine Unvollkommenheit, auf eine Lücke desselben aufmerksam. Das Gesehene wird durch das Gedachte, welches selbst nur das Ergebnis des vorher Gesehenen ist, geprüft und ergänzt. Es hat deshalb einen besonderen Reiz, das, was man nur theoretisch erschlossen hat, oder theoretisch vermutet, der Prüfung durch die Beobachtung unmittelbar zugänglich, d. h. wahrnehmbar zu ,machen.

Als ich im Jahre $188 \mathrm{I}$ in Paris einem Vortrage des belgischen Ballistikers MeLsess zuhörte, welcher die Vermutung aussprach, daß Projektile von hoher Geschwindigkeit Massen von verdichteter Luft vor sich herführen, welche an den getroffenen Körpern nach seiner Meinung - gewisse bekannte explosionsartige Wirkungen hervorbringen sollten, entstand in mir der Wunsch, diese Vorstellungen durch das Experiment zu prüfen und den Vorgang, wenn derselbe besteht, wahrnehmbar zu machen. Der Wunsch war um so lebhafter, als ich mir sagen konnte, daß alle Mittel, denselben zu erfüllen, schon bereit lagen, und als ich dieselben zum Teil schon bei anderen Arbeiten angewandt und erprobt hatte.

Machen wir uns zunächst die Schwierigkeiten klar, die wir bei Verfolgung dieses Zieles zu überwinden haben. Es soll das mit vielen hundert Metersekunden Geschwindigkeit bewegte Projektil samt den Veränderungen, welche es in der umgebenden Luft hervorbringt, beobachtet werden. Schon der undurchsichtige feste Körper, das Projektil, ist 
unter solchen Umständen nur ausnahmsweise sichtbar, nur wenn es von bedeutender Größe ist, und wenn wir die Flugbahn in starker perspektivischer Verkürzung sehen, so daß die Geschwindigkeit scheinbar sehr vermindert ist. Wir sehen ein größeres Projektil recht gut, wenn wir hinter dem Geschütz stehend in der Flugbahn visieren, oder in dem weniger behaglichen Fall, wenn das Projektil auf uns zukommt. Dennoch gibt es, da ein sehr einfaches und radikales Mittel, sehr rasch bewegte Körper so bequem $\mathrm{zu}$ beobachten, als ob dieselben an irgend einer Stelle ihrer Bahn ruhend festgebannt wären. Es ist dies die Beleuchtung durch den lichtstarken elektrischen Flaschenfunken von äußerst kurzer Dauer, natürlich im dunklen Raum. Da nun aber zur vollständigen Auffassung eines Bildes eine gewisse nicht unbeträchtliche Zeit nötig ist, so wird man" natürlich vorziehen, die Momentphotographie zur Fixięrung dieses Bildes von äußerst kurzer Dauer anzuwenden, welches man dann in aller Bequemlichkeit betrachten und analysieren kann. Diese Mittel sind nun wirklich in der nachher anzugebenden Weise verwendet worden.

$\mathrm{Zu}$ dieser Schwierigkeit kommt in Bezug auf die Luft noch eine andere, größere. Die Luft ist gewöhnlich überhaupt nicht sichtbar, auch wenn sie ruht. Nun soll aber noch sehr rasch bewegte Luft sichtbar gemacht werden.

Damit ein Körper sichtbar sei, muß derselbe entweder selbst Licht aussenden, leuchten, oder das auf denselben fallende Licht irgendwie beeinflussen, dasselbe ganz oder teilweise aufnehmen, absorbieren, oder ablenkend, also re-

Mach, Vorlesungen. 3. Auf. 
flektierend oder brechend auf dasselbe wirken. Man kann die Luft nicht wie eine Flamme sehen, denn sie leuchtet nur ausnahmsweise, etwa in einer GeIssLeRschen Röhre. Die Luft ist sehr durchsichtig und farblos; man kann sie also auch nicht so sehen wie einen dunklen oder farbigen Körper, nicht so wie Chlorgas, Brom- oder Joddampf. Die Luft hat endlich einen so kleinen Brechungsexponenten, eine so geringe ablenkende Wirkung auf das Licht, daß diese gewöhnlich ganz unmerklich ist.

Ein Glasstab in der Luft oder im Wasser ist sichtbar. Derselbe ist aber fast unsichtbar in einer Mischung von Benzol und Schwefelkohlenstoff, welche denselben mittleren Brechungsexponenten hat wie das Glas. Glaspulver in derselben Mischung zeigt eine lebhafte Farbe, weil die Gleichheit des Exponenten wegen der Farbenzerstreuung nur für eine Farbe zutrifft, welche ungehindert durch die Mischung geht, während die anderen Farben zahlreiche Reflexionen erleiden. *)

Wasser in Wasser, Alkohol in Alkohol ist unsichtbar. Mischt man aber Alkohol mit Wasser, so sieht man sofort die Flocken des Alkohols im Wasser, oder umgekehrt. So sieht man nun unter günstigen Umständen doch auch die Luft. Man sieht ein Flimmern und Zittern der Gegenstände, wenn man dieselben über ein von der Sonne beschienenes erhitztes Dach hinweg betrachtet, oder über einen der Kohlenöfen hin, die zur Asphaltierung der Straße dienen. $\mathrm{Da}$ mischen sich eben Flocken von heißer

*) Christiansen, Wiedemanns Annalen XXIII, S. 298 XXIV, S. 439. (1884, 1885.) 
und kalter Luft von merklich verschiedener Lichtablenkung.

In ähnlicher Weise erkennt man in ungleichmäßigem Glase die stärker ablenkenden Teile, die Schlieren, in der weniger ablenkenden Masse. Solche Gläser sind für optische Zwecke unbrauchbar. Man hat deshalb der Untersuchung derselben zum Zwecke der Ausscheidung besondere Aufmerksamkeit zugewendet, und dadurch hat sich eben die feine Untersuchungsmethode, die Schlierenmethode, entwickelt, welche für unsern Zweck geeignet ist.

Schon Huygens hat zur Erkennung der Schlieren die angeschliffenen Gläser in schiefer Beleuchtung, zuweilen aus größerer Entfernung, um der Wirkung der Ablenkung Raum zu geben, betrachtet, und hat dann mit Hilfe eines Fernrohres beobachtet. Zur höchsten Vollkommenheit ist die Schlierenmethode durch TOEPLER entwickelt worden, der folgendes Verfahren anwendet.

Eine kleine Lichtquelle $a$ (Fig. 48) beleuchtet eine Linse $L$, welche von ersterer ein kleines Bild $b$ entwirft. Stellt man das Auge so, daß dieses Bild in dessen Pupille fällt, so scheint jetzt die ganze Linse, wenn sie vollkommen ist, gleichmäßig erleuchtet, weil alle Stellen derselben Strahlen ins Auge senden.

Grobe Fehler der Form oder der Gleichmäßigkeit des Glases werden nur dann sichtbar, wenn die Ablenkungen so stark ausfallen, daß das Licht mancher Stellen neben der Pupille vorbeigeht. Blendet man aber das Bild $b$ mit dem Rande eines kleinen Schirmes mehr oder weniger ab, so sieht man nun auf der in abgeschwächter Helligkeit 
erscheinenden Linse jene Stellen heller, deren Licht etwa durch stärkere Ablenkung noch $\mathrm{n}$ eben der Blendung ins Auge gelangt, jene aber dunkler, welche infolge entgegen-

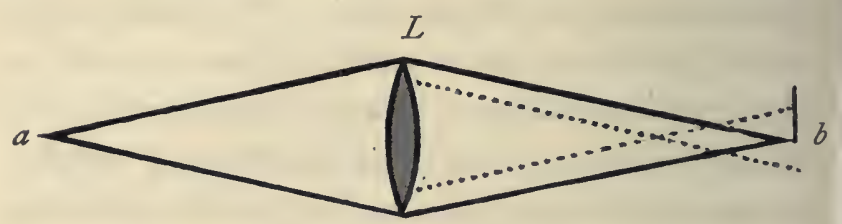

Fig. 48 .

gesetzter Ablenkung ihr Licht a uf die Blendung senden. Dieser Kunstgriff der Abblendung, welchen schon Foucault bei Untersuchung der Spiegelfehler angewendet hatte, erhöht die Empfindlichkeit der Untersuchung ungemein. Dieselbe wird noch weiter erhöht durch ToEplers Anwendung eines Fernrohres hinter der Blendung. So vereinigt also Toeplers Methode die Vorzüge des Huygensschen und des Foucaultschen Verfahrens.

Diese Methode ist nun so empfindlich, daß selbst geringe Ungleichmäßigkeiten der Luft in der Umgebung der Linse zum deutlichen Ausdruck kommen, was ich nur durch e in Beispiel erläutern will.

Ich stelle eine Kerze vor die Linse $L$ und eine zweite Linse $M$ so, daß die Kerzenflamme auf dem Schirm $S$ abgebildet wird. Sobald in den Sammelpunkt $b$ des von $a$ ausgehenden Lichtes die Blendung eingeschoben wird, sehen Sie die Abbildung der durch die Kerzenflamme in der Luft eingeleiteten Dichtenänderungen und Bewegungen auf dem Schirm hervortreten. Von der Stellung der Blendung $b$ hängt die Deutlichkeit der ganzen Er- 
scheinung ab. Beseitigung von $b$ macht alles undeutlich. Bei Ausschaltung der Lichtquelle $a$ sehen wir bloß das

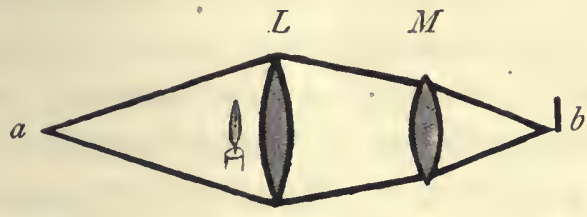

Fig. 49.

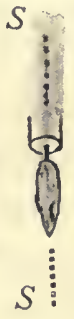

Bild der Kerzenflamme auf dem Schirm $S$. Nehmen wir nun die Flamme weg und lassen $a$ leuchten, so erscheint der Schirm $S$ gleichmäßig hell.*)

Nachdem ToEpler lange vergebens versucht hatte, die durch Schallbewegungen in der Luft erregten Ungleichmäßigkeiten nach diesem Prinzip sichtbar zu machen, führten ihm glückliche Umstände bei Untersuchung der elektrischen Funken solche Schallwellen vor. Die von den elektrischen Funken in der Luft erregten, den Knall begleitenden, Wellen sind nämlich kurz und kräftig genug, um nach diesem Verfahren sichtbar zu werden.

So sieht man, wie durch sorgfältige Beachtung der Spuren einer Erscheinung und durch sehr allmähliche zweckmäßige kleine Abänderungen der Umstände und der Methoden schließlich höchst überraschende Resultate erzielt werden können. Wer z. B. nur die Erscheinung am geriebenen Bernstein und die elektrische Straßenbeleuchtung

*) Die zu diesen Demonstrations-Experimenten nötigen achromatischen Linsen und Apparate bat Herr K. Fritsch (vorm. Prokesch) mit dankenswerter Freundlichkeit zu Verfügung gestellt. 
ohne die in kleinen Schritten von der einen Tatsache zur andern überführenden Zwischenglieder kennt, dem werden diese beiden Tatsachen einander so fremdartig erscheinen als etwa Saurier und Vogel dem gewöhnlichen Beobachter, dem die embryologischen, anatomischen und paläontologischen $Z$ wischenglieder unbekannt sind. Der Wert des Zusammenarbeitens der Forscher durch Jahrhunderte, von welchen jeder an die Arbeit der Vorgänger anknüpfen und dieselbe fortführen kann, wird an solchen Beispielen zum klaren Bewußtsein gebracht. Und diese Erkenntnis zerstört in aufklärender Art dem Zuschauer den Eindruck des Wunderbaren, und schützt zugleich in heilsamer Weise den Arbeiter der Wissenschaft vor Überhebung. Ich muß auch noch die ernüchternde Bemerkung hinzufügen, daß alle Kunst vergebens wäre, wenn nicht die Natur selbt wenigstens schwache Fäden darbieten wïrde, welche von einem verborgenen Vorgang in das Gebiet des Beobachtbaren führen. So dürfen wir uns also nicht wundern, daß einmal unter besonders günstigen Umständen z. B. eine sehr kräftige, durch einige hundert Pfund explodierendes Dynamit erregte Schallwelle im Sonnenschein einen direkt beobachtbaren Schatten wirft, wie Bors kürzlich berichtet hat. Wären die Schallwellen absolut ohne Einfluß auf das Licht, so könnte dies nicht vorkommen, aber alle unsere Künste wären dann auch vergebens. So ist auch die Erscheinung am Projektil, die ich Ihnen zeigen werde, allerdings in sehr unvollkommener Weise von dem französischen Billistiker JoURNÉE gelegentlich gesehen worden, indem derselbe einfach mit einem 
Fernrohr einem Projektil nachvisierte, wie ja auch unsere Kerzenschlieren schwach unmittelbar sichtbar sind, und bei hellem Sonnenschein sich schattenhaft auf einer gleichmäßigen weißen Wand abbilden.

Momentbeleuchtung durch den elektrischen Funken, Schlierenmethode und photographische Fixierung sind nun die Hilfsmittel, welche zur Erreichung unseres Zieles führen.

Im Sommer I 884 stellte ich meine ersten Versuche mit einer Scheibenpistole an, indem ich durch das Feld einer Schlierenaufstellung schoß, und dafür sorgte, daß das Projektil, während sich dasselbe im Felde befand, einen beleuchtenden Flaschenfunken auslöste, welcher dieses Bild im photographischen Apparat fixierte. Das Bild des Projektils erhielt ich ohne Schwierigkeiten sofort. Auch sehr zarte Bilder von Schallwellen (Funkenwellen) konnte ich mit Hilfe der damals noch etwas mangelhaften Trockenplatten leicht gewinnen. Eine vom Projektil erzeugte Luftverdichtung zeigte sich aber nicht. Ich untersuchte die Geschwindigkeit des Projektils und fand dieselbe zu 240 Metersekunden, also beträchtlich kleiner als die Schallgeschwindigkeit. Es war mir nun alsbald klar, daß unter diesen Umständen keine merkliche Verdichtung entstehen kann, da ja eine solche mit der Schallgeschwindigkeit (340 Metersekunden) fortschreitet, also dem Projektil vorauseilt und entflieht.

Von der Existenz des vermuteten Vorganges bei einer 340 Metersekunden überschreitenden Projektilgeschwindig- 
keit war ich aber so fest überzeugt, daß ich Herrn Professor Dr. Salcher in Fiume bat, einen solchen Versuch mit hoher Projektilgeschwindigkeit anzustellen. Im Sommer r 886 führte Salcher mit Professor Riegler in einem von der Leitung der k. k. Marineakademie zur Verfügung gestellten passenden Raume, ganz entsprechend meiner eigenen früheren Versuchsanordnung, solche Versuche aus, und das erwartete Ergebnis war auch sofort da. Die Erscheinung stimmte sogar der Form nach mit der Skizze, die ich voraus entworfen hatte. Bei weiteren: Versuchen traten noch neue unerwartete Züge hinzu.

Es wäre nun unbillig gewesen, als Ergebnis dieser ersten Versuche gleich sehr vollkommene und in allen Teilen deutliche Bilder zu verlangen. Genug, daß der Erfolg nun gesichert war, und daß ich überzeugt sein konnte, weitere Arbeit und weiteren Aufwand nicht nutzlos zu verlieren. Hierfür bleibe ich beiden Herrn zu großem Dank verpflichtet.

Die hohe Marinesektion des k. k. Kriegsministeriums stellte nun SALChER eine Kanone für einige Schüsse in Pola zur Verfügung, und ich selbst folgte mit meinem Sohne, damals Studenten der Medizin, einer freundlichen Einladung der Firma KRUpp nach Meppen, wQ wir mit einem für Versuche im Freien, auf dem Schießplatze, unvermeidlichen Aufwande von Apparaten einige Versuche ausführten, die sämtlich schon leidlich gute und vollständige Bilder lieferten. Es wurden hierbei einige kleine Fortschritte erzielt. Die auf den Schießplätzen gemachten Erfahrungen befestigten aber die Überzeugung, daß wirklich gute Resultate nur bei sorgfältigster Ausführung der Ver- 
suche in einem $\mathrm{zu}$ diesem Zwecke gut adaptierten Laboratorium zu erzielen seien. Es kommt auch hierbei gar nicht auf die Kostspieligkeit der Mittel an, indem z. B. die Größe des Projektils gar nicht maßgebend ist. Bei gleichen Projektilgeschwindigkeiten sind nämlich die Ergebnisse durchaus gleichartig, ob die Projektile groß oder klein sind. Die Veränderung der Anfangsgeschwindigkeit durch Veränderung der Ladung und des Projektilgewichtes hat man aber bei Laboratoriumsversuchen ganz in der Hand, sobald man sich einmal darauf eingerichtet hat. Solche Versuche habe ich nun in meinem Prager Laboratorium teils in Gemeinschaft mit meinem Sohné ausgeführt, teils sind dieselben später von diesem allein ausgeführt worden. Letztere sind die vollkommensten, und nur von diesen soll hier ausführlicher gesprochen werden.*)

Denken Sie sich also eine Aufstellung für Schlieren. beobachtungen, natürlich im Dunkelzimmer.

Damit die Beschreibung nicht zu kompliziert werde, will ich mich auf das Wesentliche beschränken, und feinere Einzelheiten, welche mehr für die Technik des Versuches von Belang sind, als für das Verständnis, weglassen. Das Projektil fliegt also durch das Feld des Schlierenapparates; es wird, während sich dasselbe in der Mitte des Feldes befindet, ein Beleuchtungsfunken ausgelöst, und das Bild wird durch die photographische Kammer hinter der Blendung fixiert. Bei den letzten und besten Versuchen war die Linse $L$ durch einen sphärischen

*) Ich habe dankend hervorzuheben, dafs zahlreiche österreichische Offiziere diese Versuche privatim gefördert haben. Vgl. auch die Studien in den Sitzungsber, d. Wiener Akademie (r875-1897). 
Glassilberspiegel von K. FRITSCH (vorm. Prokesch) in Wien èrsetzt, wodurch die Aufstellung natürlich etwas komplizierter wurde, als sie hier dargestellt ist. Die Funkenauslösung war anfänglich ungemein einfach. Das gut gezielte Projektil ging im Felde zwischen zwei vertikalen, isoliert gespannten Drähten hindurch, welche mit den Belegungen einer Leidnerflasche verbunden waren, und. löste, den

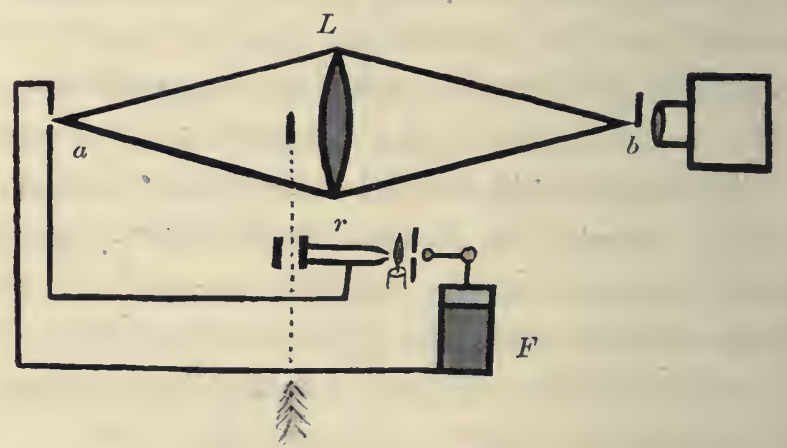

Fig. 50.

Zwischenraum der Drähte ausfüllend, die Entladung der Flasche aus. Der Schließungsbogen hatte aber noch eine zweite Unterbrechung $a$ in der Achse des Schlierenapparates, welche den Beleuchtungsfunken lieferte, dessen Bild auf die Blendung $b$ fiel. Diese Drähte im Felde, welche mancherlei Störungen verursachten, wurden später vermieden. Das Projektil fliegt, bei der neuen Aufstellung, durch einen mit Papier verklebten Holzring, in welchem es einen Luftstoß erzeugt, der als Schallwelle mit der Schallgeschwindigkeit von ungefähr 340 Metersekunden in dem Rohr $r$ forteilt, eine am Ende desselben stehende 
Kerzenflamme durch die Bohrung eines elektrischen Schirmes herauswirft, und so die Flaschenentladung einleitet. Die Rohrlänge ist so abgeglichen, daß die Entladung eintritt, sobald das Projektil sich in der Mitte des nun reinen und freien Gesichtsfeldes befindet. Wir wollen auch davon absehen, daß, zur Sicherung des Erfolges, durch die Flamme eine große Flasche $F$ entladen wird, welche erst die Entladung einer kleinen Flasche von sehr kurzer Entladungsdauer zum Zwecke der Beleuchtung des Projektils einleitet. Größere Flaschen haben nämlich schon eine merkliche Entladungsdauer und liefern wegen der großen Projektilgeschwindigkeit schon etwas verwischte Bilder. Durch die sparsame Verwendung des Lichtes im Schlierenapparat, und durch den Umstand, daß hierbei viel mehr Licht auf die photographische Platte gelangt, als ohne diese Anordnung, kann man mit unglaublich kleinen Funken schöne, kräftige und zugleich scharfe Bilder erzielen. Die Contouren der Bilder erscheinen als sehr feine, scharfe, sehr nahe aneinanderliegende Doppel'linien. Aus dem Abstand derselben und aus der Projektilgeschwindigkeit ergibt sich eine Beleuchtungsdauer oder Funkendauer von $1 / 800000$ einer Sekunde. Es liegt nun auch auf der Hand, warum analoge Versuche mit mechanischen Momentverschlüssen kein nennenswertes Resultat liefern konnten.

Betrachten wir nun ein Projektilbild zunächst in der schematischen Fig. 5 I und nachher in der photographischen Aufnahme Fig. 52, welche ich nach einem Originalnegativ auf den Schirm projiziere. Das letztere Bild entspricht

\section{Digitized by Microsoft ${ }^{\circledR}$}


einem Schusse mit dem österreichischen Mannlichergewehr. Wenn ich nicht sagen würde, was das Bild vorstellt, so könnten Sie wohl glauben, daß es das Bild ist eines rasch auf dem Wasser dahinfahrenden Bootes, aus der Vogel-

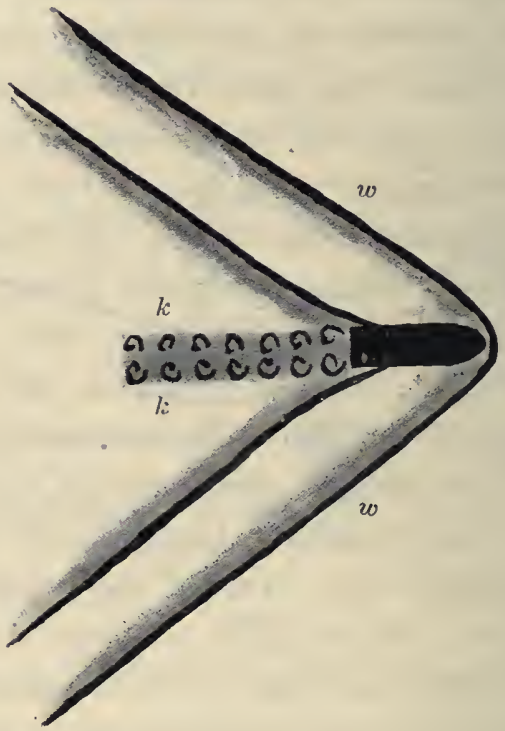

Fig. 51 .

perspektive aufgenommen. Vorn sehen sie die Bugwelle ww, hinter dem Körper eine Erscheinung $k k$, welche dem Kielwasser mit seinen Wirbeln sehr ähnlich sieht. In der Tat ist der helle, hyperbelähnliche Bogen am Scheitel des Projektils eine Luftverdichtungswelle, die ganz analog ist der Bugwelle eines Schiffes, nur daß erstere keine Oberflächenwelle ist. Sie entsteht im Luftraume und umgibt das Projektil glockenförmig von allen 
Seiten. Die Welle wird in derselben Weise sichtbar wie bei den vorher angestellten Versuchen die warme Lufthülle, welche die Kerzenflamme umschließt. Und der

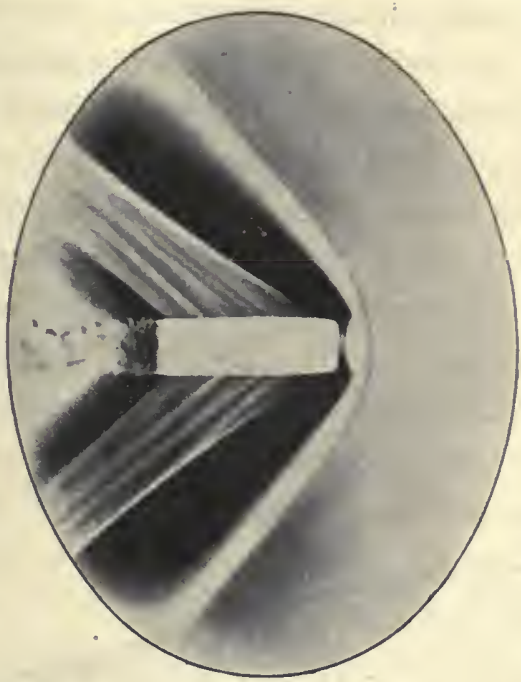

Fig. 52.

Cylinder aus durch Reibung erwärmter Luft, welche das Projektil in Form von Wirbelringen abgestreift hat, entspricht in der Tat dem Kielwasser.

So wie nun ein langsam bewegtes Boot keine Bugwelle zeigt, und so wie diese erst dann auftritt, wenn das Boot sich mit einer Geschwindigkeit bewegt, die größer ist als die Fortpflanzungsgeschwindigkeit der Wasserwellen, so kann man auch vor dem Projektil keine Verdichtungswelle sehen, so lange die Projektilgeschwindigkeit kleiner ist als die Fortpflanzungsgeschwindigkeit des Schalles. Erreicht und übersteigt aber die Projektilgeschwindigkeit 
diesen Wert, so nimmt die Kopfwelle, wie wir sie nennen wollen, zusehends an Mächtigkeit zu, und zugleich wird dieselbe immer gestreckter, d. h. der Winkel der Contouren der Welle mit der Flugrichtung wird immer kleiner, gerade so wie beim Wachsen der Bootgeschwindigkeit etwas Ähnliches geschieht. In der Tat kann man nach einem in der dargelegten Weise gewonnenen Momentbild die Projektilgeschwindigkeit ungefähr abschätzen.

Die Erklärung der Bưgwelle und der Kopfwelle beruht auf demselben schon von HuYGess verwendeten Prinzip. Denken Sie sich Steinchen in regelmäßigem Takte ins Wasser geworfen, so daß alle getroffenen Stellen in gerader Linie liegen, und daß jede später getroffene Stelle um ein bestimmtes Stuick weiter nach rechts liegt.

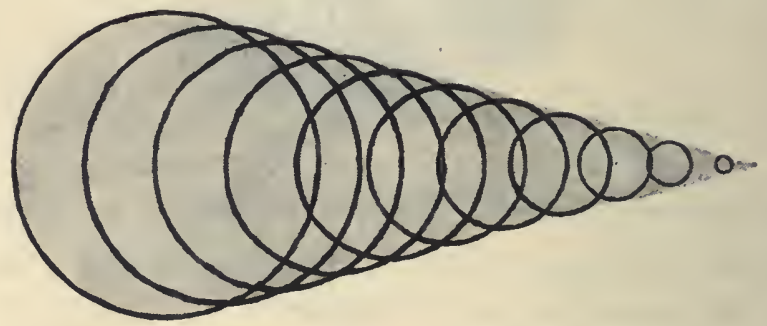

Fig. 53.

Die zuerst getroffenen Stellen werden dann die am weitesten ausgebreiteten Wellenkreise liefern, und alle zusammen werden, wo sie am dichtesten zusammentreffen, einen Wulst darstellen, der eben der Bugwelle gleicht. Die Ähnlichkeit wird um so größer werden, je kleinere Steinchen wir wählen, und je rascher wir dieselben einander folgen lassen. Taucht man einen Stab ins Wasser, 
und führt denselben an der Oberfläche hin, so findet das Steinchenwerfen, sozusagen, ununterbrochen statt, und man hat eine wirkliche Bugwelle. Setzen wir Verdichtungswellen der Luft an die Stelle der Oberflächenwellen des Wassers, so haben wir die Projektil-Kopfwelle.

Sie können nun sagen: Es ist ja recht schön und interessant, ein Projektil im Flug zu beobachten, was kann man aber praktisch damit anfangen?

Darauf antworte ich: Kriegführen kann man mit photographierten Projektilen allerdings nicht! So mußte ich oft auch meinen medizinischen Zuhörern sagen, wenn sie sich sofort nach dem praktischen Wert einer physikalischen Beobachtung erkundigten: Kurieren, meine Herren, kann man damit nicht! Ähnlich mußte ich einmal auf die Frage antworten, wie viel Physik in einer Müllerschule gelehrt werden müsse, wenn man sich auf das für den Müller Unentbehrliche beschränken wolle. Ich mußte sagen: Der Müller wird stets so viel Physik brauchen, als er wissen wird. Ein Wissen, das man nicht besitzt, kann man natürlich nicht verwenden.

Sehen wir von dem allgemeinen Umstand $a b, d a ß$ jeder wissenschaftliche Fortschritt, jede Aufklärung, jede Erweiterung oder Berichtigung unserer Kenntnisse des Tatsächlichen im allgemeinen, auch eine bessere Grundlage für die praktische Betätigung gibt. Frảgen wir insbesondere: können wir aus der genaueren Kenntnis der Vorgänge in der Umgebung des Projektils gar keinen Vorteil ziehen?

Jeder Physiker, der sich mit Schallwellen beschäftigt, 
der die Bilder derselben fixiert hat, wird an der Schallwellennatur der Luftverdichtung am Projektilkopf nicht zweifeln. Wir nannten diese Verdichtung deshalb auch ohne weiteres die Kopfwelle. Steht nun dies fest, so erweist sich die Vorstellung von MELSEns, nach welcher das Projektil Massen von Luft mit sich führt, und in die getroffenen Körper einpreßt, als nicht mehr haltbar. Eine fortschreitende Schallwelle ist keine fortschreitende Masse, sondern eine fortschreitende Bewegungsform, ebenso wie die Wasserwelle oder die Welle in einem Kornfeld nur eine fortschreitende Bewegungsform, keine Fortführung von Wasser oder Korn ist.

Durch Lichtinterferenzversuche, auf die ich hier nicht näher eingehen kann, deren Ergebnis aber in der sche-

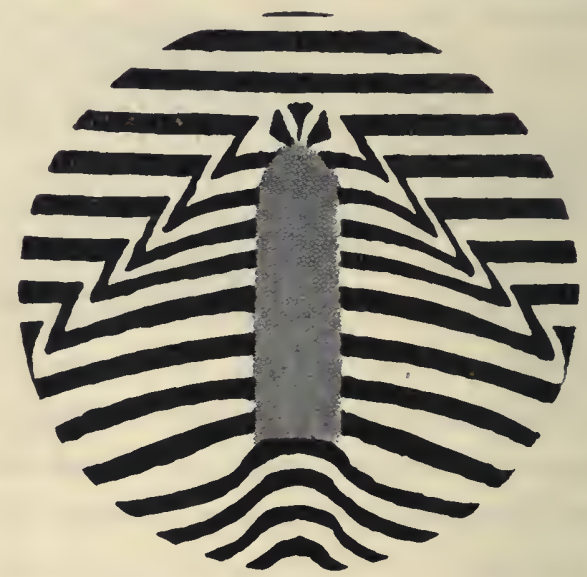

Fig. 54 .

matischen Fig. 54 dargestellt ist, hat es sich überdies gezeigt, daß die glockenförmige Kopfwelle eine recht dünne Digitized by Microsoft (B) 
Schale ist, und daß die Verdichtungen derselben recht mäßige sind, welche $2 / 10$ einer Atmosphäre kaum überschreiten.

Von Explosionswirkungen durch Luftdruck in dem vom Projektil getroffenen Körper kann also nicht die Rede sein. Die Erscheinungen an Schußwunden z. B. sind also nicht so aufzufassen, wie Melsens und $\mathrm{Busch}$, sondern so wie KOCHER und REGER es getan haben, als Druckwirkungen des Projektils selbst.

Wie gering die Rolle ist, welche die Luftreibung, das vermeintliche Mitreißen der Luft bei der Projektilbewegung, spielt, lehrt ein einfacher Versuch. Man fixiert das Bild des Projektils, während dasselbe eine Flamme, also sichtbares Gas durchdringt. Die Flamme wird nicht etwa zerrissen und deformiert, sondern glatt und rein durchbohrt, wie ein fester Körper. In- und außerhalb der Flamme sieht man die Kontouren der Kopfwelle. Das Flackern, Auslöschen u. s. w. erfolgt erst, nachdem das Projektil längst hindurch ist, durch die nacheilenden Pulvergase oder die vor denselben liegende Luft.

Der Physiker, welcher die Kopfwelle ansieht, und die Schallwellennatur derselben erkennt, sieht zugleich, daß dieselbe von derselben Art ist, wie die kurzen kräftigen Funkenwellen, daß dieselbe eine $\mathrm{Kn}$ allwelle ist. Immer also, wenn ein Teil der Kopfwelle das Ohr erreicht, wird dieses einen $\mathrm{Kn}$ all vernehmen. Es wird den Anschein haben, als ob das Projektil den Knall mit sich führen würde. Außer diesem Knall, welcher mit der Projektilgeschwindigkeit forteilt, die gewöhnlich größer ist als die Mach, Vorlesungen: (3. Aufted by Microsoft 24. 
Schallgeschwindigkeit, wird noch der Knall der Pulvergase zu hören sein, der mit der gewöhnlichen Schallgeschwindigkeit fortschreitet. Man hört also $\mathrm{zw}$ e i zeitlich getrennte Explosionen. Der Umstand, daß diese Tatsache längere Zeit von den Praktikern verkannt wurde, als sie aber erkannt war, zuweilen eine recht abenteuerliche Erklärung fand, und daß schließlich meine Meinung doch als die richtige angenommen wurde, scheint mir hinreichend $\mathrm{zu}$ beweisen, daß Untersuchungen wie die hier besprochenen auch in praktischer Beziehung nicht ganz überflüssig sind. Daß die Blitz- und Knallerscheinungen zur Schätzung der Entfernung feuernder Batterien benützt werden, ist bekannt, und selbstverständlich ist es ferner, daß eine unklare theoretische Auffassung der Vorgänge' auch der Richtigkeit der praktischen Schätzung Eintrag tun würde.

Er mag jedem, der es zum erstenmal hört, recht auffallend scheinen, daß e in Schuß einen doppelt e n Knall, und zwar von zwei verschiedenen Fortpflanzungsgeschwindig: keiten auslöst. Die Überlegung aber, welche uns lehrt; daß Projektile, deren Geschwindigkeit kleiner ist als die Schallgeschwindigkeit, keine Kopfwellen erzeugen, weil jeder auf die Luft ausgeübte Impuls mit der Schallgeschwindigkeit fort-, also vorauseilt, klärt uns, consequent fortgeführt, auch über den vorerwähnten sonderbaren Umstand auf. Bewegt sich das Projektil schneller, als der Schall fortgeht, so kann die Luft vor demselben nicht rasch genug ausweichen. Dieselbe wird verdichtet und erwärmt, und hiermit steigt bekanntlich die Schallgeschwindigkeit, bis die Kopfwelle ebenso rasch fortDigitized by Microsoft (B) 
schreitet als das Projektil, so daß die Ursache einer weiteren Steigerung der Wellengeschwindigkeit wegfällt. Würde eine solche Welle sich selbst überlassen, so würde sie sich verlängern und in eine gewöhnliche, lang. samer fortschreitende Schallwelle übergehen. Das Projektil ist aber hinter ihr her, erhält sie auf ihrer Dichte und

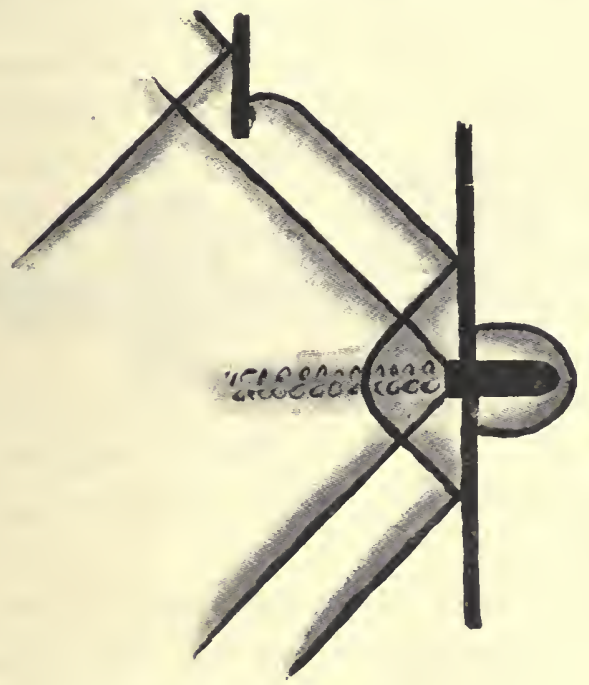

Fig. 55.

Geschwindigkeit. Selbst wenn das Projektil einen Karton oder ein Brett durchdringt, welches die Kopfwelle abfaßt und zurückhält, tritt, wie die Fig. 55 lehrt, an der durchdringenden Spitze sofort wieder eine neugebildete, um nicht zu sagen junge, Kopfwelle auf. An dem Karton kann man die Reflexion und Beugung, an einer Flamme die Brechung der Kopfwelle beobachten, so daß kein Zweifel an deren Natur übrig bleibt. 
Erlauben Sie mir, das Wichtigste von dem eben Gesagten noch durch ein schematisches Bild zu erläutern, welches nach älteren, weniger vollkommenen Photographien gezeichnet ist. In diesem Bild Fig. $5^{6}$ sehen Sie das Projektil, welches eben den Gewehrlauf verlassen hat und, einen Draht berührend, die Funkenbeleuchtung auslöst. Sie sehen an der Spitze schon die Anfänge einer kräftigen Kopfwelle, vor derselben aber einen durchsichtigen pilzförmigen Klumpen. Es ist die vor dem Projektil aus dem Laufe ausgestoßene Luft. Bogenförmige Schallwellen, Knallwellen, welche aber bald vom Projektil iberholt werden, gehen ebenfalls vom Laufe aus. Hinter dem Projektil aber dringt der undurchsichtige Pilz der Pulvergase hervor.

Es ist kaum nötig zu bemerken, daß man nach dieser Methode auch andere auf die Ballistik bezügliche Fragen, z. B. die Bewegung der Lafette während des Schusses u. s. w. studieren kann.

Ein hervorragender französischer Artillerist, Herr Gossot, hat die hier dargelegten Vorstellungen über die Kopfwelle in anderer Weise verwertet. Man pflegt die Geschoßgeschwindigkeiten $\mathrm{zu}$ bestimmen, indem man an verschiedenen Stationen aufgestellte Drahtgitter vom Geschoß zerreißen, und dadurch elektromagnetische Zeitsignale auf fallenden Schienen oder gedrehten Trommeln auslösen läßt. Gossot ließ diese Signale direkt durch den Stoß der Kopfwelle auslösen, ersparte dadurch die Drahtgitter und war außerdem im stande, selbst bei großen Elevationen, bei hoch gehenden Geschossen, noch Geschwindig- 
keiten zu messen, also in Fällen, in welchen die Anwendung der Drahtgitter ganz ausgeschlossen ist.

Die Gesetze des Widerstandes der Flüssigkeiten und der Luft bilden eine sehr verwickelte Frage. Man kann sich ja das Problem in sehr einfacher Weise zurechtphilosophieren, und hat dies ja gelegentlich getan. Derselbe Körper, mit 2-, 3- . . facher Geschwindigkeit be-

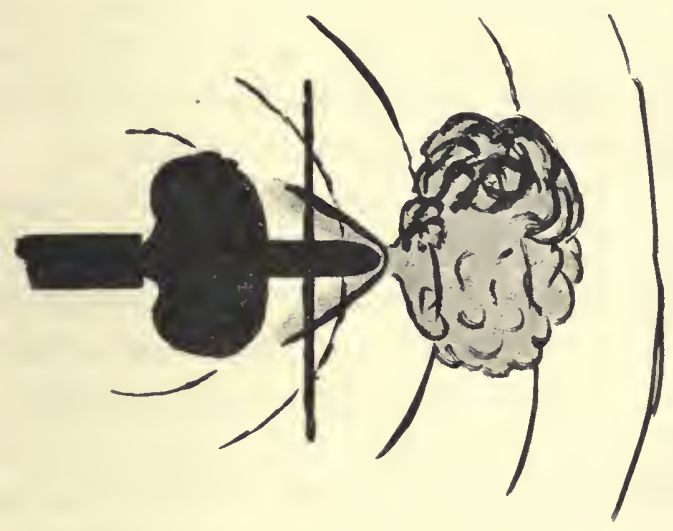

Fig. 56.

.wegt, verdrängt in derselben Zeit die 2-, 3- . . fache Flüssigkeits- oder Luftmasse, und erteilt derselben $\mathrm{z}$ u de m die $2-, 3-\ldots$ fache Geschwindigkeit. Hierzu ist aber die 4-, 9- . . fache Kraft nötig. Der Widerstand wächst also mit dem Quadrat der Geschwindigkeit.

Das sieht sehr schön, einfach und einleuchtend aus. Allein die Praxis will von dieser einfachen Theorie nichts wissen; sie sagt vielmehr, daß, wenn man die Geschwindigkeit steigert, sich das Gesetz des Widerstandes ändert. 
Für jeden Spielraum der Geschwindigkeit ist das Gesetz ein anderes.

Die Studien des genialen englischen Schiffsbau-Ingenieurs Froude haben in diese Frage Aufklärung gebracht. Froude hat gezeigt, daß der Widerstand durch eine Kombination sehr verschiedenartiger Vorgänge bedingt ist. Ein bewegtes Schiff erfährt im Wasser Reibung, es erregt Wirbel und erzeugt außerdem noch Wellen, welche ins Weite gehen. Jeder dieser Vorgänge hängt in anderer Weise von der Geschwindigkeit ab, und es ist also kein Wunder, wenn das Widerstandsgesetz kein einfaches ist.

Die hier dargelegten Beobachtungen legen ganz analoge Betrachtungen in Bezug auf die Projektile nahe. Auch hier haben wir Reibung, Wirbelbildung und Wellenerregung. Wir werden uns also nicht wundern, wenn wir kein einfaches Gesetz des Luftwiderstandes finden, und werden nicht befremdet sein, wenn die Praxis lehrt, daß das Widerstandsgesetz sich wesentlich ändert, sobald die Projektilgeschwindigkeit die Schallgeschwindigkeit überschreitet, denn gerade da tritt das eine Element des Widerstandes, die Wellenbildung überhaupt erst in Wirksamkeit.

Niemand zweifelt, daß ein spitzes Geschoß mit geringerem Widerstande die Luft durchschneidet. $\mathrm{DaB}$ für spitze Geschosse die Kopfwelle schwächer ist, lehren auch die Photographien. Es ist nun nicht unmöglich, daß Geschoßformen erdacht werden, welche geringere Wirbelbildung u. s. w. bedingen, und daß man auf photographischem Wege die betreffenden Vorgänge studiert. Ich glaube nach den wenigen Versuchen, die ich in dieser Richtung an- 
gestellt habe, allerdings $\mathrm{nicht}$, daß man bei hohen Geschwindigkeiten durch Änderung der G e s ch o B for m noch viel erzielen wird,doch bin ich dieserFrage nicht näher getreten.

Solche Untersuchungen werden iibrigens der artilleristischen Praxis ebenso gewiß wenigstens $\mathrm{n}$ i $\mathrm{cht} \mathrm{s} \mathrm{ch}$ a d e n, als in großem Maßstabe unternommene Experimente der Artilleristen der Physik sicher nützen werden.

Wer Gelegenheit hat, die heutigen Geschütze und Geschosse in ihrer Vollkommenheit, in der Gewalt und Präzision ihrer Wirkung kennen zu lernen, der muß gestehen, $\mathrm{da} B$ in diesen Objekten eine bedeutende technische und eine hohe wissenschaftliche Leistung verkörpert ist. Man kann sich diesem Eindruck so sehr hingeben, daß man zeitweilig ganz vergiß 3 , welchem furchtbaren $Z$ wecke diese Vorrichtungen dienen.

Erlauben Sie mir, bevor wir uns trennen, nur noch einige Worte über diesen Kontrast. Der bedeutendste Krieger und Schweiger unserer Zeit hat behauptet, der ewige Friede sei ein Traum und nicht einmal ein schöner Traum. Wir dürfen ja dem großen Menschenkenner ein Urteil in diesen Fragen zutrauen, und können die Furcht des Soldaten vor Versumpfung durch allzulangen Frieden begreifen. Es gehört aber doch ein starker Glaube an die Unüberwindlichkeit mittelalterlicher Barbarei dazu, keine wesentliche Verbesserung der internationalen Verhältnisse $z u$ hoffen und zu erwarten. Denken wir an unsere Vorfahren, an die Zeit des Faustrechtes zurück, da innerhalb desselben Landes und Staates brutaler Angriff und ebenso brutale Selbsthilfe allgemein waren. Diese Zustände wurden so 
drückend, daß schließlich die verschiedensten Umstände dazu drängten, denselben ein Ende zu machen. Und die Kanone hat hierbei sogar das meiste getan. Das Faustrecht war hiermit allerdings nicht so rasch aus der Welt geschafft; es war zunächst nur in andere Fäuste übergegangen. Wir dürfen uns ja auch keinēn RoussEauschen Illusionen hingeben. Rechtsfragen werden in gewissem Sinne immer auch Machtfragen bleiben. Es kommt nur sehr darauf an, wer die Macht in den Händen hat. Ist doch selbst in den Vereinigten Staaten, wo jeder grundsätzlich das gleiche Recht hat, nach J. B. Stallos treffender Bemerkung, der Stimmzettel nur ein Surrogat für den Knüttel. Sie wissen ja, daß auch manche unserer Mitbürger gar sehr noch das Echte lieben. Sehr, sehr langsam, mit fortschreitender Kultur, nimmt aber der Verkehr der Menschen doch mildere Formen an, und niemand, der die „liebe, gute 'alte Zeit" kennt, wird sie in Wirklichkeit je zurückwïnschen, so schön sie sich auch dichten und malen läßt.

Im Verkehr der Völker besteht nun das alte rohe Faustrecht noch. Weil aber dieser Zustand die intellektuellen, moralischen und materiellén Mittel der Völker schon aufs äußerste in Anspruch nimmt, kaum eine geringere Last im Frieden als im Kriege, kaum eine leichtere für den Sieger als für den Besiegten, wird derselbe immer unerträglicher. Die denkende Erwägung ist zum Glück auch nicht mehr das ausschließliche Eigentum derjenigen, welche sich bescheiden die obersten Zehntausend nennen. Wie überall wird auch hier das Übel selbst die intellektuellen und ethischen Kräfte wecken, welche geeignet sind, dasselbe 
zu mindern. Mag immerhin der Racen- und Nationalitätenhaß noch so gewaltig toben, dennoch wird der Verkehr der Völker zusehends ausgedehnter und inniger. Neben den die Völker trennenden Fragen treten nacheinander, immer deutlicher und stärker, die großen gemeinsamen Ziele hervor, welche alle Kräfte der Menschen der Zukunft vollauf in Anspruch nehmen werden.

*) [Der internationale Verkehr macht stetig erfreuliche Fortschritte. Als ein solcher ist die Verbindung der Göttinger, Leipziger, Münchner und Wiener Akademie der Wissenschaften zu bezeichnen, welche auf Anregung von Berliner und Wiener Gelehrlen entstanden ist, und die auf Vorschlag der Londoner Royal Society sich zu einer internationalen Vereinigung der Akademieen erweitert hat. Allerdings kanı eine derartige Verbindung bei weitem nicht alle die Aufgaben lösen, welche ịhr in der edelsten Absicht F. Kemény (Entwurf einer internationalen Gesamt-Akademie : "Weltakademie". Leipzig Igor) übertragen möchte. Namentlich von einer Verwirklichung der Friedensidee sind wir noch recht weit entfernt. Man wird in dieser Richtung zunächst von allen den Menschen nichts zu erwarten hab.en, welche im Hader der Völker ihren Vorteil finden. Erinnern wir uns ferner der Tatsache, dafs 1870 bei Ausbruch des Krieges das Interesse der "höheren" Schichten der Gesellschaft sich äufserte durch Ausschreibung hoher Preise für den ersten erschossenen Franzosen und den ersten erschossenen Deutschen. Die frevelhaft-mutwillige Auffassung des Krieges als Sport und zugleich die furchtbare Mifsachtung der am schwersten betroffenen grofsen Massen des fremden und eigenen Volkes, des armen Bauernjungen und Fabrikarbeiters, tritt h:er mit Grauen erregender Deutlichkeit hervor. Man übertrage diese ,vornehme" Denkweise mutatis mutandis auf die besitzlosen Klassen, und versuche es - aber aufrichtig - über die Folgen entrüstet zu sein. Betrachten wir endlich die Menge der Menschen des Mittelstandes, welche ihr vermeintliches Recht, oder auch ihr wohlbewufstes Unrecht aufs äufserste, wo möglich bis zur Vernichtung des Gegners oder Konkurrenten zu verfolgen suchen. Es kann doch nur empörend wirken, wenn diese für den allgemeinen Frieden plaidieren. Zur Verwirklichung dieser Idee fehlt vor allem die ideale ethische Erziehung und Gesinnung, die nur die gesittete Familie zu entwickeln vermag. Der Staat kann dies nicht leisten; der verhält sich als Egoist. Allmälige Milderung dieses Zustandes dürfen wir von einem nivellierenden Verkehr innerhalb eines Volkes und von innigerer Berührung der jungen Generation verschiedener Völker erlıoffen. Vielleicht ermöglicht es die fortschreitende Erleichterung des Reisens, dafs auch weniger bemittelte Familien verschiedener Nationen zeitweilig, etwa für die Dauer der Ferien, ohne zu grofse Kosten häufiger ihre Kinder austauschen. Wie wenig die Friedensidee in praktischer Beziehung gefördert worden ist, hat sich in SüdAfrika und China gezeigt, unmittelbar nach dem Versuch ein internationales Schiedsgericht zu begrïnden. Doch sind alle, welche diesen Gedanken auch nur theoretisch oder akademisch gefördert, und weitere Fortschritte vorbereitet haben, des gröfsten Dankes der künftigen Geschlechter sicher, - 1902]. 


\section{Über Orientierungsempfindungen.*)}

Durch die Zusammenwirkung einer Reihe von Forschern, unter welchen vor allen GolTZ in Straßburg und BrEuER in Wien zu nennen sind, hat sich im Laufe des verflossenen Vierteljahrhunderts unsere Kenntnis wesentlich erweitert bezüglich der Mittel, durch welche wir uns über unsere Lage und Bewegung im Raume orientieren. Es ist Ihnen ja schon durch Herrn Prof. Obersteiner die physiologische Seite der Vorgänge dargelegt worden, mit welchen unsere Bewegungsempfindungen oder, allgemeiner gesprochen, unsere Orientierungsempfindungen zusammenhängen. Ich werde mir heute erlauben, vorwiegend die physikalische Seite der Sache zu beleuchten. In der Tat bin ich selbst durch Beachtung ganz einfacher und allgemein bekannter physikalischer Tatsachen, indem ich ohne irgendwelche Gelehrsamkeit auf dem Gebiete der Physiologie nur unbefangen meinen Gedanken nachging, auf dieses Untersuchungsgebiet gelangt, und ich glaube, daß dieser ganz voraussetzungslose Weg, wenn Sie meiner Erzählung folgen wollen, auch für die meisten von Ihnen der gangbarste sein wird.

*) Vortrag, gehalten den 24. Februar 1897 im Wiener Verein zur Verbreitung naturwissenschaftlicher Kenntnisse. 
Für den einfachen Menschen von gesundem Sinn konnte es nie zweifelhaft sein, daß ein Druck, eine $\mathrm{Kraft}$ -nötig sei, um einen Körper in bestimmter Richtung in Bewegung zu setzen, und ebenso ein entgegengesetzter Druck, um den in Bewegung begriffenen Körper plötzlich aufzuhalten. Wenn auch das Trägheitsgesetz erst durch GaLILEI schärfer formuliert worden ist, so kannten doch schon lange vorher Männer wie LEONARDO DA VINCI, Rabelais u. a. die betreffende Tatsache und erläuterten dieselbe gelegentlich durch treffende Beispiele. LEONARDO weiß, daß man aus einer Säule von Brettspielsteinen durch einen scharfen Schlag mit einem Lineal einen einzelnen Stein herausschlagen kann, ohne die Säule zu zerstören. Der Versuch mit der Münze auf dem Becherdeckel, welche in den Becher fällt, sobald der Deckel rasch weggezogen wird, ist, so wie ähnliche Versuche, gewiß uralt.

Bei GalileI gewinnt die erwähnte Erfahrung eine . größere Kraft und Klarheit. In dem berühmten Dialog über das Kopernikanische System, der ihn die Freiheit gekostet hat, erläutert er die Flutwelle in unglücklicher, aber im Prinzip doch richtiger Weise durch eine mit Wasser gefüllte, hin- und hergeschwungene Schüssel. Den Aristotelikern seiner Zeit, welche die Fallbewegung eines schweren Körpers durch Darauflegen eines anderen zu beschleunigen meinten, hält er vor, daß ein Körper von dem daraufliegenden nur dann beschleunigt werden kann, wenn derselbe ersteren am Fallen hindert. Einen fallenden Körper durch einen daraufliegenden drïcken zu wollen, sei so unsinnig, wie einen Mann mit der Lanze 
treffen wollen, der dieser mit der gleichen Geschwindigkeit entflieht. Schon dies wenige von Physik kann vieles unserem Verständnis näher bringen. Sie kennen die eigentümliche Empfindung, die man im Fallen hat, wenn man etwa vom Sprungbrett aus größerer Höhe ins Wasser springt, die in geringerem Maße auch im Lift bei Beginn der Abwärtsbewegung oder auch in der Schaukel eintritt. Der gegenseitige Gewichtsdruck der Teile unseres Leibes, der ja wohl in irgend einer Weise empfunden wird, ver $\mathrm{schwindet}$ im freien Fall oder wird doch vermindert bei Beginn des Sinkens im Lift. Eine ähnliche Empfindung müßte auftreten, wenn wir etwa plötzlich auf den Mond mit seiner $\mathrm{kleinen}$ Fallbeschleunigung versetzt würden. Indem ich (1866) bei einem physikalischen Anlaß auf diese Betrachtungen geführt wurde, und auch die Veränderungen des Blutdruckes in den erwähnten Fällen ins Auge faßte, traf ich, ohne es $z u$ wissen, in manchen Punkten mit Wollaston und Purkinje zusammen. Ersterer hatte schon I8Io in seiner "Croonian lecture" über die "sea sickness" gesprochen und dieselbe auf Änderungen des Blutdruckes bezogen, - letzterer hatte (I $820-1826$ ) seiner Erklärung des Drehschwindels ähnliche Betrachtungen zugrunde gelegt. *)

Newron hatte es zuerst in voller Allgemeinheit ausgesprochen, daß ein Körper dic Geschwindigkeit und Richtung seiner Bewegung nur durch Einwirkung

7) Wollaston, Phil Transact. Royal. Soc. London, 18 ro. Daselbst be. schreibt und erklärt WW, auch das Muskelgeräusch. Auf diese Arbeit wurde ich erst kürzlich durch Dr. W. Pa uli nufmerksam gemacht. - Purkinje, Prager Medizin. Jahrbïcher, Bd. 6, Wien, 1820. 
einer $\mathrm{Kraft}$, also nur durch Mitwirkung eines andere $\mathrm{n}$ Körpers zu ändern vermag. Eine erst von EULER ausdrücklich gezogene Folgerung hieraus ist die, daß ein Körper nicht von selbst, sondern wieder nur durch Kräfte und andere Körper in Drehung geraten, oder die vorhandene Drehung aufgeben kann. Drehen Sie z. B. Ihre geöffnete abgelaufene Taschenuhr frei in der Hand hin und her. Die Unruhe bleibt gegen jede raschere Drehung zurück, sogar gegen die elastische Kraft der Unruhefeder, welche sich als zu schwach erweist, die Unruhe ganz mitzunehmen.

Bedenken wir nun, daß immer, ob wir uns selbst etwa mit Hilfe unserer Beine bewegen, oder ob wir ron einem Fuhrwerk, einem Boot mitgeführt werden, zunächst nur ein Teil unseres Leibes unmittelbar, der andere aber durch diesen bewegt wird. Wir erkennen dann, daß hierbei immer Drucke, Züge, Spannungen dieser Körperteile gegeneinander entstehen, die Empfindungen auslösen, durch welche die fortschreitenden oder drehenden Bewegungen, in die wir geraten, sich bemerklich machen.*;) Es ist aber eine natüliche Sache, daß diese uns so geläufigen Empfindungen wenig Beachtung finden, und daß sie die Aufmerksamkeit erst auf sich ziehen, wenn dieselben unter besonderen Umständen, in unerwarteter Weise, oder in ungewöhnlicher Stärke auftreten.

*) Ebenso wirken manche äufsere Kräfte nicht gleich auf alle Teile der Erde, und die inneren Kräfte, welche Deformationen herbeiführen, wirken unmittelbar zunächst nur auf begrenzte Teile. Wäre die Erde ein empfindendes Wesen, so würde ihr die Flutwelle und andere Vorgänge ähnliche Empfindungen verursachen wie uns unsere Bewegung. Vielleicht hängen auch die kleinen Änderungen der Polhöhe, welche man gegenwärtig studiert, mit unausgesetzten kleinen Deformationen des Zentralellipsoids zusammen, welche durch seïsmische Vorgänge bedingt sind. 
So ist auch meine Aufmerksamkeit einmal durch die Empfindung beim Fallen, dann aber noch durch ein anderes eigentümliches Vorkommnis erregt worden. Ich durchfuhr eine Eisenbahnkurve von starker Krümmung und

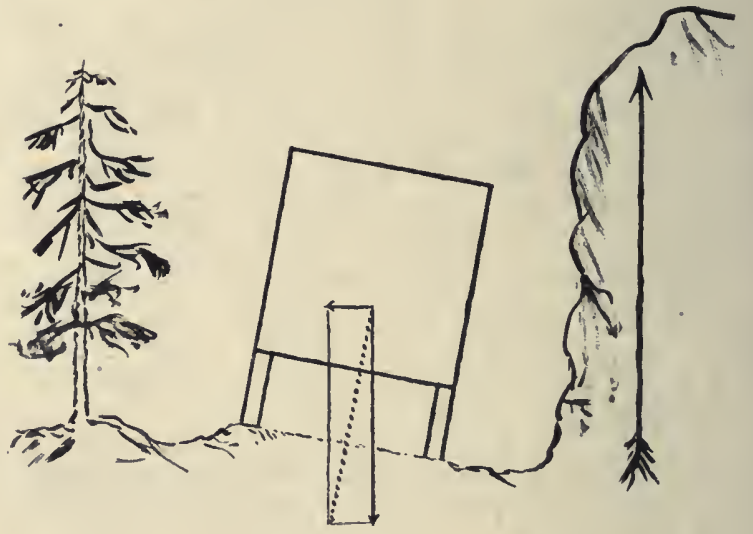

Fig. 57.

sah nun plötzlich alle Bäume, Häuser, Fabriksschlote an der Bahn nicht mehr lotrecht, sondern auffallend schief stehen. Was mir bis dahin so selbstverständlich erschienen war, daß wir das Lot so gut und scharf von jeder anderen Richtung unterscheiden, war mir mit einemmal rätselhaft. Wieso kann mir dieselbe Richtung einmal lotrecht erscheinen, ein andermal nicht? Wodurch zeichnet sich das Lot für uns aus? (Vgl. Fig. 57.)

Die Schiene wird auf der konvexen (erhabenen) Seite der Bahn höher gelegt, um trotz der Fliehkraft die Standfestigkeit des Wagens zu sichern, so zwar, daß die $\mathrm{Zu}$ : Digitized by Microsoft (B) 
sammenwirkung der Schwerkraft und Fliehkraft wieder eine zur Schienenebene senkrechte Kraft ergibt.

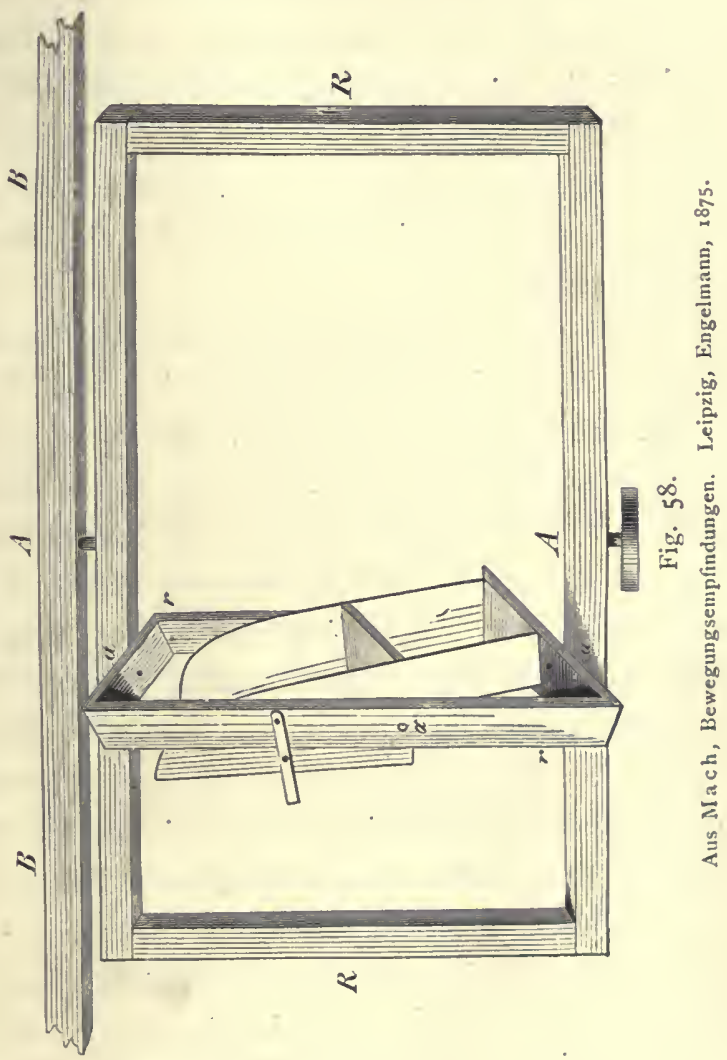

Nehmen wir nun an, daß wir die Richtung der gesamten Massenbeschleunigung, woher dieselbe auch rühren mag, unter allen Umständen in irgend einer Weise als Lotrechte empfinden, so werden die gewöhnlichen 
und die ungewöhnlichen Erscheinungen in gleicher Weise verständlich.**)

Ich hatte nun das Bedürfnis, die gewonnene Ansicht in bequemerer Weise und genauer auf die Probe zu stellen, als dies bei einer Eisenbahnfahrt möglich ist, bei welcher man die maßgebenden Umstände nicht in der Hand hat, nicht nach Belieben abändern kann. $\mathrm{Zu}$ diesem Zwecke wurde eine einfache Vorrichtung hergestellt, die hier in Fig. $5^{8}$ dargestellt ist.

In einem an den Zimmerwänden befestigten großen Rahmen $B$ dreht sich um eine lotrechte Achse $A A$ ein zweiter $R$ und in diesem ein dritter $r$, der in beliebiger Entfernung und Stellung von der Achse fest oder beweglich angebracht ist und einen Stuhl für den Beobachter trägt.

Der Beobachter setzt sich in den Stuhl und wird zur Vermeidung aller Störungen seines Urteils ganz in einen Papierkasten eingeschlossen. Wird derselbe nun mit dem Rahmen $r$ in gleichmäßige Umdrehung versetzt, so fühlt und sieht er den Beginn der Drehung nach Sinn und Ausmaß sehr deutlich, obgleich zur Beurteilung des Vorganges jeder äußere sichtbare oder greifbare Anhaltspunkt fehlt. Bei gleichmäßiger Fortsetzung der Bewegung verschwindet die Empfindung der Drehung allmählich gan $z$, man meint ruhig zu stehen Befindet sich aber $r$ a $\mathrm{B}$ er der Drehungsachse, so tritt gleich bei Beginn der Drehung

*) Für die beliebte Erklärungsweise durch unbewufste Schlüsse ist die Sache ungemein einfach. Man hält den Wagen für vertikal und schliefst daher „unbewufst" auf die Schiefstellung der Bäume. Allerdings würde das Gegenteil, dafs man die Bäume für vertikal hält, und auf die Schiefstellung des Wagens schliefst, nach dieser Theorie ebenso klar seiu. 
eine auffallende, scheinbare, fühlbare und sichtbare Neigung des ganzen Papierkastens auf, geringer bei langsamer, größer bei rascherer Drehung, welche so lange verbleibt, als die Drehung währt. Diese Schiefstellung nimmt man mit zwingender Gewalt wahr, obgleich wieder alle äußeren Anhaltspunkte für das Urteil fehlen. Sitzt z. B. der Beobachter so, daß er nach der Achse hin blickt, so hält er den Kasten für stark nach hinten übergeneigt, wie es sein muß, wenn die Richtung der Gesamtkraft als Lot empfunden wird. Ähnlich verhält es sich bei anderen Stellungen des Beobachters. ${ }^{*}$ )

Als ich nun bei einem solchen Versuch nach längerer Drehung, die ich nicht mehr wahrnahm, den Apparat plötzlich anhalten lie $\beta$, fühlte und sah ich mich samt dem Kasten sofort in lebhafter Gegendrehung begriffen, obgleich ich wußte, daß nun alles in Ruhe sei, und obgleich wieder jeder äußere Anhaltspunkt für eine Bewegungsvorstellung fehlte. Diese Erscheinungen sollte jeder kennen lernen, der die Existenz von Bewegungsempfindungen leugnet. Hätte NEwroN dieselben gekannt und erfahren, wie man sich im Raume gedreht und verstellt glaubt, ohne doch irgendwelche festliegende Körper als Anhaltspunkte zu haben, so würde ihn dies in seinen unglïcklichen Spekulationen über den absoluten Raum sicherlich noch bestärkt haben.

4) Man bemerkt, dafs die Denkweise und Versuchsweise, in die ich da geriet, sehr verwandt ist derjenigen, die Knight, Philosoph. Transactions (9. Jänner 1806), zur Erkenntnis und Untersuchung des Geotropismus der Phanzen führte. Die Beziehungen zwischen pflanzlichem und tierischem Geotropismus sind in néuerer Zeit von J. Loe b eingehend erörtert worden.

Mach, Vorlesungen, 3 Auf. 
Die Empfindung der Gegendrehung nach dem Anhalten des Rotationsapparates nimmt langsam und allmählich ab. Als ich aber während dieses Vorganges zufällig einmal den Kopf neigte, neigte sich mit diesem zugleich auch in demselben Sinne und Ausmaß die Achse der scheinbaren Drehung. Es war also klar: die Beschleunigung oder Verzögerung der Drehung wird empfunden. Die Beschleunigung wirkt als Reiz. Die Empfindung dauert aber, wie fast alle Empfindungen, mit allmählicher Abnahme merklich länger als der Reiz. Daher die lange scheinbare Drehung nach dem Anhalten des Apparates. Das Organ aber, welches diese nachdauernde Empfindung vermittelt, muß im Kopfe seinen Sitz haben, sonst könnte mit dem Kopfe die Achse der scheinbaren Drehung sich nicht mitbewegen.

Wenn ich nun sagen wollte, es sei mir im Augenblick dieser letzteren Beobachtungen ein Licht aufgegangen, so wäre das nicht zutreffend. Ich müßte sagen, eine ganze Illumination sei mir aufgegangen. Mir fielen meine Jugenderfahrungen über den Drehschwindel ein. Ich erinnerte mich der Flouressschen Versuche der Durchschneidung der Bogengänge des. Ohrlabyrinthes an Tauben und Kaninchen, wobei dieser Forscher dem Drehschwindel ähnlịche Erscheinungen beobachtet hatte, welche er aber, befangen in der akustischen Auffassung des Labyrinthes, lieber als den Ausdruck schmerzhafter Gehörsstörungen deutete. Ich erkannte, daß ein Forscher wie Goltz nicht ganz, aber fast ins Schwarze getroffen hatte mit seiner Auffassung des Bogengangapparates. GoLTz, der durch

\section{Digitized by Microsoft ${ }^{\circ}$}


seine glückliche Art, unbekümmert um Herkömmliches, sich nur von seinen Gedanken leiten zu lassen, uns so vielfach aufzuklären wußte, hatte auf Grund von Versuchen schon 1870 den Ausspruch getan: „Ob die Bogengänge Gehörorgane sind, bleibt dahingestellt. Außerdem aber bilden sie eine Vorrichtung, welche der Erhaltung des Gleichgewichtes dient. Sie sind sozusagen Sinnesorgane für das Gleichgewicht des Kopfes und mittelbar des ganzen Körpers." Ich erinnerte mich des von RITTER und PURKINJe beobachteten galvanischen Schwindels bei Durchleitung des Stromes quer durch den Kopf, wobei die Versuchspersonen nach der Kathode umzusinken meinen. Der Versuch wurde sofort wiederholt, und etwas später (1874) konnte ich denselben objektiv an Fischen demonstrieren, welche im Stromfeld wie auf Kommando alle in demselben Sinne sich seitwärts legten. *) Die Múllersche Lehre von den spezifischen Energien schien mir nun alle diese alten und neuen Beobachtungen in einen einfachen Zusammenhang $z \mathfrak{u}$ bringen.

In der Tat, denken wir uns das Gehörlabyrinth mit seinen drei $z u$ einander senkrechten Bogengangebenen, (vgl. Fig. 59) deren rätselhafte Stellung man ja schon in jeder möglichen und unmöglichen Weise aufzuklären versucht hat. Denken wir uns die Nerven der Ampullen (Erweiterungen) der Bogengänge mit der Eigenschaft ausgestattet, auf jeden beliebigen Reiz mit einer Dreh-

*) Dieser Versuch ist wohl verwandt mit dem ein Dezennium später von L. Hermann beschriebenen, "galvanotropischen" Versuch (an Froschlarven). Vgl. darüber meine Bemerkung im Anzeiger der Wiener Akademie, 1886, Nr. 21. Neuere Versuche über Galvanotropismus rühren von $\mathrm{J}$. Loe b her. 
empfindung _zu antworten, so wie etwa die Nerven der Netzhaut des Auges auf Druck, elektrischen, chemischén

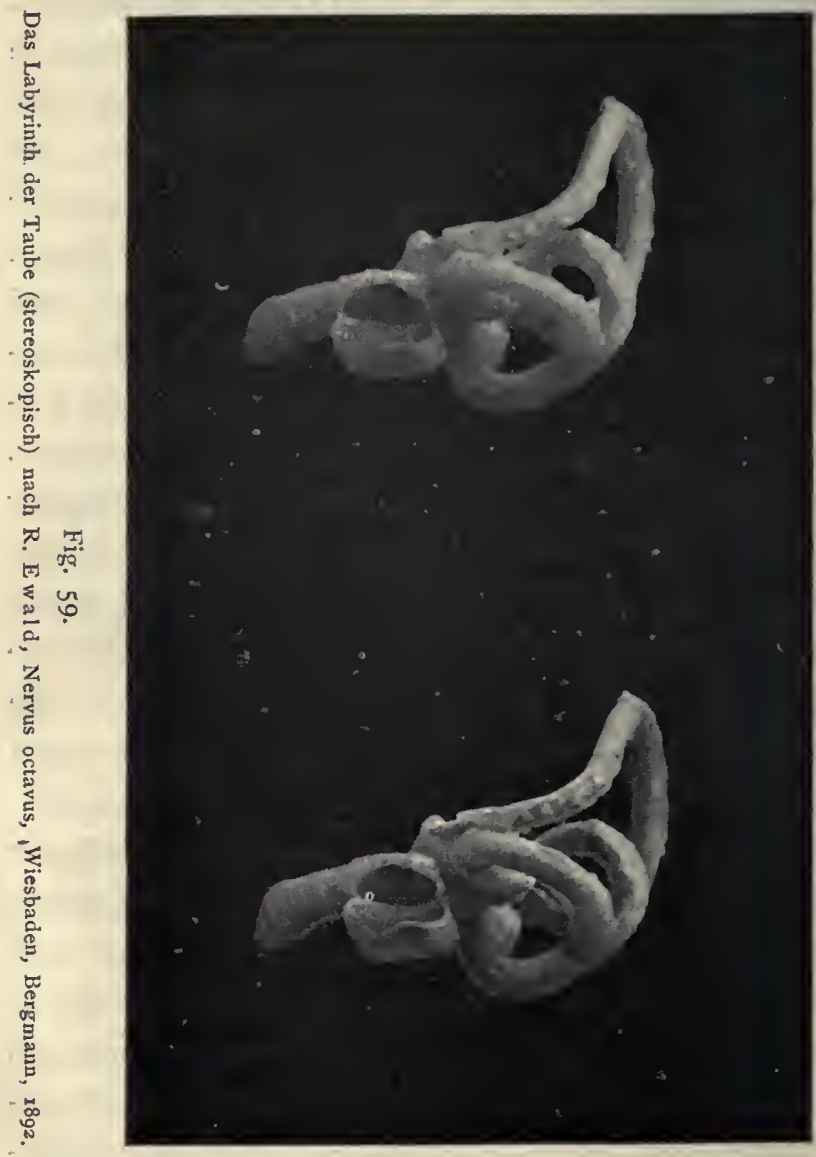

Reiz, immer nur mit Lichtempfindung antworten, stellen wir uns ferner vor, daß der gewöhnliche Reiz der Ampullennerven durch die Trägheit des Bogenganginhaltes Digitized by Microsoft (B) 
ausgeübt wird, welcher bei entsprechenden Drehungen in der Ebene des Bogenganges zurückbleibt, oder doch das Bestreben hat zurückzubleiben, und folglich einen Druck ausiibt. Man sieht, daß dann alle die einzelnen Tatsachen, welche ohne diese Auffassung als eben so viele verschiedene Sonderbarkeiten erscheinen, aus diesem einen Gesichtspunkt klar und verständlich werden.

Ich hatte nun die Freude, daß unmittelbar nach meiner Mitteilung;, in welcher ich diesen Gedanken dargelegt hatte, $\left.{ }^{*}\right)$ eine Mitteilung von BREUER erschien, ${ }^{* * *}$ ) welcher durch ganz andere Methoden zu Ergebnissen gelangt war, die in allen wesentlichen Punkten mit den meinigen übereinstimmten. Einige Wochen später kam auch CRum Brown in Edinburg, dessen Wege den meinigen näher lagen. BREUERS Arbeit war weit reicher an physiologischen Erfahrungen als die meinige, und insbesonders hatte er viel eingehender die Mitwirkung der reflektorischen Bewegungen und Orientierung der Augen bei den fraglichen Erscheinungen untersucht. $\left.{ }^{* * * \%}\right)$ Außerdem waren Versuche, die ich in meiner Mitteilung als Probe der Richtigkeit der dargelegten Auffassung vorgeschlagen hatte, von BREUER schon ausgeführt. Auch um die weitere Bearbeitung des Gebietes hat sich BREUER die größten Verdienste erworben. In physikalischer Beziehung war natürlich meine Arbeit vollständiger.

Um das Verhalten des Bogengangapparates zu veran-

*) Wiener Akad., 6. November 1873 .

\$tos) Gesellschaft der Ärzte, 14. November 1874.

\#**;) Ich habe zu letzterer Frage noch in meiner, "Analyse der Empfindungen“", 1886, S. 56, einen Beitrag geliefert. Vgl. 3. Aufl. 1902, S. 101 u. f. 
schaulichen, habe ich hier eine kleine Vorrichtung (Fig. 60) hergestellt. Die große drehbare Scheibe stellt den knöchernen, mit dem Kopfe fest verbundenen Bogengang, die auf ersterer frei drehbare kleinere Scheibe den beweg-

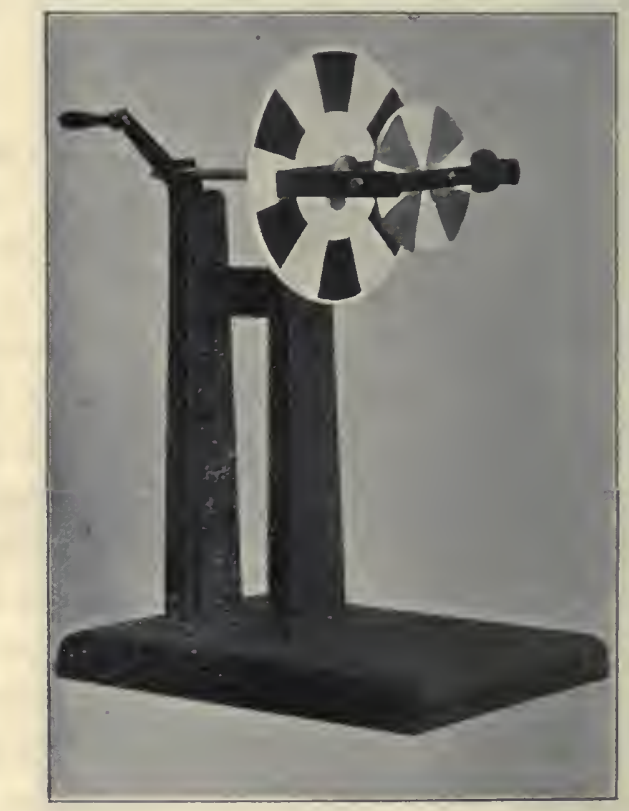

Fig. 60.

lichen, teilweise flüssigen Bogenganginhalt vor. Bei jeder Drehung der größeren Scheibe bleibt, wie Sie sehen, zunächst die kleinere Scheibe zurïck. Ich muß lange drehen, bevor die letztere durch die Reibung endlich mitgenommen wird. Halte ich aber dann die größere Scheibe an, so sehen Sie, wie die kleinere Scheibe die ursprüngliche Drehung fortsetzt. 
Nehmen Sie nun an, daß eine Drehung der kleineren Scheibe, etwa im Sinne des Uhrzeigers, die Empfindung einer Drehung im entgegengesetzten Sinne auslösen würde, und umgekehrt, so verstehen Sie schon einen guten Teil der dargelegten Tatsachen. Dieselben bleiben auch verständlich, wenn die kleinere Scheibe sich nicht wirklich ausgibig dreht, sondern etwa durch eine elastische Feder festgehalten wird, deren Spannung eine Empfindung auslöst. Solcher Vorrichtungen denken Sie sich nun drei, mit drei zu einander senkrechten Drehungsebenen zu einem Apparat verbunden. Diesem gesamten Apparat kann dann keine Drehung erteilt werden, ohne daß dieselbe durch die kleinen beweglichen oder an Federn befestigten Scheiben angezeigt wird. Sowohl das rechte wie das linke Ohr denken Sie sich mit einer derartigen Vorrichtung ausgestattet. Dieselbe entspricht dem Bogengangapparat, den Sie in Fig. 59 in einem Stereoskopbild für das Ohr der Taube dargestellt sehen.

Von den vielen Versuchen, die ich an mir selbst angestellt habe, und deren Ausfall nach der dargelegten Auffassung, nach dem Verhalten des Modells, also nach den Regeln der Mechanik vorausgesagt werden konnte, sei nur einer angeführt. Ich bringe in dem Rahmen $R$ meines Rotationsapparates ein wagrechtes Brett an, lege mich auf dasselbe, etwa auf das rechte Ohr hin, und lasse die Vorrichtung gleichmäßig drehen. Sobald ich die Drehung nicht mehr empfinde, wende ich mich auf das linke Ohr um, und sofort tritt die Empfindung der Drehung in aller Lebhaftigkeit wieder auf. Der Versuch kann be-

\section{Digitized by Microsoft ${ }^{\circledR}$}


liebig oft wiederholt werden. Selbst eine geringe Kopfwendung genügt zur jedesmaligen Auffrischung der Drehempfindung, welche bei vollkommen ruhiger Lage alsbald ganz verschwindet.

Wir wollen den Vorgang am Modell nachahmen. Ich drehe die größere Scheibe. Die kleinere wird schließlich mitgenommen. Wenn ich aber nun bei gleichmäßiger Fortsetzung der Drehung einen Faden abbrenne, so wird die kleinere Scheibe durch eine Feder in ihre eigene Ebene (um $180^{\circ}$ ) umgeklappt, so daß Ihnen dieselbe nun ihre andere Seite zuwendet, und die Gegendrehung tritt sofort auf.

Es gibt also ein sehr einfaches Mittel, zu unterscheiden, ob man sich in einer gleichmäßigen, sonst unmerklichen Drehung befindet oder nicht. Würde die Erde viel rascher rotieren, als es wirklich der Fall ist, oder wäre unser Bogengangapparat viel empfindlicher, so würde NANSEN, am Nordpol schlafend, bei jeder Umwendung durch eine Drehempfindung geweckt worden sein. Das Foucaultsche Pendel zum Nachweise der Erdrotation wäre unter solchen Verhältnissen unnötig. Es liegt in der Tat nur an der geringen. Winkelgeschwindigkeit der Erde und den hieran hängenden großen Versuchsfehlern, daß wir die Erdrotation nicht mit Hilfe unseres Modells nachweisen können.*)

*) In meinen "Grundlinien der Lehre von den Bewegungsempfindungen", I875, ist S. 20 , Zeile ${ }_{4}-\mathrm{x}_{3}$ von unten, als auf einem Irrtum beruhend, $2 u$ streichen, wie ich dies schon anderwärts bemerkt habe. Über einen anderen dem Foucaultschen verwandten Versuch vgl.meine "Mechanik", 4. Aufl. Igor S. 335 . 
Aristoteles hat behauptet: „Das Süßeste ist die Erkenntnis." Er hat damit Recht. Wenn Sie aber annehmen wollten, daß auch die $\mathrm{Publikation}$ einer neuen Einsicht eine große Süßigkeit im Gefolge habe, so wären Sie in einem gewaltigen Irrtum befangen. Niemand beunruhigt seine Nebenmenschen ungestraft mit einer ueuen Einsicht. Und damit soll gegen diese Nebenmenschen gar kein Vorwurf ausgesprochen sein. Die Zumutung, die Denkweise in Bezug auf eine Frage umzubrechen, ist keine angenehme und vor allem keine bequeme. Wer eine neue Einsicht gewonnen hat, weiß am besten, daß derselben immer auch ernste Schwierigkeiten im Wege stehen. Mit lobenswertem, aufrichtigem Eifer wird also nach allem gesucht, was mit der neuen Ansicht $\mathrm{nicht}$ im Einklang steht. Man sieht nach, ob man die Tatsachen nach den herkömmlichen Ansichten nicht besser, ebensogut, oder doch annähernd so gut erklären könnte. Und auch das ist ja gerechtfertigt. Aber auch recht ungenierte Einwendungen werden laut, die uns fast verstummen machen. . Wenn es einen sechsten Sinn gäbe, hätte man denselben schon vor Jahrtausenden entdeckt". Es war ja eine Zeit, da es nur sieben Planeten geben durfte. Ich glaube doch nicht, daß auf die philo. logische Frage, ob das berührte Erscheinungsgebiet ein Sin $n$ zu nennen sei, irgend jemand besonderen Wert legt. Das Gebiet wird auch nicht verschwinden, wenn der Name verschwindet. Sogar das bekam ich zu hören, daß es Tiere ohne Labyrinth gibt, die sich dennoch orientieren, daß also das Labyrinth mit der Orientierung 
nichts zu schaffen hat. Gewiß, wir gehen auch nicht mit unseren Beinen, da die Schlangen ohne dieselben vorwärts kommen.

Wenn nun auch die Verkünder einer neuen Einsicht von ihrer Publikation kein großes Vergnügen zu erwarten haben, so ist doch der bezeichnete kritische Prozeß der Sache sehr förderlich. Alle der neuen Ansicht notwendig anhaftenden Mängel werden nach und nach bekannt und allmählich abgestreift. Jede Überschätzung und Übertreibung muß einer nüchternen Auffassung platzmachen. So hat es sich auch herausgestellt, daß man dem Labyrinth nicht alle Funktionen der Orientierung ausschließ. lich zuweisen darf. Um diese kritische Arbeit haben sich Delage, Aubert, Breuer, Ewald u. a. in hervorragender Weise verdient gemacht. Es kann auch nicht fehlen, daß bei diesem Prozeß neue Tatsachen bekannt werden, welche nach der neuen Auffassung sich hätten voraussagen lassen, die zum Teil auch wirklich vorausgesagt worden sind, welche also für eben diese Auffassung sprechen. Es gelang BREUER und EwaLD, das Labyrinth, sogar einzelne Teile des Labyrinthes elektrisch und mechanisch zu reizen und die zugehörigen Bewegungen auszulösen. Man konnte zeigen, daß mit Wegfall der Bogengänge der Drehschwindel, mit Beseitigung des ganzen Labyrinthes auch die Kopforientierung verschwindet, daß ohne Labyrinth kein galvanischer Schwindel besteht. Ich selbst habe schon 1875 einen Apparat zur Beobachtung gedrehter Tiere konstruiert, der mehrmals in mannigfaltigen Formen nacherfunden und später Cyclostat genannt worden ist. *) Bei Versuchen mit den ver-

*) Anzeiger der Wiener Akad., 30. Dezember 1875.

Digitized by Microscit (B) 
schiedensten Tieren hat sich nun z. B. gezeigt, daß die Froschlarven erst dann Drehschwindel bekommen, wenn sich bei ihnen der Bogengangapparat entwickelt hat, der anfänglich nicht vorhanden ist (K. SCHÄFER).

Ein großer Prozentsatz der Taubstummen ist mit schweren Labyrintherkrankungen behaftet. Der amerikanische Psychologe W. JaMes hat nun mit vielen Taubstummen Drehversuche angestellt und hat bei einer großen Zahl derselben den Drehschwindel vermißt. Er hat auch gefunden, daß manche Taubstumme beim Untertauchen unter Wasser, wobei sie ihr Gewicht verlieren, wobei also der Muskelsinn keine verläßliche Anzeige mehr gibt, gänzlich desorientiert werden, nicht mehr wissen, wo oben, wo unten ist, und in die größte Angst geraten, was bei normalen Menschen nicht vorkommt. Solche Tatsachen zeigen schlagend, daß wir nicht durch das Labyrinth alle in uns orientieren, so wichtig dasselbe für uns auch ist. Dr. KREIDL hat ähnliche Versuche wie James angestellt, und hat bei gedrehten Taubstummen nicht nur den Drehschwindel, sondern auch die normalerweise durch das Labyrinth ausgelösten reflektorischen Augenbewegungen vermißt. Endlich hat Dr. Pollak bei einem beträchtlichen Prozentsatz der Taubstummen keinen galvanischen Schwindel gefunden. Weder die Ruckbewegungen, noch die Augenbewegungen traten ein, welche normale Menschen beim RitTER-PURkinjeschen Versuch zeigen.

Hat ein Physiker einmal die Ansicht gewonnen, daß die Bogengänge die Empfindung der Drehung, beziehungsweise der Winkelbeschleunigung vermitteln, so 
frägt derselbe fast notwendig nach den Organen für die Empfindung der Beschleunigung fortschreitender Bewegungen. Selbstredend sucht er für diese Funktion nicht nach einem Organ, welches in gar keiner verwandtschaftlichen und räumlichen Beziehung zu den Bogengängen steht. Hierzu kommen noch physiologische Momente. Ist einmal die vorgefaßte Meinung durchbrochen, dergemäß das ganze Labyrinth Gehörorgan ist, so bleibt, nachdem der Schnecke die 'Tonempfindung, den Bogengängen die Empfindung der Winkelbeschleunigung zugewiesen ist, noch der Vorhof für weitere Funktionen verfügbar. Dieser schien mir nun (insbesondere der Sacculus) vermöge seines Gehaltes an sogenannten Hörsteinen wohl geeignet, um die Empfindung der Progressivbeschleunigung, beziehungsweise der Kopfstellung zu vermitteln. Auch in dieser Vermutung traf ich wieder mit BreUer sehr nahe zusammen.

$\mathrm{DaB}$ eine Empfindung der Lage, der Richtung und Größe der Massenbeschleunigung existiert, lehren die Erfahrungen im Lift, und lehrt die Bewegung in krummer Bahn. Ich habe auch versucht, große Geschwindigkeiten der Fortschreitung rasch herzustellen, und $z u$ vernichten, mit Hilfe verschiedener Vorkehrungen, von welchen nur eine erwähnt werden mag. Wenn ich in dem großen Rotationsapparat außerhalb der Achse im Papierkasten eingeschlossen in gleichmäßiger Rotation bin, die ich nicht mehr empfinde, wenn ich dann den Rahmen $r$ beweglich mache und Halt kommandiere, so wird meine fortschreitende Bewegung plötzlich gehemmt, während der Rahmen $r$ fortrotiert. Da glaube ich nun entgegen der gehemmten Be- 
wegung in gerader Bahn fortzufliegen. Leider kann hier mannigfaltiger Umstände wegen der Nachweis, daß das betreffende Organ im Kopfe sitzt, nicht in überzeugender Weise gefüht werden. Nach der Meinung von DelaGe hat das Labyrinth auch mit dies er Bewegungsempfindung nichts $z u$ tun. BREUER hingegen ist der Ansicht, daB. das Organ für fortschreitende Bewegungen beim Menschen verkümmert und die Nachdauer der betreffenden Em. pfindung zu kurz ist, um ebenso deutliche Experimente zu ergeben wie für die Drehung. In der Tat hat CRUM Brown einmal in einem Reizungszustand an sich selbst eigentümliche Schwindelerscheinungen beobachtet, die sich sämtlich durch eine abnorm lange Nachdauer der Drehempfindung erklären ließen, und ich selbst habe in einem analogen Fall beim Anhalten eines Eisenbahnzuges die scheinbare Rückwärtsbewegung auffallend stark und lange empfunden.

$\mathrm{Daß}$ wir Änderungen der Vertikalbeschleunigung empfinden, ist nicht zweifelhaft. $\mathrm{DaB}$ die Otolithenorgane des Vorhofes die Empfindung der Richtung der Massenbeschleunigung vermitteln, wird nach dem Folgenden höchst wahrscheinlich. Dann ist es aber mit einer konsequenten Auffassung unvereinbar, letztere Organe für die Empfindung horizontaler Beschleunigungen für unfähig zu halten.

Bei den niederen Tieren schrumpft das Analogon des Labyrinthes zu einem mit Flüssigkeit gefüllten Hörbläschen mit auf Härchen ruhenden, spezifisch schwereren Krystallen, Hörsteinen oder Otolithen zusammen. Dieselben scheinen physikalisch sehr geeignet sowohl die Richtung der Schwere, 
als auch die Richtung einer beginnenden Bewegung anzuzeigen. Daß sie erstere Funktion wirklich haben, davon hat sich zuerst DELAGE durch Versuche an niederen Tieren überzeugt, welche nach Entfernung des Otolithenorganes gänzlich desorientiert waren und ihre normale Lage nicht mehr zu finden wußten. Ebenso hat LOEB gefunden, daß Fische ohne Labyrinth bald auf dem Bauche, bald auf dem Rücken schwimmen. Der merkwürdigste, schönste und überzeugendste Versuch ist aber der yon Dr. KREIDL mit Krebsen angestellte. Nach HENsEN führen gewisse Krebse nach der Häutung selbst feine Sandkörner als Hörsteine in die Otolithenblase ein. Dr. KREIDL nötigte solche Krebse nach dem sinnreichen Vorschlage von S. ExNER mit Eisenpulver (ferrum limatum) vorlieb zu nehmen. Wird nun dem Krebs der Pol eines Elektromagneten genähert, so wendet derselbe unter entsprechenden reflektorischen Augenbewegungen sofort den Rücken von dem Pol ab, so wie der Strom geschlossen wird, gerade so, als ob sich die Schwere nach Richtung und Sinn der magnetischen Kraft genähert hätte.*) Dies muß man in der Tat nach der dèn Otolithen zugemuteten Funktion erwarten. Werden die Augen mit Asphaltlack bedeckt und die Gehörbläschen entfernt, so sind die Krebse gänzlich desorientiert, überkugeln sich, liegen auf der Seite oder auf dem Rücken. Dies erfolgt $\mathrm{nicht}$, wenn nur die Augen gedeckt werden. Für die Wirbeltiere hat BREUER durch eine eingehende Untersuchung nachgewiesen, daß die Otolithen (oder besser

*) Der Versuch war für mich besonders interessant, da ich schon 1874 , allerdings mit sehr geringer Hoffnung, und ohne Erfolg versucht hatte, mein eigenes durchströmtes Labyrinth elektromagnetisch zu erregen. 
Statolithen) in drei den Bogengangebenen parallelen Ebenen gleiten, also wohl geeignet sind, sowohl Größen- als Richtungsänderungen der Massenbeschleunigung anzuzeigen.*)

Ich habe schon erwähnt, daß nicht jed e Orientierungsfunktion dem Labyrinth allein zugeschrieben werden darf. Die Taubstummen, welche auch noch untergetaucht, und die Krebse, welchen auch noch die Augen gedeckt werden müssen, wenn sie bei funktionslosem Gleichgewichtsorgan vollkommen desorientiert sein sollen, sind ein Beleg hiefür. Ich sah bei Hering eine junge geblendete Katze, die sich aber für den nicht sehr genauen Beobachter ganz wie eine sehende Katze verhielt. Dieselbe spielte ganz flink mit auf dem Boden rollenden Gegenständen, steckte den Kopf neugierig in offene Laden hinein, sprang geschickt auf den Stuhl, lief mit voller Sicherheit durch offene Türen hindurch, ohne jemals gegen eine geschlossene Türe anzurennen. Der Gesichtssinn war hier sehr rasch durch den Tast- und Gehörssinn ersetzt worden. So zeigt es sich nach Ewald, daB die Tiere auch nach entferntem Labyrinthe allmählich lernen, sich scheinbar wieder ganz normal $\mathrm{zu}$ bewegen, indem ein Teil des Hirnes die ausgefallene Funktion des Labyrinthes ersetzt. Nur eine gewisse, eigentümliche Muskelschwäche bleibt zurück, die EwaLD

*) Mau erinnert sich hier vielleicht der Diskussion über die stets auf die Füfse fallende Katze, welche vor einigen Jahren die Pariser Akademie und mit dieser die Pariser Gesellschaft beschäftigt hat. Ich bin der Meinung, dafs diese Fragen durch das in meinen "Bewegungsempfindungen" ( $18_{75}$ ) Gesagte mit erledigt sind. Auch die von den Pariser Gelehrten zur Erläuterung erdachten Apparate habe ich zum Teil schon 1868 in Carls Repertorium IV. 359 angegeben. Eine Schwierigkeit ist bei der Pariser Diskussion nicht berührt worden. Der Katze im freien Fall kann der Otolithenapparat nichts nützen. Sie kennt wohl, so lange sie in Ruhe ist, ihre Orientierung und kennt wohl instinktiv das Ausnıafs der Bewegung, welches sie auf die Füfse stellt. 
dem Fehlen des sonst vom Labyrinth beständig ausgehenden Reizes (Labyrinthtonus) zuschreibt. Wird aber jene die Ertsatzfunktion ausübende Hirnpartie abgetragen, so sind die Tiere nun ganz desorientiert und hilfos.

Man kann sagen, daß die 1873 und 1874 von BreUER, CRUM BROwn und mir ausgesprochenen Ansichten, welche eine weitere und reichere Entwicklung der GoLtzschen Auffassung darstellen, sich im ganzen bewährt haben. Mindestens aber haben dieselben fördernd und anregend gewirkt. Selbstredend sind im Verlaufe der Untersuchung wieder neue Probleme aufgetreten, die ihrer Erledigung harren, und viel Arbeit bleibt übrig. Zugleich sehen wir aber, wie fruchtbar nach zeitweiliger Isolierung und Kräftigung der naturwissenschaftlichen Spezialfächer gelegentlich deren Zusammenwirkung ist.

Es sei deshalb gestattet, die Beziehung zwischen Hören und Orientierung noch unter einem allgemeinern Gesichtspunkt zu betrachten. Was wir Gehörorgan nennen, ist bei den niederen Tieren ein Bläschen mit Hörsteinen. Bei höherer Entwicklung wachsen aus demselben nach und nach x, 2, 3 Bogengänge heraus, während der Bau des Otolithenorganes selbst zugleich komplizierter wird. Aus einem Teil des letzteren (lagena) wird endlich bei den höheren Wirbeltieren, insbesonders bei den Säugetieren die Schnecke, die HeLnhol.tz als das Organ der Tone m p fin dung gedeutet hat. Noch befangen in der Ansicht, daß das ganze Labyrinth Gehörorgan sei, suchte HeLmHoltz anfänglich, ungetreu den Ergebnissen seiner eigenen musterhaften Analyse, einen anderen Teil des Labyrinthes als 
Organ für Geräusche zu deuten. Ich habe vor langer Zeit (1873) gezeigt, daß jeder Tonreiz durch Abkürzung der Reizdauer auf eine geringe Anzahl Schwingungen den Charakter der Tonhöhe allmählich einbüßt, und jenen eines trockenen Schlages, eines Geräusches annimmt. Alle Zwischenglieder zwischen Ton und Geräusch lassen sich so aufweisen. Man wird nicht geneigt sein, anzunehmen, $\mathrm{da} ß \mathrm{da}$ an die Stelle eines Organes auf einmal ein ganz anderes in Funktion tritt. Auf Grund anderer Versuche und Erwägungen hält S. ExNER die Annahme eines besonderen Organs zur Empfindung der Geräusche ebenfalls für unnötig.

Bedenken wir nur, ein wie geringer Teil des Labyrinthes der höheren Tiere dem Hören zu dienen scheint, wie beträchtlich dagegen der Teil noch ist, welcher wahrscheinlich der Orientierung dient, wie gerade die erste Anlage des Hörbläschens der niederen Tiere dem Teile des ausgebildeten Labyrinthes gleicht, welcher nicht hört, so drängt sich wohl die Ansicht auf, die BREUER und ich (1873, I874) ausgesprochen haben, daß das Gehörorgan sich aus einem Organ für Empfindung von Bewegungen entwickelt hat, durch Anpassung an schwache periodische Bewegungsreize, und daß viele bei niederen Tieren für Gehörorgane gehaltenen Apparate gar keine eigentlichen Gehörorgane sind. *)

* [Vgl. über die hier beruhrten Punkte: "Physik. Versuche iiber den Gleichgewichtssinn." Sitzgsber. d. Wiener Akad. III Abt. 1873 S. 133, 136, "Bewegungsempfindungen" 1875, S. $110-$ Analyse d. Empfiindungen. 1886, S. I17, 133, 3. Aufl. 1902, S. 202, 221. - Obwohl mir schon durch die erwähnte Erfahrung bei der Eisenbahnfahrt klar geworden war, dafs Menschen und Tiere in ihrer Art ebenso geotropisch sind wie die Pflanzen, obwohl ich vielleicht einer

$\mathrm{Mach}$, Vorlesungen. 3. Aufl. 
Diese Ansicht scheint zusehends mehr Boden zu gewinnen. Dr. KREIDL ist durch gut angelegte Versuche zu dem Schlusse gelangt, daß selbst die Fische noch nicht hören, während seinerzeit E. H. WEBER die Knöchelchen, welche die Schwimmblase der Fische mit dem Labyrinth in Verbindung setzten, geradezu als Schalleitungsapparate von ersterer zu letzterem betrachtet. *) STÖRENSEN hat die Erregung von Tönen durch die Schwimmblase, sowie die Fortleitung von Erschütterungen durch die WEBERschen Knöchelchen beobachtet. Er hält die Schwimmblase für besonders geeignet, die von anderen Fischen erregten Geräusche aufzunehmen und zum Labyrinth zu leiten. Er hat in dem Wasser südamerikanischer Flüsse die lauten grunzenden Töne gewisser Fische gehört und meint, daß sich dieselben auf diese Weise locken und finden. Hiernach wären wieder manche Fische weder taub noch stumm. ${ }^{*}$ ), Die Frage, welche hier liegt, dïrfte sich lösen durch eine scharfe Unterscheidung zwischen Tonempfindung (eigentlichem Hören) und Wahrnehmen von Erschütterungen. Erstere mag ja selbst bei manchen Wirbeltieren sehr eingeengt sein, vielleicht auch ganz fehlen. Neben der Hörfunktion könnten aber die WEBERschen Knöchelchen ganz.

der ersten war, der die Otolithen in ihrer eigentlichen Bedeutung als Statolithen erkannte, so blieb mir doch gerade der Geotropismus der Pflanzen ein unerklärtes. Rätsel. Ich war daher sehr angenehm überrascht, als es sich durch die Studien. von G. Haberlandt und B. Němec herausstellte, dafs wahrscheinlich die Stärkekörner in ähnlicher Weise als Wachstumsreize wirken, wie die Otolithen. als Empfindungsreize. Vgl Haberlandt, "Sinnesorgane im Pflanzenreich", . 19or, S. 142, Anmk. ferner "Über die Perception des geotropischen Reizes", Ber. d. D. botan. Gesellsch. XVIII S. 26r. - rgoz].

*) E. H. We ber, De aure et auditu hominis et animalium, Lipsiae r82o.

**) Störensen, Journ. Anat. Phys. London, vol. 29 (1895). Ich verdanke: die Kenntuis dieser Arbeit meinem Kollegen K. Grobben. 
wohl noch eine andere Funktion haben. Wenn auch die Schwimmblase nicht in dem einfachen physikalischen Sinn BORellis ein Gleichgewichtsorgan ist, wie MOREAU gezeigt hat, so bleibt für sie wahrscheinlich doch noch irgend eine derartige Funktion übrig. Die Verbindung mit dem Labyrinth begünstigt diese Auffassung. Und so liegt hier noch eine Fülle von Problemen.

Eine Reminiscenz aus dem Jahre $r 863$ ist es, mit welcher ich schließen möchte. HeLmholtz' „Tonempfindungen" waren eben erschienen, und die Funktion der Schnecke schien nun aller Welt klar. In einem Zwiegespräch, welches ich mit einem Doktor der Medizin hatte, erklärte es dieser als ein fast hoffnungsloses Unternehmen, auch die Funktion der anderen Labyrinthteile ergründen zu wollen, während ich in jugendlichem Übermut behauptete, diese Frage müßte gelöst werden, und zwar bald, ohne natürlich eine Ahnung zu haben, wie. Zehn Jahre später war die Frage im wesentlichen gelöst.

Ich glaube heute, nachdem ich mich an mancher Frage oft und vergebens versucht habe, nicht mehr, dab man die Probleme nur so übers Knie brechen kann. Allein ein "Ignorabimus“ würde ich doch nicht für den Ausdruck der Bescheidenheit halten, sondern eher für das Gegenteil. Richtig angebracht ist dasselbe nur gegenüber verkehrt gestellten Problemen, die also eigentlich keine Probleme sind. Jedes wirkliche Problem kann und wird bei genügender Zeit gelöst werden, ohne alle tibernatürliche Divination, ganz allein durch scharfe Beobachtung und umsichtige, denkende Erwägung. 


\section{Verbesserung :}

S. 33 Z. ro v. o. lies 300 statt 500 .

Lippert \& Co (G. Pätz'sche Buchdr.), Naumburg a $\mathrm{S}$. Digitized by Microsoft $\stackrel{(}{9} 974$ 
Digitized by Microsoft ${ }^{\circledR}$ 
Digitized by Microsoft $($ B 
Digitized by Microsoft ${ }^{\circledR}$ 
